\title{
Design And Implementation Of An Instantaneous Fuel Mass Flow Measurement System For Use In Verification Of Locomotive Emissions
}

\author{
Adam Wayne James \\ West Virginia University, ajames7@mix.wvu.edu
}

Follow this and additional works at: https://researchrepository.wvu.edu/etd

Part of the Acoustics, Dynamics, and Controls Commons

\footnotetext{
Recommended Citation

James, Adam Wayne, "Design And Implementation Of An Instantaneous Fuel Mass Flow Measurement System For Use In Verification Of Locomotive Emissions" (2019). Graduate Theses, Dissertations, and Problem Reports. 3781.

https://researchrepository.wvu.edu/etd/3781

This Thesis is protected by copyright and/or related rights. It has been brought to you by the The Research Repository @ WVU with permission from the rights-holder(s). You are free to use this Thesis in any way that is permitted by the copyright and related rights legislation that applies to your use. For other uses you must obtain permission from the rights-holder(s) directly, unless additional rights are indicated by a Creative Commons license in the record and/ or on the work itself. This Thesis has been accepted for inclusion in WVU Graduate Theses, Dissertations, and Problem Reports collection by an authorized administrator of The Research Repository @ WVU. For more information, please contact researchrepository@mail.wvu.edu.
} 
DESIGN AND IMPLEMENTATION OF AN INSTANTANEOUS FUEL MASS FLOW MEASUREMENT SYSTEM FOR USE IN VERIFICATION OF LOCOMOTIVE EMISSIONS

\author{
Adam W. James \\ Thesis submitted to the Benjamin M. Statler College of Engineering \\ at West Virginia University \\ in partial fulfillment of the requirements \\ for the degree of \\ Master of Science \\ in \\ Mechanical Engineering
}

Scott W. Wayne, Ph.D., Committee Chairperson

Arvind Thiruvengadam, Ph.D.

Derek R. Johnson, Ph.D.

Department of Mechanical and Aerospace

Morgantown, West Virginia

2019

Keywords: Diesel, Locomotive, Emissions, Verification, Fuel Flow Measurement Copyright 2019 Adam James 


\title{
ABSTRACT \\ DESIGN AND IMPLEMENTATION OF AN INSTANTANEOUS FUEL MASS FLOW MEASUREMENT SYSTEM FOR USE IN VERIFICATION OF LOCOMOTIVE EMISSIONS
}

\author{
Adam W. James
}

Located in Altoona, PA, the Juniata Thoroughbred Emissions Research lab has provided emissions testing and research for several locomotive companies such as CSX, Electro Motive Diesel (EMD), and General Electric (GE). The emissions laboratory measures locomotive emissions through partial flow dilution (PFD) sampling for particulate matter (PM) using a Sierra Instruments BG3 and measures raw gaseous emissions using a MEXA 7100D gaseous emission analyzer. Fuel consumption is measured on a gravimetric basis and is used in verification of proportional sampling of exhaust flow. There were two research goals for this study which were (1) verify that the emissions measurement system used at the Juniata emissions lab is compliant to 40 CFR Parts 1033 and 1065 specifically that verification of proportional sampling can be performed and met using gravimetric fuel measurement and (2) design and implement an instantaneous fuel mass flow measurement system for use in verification of locomotive emissions.

The emissions data acquisition (DAQ) system used at the Juniata lab, Scimitar, was used to compare a $\mathrm{MATLAB}^{\circledR}$ code that performed a carbon balance of the raw gaseous emissions and was used to calculate brake-specific emissions and exhaust flow rates. The brake-specific emissions from MATLAB $^{\circledR}$ were compared to Scimitar as other factors were used in verification compliance calculations. For this study, a 2016 EMD SD60E with a model year 1990 engine was evaluated. Emissions calculations were performed for Idle and Notch 8 as they provided the extremes of fuel flow. The percent differences between MATLAB ${ }^{\circledR}$ and Scimitar brake-specific emissions for Idle were 2.10\%, $0.00 \%, 2.25 \%$, and $3.86 \%$ for the constituents CO2, CO, NOx, and THC, respectively, and $0.12 \%, 0.24 \%$, $4.96 \%$, and $11.6 \%$ for the same constituents at Notch 8 . It was concluded that differences between each constituent came from their magnitude (i.e. low number brake-specific emissions caused higher errors).

Furthermore, the dilution flow from the BG3 was compared against the sample flow of PM for verification of proportional flow per federal regulation using standard estimate of the error (SEE) calculations. Allowable per proportional verification regulation, the first $5 \%$ of data points were omitted during the notch. The SEE was calculated at 2.63\% at Notch 8 , and $5.62 \%$ at Idle. While the Idle SEE was not within regulation, the omission techniques used were changed to reduce the SEE. For this example, omitting $5 \%$ of the highest or lowest data points outside of the mean exhaust flow rate plus 
or minus one standard deviation (n்exh $\pm \sigma$ ) resulted in a new Idle SEE of 3.17\%, which was compliant to 1065.545 .

While in this particular example the SEE was met, moving towards instantaneous methods of fuel flow for instantaneous exhaust flow calculations was more desirable as several factors such as EMD Notch 6 engine speed increase, or radiator fans cycling on mid-notch can alter the fuel consumption of the engine which would not be accounted for and provide inaccurate verification of proportional flow during the notch.

Volumetric fuel consumption was evaluated with two KRAL-USA volumetric flow meters. The meters were placed in the supply and return lines of the gravimetric system to measure the difference between the flows which would provide the net flow of fuel that the locomotive's engine consumed. For the same SD60, the SEE was calculated at $2.67 \%$ for Notch 8 , which was consistent with gravimetric analysis, and $11.69 \%$ at Idle. While the SEE was non-compliant, it was due to the large errors of fuel consumption measurement. For this study, Notch 8 average fuel flow had a $\pm 0.29 \%$ error and Idle fuel flow had $\pm 20.8 \%$ error. The maximum instantaneous errors were $\pm 0.38 \%$ at Notch 8 and greater than $\pm 3200 \%$ at Idle. It was determined that the large errors due to the subtraction of the flows at lower engine power levels affected the measured fuel flow rates significantly, which was undesirable and thus direct mass flow measurement was hypothesized to reduce the errors as a single flow measurement would be taken.

A Coriolis mass flow measurement system was designed and implemented for the verification of proportional sampling. The mass flow measurement system was designed to measure fuel level in a temperature conditioned reservoir tank and work in PID control with a flow controller. Fuel burned by the locomotive dropped the level in the fuel reservoir tank. Fuel was replaced by a positive displacement pump through a flow controller which allowed fuel back into the reservoir tank. The replaced fuel was measured by a Coriolis meter which provided direct mass flow measurement.

For this study, a 2003 SD70M with a model year 2003 EMD engine was tested with the mass flow measurement system. Manual PID control techniques were used to control level set point for fuel level reading. For this test, only PI terms used and set to 5. Carbon balances for Idle and Notch 8 were performed and the results were used to calculate the molar exhaust flow rate of the locomotive. The calculated exhaust flow rates were compared against the diluted flow rates from the BG3 for SEE evaluation. The SEE was calculated to be $1.38 \%$ during Notch 8 , and $39.89 \%$ during Idle.

It was determined that PI control of level was sufficient for proportional verification of exhaust flow during Notches 5, 6, 7, and 8 but not for other notches. Issues arose due to overshoot and undershoot of the level set point which caused large fluctuations in mass flow measurement. This 
resulted in inaccurate exhaust flow rates. It was concluded that further PID control tuning would be required to address the issues of overshoot. 


\section{ACKNOWLEDGEMENTS}

I would like to express my sincerest gratitude to my research advisor, Dr. Scott Wayne, for his support, guidance, patience, and willingness to provide help and feedback. This thesis would not have been completed without you. Thank you for your help on this project and through the Formula SAE program. Your mentorship has provided me with experience that has been invaluable to my education.

Thank you to my supervisor engineer, Dave McKain, for helping me with this project. Your help and guidance on the design, build, and implementation of this device made this project possible.

Thank you to my research committee Dr. Derek Johnson and Dr. Arvind Thiruvengadam. Both of you have provided assistance on this project in many ways and I have appreciated all of your help.

To my family members, Robin and Joe Hale, my grandparents, thank you for support and believing in me and my dream to become an engineer. To my sister, Rachel, I would not be where I am today without you. I am lucky, and proud to be your little brother.

To Pam Gelet and Pat Goldie, you are my family away from family and have helped me so much throughout my academic career. I am forever grateful and indebted to both of you.

To the wonderful women of SSS TRiO, Vivian Céspedes, Kylie Evans, and Cindy Drumm you have helped me become the person I am today. I am grateful to have been in the SSS program and I appreciate all that you have done for me.

Thank you to Mr. Miller, you have always been there for me when I needed a morale boost.

And lastly, thank you to all of my friends for keeping me sane. I cannot thank you guys enough for your support throughout my study and being there when I needed it most. 


\section{TABLE OF CONTENTS}

ABSTRACT

ACKNOWLEDGEMENTS $\quad \mathrm{V}$

1 INTRODUCTION 1

1.1 Introductory Background on Locomotive Testing 1

1.2 Juniata Thoroughbred Emissions Lab Emissions Measurement System 3

1.3 Moving from Gravimetric Fuel Measurement to Continuous Fuel Measurement $\quad 5$

1.4 Research Goals and Objectives $\quad 6$

$\begin{array}{ll}2 \text { LITERATURE REVIEW } & 7\end{array}$

2.1 Background on the Environmental Protection Agency and Locomotive Freight $\quad 7$

2.2 Diesel Locomotive Design Features 9

2.3 Diesel Locomotive Emissions and Future Emissions Predictions 10

2.4 The Code of Federal Regulations 12

2.4.1 Emission Standards and Related Requirements 12

$\begin{array}{ll}\text { 2.4.2 Locomotive Engine Testing Conditions } & 13\end{array}$

2.5 40 CFR Part 1065 - Engine-Testing Procedures 14

$\begin{array}{ll}2.6 \text { Overview of the Calculations of Emissions } & 15\end{array}$

2.7 Southwest Research Institute 17

2.7.1 SwRI - Progress Rail PR30 Locomotive SJVR3003 3000-Hour Emissions Test Report

\begin{tabular}{l} 
2.8 Fuel Flow Measurement Technologies \\
\hline
\end{tabular}

2.9 Proportional - Integral - Derivative (PID) Control 22

2.9.1 Functions of PID Control 24

2.10 NIST Traceable Calibration $\quad 30$

3 METHODOLOGY - EMISSION MEASUREMENT AND VERIFICATION THROUGH GRAVIMETRIC, VOLUMETRIC, AND MASS MEASUREMENT

$\begin{array}{ll}3.1 \text { System Setup } & 31\end{array}$

3.1.1 Opacity Meter 33

3.1.2 Raw Exhaust and Particulate Emissions Sampling 33

3.1.3 Sensor Placements

3.1.4 Linear Verification of Sensors 38

3.2 Design and Analysis of the Juniata Emissions Measurement System 44

3.3 Particulate Matter Filter Weighing $\quad 53$ 
3.4 Validation and Verification of Gravimetric Fuel Measurement 56

3.5 Fuel Flow Measurement by Volumetric Flow Meter Technology 60

$\begin{array}{ll}\text { 3.5.1 Installation of Volumetric Flow Meters } & 61\end{array}$

3.5.2 Calibration and Verification of KRAL Volumeters 63

3.5.3 Analysis of Volumetric Fuel Measurement $\quad 64$

3.6 Development of a Fuel Mass Flow Measurement System 71

$\begin{array}{ll}\text { 3.6.1 System Equipment and Sensors Selection } & 73\end{array}$

3.6.2 Mass Flow Measurement System CAD Design $\quad 85$

$\begin{array}{ll}\text { 3.6.3 System Construction and Implementation } & 87\end{array}$

$\begin{array}{ll}3.7 \text { System Calibration } & 92\end{array}$

3.7.1 Level Sensor Calibration $\quad 92$

3.7.2 Micro Motion Coriolis Flow Meter Calibration $\quad 95$

3.7.3 Pressure Relief Valve Setting 96

$\begin{array}{ll}\text { 3.7.4 Controller Box } & 97\end{array}$

4 ANALYSIS OF MASS FLOW MEASUREMENT BY CORIOLIS TECHNOLOGY 99

4.1 Analysis of the Mass Flow Measurement System 99

5 SUMMARY, CONCLUSIONS AND RECOMMENDATIONS 108

$\begin{array}{ll}\text { 5.1 Future Work and Recommendations } & 108\end{array}$

BIBLIOGRAPHY 111

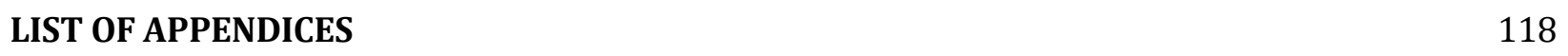

APPENDIX A - MATLAB® CODES 119

Appendix A1 - Chiller Calculations 119

Appendix A2 - Fuel Drum Sizing Calculations 119

$\begin{array}{ll}\text { Appendix A3 - Carbon Balancers } & 120\end{array}$

Appendix A3.1 - Carbon Balance for Test R0007-002-198 120

Appendix A3.2 - Carbon Balance for Test R0007-002-264 127

Appendix B1 - Micro Motion, Inc. Coriolis Mass Flow Meter Calibration Certificate Sheets 135

Appendix B1.1 - Calibration Sheet for Test 12154968

Appendix B1.2 - Calibration Sheet for Test 12154969

Appendix B2 - Troemner, LLC Traceable Certificate for Calibration Weights 139

APPENDIX C - ADDITIONAL FIGURES AND TABLES 140

Appendix C1 - Projected Future Emission Factors Complete Tables [31] 140

Appendix C2 - Preliminary Test Data for Test ID: R0007-002-198 143 
Appendix C3 - Omega ${ }^{\mathrm{TM}}$ Engineering FMC-5000 Coriolis Mass Flow Meter Specifications 148

Appendix C4 - Siemens FCS400 DN 15 sensor flow meter calculations 149

Appendix C5 - Micro Motion CMFS040M calculation summary 150

Appendix C6 - Emerson MR98H Series Operational Schematics 151

Appendix C7 - Test ID: R0007-002-198 Emissions Analyzer Data 152

Appendix C7.1 - Test ID: R0007-002-198 Notch 8 Emissions Analyzer Data 152

Appendix C7.2 - Test ID: R0007-002-198 Idle Emissions Analyzer Data 155

Appendix C8 - Test ID: R0007-002-198 Idle Carbon Balance Results 158

Appendix C9 - Mass Flow Rate Measurements during Test ID: R0007-002-264 159 


\section{LIST OF FIGURES}

Figure 1 - Simplified diagram of a partial sampling emissions measurement system [8] ...........................2

Figure 2 - Picture of the Juniata Thoroughbred Emissions Research lab ...........................................................4

Figure 3 - Picture of the gravimetric fuel measurement system implemented in the fuel measurement apparatuses area at the Juniata Thoroughbred Emissions Research lab ...........................................................

Figure 4 - Flow diagram of the gravimetric fuel measurement component ...................................................5

Figure 5 - Percent breakdown of how freight is transported in the U.S. on a percent tons and percent

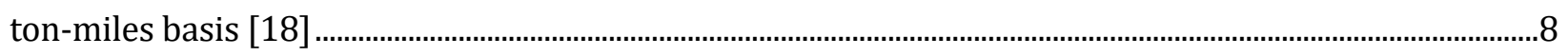

Figure 6 - Diagram of a diesel locomotive and its engine and electrical components interactions that

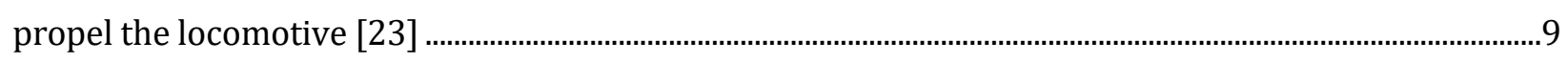

Figure 7 - Schematic of SwRI Fuel Mass Flow Measurement System [41] ....................................................18

Figure 8 - Graduated Cylinder measurement method [43] ………....................................................................19

Figure 9 - Example diagram of how a fluid passes through a PD flow meter [46] ……...............................20

Figure 10 - Twisting motion of tubes due to the Coriolis Effect [49] .............................................................21

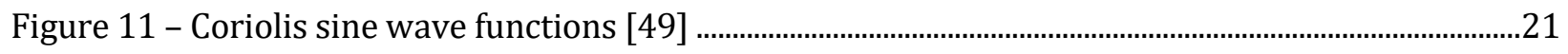

Figure 12 - Block diagram of a PID controller in a feedback loop [52] ……...................................................22

Figure 13 - Visual of an operator manually controlling temperature based on sight reading a

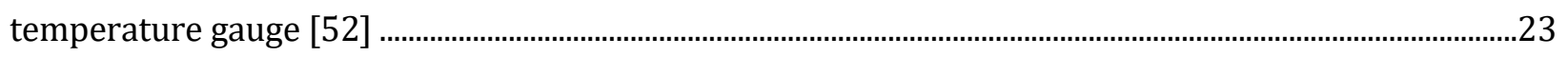

Figure 14 - Visual of temperature control process being done by PID control [52] ..................................23

Figure 15 - Graph of system response for various proportional gain terms [55] .........................................24

Figure 16 - Graph of system response for various integral gain terms [55] ................................................25

Figure 17 - Graph of system response for various derivative gain terms [55] ...........................................25

Figure 18 - Example of a quarter amplitude decay response after a process disturbance [57]..............26

Figure 19 - Example system response from an input [58]...............................................................................27

Figure 20 - Example system response from an input with an increased proportional term [58]...........27

Figure 21 - Example system response from an input with increased proportional and integral terms

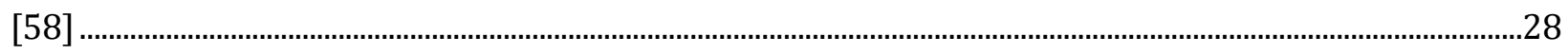

Figure 22 - Example system response from an input with increased proportional, integral, and

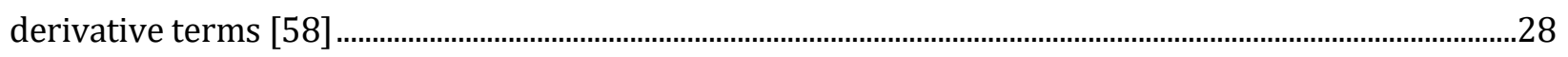

Figure 23 - Summary of Cohen-Coon PID tuning terms based on process gain (gp) dead time (td) and

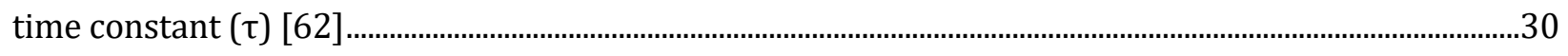

Figure 24 - Photo of inside the Juniata locomotive emissions lab test facility ...............................................31 
Figure 25 - Underside of catwalk with future fuel system in place beside the gravimetric fuel measurement system (right) and flexible fuel line reel hookup (center) ......................................................32

Figure 26 - Fuel drum with rerouted fuel lines ..................................................................................................32

Figure 27 - Exhaust routing apparatus with emissions lines and opacity meter connected......................33

Figure 28 - Photo of exhaust probes in exhaust rerouting hood …………….......................................................34

Figure 29 - BG3 (left) and MEXA (right) gaseous emissions analyzers .........................................................35

Figure 30 - Left side of a diagram of a SOO SD60M diesel locomotive with location of sensor callouts to measure temperature for ambient, exhaust, jacket water, and radiators [67] ................................................36

Figure 31 - Right side of a diagram of a SOO SD60M diesel locomotive with location of sensor callouts to measure temperature for ambient, exhaust, jacket water, and radiators [67] .........................................36

Figure 32 - Screenshot of some of Scimitar's data in Excel output for an EDM/JLS 2016 SD60E equipped with a model year 1990 engine Test ID: R0007-002-198_.................................................................................45 Figure 33 - Screenshot of preliminary test report from Scimitar compiled data for an EDM/JLS 2016 SD60E equipped with a model year 1990 engine Test ID: R0007-002-198 ……………...............................46 Figure 34 - Simplified diagram of BG3 PM sampling system [7] …….................................................................53 Figure 35 - Sartorius SE2-F Filter Microbalance in the CAFEE ERC controlled filter weighing room ...55 Figure 36 - Particulate matter filter before (left) and after (right) use in an emissions test ....................56 Figure 37 - Dilution Flow Rate [SLPM], Total PM Flow Rate [SLPM], and Dilution Ratio during Notch 8

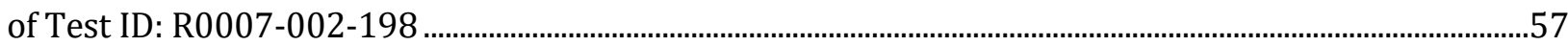

Figure 38 - Dilution Flow Rate [SLPM], Total PM Flow Rate [SLPM], and Dilution Ratio with first 5\% of data points omitted during Notch 8 of Test ID: R0007-002-198 .58 Figure 39 - Dilution Flow Rate [SLPM], Total PM Flow Rate [SLPM], and Dilution Ratio during Idle of

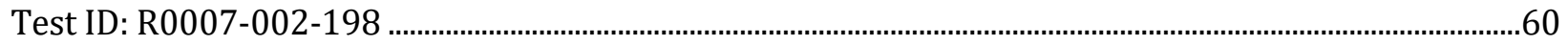

Figure 40 KRAL - USA, Inc. dual volumeter fuel flow measurement diagram [77] .....................................61

Figure 41 - Picture of KRAL volumeter placed in fuel supply line ........................................................................62

Figure 42 - Picture of KRAL volumeter placed in fuel return line .......................................................................62

Figure 43 - Flow diagram of volumeters plumbed into fuel measurement system......................................63

Figure 44 - Screenshot of Scimitar's data output with KRAL volumeter's data for Notch 8 for test R0007-

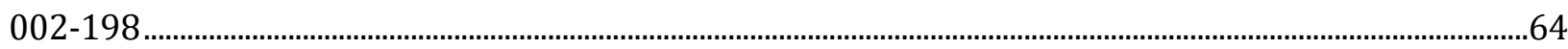

Figure 45 - KRAL volumetric fuel flow rate measurements at Notch 8 for test R0007-002-198 _...........65

Figure 46 - Measured Supply and Return temperatures of the fuel in degree Celsius during Notch 8 for

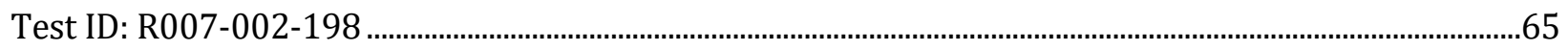

Figure 47 - Density of diesel fuel plotted against temperature (data from ISEDC) [80] ............................66 
Figure 48 - Calculated mass flow rates from KRAL volumetric fuel flow rate measurements at Notch 8

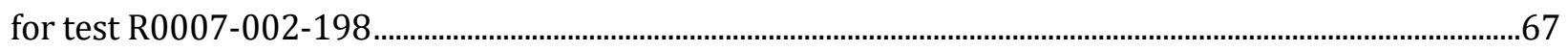

Figure 49 - Calculated exhaust molar flow rate from calculated KRAL mass flow ......................................68

Figure 50 - KRAL net volumetric flow rate [L/hr] during Idle for Test ID: R0007-002-198 ...................69

Figure 51 - Calculated net mass flow rate $[\mathrm{g} / \mathrm{s}]$ from KRAL net volumetric flow rate $[\mathrm{L} / \mathrm{hr}]$ during Idle

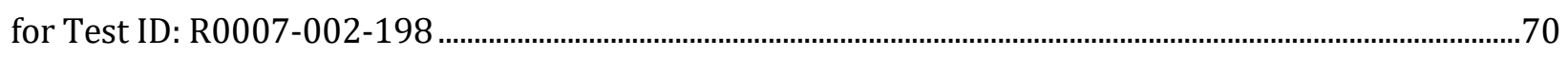

Figure 52 - Schematic diagram of the fuel mass flow measurement system ...................................................72

Figure 53 - Projected Accuracy of FMC 5000 Coriolis Mass Flow Meter …………………...............................76

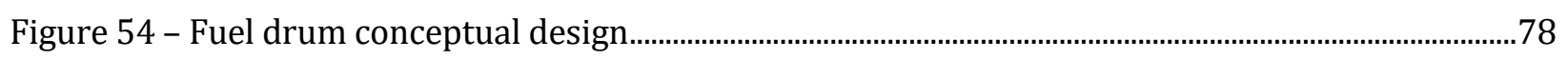

Figure 55 - Changes in height of fuel in fuel drum based on a fuel temperature change of $0.1^{\circ} \mathrm{C}$ for various fuel drum diameters (data from Table 37) ...........................................................................................79

Figure 56 - LTX60 capacitance level sensor specifications sheet (specifications via Instrumart.com) 81 Figure 57 - Emerson's Baumann ${ }^{\mathrm{TM}}$ 24000SVF stainless steel flanged control valve with Fisher FIELDVUE $^{\mathrm{TM}}$ digital valve controller plumbed into mass flow measurement system .................................83

Figure 58 - Emerson MR98H pressure relief valve plumbed into the mass flow measurement system

Figure 59 - Photo of Ashcroft analog (front) and ProSense digital (behind) pressure gages plumbed into mass fuel measurement system. . .85

Figure 60 - Top view of annotated mass flow measurement system CAD model on 48 inch x 48 inch

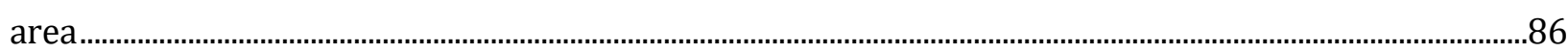

Figure 61 - Left isometric view of mass flow measurement system CAD model on 48 inch x 48 inch area . .86

Figure 62 - Right isometric view of mass flow measurement system CAD model on designed 52 inch $\mathrm{x}$ 52 inch steel pallet. .. .87

Figure 63 - Revised schematic diagram of the mass flow measurement system. .88

Figure 64 - Top view annotated picture of mass flow measurement system in place at Juniata emissions lab. . .89

Figure 65 - Left isometric picture of mass flow measurement system in place at Juniata emissions lab .. .90

Figure 66 - Right isometric picture of mass flow measurement system in place at Juniata emissions lab

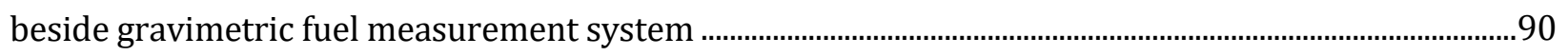

Figure 67 - Final fuel flow diagram for the gravimetric and mass flow measurement systems ..............91

Figure 68 - Fuel Calibration Drain and Fuel Weight Measurement Setup ......................................................93 
Figure 69 - Level measurement in grams of fuel per inch drop in the amplifier tube 94

Figure 70 - Picture of pressure relief valve, pressure gauge, and pressure transducer plumbed into mass flow measurement system and operating at 60psig line pressure........................................................97

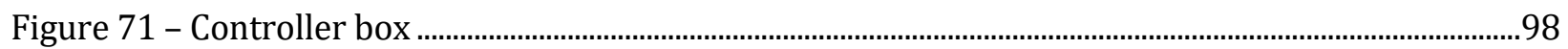

Figure 72 - drive.web ${ }^{\circledR}$ Smarty ${ }^{\circledR}$ PID controller block diagram (available driveweb.com) .......................99

Figure 73 - Mass rate [g/s] of fuel flow measured through Coriolis flow meter........................................100

Figure 74 - Fuel level reading from the bottom of the fuel level sensor ......................................................100

Figure 75 - Control valve percentage of open during Notch 8 for Test ID: R0007-002-264 ...................101

Figure 76 - Fuel reservoir temperature $\left[{ }^{\circ} \mathrm{C}\right]$ during Notch 8 for Test ID: R0007-002-264 .....................102

Figure 77 - Fuel return temperature $\left[{ }^{\circ} \mathrm{C}\right]$ during Notch 8 for Test ID: R0007-002-264..........................102

Figure 78 - Molar Exhaust Flow Rate [mol/s] calculated through mass fuel flow measured by Coriolis

flow meter during Notch 8 for Test ID: R0007-002-264 …...........................................................................103

Figure 79 - Fuel level reading during Idle for Test ID: R0007-002-264 ……..............................................105

Figure 80 - Mass flow rate measurement during Idle for Test ID: R0007-002-264 ..................................105

Figure 81 - Calculated molar exhaust flow rate [mol/s] during Idle for Test ID: R0007-002-264 ...... 107

Figure 82 - Example output and input system response in the MATLAB ${ }^{\circledR}$ pidTuner application [83]

Figure 83 - Notch 8 engine speed transition from Test ID: R0007-002-264 in MATLAB ${ }^{\circledR}$ pidTuner

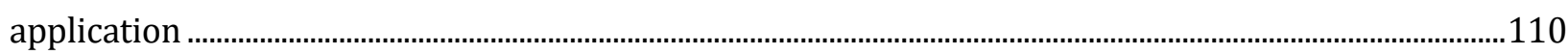

Figure 84 - THC emissions level measurement during Notch 8 for Test ID: R0007-002-198...............152

Figure 85 - CO emissions level measurement during Notch 8 for Test ID: R0007-002-198...................152

Figure 86 - NOx emissions level measurement during Notch 8 for Test ID: R0007-002-198................153

Figure 87 - CO2 emissions level measurement during Notch 8 for Test ID: R0007-002-198 ................153

Figure 88 - NO emissions level measurement during Notch 8 for Test ID: R0007-002-198 .................154

Figure 89 - THC emissions level measurement during Idle for Test ID: R0007-002-198 .......................155

Figure 90 - CO emissions level measurement during Idle for Test ID: R0007-002-198 ..........................155

Figure 91 - NOx emissions level measurement during Idle for Test ID: R0007-002-198 ......................156

Figure 92 - CO2 emissions level measurement during Idle for Test ID: R0007-002-198 .......................156

Figure 93 - NO emissions level measurement during Idle for Test ID: R0007-002-198.........................157

Figure 94 - Mass flow rate of fuel during Dynamic Braking for Test ID: R0007-002-264 ......................159

Figure 95 - Mass flow rate of fuel during Notch 1 for Test ID: R0007-002-264.........................................159

Figure 96 - Mass flow rate of fuel during Notch 2 for Test ID: R0007-002-264.........................................160

Figure 97 - Mass flow rate of fuel during Notch 3 for Test ID: R0007-002-264..........................................160 
Figure 98 - Mass flow rate of fuel during Notch 4 for Test ID: R0007-002-264.........................................161

Figure 99 - Mass flow rate of fuel during Notch 5 for Test ID: R0007-002-264..........................................161

Figure 100 - Mass flow rate of fuel during Notch 6 for Test ID: R0007-002-264 ……...............................162

Figure 101 - Mass flow rate of fuel during Notch 7 for Test ID: R0007-002-264 ……...............................162 


\section{LIST OF TABLES}

Table 1 - Summary of ERTAC Rail Inventories: U.S. Locomotive Emissions and Fuel Use for 2007/2008 $[29,30]$ .10

Table 2 - EPA's emissions factors of NOx [g/gal] for years 2006 - 2040 [31] ...........................................11

Table 3 - Breakdown percentages of yearly fuel consumption for each locomotive service.....................11

Table 4 - Line-Haul Locomotive Emission Standards [6] .................................................................................12

Table 5 - Switch Locomotive Emission Standards [6] .......................................................................................13

Table 6 - Smoke Standards for Locomotives (Percent Opacity) [6] …….........................................................13

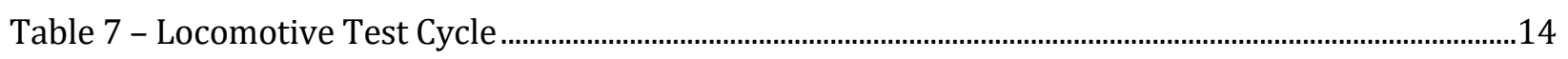

Table 8 - PID controller tuning methods advantages and disadvantages [52, 55].....................................26

Table 9 - Effects of increasing a parameter independently [59] ...................................................................29

Table 10 - Summary of Ziegler-Nichols PID tuning terms based on ultimate gain $(\mathrm{Ku})$ and oscillation

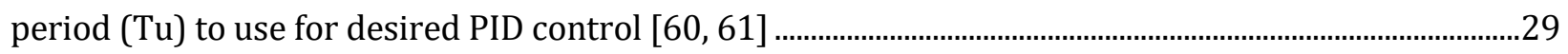

Table 11 - Sensor abbreviations and purposes list for Figure 30 and Figure 31 .........................................37

Table 12 - Measurement Systems That Require Linearity Verification as per ...............................................39

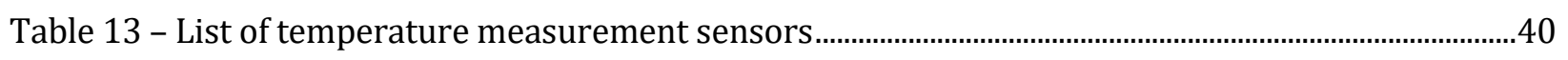

Table 14 - List of pressure measurement sensors.............................................................................................41

Table 15 - List of engine parameter sensors ..................................................................................................41

Table 16 - Radiator Left 1 thermocouple linearity values ...............................................................................42

Table 17 - Corresponding statistical data for Radiator Left 1 data.......................................................................42

Table 18 - Recalculated reference values with updated temperature coefficient.........................................43

Table 19 - a1 coefficient values for recalculated data in Table 18 ….............................................................43

Table 20 - Updated reference values for temperature sensor 'Radiator Left 1" .........................................44

Table 21 - Corresponding statistical analysis for updated values to temperature sensor "Radiator Left $1 "$

Table 22 - Comparison of iterated values from MATLAB ${ }^{\circledR}$ and Scimitar from Notch 8 of..........................49

Table 23 - Comparison of emissions concentrations from MATLAB ${ }^{\circledR}$ and Scimitar from Notch 8 of Test

ID: R0007-002-198.

Table 24 - Standard duty cycle weighting factors for calculating emission rates for locomotives from

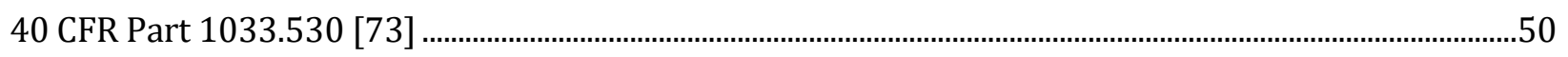

Table 25 - Scimitar emission results from Notch 8 of Test ID: R0007-002-198 ….......................................51

Table 26 - MATLAB $^{\circledR}$ emission results from Notch 8 of Test ID: R0007-002-198 ……….............................51 
Table 27 - Fuel burned over an emissions test for a 2016 SD60E equipped with a model year 1990 engine (data from Appendix C2 - Preliminary Test Data for Test ID: R0007-002-198) ... . .52

Table 28 - Brake-specific fuel consumption for a 2016 SD60E equipped with a model year 1990 engine (data from Appendix C2 - Preliminary Test Data for Test ID: R0007-002-198)..... .52

Table 29 - Portion of data for SEE calculation of Dilution and PM flow rates during Notch 8 of Test ID: R0007-002-198. .58

Table 30 - Tabulated data of KRAL calibration flow test. .63

Table 31 - Portion of data from time 3900 seconds to 3900.5 seconds of Notch 8 . .68

Table 32 - Initial overview comparison of mass flow and density accuracies for OMEGA ${ }^{\mathrm{TM}}$, Siemens, and Emerson mass flow meters (info used from company websites) .74

Table 33 - 1065.205 Recommended performance specifications for measurement instruments [79]75 Table 34 - Omega $^{\text {TM }}$ flow meter specifications for Coriolis flow meter at various flow rates (full data sheet in Appendix C3 - Omega ${ }^{\mathrm{TM}}$ Engineering FMC-5000 Coriolis Mass Flow Meter Specifications).....75 Table 35 - Siemens flow meter specifications for FCS400 DN 15 Coriolis flow meter at various flow rates at $840 \mathrm{~kg} / \mathrm{m}^{3}$ (full data sheet in Appendix C4 - Siemens FCS400 DN 15 sensor flow meter calculations) .76

Table 36 - Emerson's Micro Motion flow meter specifications for CMFS040 Coriolis flow meter at various flow rates at $840 \mathrm{~kg} / \mathrm{m}^{3}$ and 100 psig line pressure (full data sheet in Appendix C5 - Micro Motion CMFS040M calculation summary) .77

Table 37 - Changes in height of fuel in fuel drum based on a fuel temperature change of $0.1^{\circ} \mathrm{C}$ for various

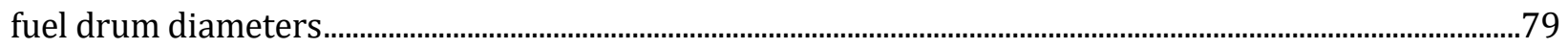

Table 38 - Troemner Calibration Weights Measurement …….......................................................................94

Table 39 - Micro Motion, Inc. mass flow meter calibration trends for test 12154968 (Appendix B1.1 Calibration Sheet for Test 12154968) .96

Table 40 - Micro Motion, Inc. mass flow meter calibration trends for test 12154969 (Appendix B1.2 Calibration Sheet for Test 12154969) …………….......................................................................................96

Table 41 - MATLAB ${ }^{\circledR}$ emission results from Notch 8 of Test ID: R0007-002-264 103

Table 42 - Portion of data between 100 seconds to 110 seconds of Sample Flow Rate [mol/s] versus Calculated Exhaust Flow Rate [mol/s] during Notch 8 for Test ID: R0007-002-264 ...............................104

Table 43 - MATLAB $^{\circledR}$ emission results from Notch 1 of Test ID: R0007-002-264 ….................................106

Table 44 - SEE with and without 5\% omission of data points for all notches for .......................................107

Table 45 - NOx Emission Factors (g/gal) …………....................................................................................... 140

Table 46 - PM Emission Factors (g/gal) ......................................................................................................... 141 
Table 47 - HC Emission Factors (g/gal) . 142

Table 48 - Scimitar results for Idle for Test ID: R0007-002-198. 158

Table 49 - Scimitar results for Idle for Test ID: R0007-002-198. 158 


\section{LIST OF SYMBOLS/NOMENCLATURE}

AAR Association of American Railroads

BIPM International Bureau of Weight and Measures

bhp brake-horsepower

BSFC Brake-Specific Fuel Consumption

CAFEE Center for Alternative Fuels Engines and Emissions

CEM Clean Emissions Module

CFR Code of Federal Regulations

CO Carbon Monoxide

CO2 Carbon Dioxide

CVS Constant-Volume Sampling (Sampler)

DAQ Data Acquisition

DEF Diesel Exhaust Fluid

DOC Diesel Oxidation Catalyst

DPF Diesel Particulate Filter

ERC Engines and Emissions Research Center

ERTAC Eastern Regional Technical Advisory Committee

EPA Environmental Protection Agency

FEL Family Emissions Limit

${ }^{\circ} \mathrm{C} \quad$ degrees Celsius

${ }^{\circ} \mathrm{F} \quad$ degrees Fahrenheit

g gram

HC Hydrocarbon

hp horsepower

hr hour

ISEDC Innovation, Science and Economic Development Canada

$\mathrm{Kd} \quad$ Derivative term (PID)

Kh NOx correction factor

$\mathrm{Ki} \quad$ Integral term (PID)

Kp Proportional term (PID)

kW kilowatt

LADCO Lake Michigan Air Directors Consortium

NIST National Institute of Standards and Technology 


\begin{tabular}{ll} 
NO & Nitric Oxide \\
NOx & Nitrogen Oxide \\
NPT & National Pipe Thread \\
PEMS & Portable Emissions Measurement System \\
PID & Proportional - Integral - Derivative \\
PM & Particulate Matter \\
PD & Positive Displacement \\
psi & pounds per square inch \\
RTD & Resistance Temperature Detector \\
S & second \\
SEE & Standard Estimate of the Error \\
SCCM & Standard Cubic Centimeters per Minute \\
SCR & Selective Catalytic Reduction \\
SESARM & Southeastern States Air Resource Managers \\
SI & International System of Units \\
SLPM & Standard Liters per Minute \\
STB & Surface Transportation Board \\
SwRI & Southwest Research Institute \\
$\sigma$ & Standard Deviation \\
\hline
\end{tabular}




\section{INTRODUCTION}

Located in Altoona, Pennsylvania, the Juniata Thoroughbred Emissions Research lab has provided locomotive emissions research for several railways including Association of American Railroads (AAR), Norfolk Southern (NS), General Electric (GE), and Electro-Motive Diesel (EMD) for many years. The emissions research lab developed an emissions measurement system in conjunction with engineers from West Virginia University's (WVU) Center for Alternative Fuels Engines and Emissions (CAFEE) that is compliant to federal emissions code, more explicitly known as the Code of Federal Regulations (CFR). The CFR outlines the procedures for locomotive emissions testing through Title 40 CFR Part 1033 - Control of Emissions From Locomotives [1] and Title 40 CFR Part 1065 Engine Testing Procedures [2].

\subsection{Introductory Background on Locomotive Testing}

To perform an emissions test at the Juniata emissions lab, the desired test locomotive is moved into the facility with the exhaust stack of the locomotive positioned beneath the exhaust hood. Sensors and instrumentation (thermocouples, pressure transducers, gas analyzers, and power analyzers) are installed and prepared for testing following the applicable CFR specifications, discussed in further detail in Section 3 METHODOLOGY - EMISSION MEASUREMENT AND VERIFICATION THROUGH GRAVIMETRIC, VOLUMETRIC, AND MASS MEASUREMENT. After preparations are finalized, an emissions test is performed per Title 40 CFR Part 1033 [1] and Title 40 CFR Part 1065 [2]. A general overview of a locomotive testing procedure is described as follows [3]:

1) Prepare the engine, equipment, and measurement instruments for an emission test.

2) Perform pre-test procedures to verify proper operation of equipment and analyzers.

3) Record pre-test data.

4) Start or restart the engine and sampling systems.

5) Sample emissions throughout the duty cycle.

6) Record post-test data.

7) Perform post-test procedures to verify proper operation of certain equipment and analyzers.

8) Weigh particulate matter (PM) samples.

When testing locomotives, fuel consumption and exhaust emission concentrations are measured and used to determine exhaust flow and emission rates for different locomotive power levels which are more commonly referred to as notches. 40 CFR Part 1033.501 - General Provisions [4], outlines the use of equipment and procedures for compression-ignition engines. This 
regulation, in conjunction with 40 CFR Part 1065 - Engine-Testing Procedures [5], is used to determine whether a locomotive meets the duty-cycle emission standards as specified in 40 CFR Part 1033.101 - Exhaust Emissions Standards [6].

To determine the emissions produced by a locomotive, a partial amount of the raw exhaust flow is diverted from the full exhaust flow and sent through gaseous emissions analyzers. However, before the measurement of emissions through the analyzers can take place, the exhaust flow is conditioned to meet the emissions measurement instruments requirements, such as concentration of the gaseous emissions, temperature, and moisture content, while minimizing chemical reactions that can take place between the exhaust stack and the emissions analyzer [7].

Dilution of exhaust flow, or measurement of undiluted raw exhaust flow can be done depending on the emissions analyzer used. Diluting the exhaust gas with particle free, humidity and temperature controlled ambient air is a method used to meet instrument requirements which limits chemical reactions. This method also cools the exhaust to acceptable temperatures required by the gaseous analyzers. Cooling the exhaust through dilution is helpful in preventing supersaturation which can result in condensation and/or nucleation of new particle species $[7,8]$.

A partial flow sampling system is designed to measure the mass of emissions in exhaust flow without directly measuring the total exhaust flow, fuel flow rate, or intake air flow [9]. Partial flow sampling utilizes a constant volume sampler (CVS) device which is used to control the amount of dilution flow through the measurement system. Dilution air flow rate, total dilution air flow rate, and exhaust emissions concentrations are measured and used to calculate the total mass of emissions from an engine [7,9]. Figure 1 shows a simplified diagram of a partial flow sampling system.

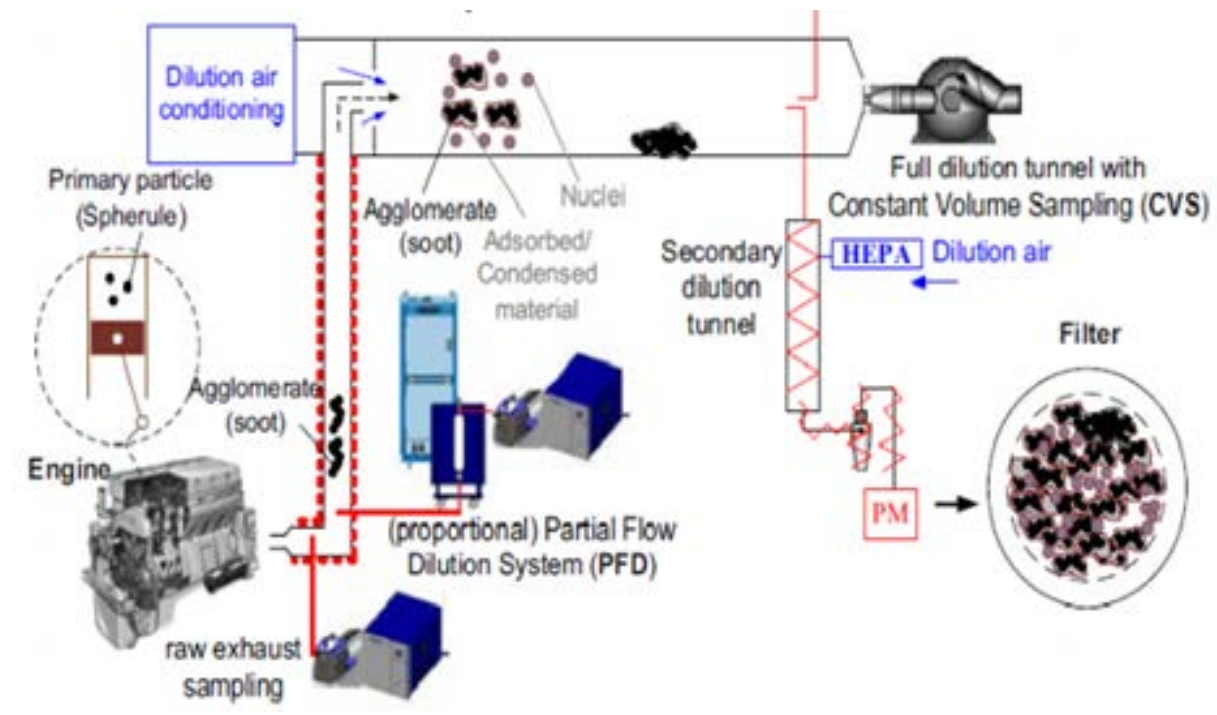

Figure 1 - Simplified diagram of a partial sampling emissions measurement system [8] 
In the partial flow sampling system seen in Figure 1, exhaust gas is diverted off and sent through a pipe to a CVS. A probe for a partial flow dilution (PFD) system which measures the raw exhaust gas emissions is placed before the CVS. The PFD system is used in raw exhaust gas emissions concentrations measurement. The CVS is used to dilute the exhaust air such that particulate matter (PM) can be weighed on a filter further downstream. In probes for diluted or raw gas flow, it is ideal that the sampling line flow velocity should be the same as the exhaust flow velocity. This condition is referred to as isokinetic sampling and is important to maintain as it allows the particles of emissions to enter the probe undisturbed by undesirable factors such as aerodynamic effects which can manipulate the reading and provide incorrect measurement of emissions $[7,10]$.

To meet the testing and measurement requires of the CFR, the Juniata lab measures particulate matter (PM) through a Sierra Instruments BG3 partial flow dilution (PFD) PM system(compliant to 40 CFR Part 1065 Subpart C - Measurement Instruments [11]), and a HORIBA MEXA-7100D exhaust gas analyzer for raw emissions sampling (compliant to 40 CFR Part 1065 Subpart C - Measurement Instruments [11]), and measures fuel consumption through gravimetric measurement.

Regulation 1033.501 [4] specifies that locomotive notch testing is discrete-mode testing and that, with respect to the test operator demand, the test cycle is steady-state. This means that each locomotive power notch is a steady-state mode. However, while the notch is steady-state, fuel rates and emissions rates can vary due to notch transitions or increased electrical loads, such as radiator fans cycling on mid-notch. Furthermore, the same regulation states that if discrete-mode testing is used, only one batch fuel measurement may be used to determine the mean raw exhaust flow rate.

Additionally, a constant dilution sample flow rate of exhaust gases must be achieved over the mode as these flow rates are used to verify that the proportional sampling of dilution air was maintained as described in 40 CFR Part 1065.545 - Verification of proportional flow control for batch sampling [12]. Fuel measurement is the method used at the Juniata lab to verify exhaust gas proportional sampling compliant to 40 CFR Part 1065.545 [12]. This method uses the calculated mean molar exhaust flow rate determined from the measured gravimetric fuel flow rate to determine if proportional sampling was met over the notch.

\subsection{Juniata Thoroughbred Emissions Lab Emissions Measurement System}

As stated previously, a BG3 PFD PM sampling system is used for PM measurement, a HORIBA MEXA exhaust gas analyzer is used for raw exhaust gas emissions sampling, and fuel consumption is 
measured gravimetrically. Figure 2 shows a picture and layout callouts at the Juniata locomotive emissions research lab. Figure 3 shows a picture of the gravimetric fuel measurement system. Figure 4 shows a diagram of the gravimetric fuel measurement system.

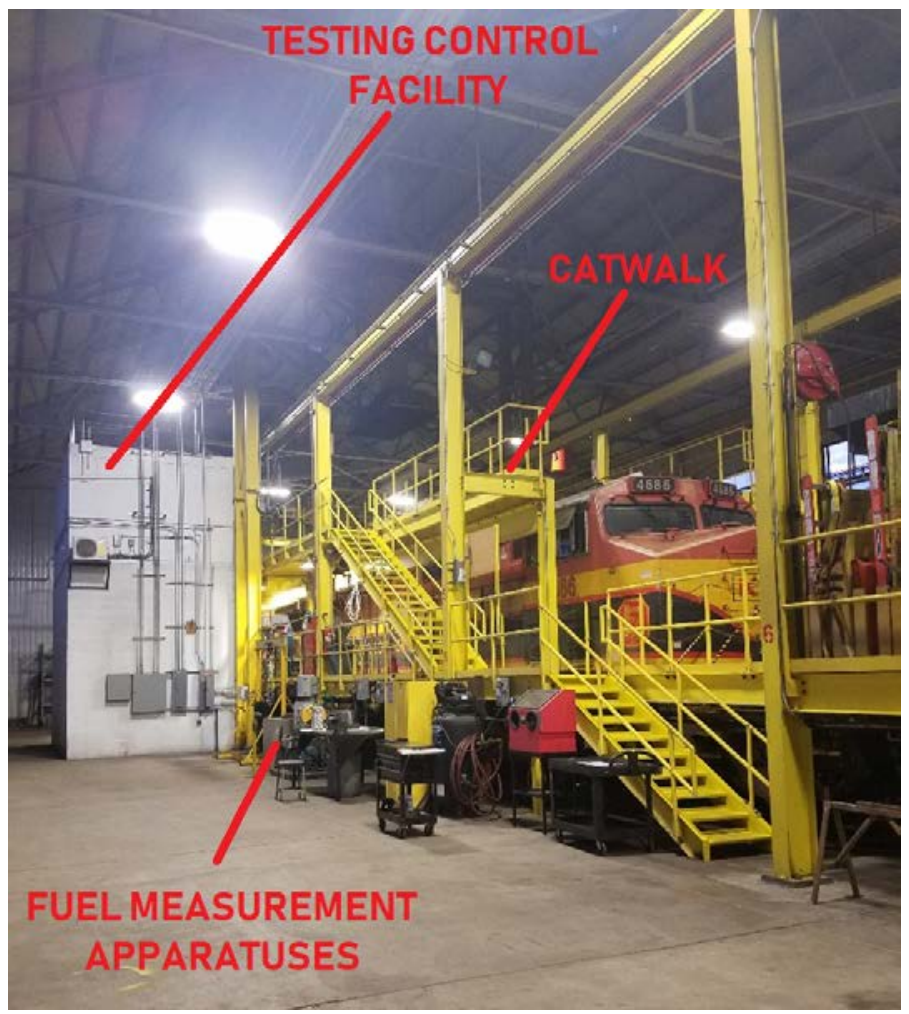

Figure 2 - Picture of the Juniata Thoroughbred Emissions Research lab

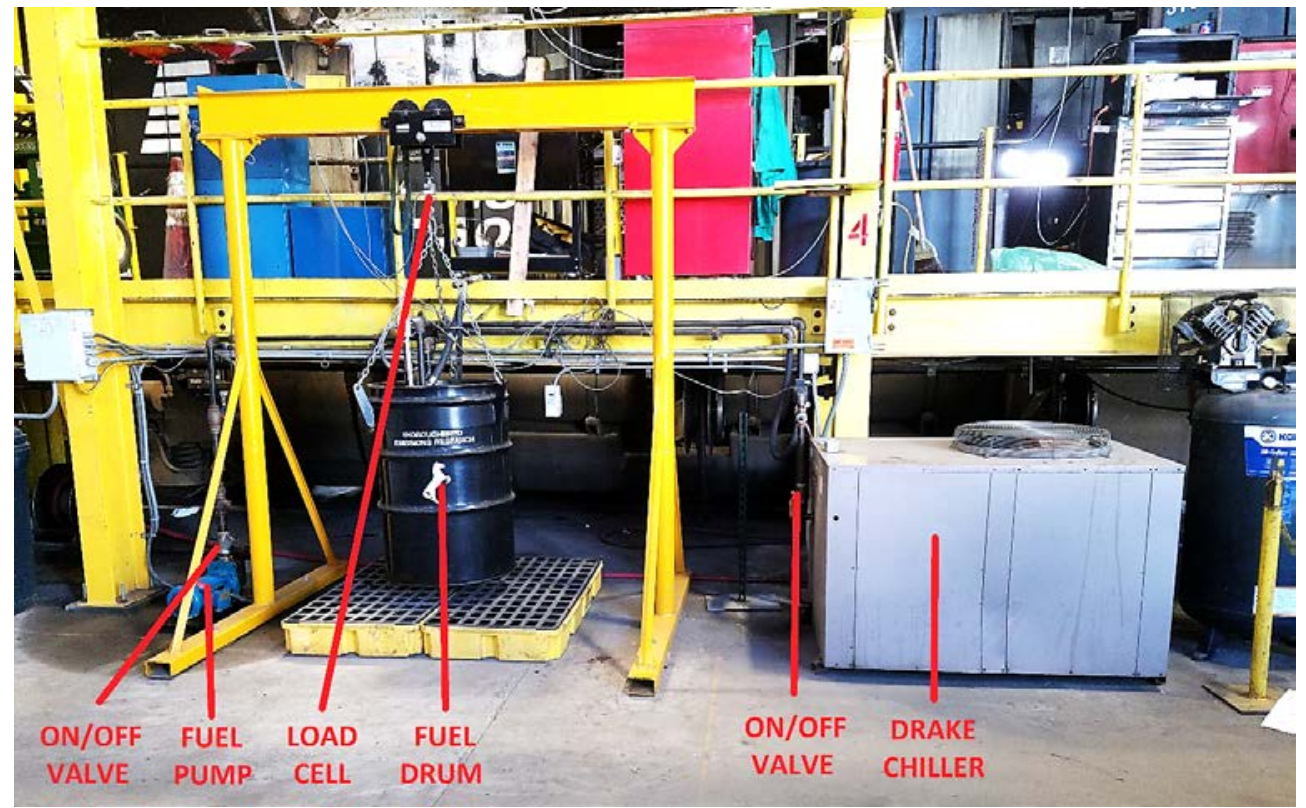

Figure 3 - Picture of the gravimetric fuel measurement system implemented in the fuel measurement apparatuses area at the Juniata Thoroughbred Emissions Research lab 


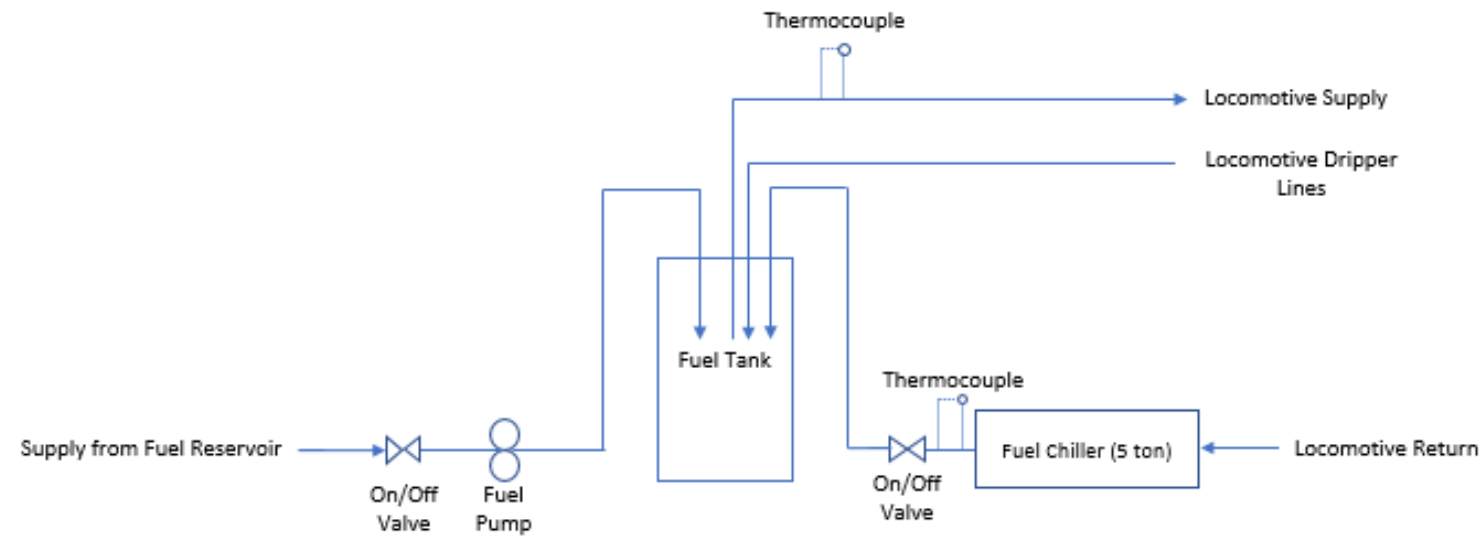

Figure 4 - Flow diagram of the gravimetric fuel measurement component

The fuel measurement system pumps fuel by an external, 3/4 horsepower, self-priming, centrifugal, Burks Pumps fuel pump into a 55 gallon fuel drum suspended on an Omega S-Beam load cell. The fuel in the drum is then pumped to the locomotive by the locomotive's onboard fuel pump. The excess fuel not used in the engine combustion process is cycled through a Drake Refrigeration Inc. 5 ton fuel chiller and returned into the fuel drum to be recirculated through the system. Locomotives that require excess fuel that is used in the fuel rail to cool and lube the fuel injectors is routed back to the fuel drum for measurement through dripper tubes. These are fuel lines that route the excess fuel back to the fuel tank during normal operation.

The weight of the fuel tank, fuel temperatures (to and from the locomotive, and out of the chiller), and several other parameters on the locomotive are measured. These parameters include atmospheric conditions (e.g. intake and exhaust temperatures, barometric pressure, humidity), radiator temperatures, and particulate matter and exhaust gas emissions collected by BG-3 particulate matter sampling system and MEXA gaseous emissions analyzer. These parameters are collected by a data acquisition (DAQ) software, named Scimitar, developed by engineers at CAFEE.

Scimitar collects the data from the sampling system gas analyzers, opacity meter, all engine and ambient parameters listed above, and the fuel drum weight and continuously records the data. After testing, Scimitar archives all data, runs the emissions calculations from 40 CFR Parts 1033 [1] and 1065 [2], and compiles it into a data test report sheet that lists the brake-specific emissions.

\subsection{Moving from Gravimetric Fuel Measurement to Continuous Fuel Measurement}

By its design, the gravimetric fuel system does not measure instantaneous fuel consumption rate, but rather average fuel consumption in each locomotive power notch setting. Before a power notch begins, the fuel drum is filled and the weight recorded. During a notch transition and during the 
power notch mode test, the drum is not filled. Thus, the fuel is continuously cycled through the drum to the locomotive, through the chiller, and back to the fuel drum. At the end of the mode the drum weight is recorded again. The difference in weight between the beginning and end of the notch divided by the duration of the notch provides the average fuel consumption rate of the notch. At the end of the notch, the drum is refilled, and the next notch begins.

During power notch transitions (for exampling, increasing power from Notch 7 to Notch 8) the locomotive engine control system ramps power up over a small time period. Typically, the time during ramp up can be as long as 30 seconds. During this time, the fuel consumption and exhaust flow rates are changing. Additionally, electrical loads, such as radiator fans cycling on, can occur mid-notch which results in non-steady fuel consumption and exhaust flow rates. It is important that exhaust and fuel flow rates, as well as corresponding exhaust emissions, are measured accurately so that brake-specific fuel consumption (BSFC) and brake-specific emissions can be calculated correctly.

This sequential nodal testing where separate groups of data are collected is batch testing. 40 CFR 1033.501 (4) [4] states that, "If you perform discrete-mode testing and use only one batch fuel measurement to determine your mean raw exhaust flow rate, you must target a constant sample flow rate over the mode. Verify proportional sampling as described in 40 CFR 1065.545 using the mean raw exhaust molar flow rate paired with each recorded sample flow rate." This means that over a single notch, and for every other notch during an emission test, emissions rates and fuel consumption is averaged over each sampling period. The average emissions rates, in grams per hour (g/hr), and engine horsepower, in brake-horse power (bhp), are used in 40 CFR 1065.650 (g) [13], in conjunction with 40 CFR 1033.245 [14], to calculate brake-specific emissions to determine if a locomotive is compliant to emissions standards.

The gravimetric fuel measurement system is a batch sampling fuel measurement system. The CFR allows for batch sampling, as stated above, so long as proportional sampling criteria is met and as such the system could still be used for further emissions testing. However, for more in-depth diagnostics to the system, specifically how fuel consumption rates can change during a notch, continuous fuel mass flow measurement was desired and as such development of a new fuel mass flow measurement system was decided to be undertaken.

\subsection{Research Goals and Objectives}

There were two research goals for this project. (1) Verify the emissions measurement system used at the Juniata emissions lab is compliant to 40 CFR parts 1033 and 1065, specifically that verification of proportional sampling can be performed and met using gravimetric fuel measurement 
and (2) Design and implement an instantaneous fuel mass flow measurement system for use in verification of locomotive emissions. The objectives of this thesis are to:

- Provide background on locomotive testing and emissions measurement

- Discuss the current emissions and fuel flow measurement system at the Juniata Locomotive Emissions lab

- Discuss how the emissions and fuel measurement systems at the Juniata emissions lab meet 40 CFR parts 1033 and 1065 emissions testing protocol

- Detail the design and implementation of an instantaneous fuel mass flow measurement system for use in locomotive emissions measurement that is compliant to 40 CFR Parts 1033 and 1065 emissions testing protocol

- Determine the validity of the new fuel flow measurement system for future emissions testings

\section{LITERATURE REVIEW}

\subsection{Background on the Environmental Protection Agency and Locomotive Freight}

Since its establishment in 1970 the Environmental Protection Agency (EPA) has sought to protect human health and the environment from significant risks where they live, learn, and work. In order to succeed in their mission, the EPA develops and enforces regulations that are national standards that states and tribes must abide [15]. These standards regulate emissions from all types of vehicles including automobiles, heavy-duty (e.g. semi-trucks), marine vessels, and locomotives.

Formed in 1966, the Surface Transportation Board (STB) is an adjudicatory body that regulates various modes of surface transportation and deals with railway rate and service issues, including the classification of railroads. In the United States (U.S.), freight railroads are divided into three classes based on annual revenue by the federal government's STB. The STB's 1994 Railroad Index classified a railroad as a Class I railroad if its annual operating revenue is greater than $\$ 255.9$ million, a Class II railroad with an annual operating revenue between $\$ 20.5$ million and $\$ 255.8$ million, a Class III railroad with an annual operating revenue less than $\$ 20.5$ million $[16,17]$.

Class I railroads are the long distance, line-haul railroads that carry the bulk of railroad commerce such as grain and coal [17]. As of 2018, there are 7 Class I freight railroad systems in the U.S., and eight total Class I railroads; Burlington Northern Santa Fe (BNSF), Canadian National (CN), Canadian Pacific (CP), CSX, Ferromex (FXE), Kansas City Southern (KCS), Norfolk Southern (NS), and Union Pacific (UP). Each railway is classified as Class I if it has an annual operating revenue of $\$ 250$ million in 1991 dollars or more (adjusted for inflation is \$467.1 million in 2018). Combined, there are 21 regional railroads, and 510 local railroads with over 26,000 locomotives in service [17- 
19]. These rail networks account for 40 percent of freight transported in the U.S. per ton-miles [20]. Figure 5 shows a breakdown percentage of how much freight is transported in the U.S.

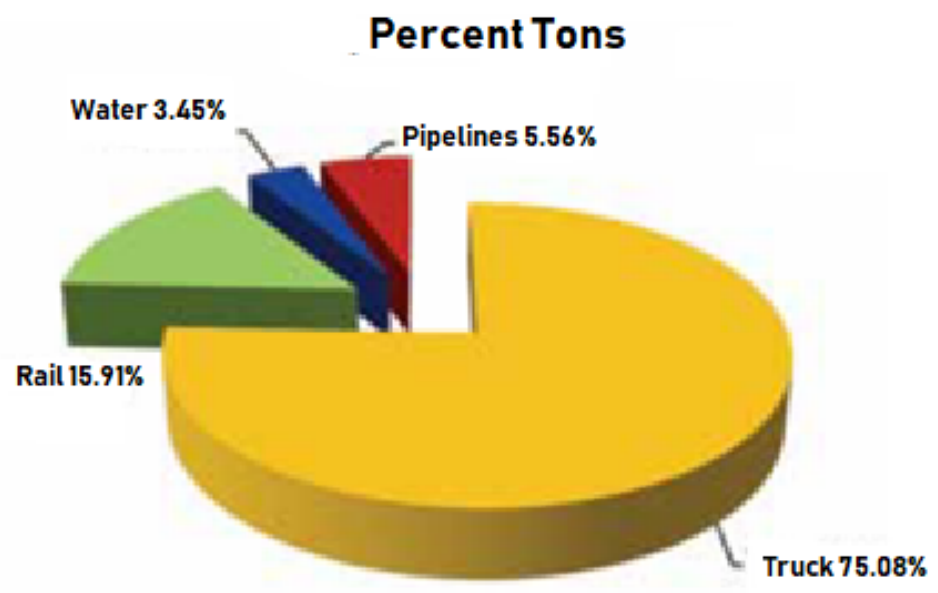

\section{Percent ton-miles}

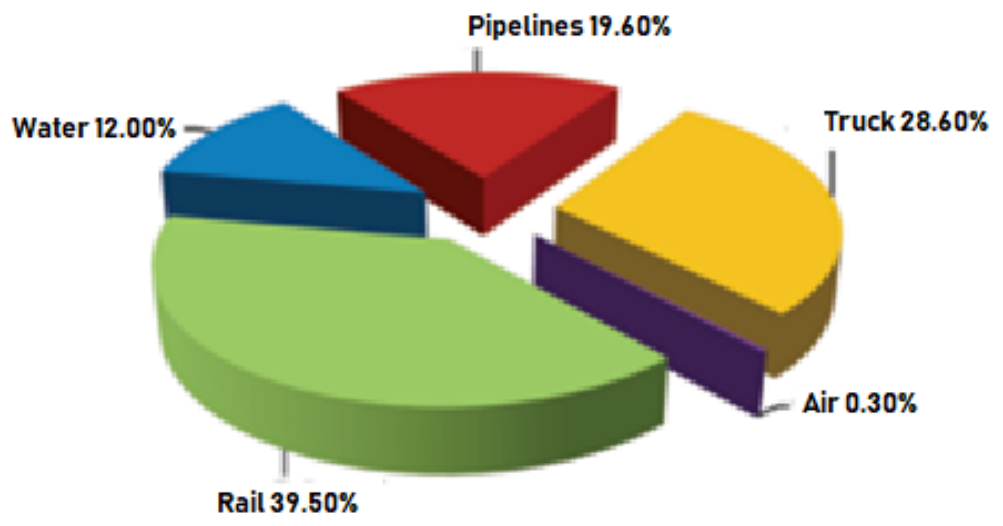

Figure 5 - Percent breakdown of how freight is transported in the U.S. on a percent tons and percent ton-miles basis [18]

From the 'Percent Tons' pie graph (Figure 5 - top), it can be seen that Rail (15.91\%) and Truck (75.08\%) transport the largest percentages of freight per year. The 'Percent ton-miles' pie graph (Figure 5 - bottom) shows that Rail transports the most amount of freight per mile at 39.50\% while Trucks transport 28.60\%. Both of these modes of transportation utilize heavy-duty diesel engines for transporting goods. The EPA regulates these so heavily due to their significant emissions outputs which would harm human health and the environment. 


\subsection{Diesel Locomotive Design Features}

Locomotives are not only classified by how much they transport, but also how much horsepower the locomotive produces. Switch, or yard, locomotives are the least powerful locomotives and are used to assemble and disassemble railcars within the railyard or used to transport cars over short distances and have between 1,000 and 2,300 hp. Medium horsepower locomotives are larger switcher locomotives which are passenger locomotives and have between 2,300 and 3,800 horsepower. Interstate, or freight line haul locomotives, are locomotives that travel over long distances and are the most powerful locomotives which typically have between 3,800 and 6,000 horsepower [16, 21].

Most transportation vehicles, such as cars and heavy-duty trucks, utilize a mechanical means to transfer power (i.e. a transmission) from the engine to the wheels. The engine is controlled by the operator through a throttle which results in transient engine speeds and loads. Locomotives, however, lack a direct mechanical connection between the engine and wheels (i.e. their engines are connected to an electrical alternator or generator to convert mechanical energy to electricity). This electricity is used to power traction motors which sends power to the wheels. Due to the way locomotive power is controlled, the locomotive operator can operate in steady-state modes, in a set number of discrete power settings, or notches [16, 22].

Most modern diesel locomotives have 8 discrete notch power settings in addition to idle and the dynamic braking functions on a locomotive's throttle gate. A diesel locomotive has its diesel engine and electrical generator connected on the same shaft as seen in Figure 6 below [23, 24].

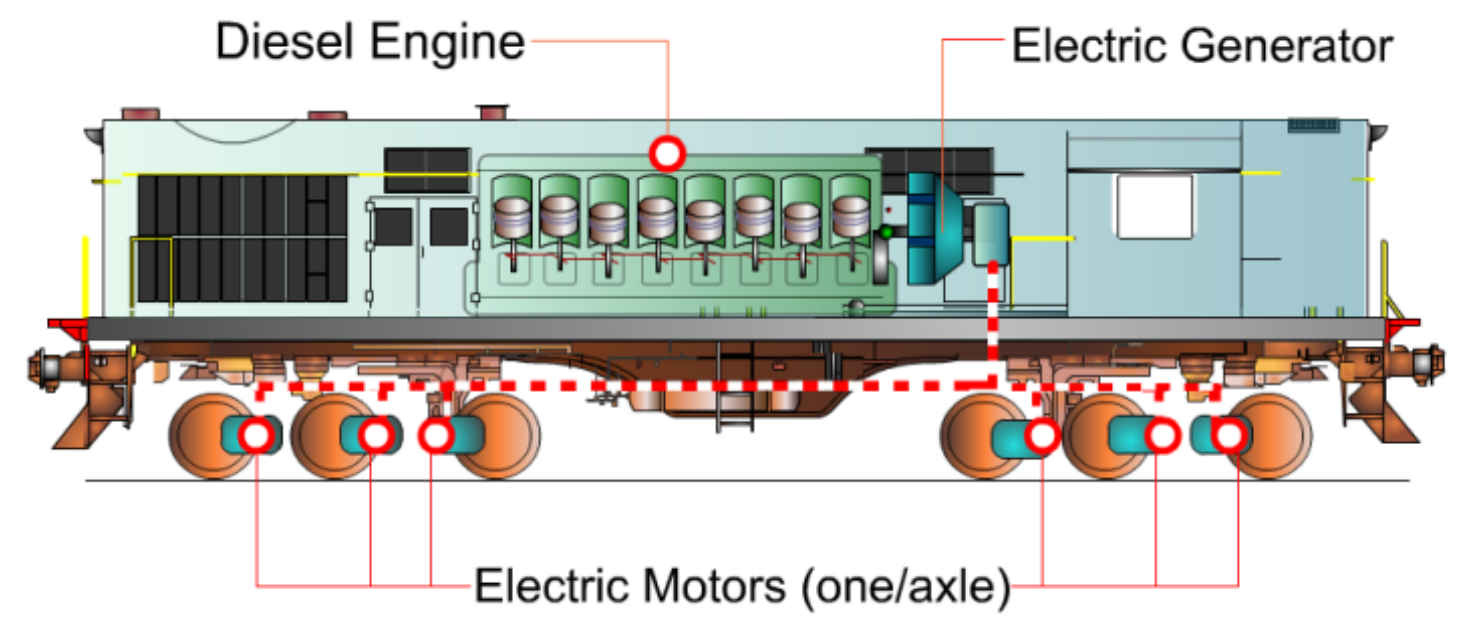

Figure 6 - Diagram of a diesel locomotive and its engine and electrical components interactions that propel the locomotive [23] 
Each power setting corresponds to the amount of fuel delivery to the engine. As more fuel is injected into the diesel engine, more mechanical output power is produced and sent to the electrical generators. Idle is the lowest power setting where the engine operates at its lowest RPM and typically does not send enough power to the wheels to propel the locomotive. Dynamic braking is the next power setting, however dynamic braking is used to stop or slow a locomotive's forward movement unlike the other notches.

During dynamic braking, the traction motors act as generators to create resistance against the electrical generator which slows the locomotive. The generated electricity is dissipated through an electrical resistance grid which produces considerable amounts of heat [16, 23-26]. The eight notch power settings follow, each of which produce more power than the last up to the locomotive's maximum power. Each power notch setting is tested during an emissions test to determine the weighted BSFC and brake-specific emissions of the locomotive.

\subsection{Diesel Locomotive Emissions and Future Emissions Predictions}

In June 2008, the EPA released their Report on the Environment which finalized a three-part program that required more stringent regulations on diesel locomotives [27, 28]. This ruling required reduction of particulate matter (PM) emissions up to $90 \%$ and nitrogen oxides (NOx) emissions, consisting of nitric oxide (NO) and nitrogen dioxide (NO2), up to 80\% [28].

The Eastern Regional Technical Advisory Committee (ERTAC) is a committee formed in 2008 which sought to improve the quality of data for emissions inventories to help with future emissions projections [29, 30]. Their findings for locomotives emissions inventories in 2007/2008 are listed in Table 1 below [29].

Table 1 - Summary of ERTAC Rail Inventories: U.S. Locomotive Emissions and Fuel Use for $2007 / 2008[29,30]$

\begin{tabular}{|c|c|c|c|c|c|c|c|c|}
\hline & \multirow{2}{*}{$\begin{array}{c}\text { Fuel Use } \\
\text { (gal/yr) }\end{array}$} & \multicolumn{7}{|c|}{ Emissions (tons/yr) } \\
\hline & & NOx & $\mathbf{P M}$ & HC & SO2 & $\mathrm{CO}$ & NH3 & $\mathrm{CO2}$ \\
\hline $\begin{array}{c}\text { Class I line- } \\
\text { haul }\end{array}$ & $3,770,914,002$ & 754,443 & 23,439 & 37,941 & 7,836 & 110,969 & 347 & $42,305 \mathrm{k}$ \\
\hline $\begin{array}{c}\text { Class I } \\
\text { switcher }\end{array}$ & $301,046,290$ & 74,431 & 2,042 & 4,867 & 624 & 9,230 & 28 & $3367 \mathrm{k}$ \\
\hline $\begin{array}{c}\text { Class II and } \\
\text { III }\end{array}$ & $157,800,000$ & 47,035 & 1,065 & 1,737 & 327 & 4,631 & 14 & $1,765 \mathrm{k}$ \\
\hline
\end{tabular}

The ERTAC information provides accurate information on locomotive inventories and locomotive inventory projections. In 2009, the EPA released their future emissions factors 
regulations for locomotives up to the year 2040 [31]. The emissions factors can be seen in Table 2, below.

Table 2 - EPA's emissions factors of NOx [g/gal] for years 2006 - 2040 [31]

\begin{tabular}{|c|c|c|c|c|c|}
\hline Calendar & Large Line- & Large & Small & & Overall \\
\hline $\begin{array}{l}\text { Year } \\
2006\end{array}$ & $\begin{array}{l}\text { haul } \quad 180 \\
\end{array}$ & $\begin{array}{l}\text { Switch } \\
250\end{array}$ & $\begin{array}{l}\text { Railroads } \\
242\end{array}$ & $\begin{array}{r}\text { Passenger/Commuter } \\
244\end{array}$ & $\begin{array}{r}\text { Average } \\
188\end{array}$ \\
\hline 2007 & 175 & 249 & 242 & 229 & 183 \\
\hline 2008 & 169 & 243 & 242 & 214 & 177 \\
\hline 2016 & 121 & 208 & 239 & 119 & 129 \\
\hline 2017 & 114 & 206 & 237 & 112 & 122 \\
\hline 2018 & 108 & 202 & 236 & 105 & 117 \\
\hline 2038 & 31 & 67 & 177 & 26 & 36 \\
\hline 2039 & 29 & 63 & 174 & 24 & 34 \\
\hline 2040 & 28 & 60 & 171 & 23 & 32 \\
\hline
\end{tabular}

From Table 2, and other future emission factors tables (Table 44, Table 45, and Table 46 in Appendix C1 - Projected Future Emission Factors Complete Tables [31]), the EPA estimates that locomotives consume 4 billion gallons of diesel fuel in total every year which is spread across national/regional freight (line-haul), switchers, local freight, and passenger locomotives. Compared to ERTAC, from Table 2 above (3.7 billion gallons), an estimated 4.2 billion gallons of diesel fuel is consumed by locomotives. In terms of percentage breakdown, the EPA and ERTAC both agree. Table 3 shows the percentage breakdown for yearly locomotive fuel consumption by each freight service.

Table 3 - Breakdown percentages of yearly fuel consumption for each locomotive service

\begin{tabular}{|c|c|c|}
\hline Service & ERTAC Percentage & EPA Percentage \\
\hline National and Regional Freight Line-Haul & $89.2 \%$ & $88 \%$ \\
\hline National Freight Switcher & $7.1 \%$ & $7 \%$ \\
\hline Local Freight & - & $<2 \%$ \\
\hline Passenger & $3.7 \%$ & $3 \%$ \\
\hline
\end{tabular}

As seen in Table 3, both ways to find fuel consumption for each locomotive services are in agreement. Thus, future emissions prediction calculations can be performed in an accurate manner. The equation below shows how to estimate each set of emissions based on the emissions factor for that year.

$$
\text { Emissions }_{\text {year }}\left[\frac{\text { tons }}{\mathrm{yr}}\right]=\text { Fuel Use }\left[\frac{\mathrm{gal}}{\mathrm{yr}}\right] * \text { Emissions Factor }\left[\frac{\mathrm{g}}{\text { gal }}\right] * 1.10 \mathrm{e}^{-6}\left[\frac{\text { tons }}{\mathrm{g}}\right]
$$

It can be seen from Table 2 that the EPA will continue to become more stringent with their strategies for emissions regulations. For this reason, it is critical to measure accurate emissions to validate that engine manufacturers are meeting the emissions criteria. 


\subsection{The Code of Federal Regulations}

The CFR is the codification of the 50 titles of general and permanent federal regulation published in the Federal Register by the Federal Government. Each title of the CFR is divided into chapters that are further subdivided into parts that outline specific regulatory areas. These titles are updated once a year and issued on a quarterly basis. The title's annual release dates are as follows [32, 33]:

- $\quad$ Titles 1-16 are updated as of January 1st

- Titles 17-27 are updated as of April 1st

- Titles 28-41 are updated as of July 1st

- $\quad$ Titles 42-50 are updated as of October 1 st

Title 40 of the CFR is "Protection of the Environment" and mainly covers the environmental regulations set by the Environmental Protection Agency (EPA). Specifically related to locomotives, are Parts 1033 and 1065 which cover all regulations for locomotive emissions and locomotive engine testing procedures, respectively.

\subsubsection{Emission Standards and Related Requirements}

40 CFR Part 1033.101 outlines the current locomotive emissions standards that must be measured using the applicable test procedures outlined in subpart F [34] for each type of locomotive (new and in-use). Table 4 and Table 5 list each emissions standard that may not be exceeded for LineHaul and Switch locomotives respectively.

Table 4 - Line-Haul Locomotive Emission Standards [6]

\begin{tabular}{|c|c|c|c|c|c|}
\hline \multirow{2}{*}{$\begin{array}{c}\text { Year of original } \\
\text { manufacture }\end{array}$} & \multirow{2}{*}{$\begin{array}{c}\text { Tier of } \\
\text { standards }\end{array}$} & \multicolumn{4}{|c|}{ Standards (g/bhp-hr) } \\
\cline { 3 - 6 } & NOx & PM & HC & Co \\
\hline $1973-1992$ & Tier 0 & 8 & 0.22 & 1 & 5 \\
\hline $1993-2004$ & Tier 1 & 7.4 & 0.22 & 0.55 & 2.2 \\
\hline $2005-2011$ & Tier 2 & 5.5 & 0.10 & 0.3 & 1.5 \\
\hline $2012-2014$ & Tier 3 & 5.5 & 0.1 & 0.3 & 1.5 \\
\hline 2015 or later & Tier 4 & 1.3 & 0.03 & 0.14 & 1.5 \\
\hline
\end{tabular}


Table 5 - Switch Locomotive Emission Standards [6]

\begin{tabular}{|c|c|c|c|c|c|}
\hline \multirow{2}{*}{$\begin{array}{c}\text { Year of original } \\
\text { manufacture }\end{array}$} & \multirow{2}{*}{$\begin{array}{c}\text { Tier of } \\
\text { standards }\end{array}$} & \multicolumn{4}{|c|}{ Standards (g/bhp-hr) } \\
\cline { 3 - 6 } & NOx & PM & HC & Co \\
\hline $1973-2001$ & Tier 0 & 11.8 & 0.26 & 2.1 & 8 \\
\hline $2002-2004$ & Tier 1 & 11 & 0.26 & 1.2 & 2.5 \\
\hline $2005-2010$ & Tier 2 & 8.1 & 0.13 & 0.6 & 2.4 \\
\hline $2011-2014$ & Tier 3 & 5 & 0.1 & 0.6 & 2.4 \\
\hline 2015 or later & Tier 4 & 1.3 & 0.03 & 0.14 & 2.4 \\
\hline
\end{tabular}

The smoke opacity standards in Table 6 apply to locomotives certified to one or more PM standards or Family Emissions Limit (FEL) greater than 0.05 grams per brake-horsepower-hour (g/bhp-hr). These emissions, measured according to subpart F [34], may not exceed these standards.

Table 6 - Smoke Standards for Locomotives (Percent Opacity) [6]

\begin{tabular}{|c|c|c|c|}
\hline & Steady-state & $\begin{array}{c}\text { 30-sec } \\
\text { peak }\end{array}$ & $\begin{array}{c}\text { 3-sec } \\
\text { peak }\end{array}$ \\
\hline Tier 0 & 30 & 40 & 50 \\
\hline Tier 1 & 25 & 40 & 50 \\
\hline Tier 2 and later & 20 & 40 & 50 \\
\hline
\end{tabular}

\subsubsection{Locomotive Engine Testing Conditions}

40 CFR Part 1033 subpart F [34] outlines the instructions for conducting an emissions test procedure. These procedures are used for compression-ignition engines (as outlined in 40 CFR Part 1065 [35]) to determine if the locomotive meets the duty-cycle emissions standards (40 CFR Part 1033 subpart F) as outlined in Table 4 and Table 5 in Section 2.4.1 Emission Standards and Related Requirements, plus Carbon Dioxide (CO2). General test procedures are outlined in 40 CFR Part 1065 for steady-state discrete-mode cycles. Certified fuel, as outlined in, 40 CFR Part 1065 Subpart H [36], must be used to perform valid tests. Ultra-low sulfur \#2 diesel fuel was used for the locomotives used in this research.

\subsection{2-1 Discrete-mode steady-state emission tests of locomotives and locomotive engines}

Title 40 CFR Part 1033.515 [37] outlines the procedures to test locomotives at each notch power setting such that emissions can be weighted according to the appropriate duty cycle (line-haul or switcher). Each locomotive test cycle consists of a warm-up followed by a sequence of nominally steady-state discrete test modes. These test modes are steady-state in respect to the notch power setting of the locomotive but the engine speeds and loads are not necessarily steady-state. Table 7 , below, shows the locomotive test cycle sequence. 
Table 7 - Locomotive Test Cycle

\begin{tabular}{|c|c|c|c|}
\hline Test mode & Notch setting & $\begin{array}{c}\text { Time in mode } \\
\text { (minutes) }\end{array}$ & $\begin{array}{c}\text { Sample averaging } \\
\text { period for emissions }\end{array}$ \\
\hline Pre-test idle & Lowest idle setting & 10 to 15 & Not applicable \\
\hline A & Low idle & 5 to 10 & $300 \pm 5$ seconds \\
\hline B & Normal idle & 5 to 10 & $300 \pm 5$ seconds \\
\hline C & Dynamic brake & 5 to 10 & $300 \pm 5$ seconds \\
\hline 1 & Notch 1 & 5 to 10 & $300 \pm 5$ seconds \\
\hline 2 & Notch 2 & 5 to 10 & $300 \pm 5$ seconds \\
\hline 3 & Notch 3 & 5 to 10 & $300 \pm 5$ seconds \\
\hline 4 & Notch 4 & 5 to 10 & $300 \pm 5$ seconds \\
\hline 5 & Notch 5 & 5 to 10 & $300 \pm 5$ seconds \\
\hline 6 & Notch 6 & 5 to 10 & $300 \pm 5$ seconds \\
\hline 7 & Notch 7 & 5 to 10 & $300 \pm 5$ seconds \\
\hline 8 & Notch 8 & 10 to 15 & $600 \pm 5$ seconds \\
\hline
\end{tabular}

As seen in Table 7, there are 12 sequential steps that are taken during an emissions test. However, not all locomotives are equipped with all the power settings listed above so only the applicable notches are used during the emissions test. It can also be seen that all but pre-test idle lasts 300 seconds except Notch 8, which lasts 600 seconds. Before testing, the locomotive must be setup per the pre-test procedure provisions set in 40 CFR Part 1065 subpart F [34], which includes engine and emissions sampling system pre-conditioning.

\subsection{CFR Part 1065 - Engine-Testing Procedures}

40 CFR Part 1065 Subpart F [34] are the procedures set to perform an emissions test over specified duty cycles and how to measure the emissions. Subpart F outlines how to [3]:

1) Map a locomotive engine for testing

2) Transform normalized duty cycles into reference duty cycles for an engine by using an engine map

3) Prepare the engine, equipment, and measurement instruments for an emission test.

4) Perform pre-test procedures to verify proper operation of certain equipment and analyzers

5) Record pre-test data

6) Start or restart the engine and sampling systems

7) Sample emissions throughout the duty cycle

8) Record post-test data 
9) Perform post-test procedures to verify proper operation of certain equipment and analyzers

10) Weigh PM samples

Emissions measurement typically requires engine, equipment and emissions instruments preparation, verification of proper operation of equipment, emissions sampling throughout duty cycle, recording of test data, and post-test procedures such as reverification of equipment operation and weighing PM sample filters. There are two types of duty cycles that the engine may follow over an emissions test:

1) Transient duty cycles - Second-by-second sequences of speed and load commands to the engine that follow predetermined target values. This type of cycle can be performed for cold-start, hot-start, and/or hot running transient cycles which are, respectively, performed on an engine that has been shut off for a period of time and restarted, an engine that has just been warmed up, or an engine that has been warmed up and running.

2) Steady-state duty cycles - Discrete set of operating points (modes or notches) where each point has a set engine speed and engine load command that are ramped up between each mode or notch. This cycle follows a hot running cycle.

\subsection{Overview of the Calculations of Emissions}

40 CFR Part 1065.655 [38] outlines the guidelines to calculate the brake-specific emissions of a locomotive. 1065.655 states that, "Chemical balances of fuel, intake air, and exhaust may be used to calculate flows, the amount of water in their flows, and the wet concentration of constituents in their flows. With one flow rate of either fuel, intake air, or exhaust, you may use chemical balances to determine the flows of the other two [38]." The chemical balance involves a system of equations that are solved via iteration. 40 CFR Part 1065.655 [38] uses the following nomenclature:

- $\quad x d i l / e x h=$ amount of dilution gas or excess air per mole of exhaust.

- $\quad x H 2 O e x h=$ amount of H2O in exhaust per mole of exhaust.

- $\quad x C c o m b d r y=$ amount of carbon from fuel in the exhaust per mole of dry exhaust.

- $\quad x H 2 d r y=$ amount of $H 2$ in exhaust per amount of dry exhaust.

- KH2Ogas = water-gas reaction equilibrium coefficient. You may use 3.5 or calculate your own value using good engineering judgment.

- $\quad x H 2 O e x h d r y=$ amount of H2O in exhaust per dry mole of dry exhaust.

- $\quad$ xprod/intdry = amount of dry stoichiometric products per dry mole of intake air.

- $\quad x d i l / e x h d r y=$ amount of dilution gas and/or excess air per mole of dry exhaust. 
- $\quad$ xint/exhdry = amount of intake air required to produce actual combustion products per mole of dry (raw or diluted) exhaust.

- $\quad x r a w / e x h d r y=$ amount of undiluted exhaust, without excess air, per mole of dry (raw or diluted) exhaust.

- $\quad$ OO2int = amount of intake air 02 per mole of intake air.

- $\quad$ CCO2intdry = amount of intake air CO2 per mole of dry intake air. You may use $\chi C O 2 i n t d r y=$ $375 \mu \mathrm{mol} / \mathrm{mol}$, but we recommend measuring the actual concentration in the intake air.

- $\quad x$ H2Ointdry = amount of intake air H2O per mole of dry intake air.

- $\quad x$ CO2int = amount of intake air CO2 per mole of intake air.

- $\quad x C O 2 d i l=$ amount of dilution gas CO2 per mole of dilution gas.

- $x$ CO2dildry = amount of dilution gas CO2 per mole of dry dilution gas. If you use air as diluent, you may use $\chi C O 2$ dildry $=375 \mu \mathrm{mol} / \mathrm{mol}$, but we recommend measuring the actual concentration in the intake air.

- $\quad x H 2 O d i l d r y=$ amount of dilution gas H2O per mole of dry dilution gas.

- $\quad x H 2 O d i l=$ amount of dilution gas H2O per mole of dilution gas.

- $x$ [emission]meas $=$ amount of measured emission in the sample at the respective gas analyzer .

- $\quad x$ [emission]dry = amount of emission per dry mole of dry sample.

- $x H 2 O[e m i s s i o n] m e a s=$ amount of H2O in sample at emission-detection location. Measure or estimate these values according to $\$ 1065.145(e)(2)$.

- $x$ H2Oint = amount of H2O in the intake air, based on a humidity measurement of intake air.

- $\quad \alpha=$ atomic hydrogen-to-carbon ratio of the fuel (or mixture of test fuels) and any injected fluids.

- $\quad \beta=$ atomic oxygen-to-carbon ratio of the fuel (or mixture of test fuels) and any injected fluids.

- $\gamma=$ atomic sulfur-to-carbon ratio of the fuel (or mixture of test fuels) and any injected fluids.

- $\delta=$ atomic nitrogen-to-carbon ratio of the fuel (or mixture of test fuels) and any injected fluids.

Initial guesses to the iteration constituents, xH2Oexh, xdil/exh, and xCcombdry, are used to perform the iteration. The CFR recommends, "guessing an initial amount of water (xH2Oexh) that is about twice the amount of water in your intake or dilution air. Guessing an initial value of xCcombdry as the sum of measured CO2, CO, and THC values. Guessing an initial xdil/exh between 0.75 and 0.95, such as 0.8 [38]." Furthermore, the CFR states to, "Iterate values in the system of equations until the most recently updated guesses are all within $\pm 1 \%$ of their respective most recently calculated values [38]." The 
constituents for $\mathrm{x}$ [emission]meas (e.g. xCO2meas) come from the averaged, time-shifted, measured emission from the MEXA exhaust gas analyzer.

After setting the constituents to be iterated, the equations in 1065.655 [38] are used to complete the iteration. The iterated constituents xH2Oexhdry, and xCcombdry are used to find the molar exhaust flow rate and furthermore the weighted brake-specific emissions.

Additionally, it is important that accurate fuel consumption is performed as it relates directly to the molar exhaust flow rate and the verification of proportional sampling of the exhaust flow in 40 CFR 1065.545 [12] which provides the particulate matter emissions weighing. A complete iteration of emissions and emissions calculations can be found in Appendix A3 - Carbon Balancers.

\subsection{Southwest Research Institute}

Founded in 1947 and headquartered in San Antonio, Texas, Southwest Research Institute (SwRI) has become one of the largest independent, nonprofit, applied research and development (R\&D) organizations in the U.S. SwRI provides many R\&D service projects to government entities and industrial clientele. The range of research projects range from space science, bioengineering, emissions research, machinery dynamics, oil and gas, with the list encompassing most modern technologies [39, 40].

\subsubsection{SwRI - Progress Rail PR30 Locomotive SJVR3003 3000-Hour Emissions Test Report}

In 2013 SwRI was contracted by Progress Rail to complete triplicate locomotive emissions tests before and after a 3000-hour field trial on a PR30 SJVR3003 locomotive. The locomotive was equipped with a Caterpillar 3516C-HD engine and a Clear Emissions Module (CEM) - an advanced exhaust aftertreatment system based on selective catalytic reduction (SCR) and diesel oxidation catalyst (DOC) technology. The SJVR3003 was tested for 0-hour testing in November 2013 using the discrete-mode steady-state emission test for locomotives and locomotive engines, as detailed in Subpart F of 40 CFR Part 1033 and 40 CFR Part 1065. Returning in November 2015, after an accumulated 4015 field trial hours, the locomotive was tested for 3000-hour emissions testing. In both 0-hour and 3000-hour emissions tests, all emissions were within the allowable Tier 4 Line-Haul emissions limits. For both emissions tests, SwRI utilized their fuel mass flow emissions measurement system as shown in Figure 7, below. 


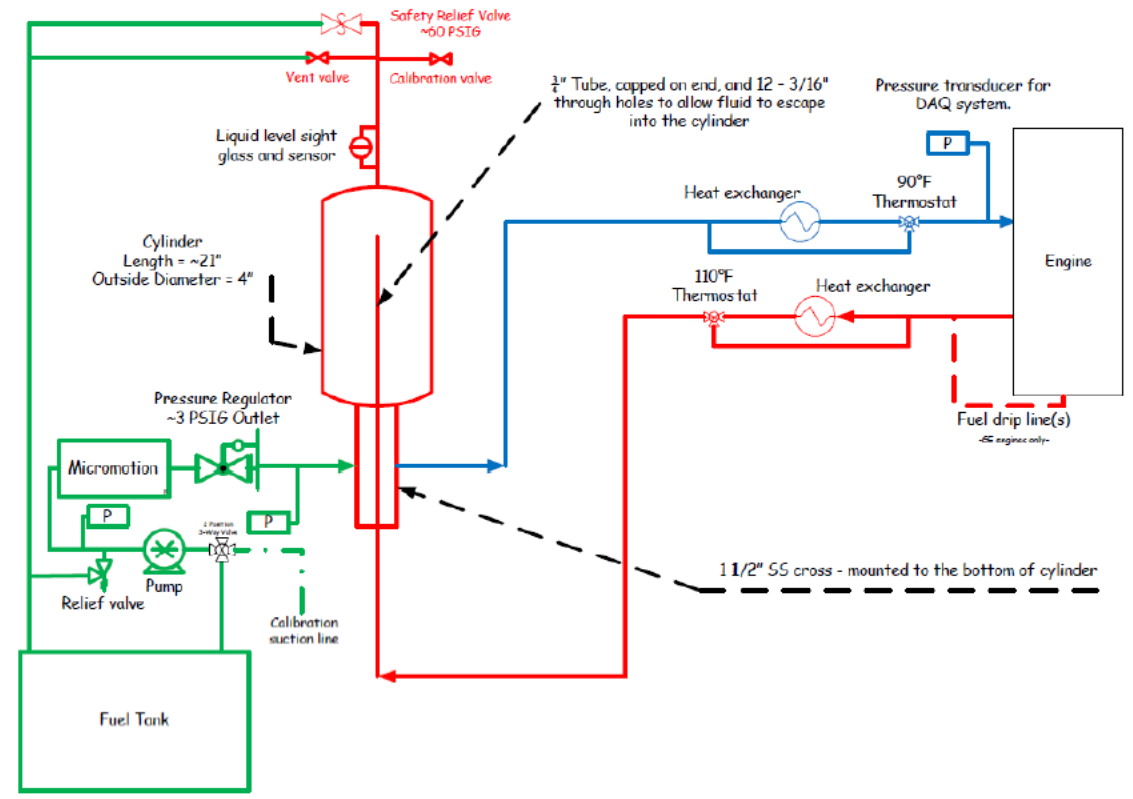

Figure 7 - Schematic of SwRI Fuel Mass Flow Measurement System [41]

The SwRI fuel flow measurement system had one known part; a Micro Motion mass flow meter. While the system and diagram were not discussed in depth by SwRI, there was information from the schematic that could be noted which lead to an interpretation on how the system functioned and performed fuel flow measurement.

Fuel was pumped from the fuel tank and through a Micro Motion mass flow meter in a pressurized line. The fuel supply pressure after the flow meter and to a reservoir cylinder was relieved to 3 pounds per square inch gage (psig). The reservoir cylinder was 4 inches in diameter and 21 inches long. Inside the reservoir cylinder was a sight glass and a level sensor. There was a relief valve in the top of the cylinder in case back flow or overfilling happened. The fuel supply to the locomotive was regulated at a target $32^{\circ} \mathrm{C}\left[90^{\circ} \mathrm{F}\right]\left( \pm 5^{\circ} \mathrm{C}\right)\left[86^{\circ} \mathrm{F}-97^{\circ} \mathrm{F}\right]$. The dripper collection lines were plumbed into the fuel return line from the locomotive and both were regulated and conditioned at a target $43^{\circ} \mathrm{C}$ $\left[110^{\circ} \mathrm{F}\right]$.

With the above information, a few conclusions were made about how the system performs fuel flow measurement. The fuel flow meter required a pressurized line to perform flow measurement. A fuel regulator was plumbed after the flow meter so that the depressurized fuel going to the reservoir cylinder did not disturb the fuel being measured at the level sensor. Heat exchangers were used to and from the locomotive so that the fuel properties were held constant since fuel has a thermal expansion property that is proportional to the temperature of the liquid. It was deduced that, per standard engine operation, fuel was pulled from a reservoir, through the engine, with the unused fuel pumped back to 
the reservoir. While trying to hold the fuel reservoir level constant, this system pumped fuel back into the cylinder reservoir that was equal to the amount of fuel consumed by the engine. The fuel pumped into the fuel reservoir provided the amount of fuel burned.

The information gathered from the SwRI fuel flow measurement system provided a background on how a new fuel measurement system could be designed. The new system would use a flow meter to measure fuel that would be pumped into a reservoir with a level sensor in it. The temperature of the fuel to and from the locomotive would be regulated via heat exchangers. The fuel pumped back into the reservoir to fill it up to a set level would be measured by the flow meter and give the amount of fuel burned by the locomotive. The flow regulator and level sensor would be controlled by a PID controller to keep the fuel level in the reservoir cylinder at the set point. The selection of flow meters, fuel pumps, level sensors, heat exchangers, cylinder reservoir size, and other control components was decided after performing analysis on which types, manufactures, and sizes would perform well with different measurement parameters.

\subsection{Fuel Flow Measurement Technologies}

In general, there are three ways to measure fuel flow; gravimetric, volumetric, or instantaneous mass rate. Understanding how each type of fuel flow measurement is performed is important to understanding the benefits and uses of each as all three types of measurement were used in fuel flow measurement for use in emissions calculations.

In chemistry, gravimetric analysis is the procedure by which the amount of an analyte (the species being analyzed) is measured through the measurement of mass [42]. To measure fuel flow on a gravimetric time basis, the weight of fuel is measured in a weigh tank over a period of time. The weight of fuel is measured with a calibrated load cell or precision balance. Figure 8 shows the graduated cylinder method of gravimetric fuel measurement.

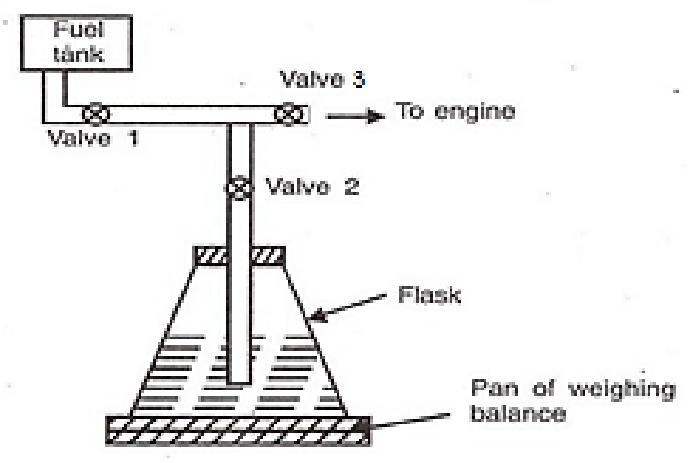

Figure 8 - Graduated Cylinder measurement method [43]

At the beginning of the test Valve 1 and Valve 2 are open and Valve 3 is closed. The weight of the empty Flask is recorded. Valve 1 closes when the Flask is filled to a set height. The new weight of 
the Flask is recorded as well as the time it took to fill the Flask. The difference in weight of the Flask from the beginning and end of the test is divided by the time it took to fill it. This number is the average fuel consumption rate [43]. Some advantages to gravimetric measurement are that the temperature does not affect the measurement and it avoids the determination of the specific gravity of the fuel [44, 45].

The simplest method to measure volumetric fuel consumption is by measuring the time it takes for an engine to consume a known volume of fuel. The volume divided by this time yields the volumetric flow rate [45]. This technique is similar to the gravimetric method through the graduated cylinder measurement except the volume is noted. A more accurate method of volumetric flow rate measurement is through the Positive Displacement (PD) flow meter. This technology directly measures the volume of fluid that passes through the flow meter [46]. Figure 9 shows an example of how fluid passes through a volumetric flow meter.

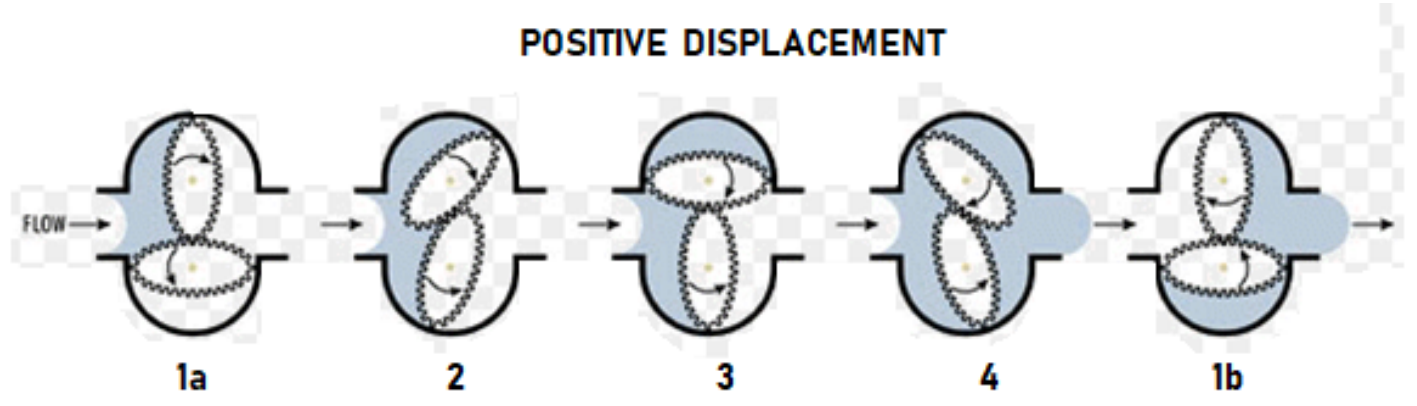

Figure 9 - Example diagram of how a fluid passes through a PD flow meter [46]

There are many designs for volumetric flow meters but the volume they measure is proportional to the flow rate. Advantages to PD flow meters include their high accuracy for small line sizes, low flow rates, and ability to measure high viscosity fluids. Some disadvantages of PD flow meters are that they are highly sensitive to snag on impurities in the liquid and require a lot of maintenance due to their multiple moving parts [46]. Additionally, errors start to accumulate through density and temperature corrections used to calculate mass flow rates. This is why direct mass flow measurement is preferred over calculated mass flow rate.

Mass flow is measured through the Coriolis Effect. Coriolis flow meters measure the force that results from the acceleration caused by mass flowing through oscillating tubes. The twist in the tubes due to inertia forces is proportional to the mass flow rate. Most Coriolis flow meters have two tubes that vibrate in opposition to each other by way of a magnetic coil. Magnetic coil sensors assemblies are mounted on the inlet and outlet of both flow tubes. As these coils move through the magnetic field created, they generate a voltage in the form of a sine wave. These sine waves are the 
critical component to determining mass flow rate $[47,48]$. Figure 10 shows a diagram of the tubes inside a Coriolis meter and how they move with a fluid, and Figure 11 shows how the sine wave functions determine mass flow.
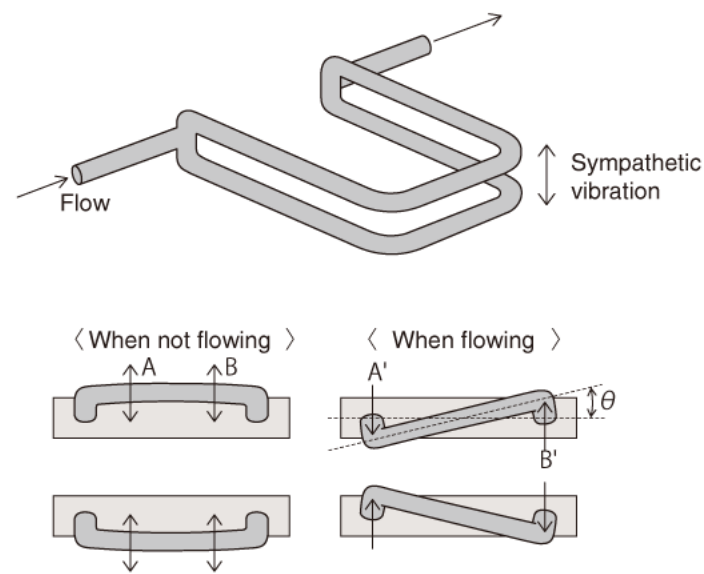

Figure 10 - Twisting motion of tubes due to the Coriolis Effect [49]

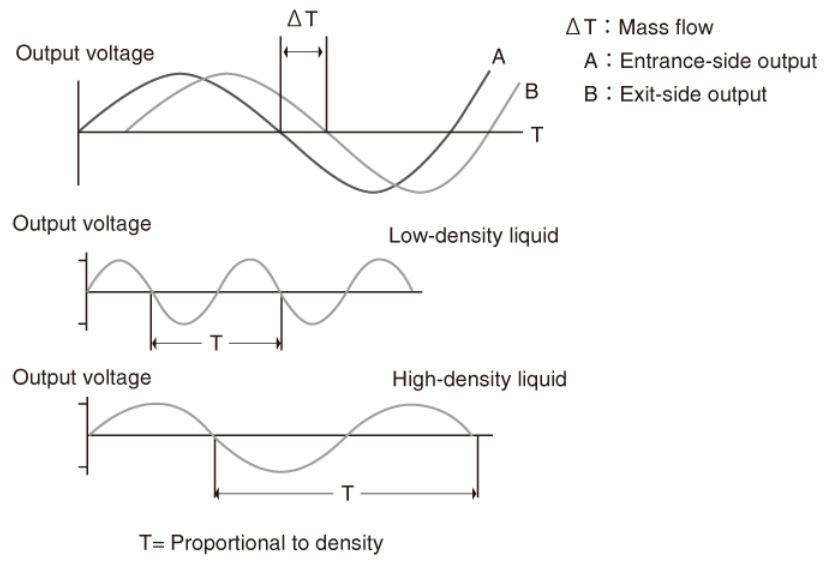

Figure 11 - Coriolis sine wave functions [49]

It can be seen in Figure 10 that when there is no flow in the meter, the tubes oscillate with each other. From Figure 11, this is effect would be equivalent to $\Delta T=0$ where the waves are collinear. When there is fluid flow there is a phase shift in the sine waves which is directly proportional to mass flow rate.

Advantages of the Coriolis flow meter include its high accuracy, direct measurement of mass flow, high response time, and ability to measure high viscosity liquids. Disadvantages include its high price as compared to other flow meters, high pressure loss, and its low resistance to external vibration effects $[50,51]$. 


\subsection{Proportional - Integral - Derivative (PID) Control}

A Proportional - Integral - Derivative (PID) controller is a closed loop feedback system that functions as a control mechanism for a system requiring constant adjustments. PID control is used in a wide variety of industrial applications to regulate flow, temperature, pressure, fluid level, and many other automatic processes [52]. As a PID controller was used in the final design of the new instantaneous mass flow measurement system, understanding how a PID controller works was important. Figure 12 shows a block diagram of a PID control system.

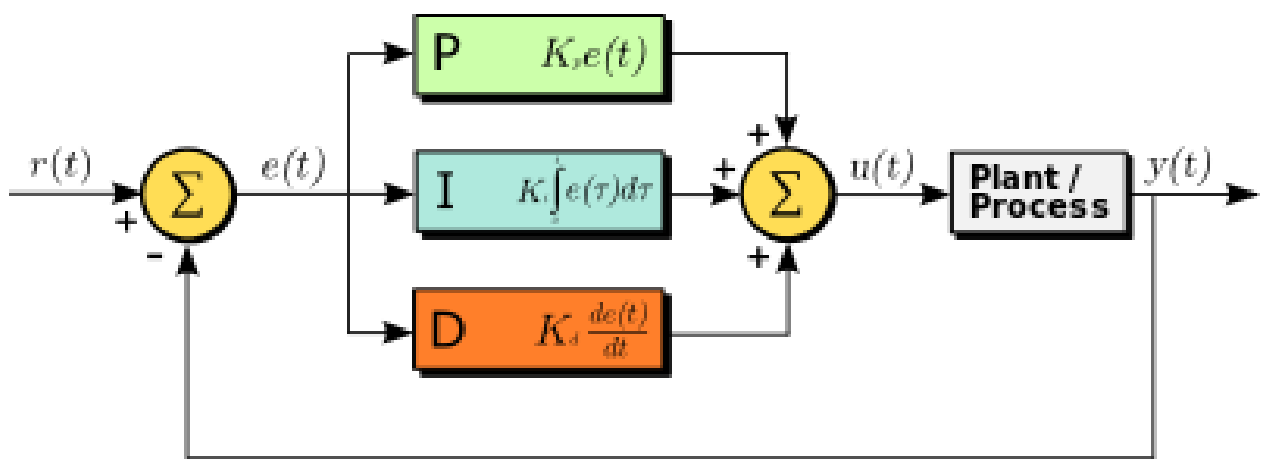

Figure 12 - Block diagram of a PID controller in a feedback loop [52]

A PID controller is distinguished by the three control terms that apply accurate and efficient output control. A PID controller works by calculating the error $(e(t))$ between the difference of the process, or measured, variable $(y(t))$ and the set point $(r(t))$ and applies corrections to the process variable to give a new output variable $(u(t))$. The proportional, integral, and derivative terms work to minimize the error over time [52,53]. The three PID terms affect 4 major dynamics of a closedloop system response [54].

1. Rise Time - The time it takes for the response of the system to rise from $10 \%$ to $90 \%$ of the steady-state response

2. Overshoot - How much higher the peak amplitude of the system response is compared to the set point

3. Settling Time - The time it takes for the response of the system to converge back to its system set point

4. Steady-State Error - The difference between the steady-state response and the system set point

An example application that a PID controller is used for is temperature control as seen in Figure 13. 


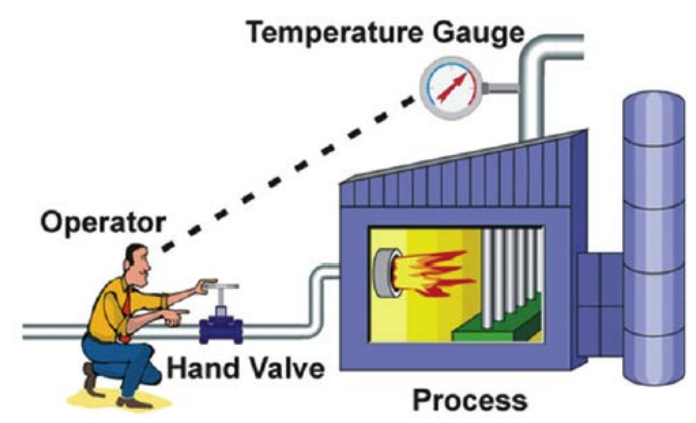

Figure 13 - Visual of an operator manually controlling temperature based on sight reading a temperature gauge [52]

In Figure 13, an operator is seen manually adjusting a flow valve for a gas powered heat exchanger. As fluid flows into the heat exchanger (i.e. "process"), it is heated. The temperature of the fluid after the process is read by the operator from a temperature gauge and the amount of heat is changed based on the need for output temperature requirements through the hand valve. As the process temperature can vary, the need for output temperature can vary and the flow requirements may change and thus the operator must work continuously to change the heat of the process to meet these needs. This is where a PID controller may be used. Figure 14 shows how a PID controller can replace manual operation of the hand valve.

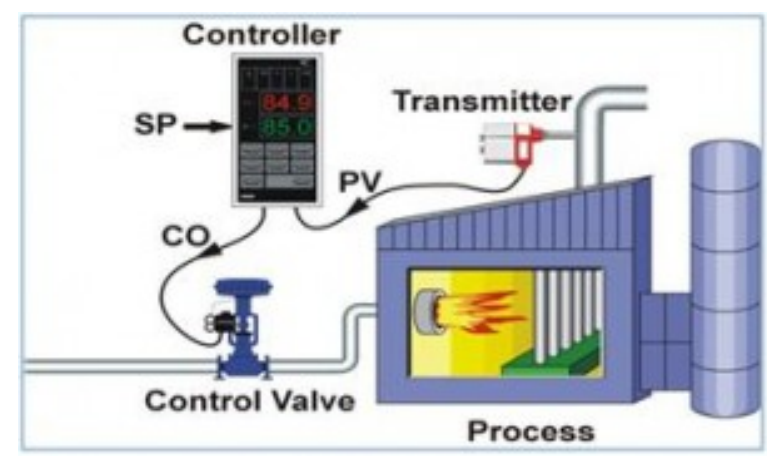

Figure 14 - Visual of temperature control process being done by PID control [52]

Figure 14 shows a PID controller in place of the operator. The set point temperature of the fluid is fixed and the controller constantly reads the output temperature from the transmitter and adjusts the control valve heat based on the difference of output and set point.

Before a PID controller can be used to automatically adjustment a system, it must first be tuned. Each of the three control terms must be set to perform to an operators specifications. As each control term is adjusted, the PID controller will react in different ways such as response time and time to steady state. 


\subsubsection{Functions of PID Control}

The proportional controller is used to control the error term which is the error multiplied by the proportional gain, Kp. A large gain can result in fast, but large, correction changes which can either cause overshoot or system instability. A small gain term can result in sluggish response times but provide minimal to no overshoot $[52,55]$. Figure 15 shows various proportional gain terms and how they affect the system control.

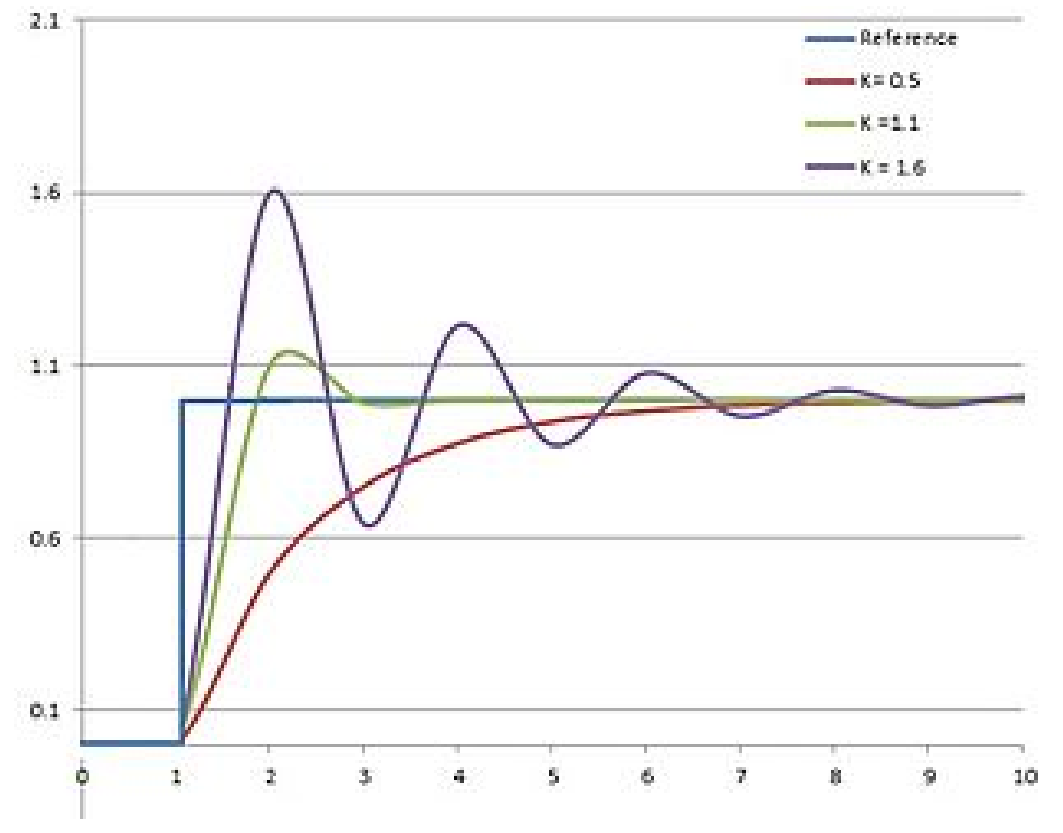

Figure 15 - Graph of system response for various proportional gain terms [55]

Using a proportional controller alone requires a biasing, or manual reset, as it does not return to the steady-state set point condition. Due to the nature of the proportional controller where an offset error is always present, the integral controller integrates the terms to reduce the error to zero. The integral term, Ki, affects system response and stability. As the integral term becomes smaller, so does the steady state error and system response time $[52,53,55,56]$. Figure 16 shows various integral gain terms and how they affect the system control. 


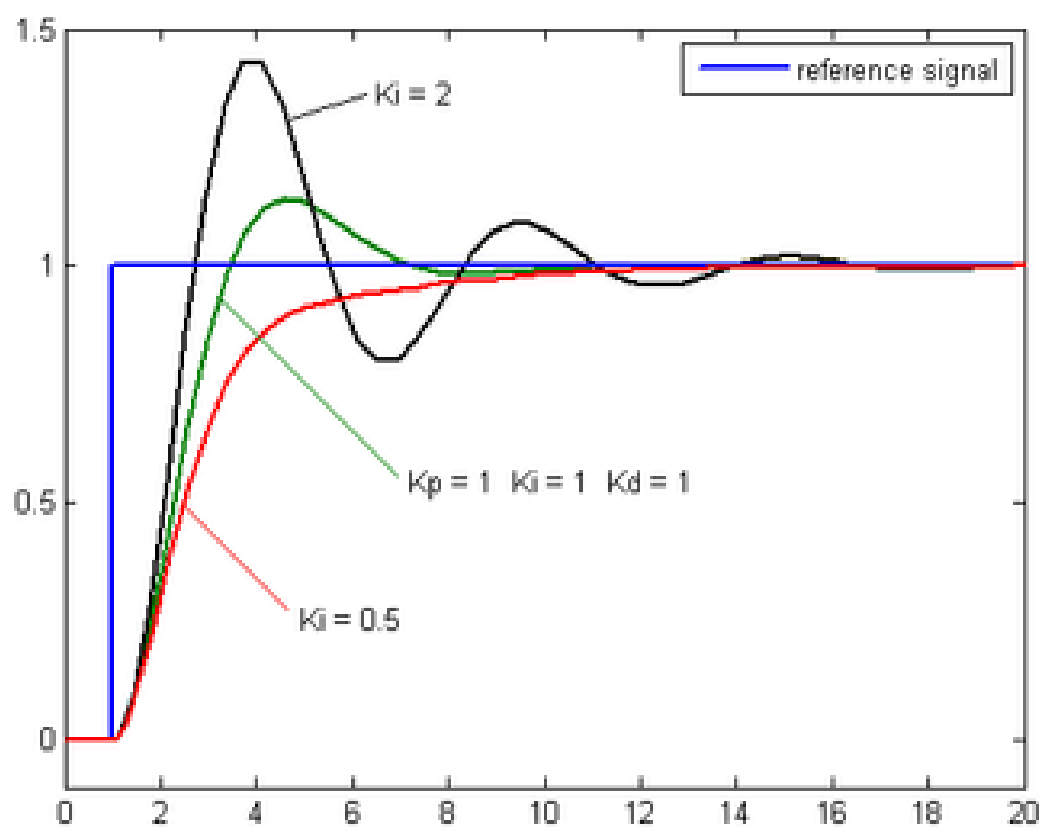

Figure 16 - Graph of system response for various integral gain terms [55]

The integral term is able to decrease the error but cannot react accordingly to future system changes. This is where the third term, derivative, works to function. As the outputs error rate of change fluctuates, the derivative term, $\mathrm{Kd}$, works to predict how the system is changing thereby increasing system response time. The derivate term improves the time it takes for the system to return to the set point, called the settling time, as well as improving system stability [52, 53, 55, 56]. Figure 17 shows various derivative gain terms and how they affect the system control.

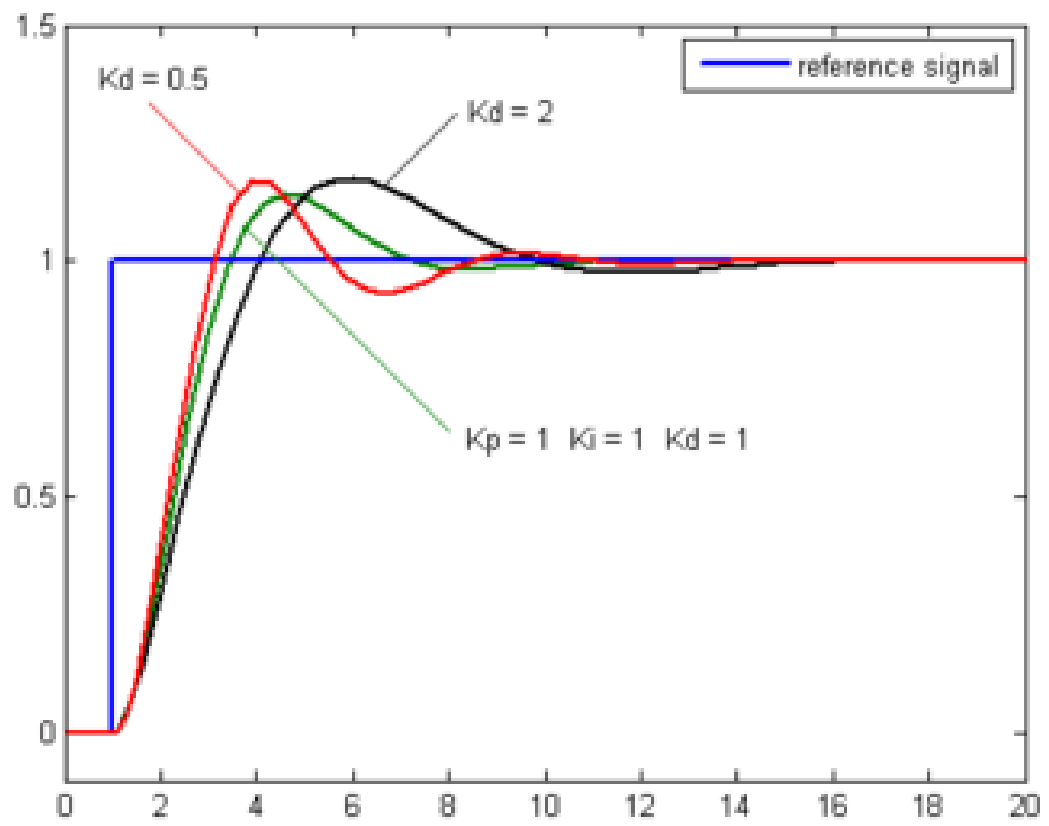

Figure 17 - Graph of system response for various derivative gain terms [55] 
PID controller tuning is often times difficult as multiple criterion (e.g. appropriate response time, settling time, steady state error, and system stability) needs to be met. Some systems require fast response times but little to no overshoot, while others may be more forgiving with a large overshoot but need fast settling times. PID tuning software is available but an operator may chose a manual route. Table 8, below, shows advantages and disadvantages of various tuning methods.

Table 8 - PID controller tuning methods advantages and disadvantages [52, 55]

\begin{tabular}{|c|c|c|}
\hline Method & Advantages & Disadvantages \\
\hline Manual & No math required & $\begin{array}{c}\text { Requires experience from } \\
\text { previous systems tuning }\end{array}$ \\
\hline Ziegler-Nichols & Proven method & $\begin{array}{c}\text { Requires some trial and error; } \\
\text { Very aggressive }\end{array}$ \\
\hline Cohen-Coon & $\begin{array}{c}\text { Good process models; } \\
\text { Fast response times }\end{array}$ & High oscillatory Response \\
\hline Software Tools & $\begin{array}{c}\text { Consistent tuning; } \\
\text { Can implement computer- } \\
\text { automated control system } \\
\text { design }\end{array}$ & $\begin{array}{c}\text { More expensive } \\
\text { Requires training }\end{array}$ \\
\hline
\end{tabular}

\subsection{1-1 Manual PID Control}

In Manual PID controller tuning, the operator sets the PID terms to various numerical values until desired system control is met. Typically, all three PID terms are initially set to 0 . The proportional term is increased until the "quarter amplitude decay" of the system occurs. The quarter amplitude of decay is when the system between each successive overshoot of the response decays at one quarter of the value of the previous overshoot. Figure 18 shows a quarter amplitude decay in a system response [57].

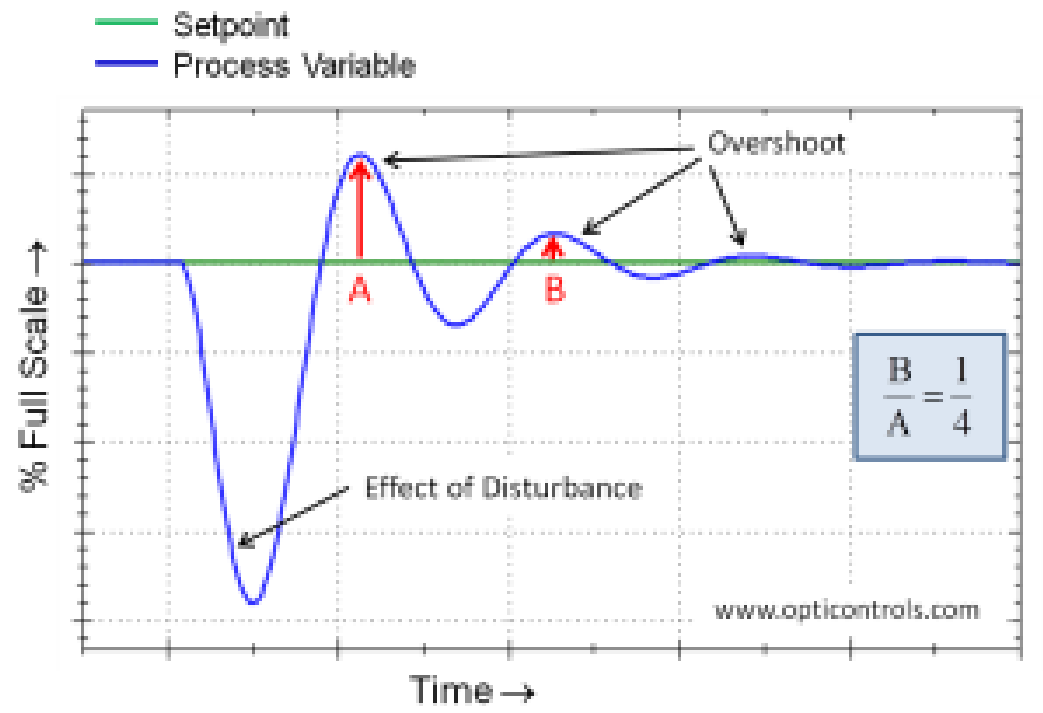

Figure 18 - Example of a quarter amplitude decay response after a process disturbance [57] 
After setting the proportional term, the integral term is increased until the error offset from system set point to system response offset is as close to 0 as possible. Then the derivative term is increased until the overshoot of system response approaches the set point. Figure 19 shows an example system reacting to an input. Figure 20 shows the corresponding increase of the proportional term and its effect on the system. Figure 21 shows the corresponding increase of the integral term and its effect on the system after increasing the proportional term. Figure 22 shows the corresponding increase of the derivative term and its effect on the system after increasing the proportional and integral terms.

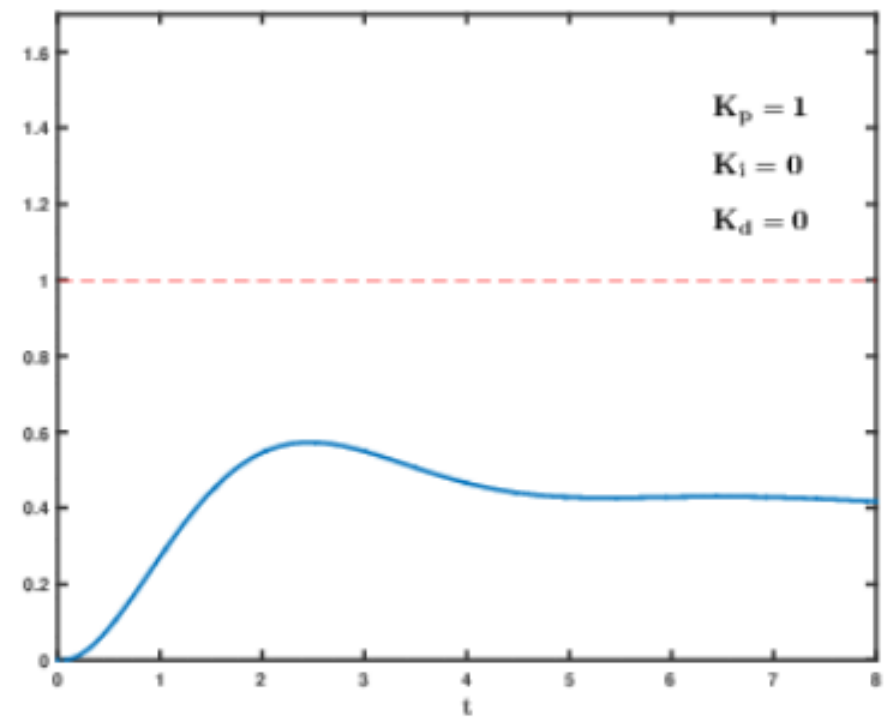

Figure 19 - Example system response from an input [58]

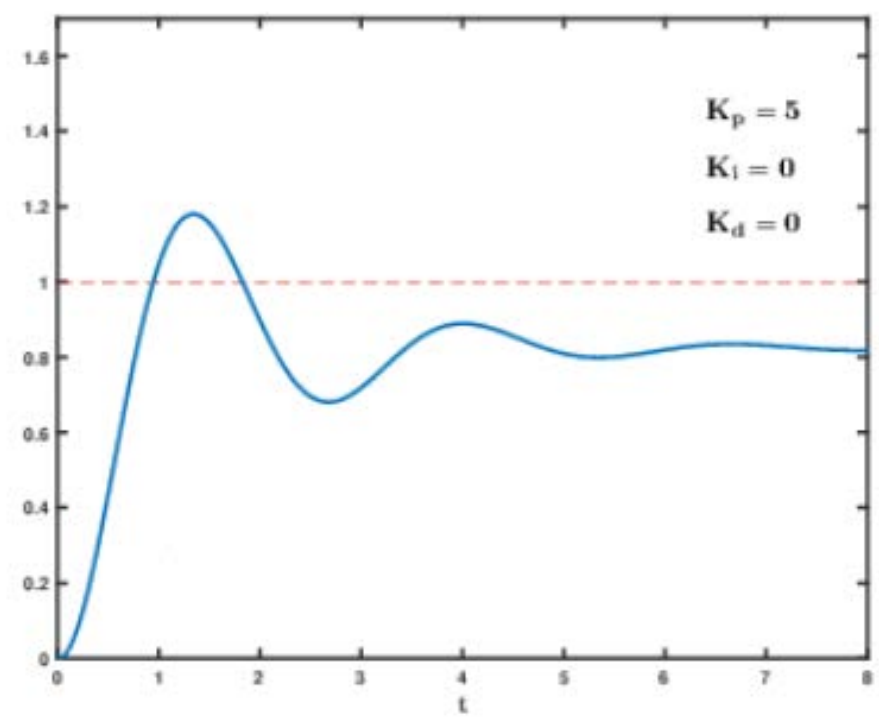

Figure 20 - Example system response from an input with an increased proportional term [58] 


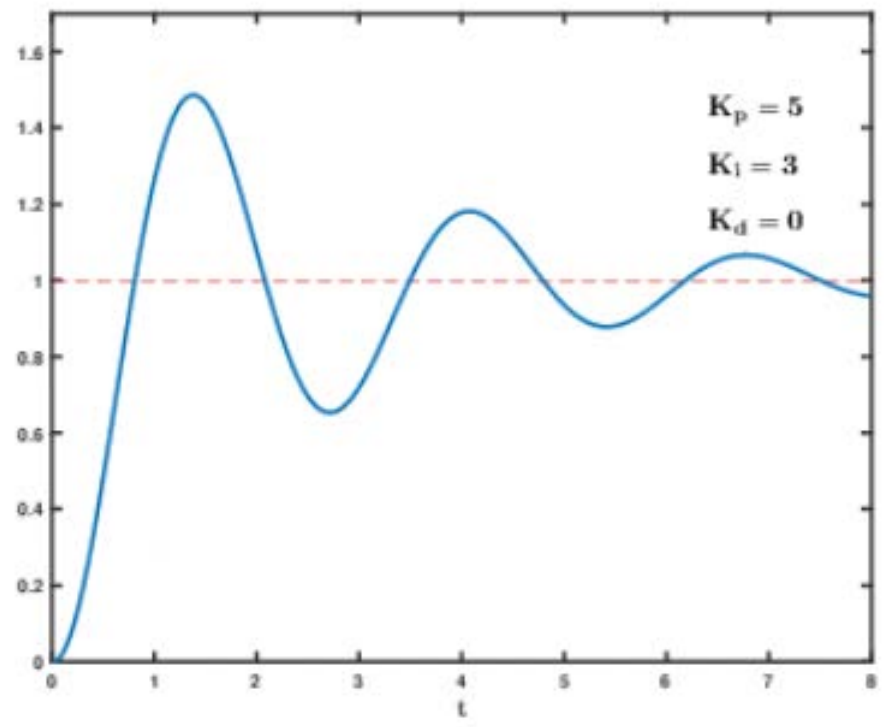

Figure 21 - Example system response from an input with increased proportional and integral terms [58]

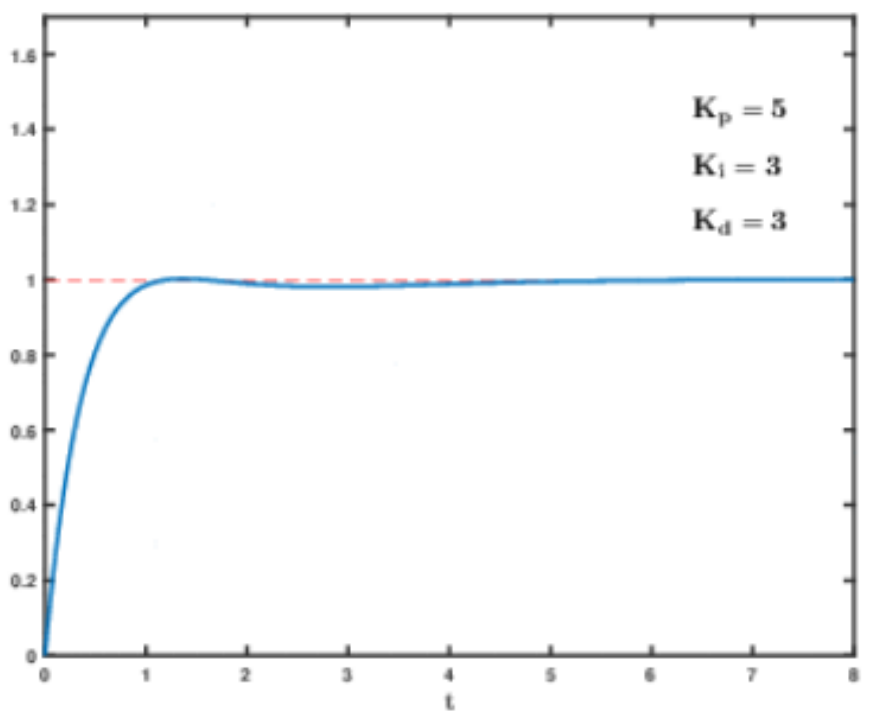

Figure 22 - Example system response from an input with increased proportional, integral, and derivative terms [58]

It should be noted that not all systems react the same and not every system will respond the same way to each PID term. Table 9 shows the effects of increasing each PID term independently through manual tuning and can be used to help meet the desired response of the PID controller. 
Table 9 - Effects of increasing a parameter independently [59]

\begin{tabular}{|c|c|c|c|c|c|}
\hline Parameter & Rise time & Overshoot & Settling time & $\begin{array}{c}\text { Steady-state } \\
\text { error }\end{array}$ & Stability \\
\hline Proportional & Decrease & Increase & Small change & Decrease & Degrade \\
\hline Integral & Decrease & Increase & Increase & Eliminate & Degrade \\
\hline Derivative & Minor change & Decrease & Decrease & $\begin{array}{c}\text { No effect in } \\
\text { theory }\end{array}$ & $\begin{array}{c}\text { Improved if } \\
\text { derivative } \\
\text { term is small }\end{array}$ \\
\hline
\end{tabular}

\subsection{1-2 Ziegler-Nichols PID Control}

The Ziegler-Nichols (Z-N) PID controller tuning method was developed in 1942 by John Ziegler and Nathaniel B. Nichols. The Z-N method sets the integral and derivative terms to zero and increases the proportional term until the system response has stable and constant oscillations of overshoot and undershoot to the system set point. The proportional "ultimate gain" term $(\mathrm{Ku})$ and the corresponding oscillation period (Tu) are used to set the PID terms based on the findings of Ziegler and Nichols $[60,61]$. These terms are used to set the controller's gain term (Kp), integrator time constant (Ti), derivative time constant (Td), integral term (Ki), and derivative term (Kd). Table 10 lists a summary of the Z-N PID tuning terms.

Table 10 - Summary of Ziegler-Nichols PID tuning terms based on ultimate gain (Ku) and oscillation period $(\mathrm{Tu})$ to use for desired PID control $[60,61]$

\begin{tabular}{|c|c|c|c|c|c|}
\hline Control Type & Kp & Ti & Td & Ki & Kd \\
\hline P & $0.5 \mathrm{Ku}$ & - & - & - & - \\
\hline PI & $0.45 \mathrm{Ku}$ & $\mathrm{Tu} / 1.2$ & - & $0.54 \mathrm{Ku} / \mathrm{Tu}$ & - \\
\hline PD & $0.8 \mathrm{Ku}$ & - & $\mathrm{Tu} / 8$ & - & $\mathrm{KuTu} / 10$ \\
\hline PID & $0.6 \mathrm{Ku}$ & $\mathrm{Tu} / 2$ & $\mathrm{Tu} / 8$ & $1.2 \mathrm{Ku} / \mathrm{Tu}$ & $3 \mathrm{KuTu} / 40$ \\
\hline $\begin{array}{c}\text { Pessen Integral } \\
\text { Rule }\end{array}$ & $7 \mathrm{Ku} / 10$ & $2 \mathrm{Tu} / 5$ & $3 \mathrm{Tu} / 20$ & $1.75 \mathrm{Ku} / \mathrm{Tu}$ & $14 \mathrm{KuTu} / 3$ \\
\hline Some Overshoot & $\mathrm{Ku} / 3$ & $\mathrm{Tu} / 2$ & $\mathrm{Tu} / 3$ & $0.666 \mathrm{Ku} / \mathrm{Tu}$ & $\mathrm{KuTu} / 10$ \\
\hline No Overshoot & $\mathrm{Ku} / 5$ & $\mathrm{Tu} / 2$ & $\mathrm{Tu} / 3$ & $2 \mathrm{Ku} / 5 \mathrm{Tu}$ & $\mathrm{KuTu} / 15$ \\
\hline
\end{tabular}

\subsection{1-3 Cohen-Coon PID Control}

Developed in 1953, the Cohen-Coon PID tuning method is an alternative to the ZieglerNichols method. Unlike the Ziegler-Nichols method, the Cohen-Coon method is better suited for self-regulating processes requiring fast response times. The method utilizes three processes characteristics which are process gain (gp), dead time (td), and time constant $(\tau)$. Figure 23 shows a summary of the Cohen-Coon PID tuning terms [62]. 


\begin{tabular}{|l|c|c|c|}
\hline www.opticontrols.com & Controller Gain & Integral Time & Derivative Time \\
\hline P Controller: & $K_{C}=\frac{1.03}{g_{p}}\left(\frac{\tau}{t_{d}}+0.34\right)$ & & \\
\hline PI Controller: & $K_{C}=\frac{0.9}{g_{p}}\left(\frac{\tau}{t_{d}}+0.092\right)$ & $T_{I}=3.33 t_{d} \frac{\tau+0.092 t_{d}}{\tau+2.22 t_{d}}$ & \\
\hline PD Controller: & $K_{C}=\frac{1.24}{g_{p}}\left(\frac{\tau}{t_{d}}+0.129\right)$ & $T_{D}=0.27 t_{d} \frac{\tau-0.324 t_{d}}{\tau+0.129 t_{d}}$ \\
\hline $\begin{array}{l}\text { PID Controller: } \\
\text { (Noninteracting) }\end{array}$ & $K_{c}=\frac{1.35}{g_{p}}\left(\frac{\tau}{t_{d}}+0.185\right)$ & $T_{I}=2.5 t_{d} \frac{\tau+0.185 t_{d}}{\tau+0.611 t_{d}}$ & $T_{D}=0.37 t_{d} \frac{\tau}{\tau+0.185 t_{d}}$ \\
\hline
\end{tabular}

Figure 23 - Summary of Cohen-Coon PID tuning terms based on process gain (gp) dead time (td) and time constant $(\tau)[62]$

\subsection{NIST Traceable Calibration}

The International Bureau of Weights and Measures (BIPM) is an international organization established to maintain the International System of Units (SI) under the terms of the Metre Convention and acts on matters related to measurement science and measurement standards. The BIPM works in conjunction with several other organizations that makeup the Joint Committee for Guides in Metrology (JCGM). The JCGM has developed the International Vocabulary of Metrology (VIM) which is a set of definitions and terms to develop a common vocabulary in metrology which is "the science of measurements, across different fields of science, legislature and commerce." The VIM defines calibration as the "operation that, under specified conditions, in a first step, establishes a relation between the quantity values with measurement uncertainties provided by measurement standards and corresponding indications with associated measurement uncertainties and, in a second step, uses this information to establish a relation for obtaining a measurement result from an indication [63]." This means that calibration is comparison between two values but introduces a measurement uncertainty in the accuracies of the device performing the measurement.

The quality of the calibration is important as the measurements given by a measurement device should be accepted by national organizations such that the subsequent measurements are traceable to internationally defined measurement units. Traceable calibration in the U.S. is certified by the National Institute of Standards and Technology (NIST). NIST traceable calibration certifies that measurement devices are maintained at these international standards and as such the device will produce repeatable results. NIST does not monitor whether a measurement device has been calibrated to their standards. That responsibility falls on the end-user of the device. Manufacturers of measurement devices may provide users with their calibration methods and procedures, their calibrated uncertainties of the 
device, traceability records, and laboratory accreditation $[64,65]$. NIST traceability is required by the CFR for all instrumentation used in emissions measurement and thus an understanding of calibration and uncertainty is needed for creating repeatable results with the same measurement devices.

\section{METHODOLOGY - EMISSION MEASUREMENT AND VERIFICATION THROUGH GRAVIMETRIC, VOLUMETRIC, AND MASS MEASUREMENT}

\subsection{System Setup}

The Juniata locomotive emissions testing lab is an indoor testing facility with emissions testing capabilities for most, if not all, locomotives. The facility is equipped with several fans and shutters for regulating temperature and a large roller door for moving locomotives in and out of the facility. Figure 24 is a photo of inside of the test facility which shows the catwalk, upper control facility, and the fuel measurement testing apparatuses.

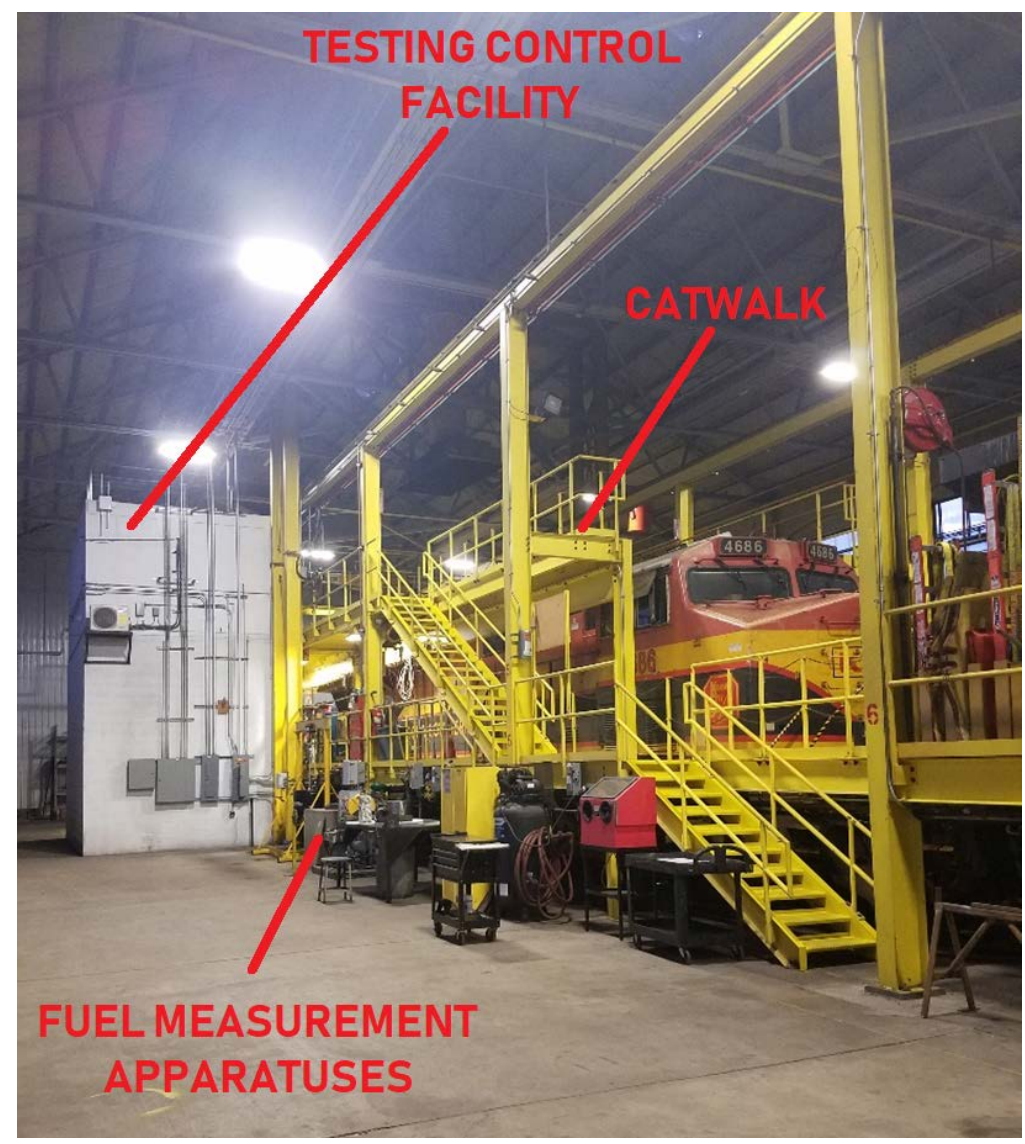

Figure 24 - Photo of inside the Juniata locomotive emissions lab test facility

Setup of a locomotive requires pulling a test locomotive in and stopping it at the exhaust hood when a locomotive's exhaust is lined up. A secondary locomotive is typically pulled in behind the test locomotive and is equipped with a fuel tank that carries test fuel that is certified to 40 CFR Part 1065 Subpart H [36] fuel standards. The fuel lines and dripper lines are disconnected from the locomotives 
onboard fuel tank and rerouted by flexible fuel line and fuel line reels to the gravimetric fuel reservoir tank as seen in Figure 26 and Figure 25.

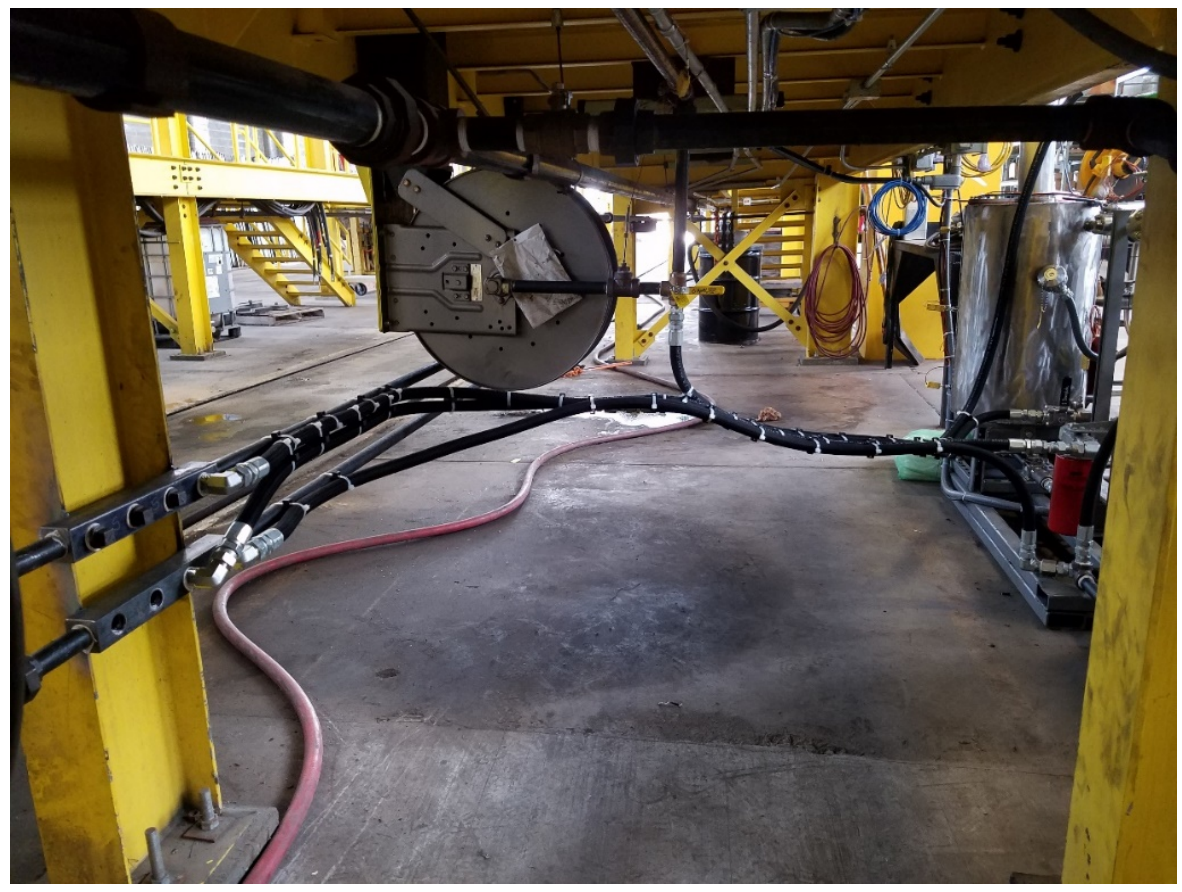

Figure 25 - Underside of catwalk with future fuel system in place beside the gravimetric fuel measurement system (right) and flexible fuel line reel hookup (center)

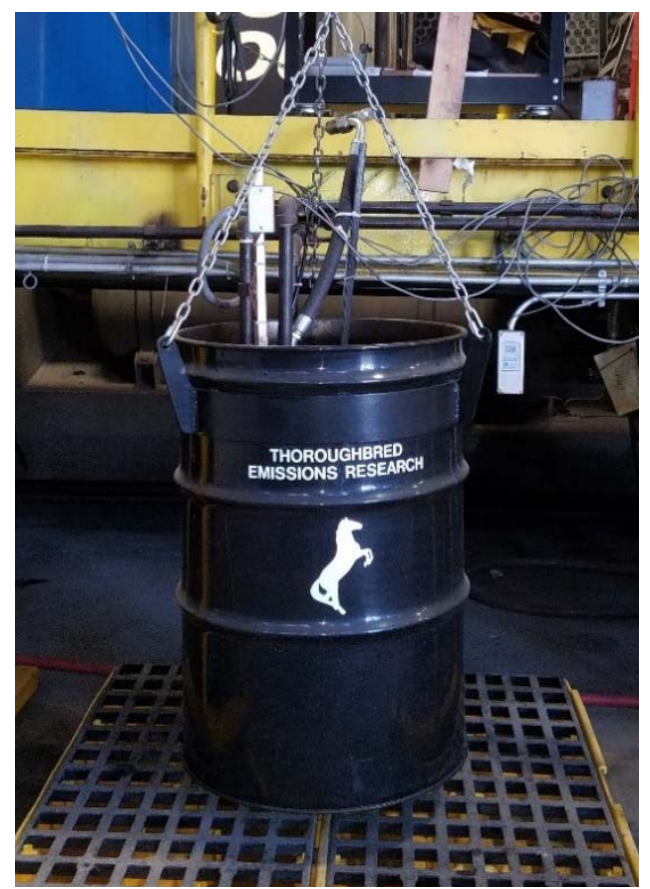

Figure 26 - Fuel drum with rerouted fuel lines 


\subsubsection{Opacity Meter}

Smoke opacity is measured by a Wager 7500 opacity meter mounted directly above the exhaust stack by means of an exhaust routing apparatus which also houses the sampling probes for PM and gaseous emissions as seen in Figure 27, below.

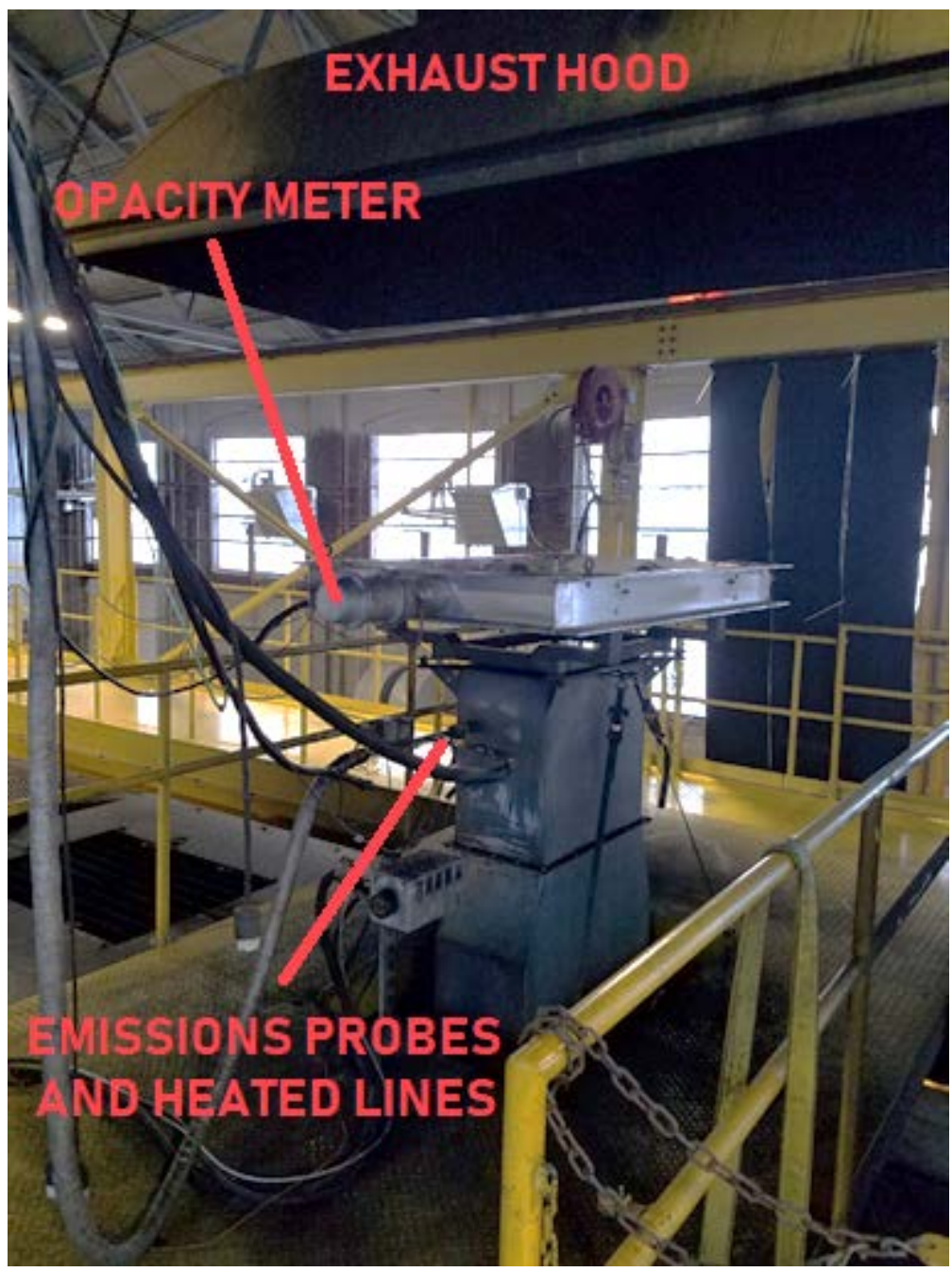

Figure 27 - Exhaust routing apparatus with emissions lines and opacity meter connected

\subsubsection{Raw Exhaust and Particulate Emissions Sampling}

As seen in Figure 27, the raw exhaust and particulate matter emissions probes and heated lines for emissions transfer are attached to the exhaust stack hood. Figure 28 shows the inside of the exhaust stack hood with the emissions and exhaust temperature probes mounted. 


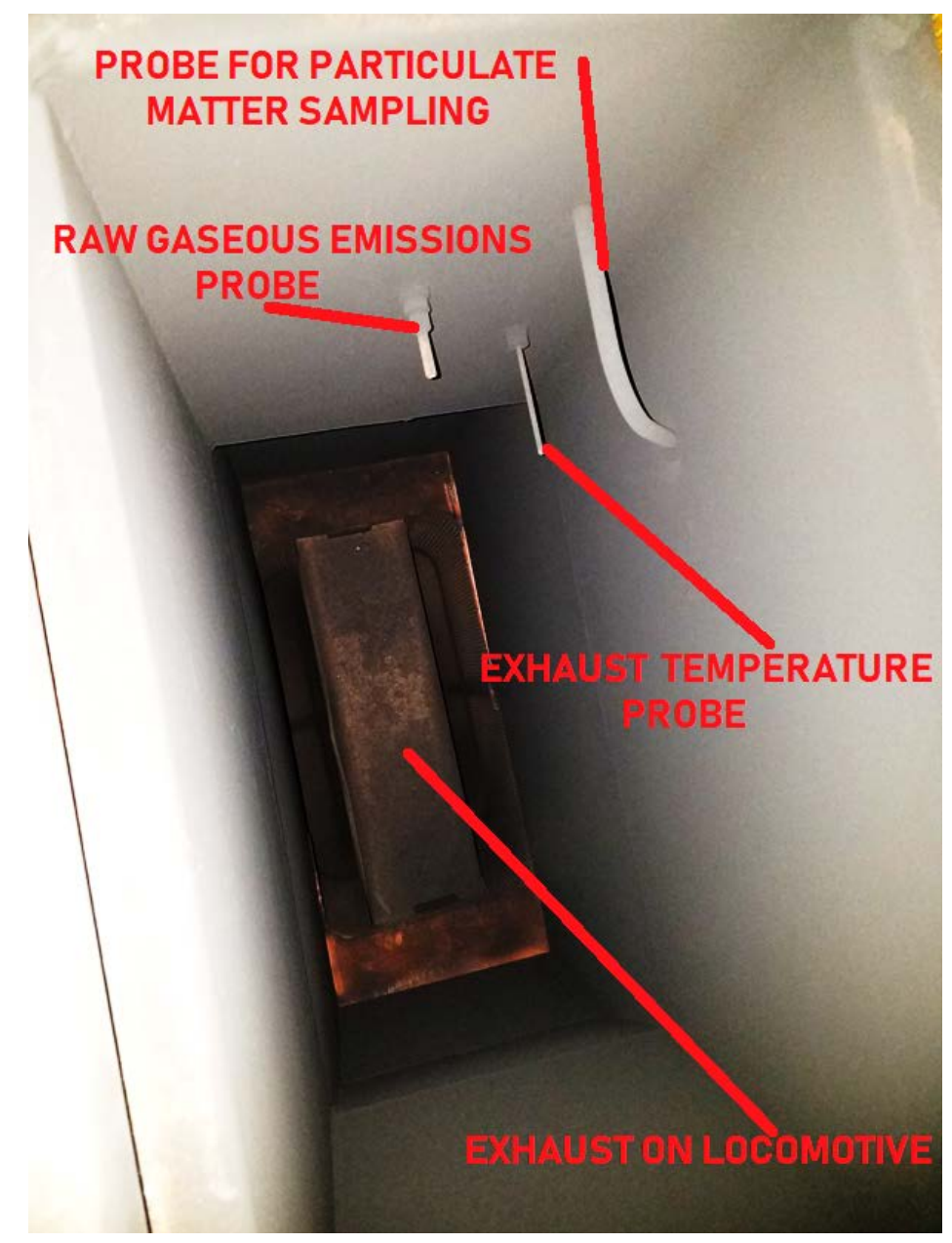

Figure 28 - Photo of exhaust probes in exhaust rerouting hood

From the exhaust hood, as seen in Figure 27, the gaseous emissions are transferred to a Sierra Instruments BG3 PFD PM sampling system and a HORIBA MEXA-7100D gas analyzer through heated transfer lines. Figure 29 shows a photo of the BG3 and MEXA analyzers. 


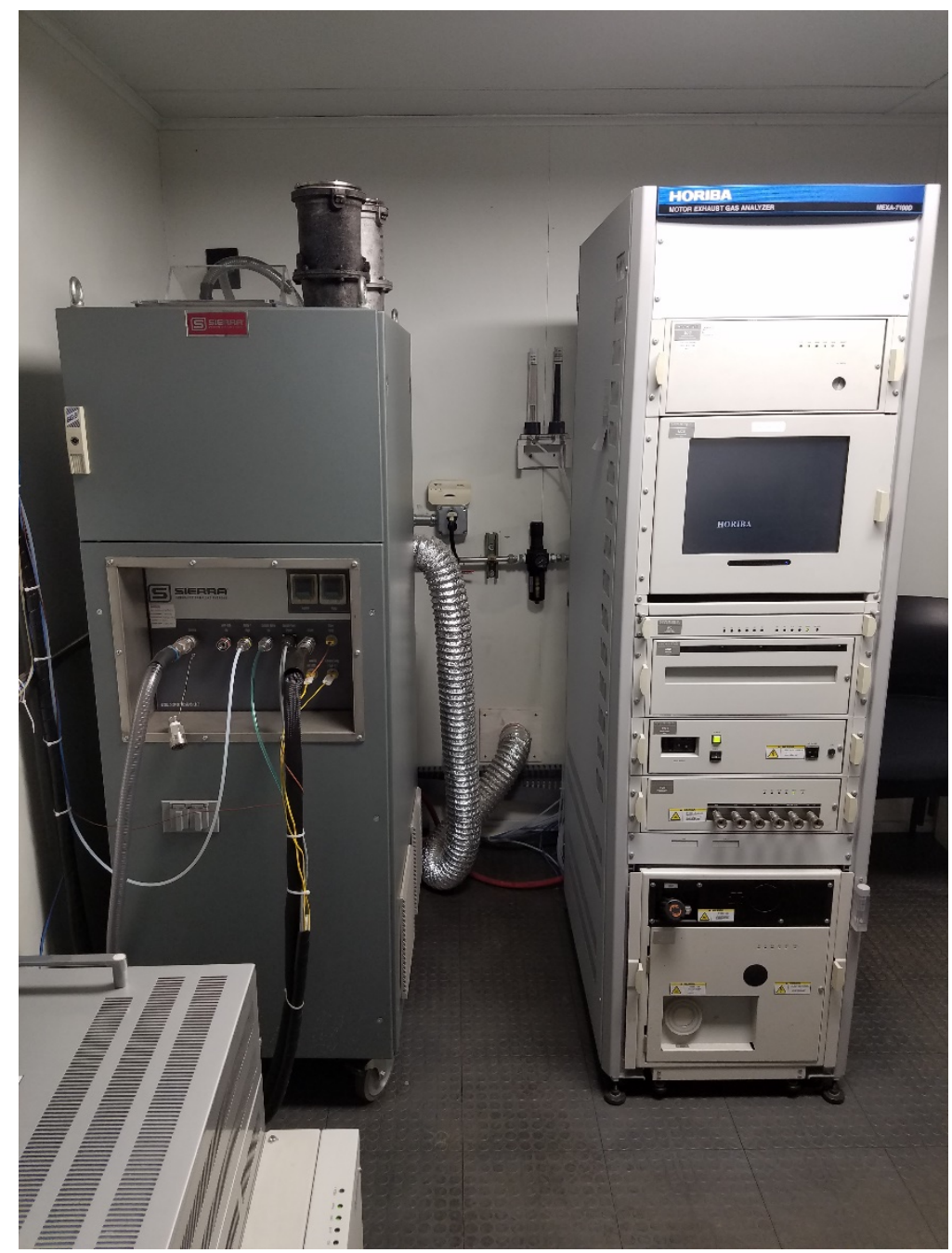

Figure 29 - BG3 (left) and MEXA (right) gaseous emissions analyzers

\subsubsection{Sensor Placements}

As per 40 CFR 1033.505 - Ambient Conditions [66], ambient testing conditions must be compensated for as they affect emissions. For example, nitrogen oxide (NOx) emissions must be corrected to compensate for these temperature effects (i.e. humidity correction). Tests may be performed with ambient air temperatures ranging from $15.5^{\circ} \mathrm{C}\left(60^{\circ} \mathrm{F}\right)$ to $40.5^{\circ} \mathrm{C}\left(105^{\circ} \mathrm{F}\right)$ [66]. The outside climate at the Altoona emissions test facility can reach temperatures lower than this during the winter season but since emissions tests there are performed inside a closed, temperature controlled, test facility, the temperature is always within range. Figure 30 and Figure 31 show sensor callouts that are located on the locomotive and Table 11 provides a list of sensor abbreviations and purposes from the figures. 


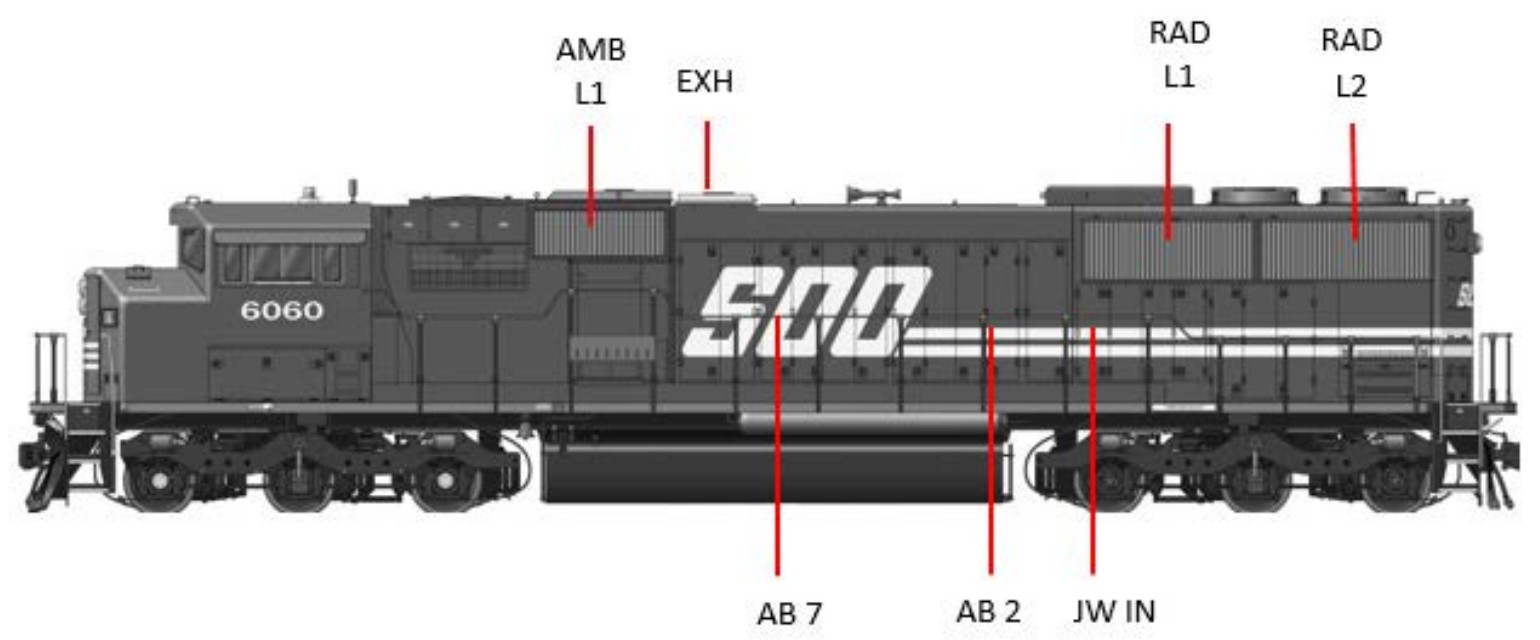

Figure 30 - Left side of a diagram of a SOO SD60M diesel locomotive with location of sensor callouts to measure temperature for ambient, exhaust, jacket water, and radiators [67]

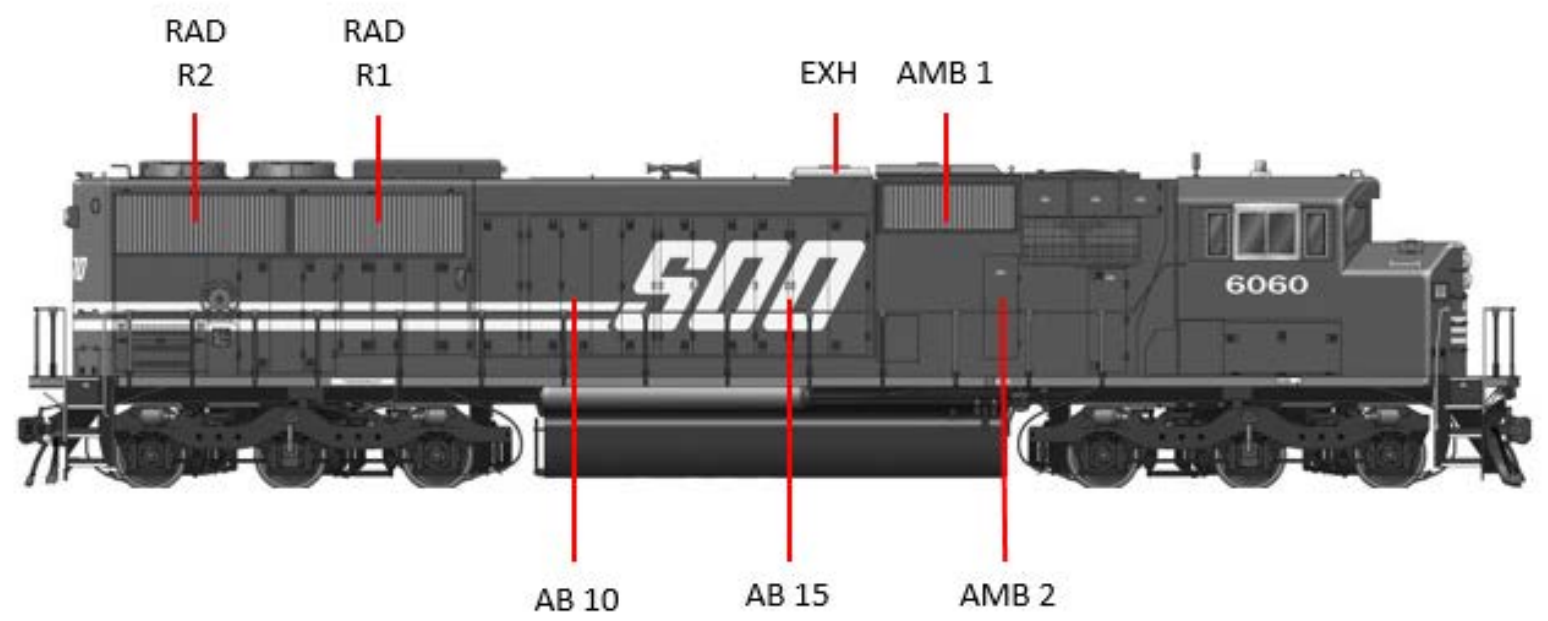

Figure 31 - Right side of a diagram of a SOO SD60M diesel locomotive with location of sensor callouts to measure temperature for ambient, exhaust, jacket water, and radiators [67] 
Table 11 - Sensor abbreviations and purposes list for Figure 30 and Figure 31

\begin{tabular}{|c|c|}
\hline $\begin{array}{c}\text { Sensor } \\
\text { Abbreviation }\end{array}$ & Sensor Purpose \\
\hline AMB L1 & $\begin{array}{c}\text { Measure ambient temperature } \\
\text { on left side of locomotive }\end{array}$ \\
\hline EXH & Measure exhaust temperature \\
\hline RAD L1 & $\begin{array}{c}\text { Measure radiator temperature } \\
\text { on left side of locomotive }\end{array}$ \\
\hline RAD L2 & $\begin{array}{c}\text { Measure second radiator } \\
\text { temperature on left side of } \\
\text { locomotive }\end{array}$ \\
\hline $\mathrm{AB} 7$ & Measure intake temperature \\
\hline $\mathrm{AB} 2$ & Measure intake temperature \\
\hline JW IN & $\begin{array}{l}\text { Measure radiator water jacket } \\
\text { temperature going into engine }\end{array}$ \\
\hline RAD R1 & $\begin{array}{c}\text { Measure radiator temperature } \\
\text { on right side of locomotive }\end{array}$ \\
\hline RAD R2 & $\begin{array}{c}\text { Measure second radiator } \\
\text { temperature on right side of } \\
\text { locomotive }\end{array}$ \\
\hline $\mathrm{AB} 10$ & Measure intake temperature \\
\hline $\mathrm{AB} 15$ & Measure intake temperature \\
\hline AMB 1 & $\begin{array}{c}\text { Measure ambient temperature } \\
\text { on right side of locomotive }\end{array}$ \\
\hline AMB 2 & $\begin{array}{c}\text { Measure ambient temperature } \\
\text { on right side of locomotive }\end{array}$ \\
\hline
\end{tabular}

Furthermore sections (b) altitude/pressure, (c) humidity, and (d) wind conditions of 40 CFR Part 1033.505 [66] are always within range in Altoona due to the covered testing facility or because they are corrected in emissions calculations. The altitude in Altoona, PA is approximately 1,161 $\mathrm{ft}$. above sea level which is below the $4000 \mathrm{ft}$. requirement, or from $88.000 \mathrm{kPa}(26.0 \mathrm{in} \mathrm{Hg}$ ) to 103.325 $\mathrm{kPa}$ (30.5 in Hg). As previously stated, testing may be performed with any ambient humidity level with corrected $\mathrm{NO}_{\mathrm{x}}$ emissions, so the humidity is always being corrected. Lastly, since the locomotive is 
tested inside a covered testing facility, wind is never an issue that needs to be addressed as the facility serves as a barrier from excessive wind.

\subsubsection{Linear Verification of Sensors}

As per 40 CFR Part 1065.307 - Linearity Verification [68], linearity verification must be performed on all measurement systems listed in Table 12, below, and performed as frequently as listed in Table 1 of 1065.303 [69]. Verification must be performed as Part 1065.307 [68] states where at least 10 reference values are introduced to the measurement system and recorded. The measured values are collectively compared to the reference values using a least-squares regression and must meet the linearity criteria in Part 1065.307 [68]. 
Table 12 - Measurement Systems That Require Linearity Verification as per

40 CFR Part 1065.307 and Part 1065.303 [68, 69]

\begin{tabular}{|c|c|c|c|c|c|c|}
\hline \multirow{2}{*}{$\begin{array}{c}\text { Measurement } \\
\text { system }\end{array}$} & \multirow{2}{*}{ Quantity } & \multicolumn{4}{|c|}{ Linearity criteria } & \multirow{2}{*}{$\begin{array}{c}\text { Minimum } \\
\text { Frequency }\end{array}$} \\
\hline & & $\left|x_{\min }\left(a_{1}-1\right)+a_{0}\right|$ & $\mathbf{a}_{1}$ & SEE & $\mathbf{r}^{2}$ & \\
\hline Speed & $\mathrm{f}_{\mathrm{n}}$ & $\leq 0.05 \% \cdot f_{\mathrm{nmax}}$ & $0.98-1.02$ & $\leq 2 \% \cdot f_{\text {nmax }}$ & $\geq 0.990$ & 370 days \\
\hline Torque & $\mathrm{T}$ & $\leq 1 \% \cdot T_{\max }$ & $0.98-1.02$ & $\leq 2 \% \cdot T_{\max }$ & $\geq 0.990$ & 370 days \\
\hline $\begin{array}{c}\text { Electrical } \\
\text { power }\end{array}$ & $\mathrm{P}$ & $\leq 1 \% \cdot P_{\max }$ & $0.98-1.02$ & $\leq 2 \% \cdot P_{\max }$ & $\geq 0.990$ & 370 days \\
\hline Current & I & $\leq 1 \% \cdot I_{\max }$ & 0.98-1.02 & $\leq 2 \% \cdot I_{\max }$ & $\geq 0.990$ & 370 days \\
\hline Voltage & $\mathrm{U}$ & $\leq 1 \% \cdot U_{\max }$ & $0.98-1.02$ & $\leq 2 \% \cdot U_{\max }$ & $\geq 0.990$ & 370 days \\
\hline Fuel flow rate & $\dot{\mathrm{m}}$ & $\leq 1 \% \cdot \dot{m}_{\max }$ & 0.98-1.02 & $\leq 2 \% \cdot \dot{m}_{\max }$ & $\geq 0.990$ & 370 days \\
\hline Intake-air & \multirow{2}{*}{$\dot{\mathrm{n}}$} & \multirow{2}{*}{$\leq 1 \% \cdot \dot{n}_{\max }$} & \multirow{2}{*}{$0.98-1.02$} & \multirow{2}{*}{$\leq 2 \% \cdot \dot{n}_{\max }$} & \multirow{2}{*}{$\geq 0.990$} & 370 days \\
\hline flow rate ${ }^{1}$ & & & & & & 370 days \\
\hline $\begin{array}{l}\text { Dilution air } \\
\text { flow rate }^{1}\end{array}$ & $\dot{\mathrm{n}}$ & $\leq 1 \% \cdot \dot{n}_{\max }$ & $0.98-1.02$ & $\leq 2 \% \cdot \dot{n}_{\max }$ & $\geq 0.990$ & 370 days \\
\hline $\begin{array}{c}\text { Diluted } \\
\text { exhaust flow } \\
\text { rate }^{1} \\
\end{array}$ & $\dot{\mathrm{n}}$ & $\leq 1 \% \cdot \dot{n}_{\max }$ & $0.98-1.02$ & $\leq 2 \% \cdot \dot{n}_{\max }$ & $\geq 0.990$ & 370 days \\
\hline $\begin{array}{l}\text { Raw exhaust } \\
\text { flow rate }{ }^{1}\end{array}$ & $\dot{\mathrm{n}}$ & $\leq 1 \% \cdot \dot{n}_{\max }$ & $0.98-1.02$ & $\leq 2 \% \cdot \dot{n}_{\max }$ & $\geq 0.990$ & 185 days \\
\hline $\begin{array}{l}\text { Batch sampler } \\
\text { flow rates }{ }^{1}\end{array}$ & $\dot{\mathrm{n}}$ & $\leq 1 \% \cdot \dot{n}_{\max }$ & $0.98-1.02$ & $\leq 2 \% \cdot \dot{n}_{\max }$ & $\geq 0.990$ & 370 days \\
\hline Gas dividers & $\mathrm{x} / \mathrm{x}_{\text {span }}$ & $\leq 0.5 \% \cdot x_{\max } / \mathrm{x}_{\mathrm{span}}$ & $0.98-1.02$ & $\begin{array}{c}\leq 2 \% \\
\cdot x_{\max } / \mathrm{x}_{\text {span }} \\
\end{array}$ & $\geq 0.990$ & 370 days \\
\hline $\begin{array}{c}\text { Gas analyzers } \\
\text { for laboratory } \\
\text { testing }\end{array}$ & $\mathrm{x}$ & $\leq 0.5 \% \cdot x_{\max }$ & $0.99-1.01$ & $\leq 1 \% \cdot x_{\max }$ & $\geq 0.998$ & 35 days \\
\hline $\begin{array}{c}\text { Gas analyzers } \\
\text { for field } \\
\text { testing } \\
\end{array}$ & $\mathrm{x}$ & $\leq 1 \% \cdot x_{\max }$ & $0.99-1.01$ & $\leq 1 \% \cdot x_{\max }$ & $\geq 0.998$ & 35 days \\
\hline PM balance & $\mathrm{m}$ & $\leq 1 \% \cdot m_{\max }$ & $0.99-1.01$ & $\leq 1 \% \cdot m_{\max }$ & $\geq 0.998$ & 370 days \\
\hline Pressures & $\mathrm{p}$ & $\leq 1 \% \cdot p_{\max }$ & $0.99-1.01$ & $\leq 1 \% \cdot p_{\max }$ & $\geq 0.998$ & 370 days \\
\hline $\begin{array}{l}\text { Dewpoint for } \\
\text { intake air, PM- } \\
\text { stabilization } \\
\text { and balance } \\
\text { environments }\end{array}$ & $\mathrm{T}_{\text {dew }}$ & $\leq 0.5 \% \cdot T_{\text {dewmax }}$ & $0.99-1.01$ & $\begin{array}{c}\leq 0.5 \% \\
\cdot T_{\text {dewmax }}\end{array}$ & $\geq 0.998$ & 370 days \\
\hline $\begin{array}{c}\text { Other } \\
\text { dewpoint } \\
\text { measurements }\end{array}$ & $\mathrm{T}_{\mathrm{dew}}$ & $\leq 1 \% \cdot T_{\text {dewmax }}$ & $0.99-1.01$ & $\begin{array}{c}\leq 1 \% \\
\cdot T_{\text {dewmax }}\end{array}$ & $\geq 0.998$ & 370 days \\
\hline $\begin{array}{l}\text { Analog-to- } \\
\quad \text { digital } \\
\text { conversion of } \\
\text { temperature } \\
\quad \text { signals } \\
\end{array}$ & $\mathrm{T}$ & $\leq 1 \% \cdot T_{\max }$ & $0.99-1.01$ & $\leq 1 \% \cdot T_{\max }$ & $\geq 0.998$ & 370 days \\
\hline
\end{tabular}


Table 13, Table 14, and Table 15 show lists of the sensors that the Juniata emission lab measures in order to perform an emissions test that is compliant to 40 CFR Part 1033 [1] and Part 1065 [2]. It should be noted these are all of the sensors that Scimitar records and not all are needed for emissions calculations. Important sensors used in emissions calculations and corrections are in bold in the tables. However, it is useful to record many of these for diagnostic purposes.

Table 13 - List of temperature measurement sensors

\begin{tabular}{|l|c|}
\hline \multicolumn{1}{|c|}{ SENSOR } & UNIT \\
\hline $\begin{array}{l}\text { Ambient Temperature } \\
\text { Right 1 }\end{array}$ & ${ }^{\circ} \mathrm{F}$ \\
\hline $\begin{array}{l}\text { Ambient Temperature } \\
\text { Right 2 }\end{array}$ & ${ }^{\circ} \mathrm{F}$ \\
\hline $\begin{array}{l}\text { Ambient Temperature } \\
\text { Left 1 }\end{array}$ & ${ }^{\circ} \mathrm{F}$ \\
\hline $\begin{array}{l}\text { Dilution Air } \\
\text { Temperature }\end{array}$ & ${ }^{\circ} \mathbf{C}$ \\
\hline $\begin{array}{l}\text { Pm Filter } \\
\text { Temperature }\end{array}$ & ${ }^{\circ} \mathbf{C}$ \\
\hline Exhaust Temperature & ${ }^{\circ} \mathrm{F}$ \\
\hline $\begin{array}{l}\text { Pre-Turbo Exhaust } \\
\text { Temperature }\end{array}$ & ${ }^{\circ} \mathrm{F}$ \\
\hline Air Box Left & ${ }^{\circ} \mathrm{F}$ \\
\hline Air Box Right & ${ }^{\circ} \mathrm{F}$ \\
\hline Air Box 15 & ${ }^{\circ} \mathrm{F}$ \\
\hline Jacket Water In & ${ }^{\circ} \mathrm{F}$ \\
\hline Jacket Water Out & ${ }^{\circ} \mathrm{F}$ \\
\hline $\begin{array}{l}\text { Radiator Air } \\
\text { Temperature Left }\end{array}$ & ${ }^{\circ} \mathrm{F}$ \\
\hline Radiator Air Right & ${ }^{\circ} \mathrm{F}$ \\
\hline Fuel Temp In Barrel & ${ }^{\circ} \mathbf{F}$ \\
\hline $\begin{array}{l}\text { Supply Fuel } \\
\text { Temperature }\end{array}$ & ${ }^{\circ} \mathbf{C}$ \\
\hline $\begin{array}{l}\text { Return Fuel } \\
\text { Temperature }\end{array}$ & ${ }^{\circ} \mathbf{C}$ \\
\hline Ambient Dewpoint & ${ }^{\circ} \mathbf{C}$ \\
\hline Relative Humidity & ${ }^{\mathbf{O}} \mathrm{O}$ \\
\hline Chiller Temperature & ${ }^{\circ} \mathbf{C}$ \\
\hline
\end{tabular}


Table 14 - List of pressure measurement sensors

\begin{tabular}{|l|c|}
\hline \multicolumn{1}{|c|}{ SENSOR } & UNIT \\
\hline Barometric Pressure & In Hg \\
\hline $\begin{array}{l}\text { Delta Pressure At } \\
\text { Filter }\end{array}$ & kPa \\
\hline Air Box Pressure Left & psi \\
\hline Air Box Pressure Right & psi \\
\hline Fuel Pressure Engine In & psi \\
\hline
\end{tabular}

Table 15 - List of engine parameter sensors

\begin{tabular}{|l|c|}
\hline \multicolumn{1}{|c|}{ SENSOR } & UNIT \\
\hline Engine Speed & RPM \\
\hline Trac Current & A \\
\hline Trac Voltage & V \\
\hline Trac Power & $\mathrm{kW}$ \\
\hline Electrical Power & kW \\
\hline Gross Power & HP \\
\hline
\end{tabular}

40 CFR Part 1065.307 paragraph (c)(1-13) [68] specifies the procedure to perform linear verification of sensors. The procedure overview follows:

1. Zero the instrument via applicable reference signal

2. Span the instrument and compare to the zero signal

3. Introduce reference signal to measurement instrument

4. Allow instrument to stabilize reading

5. Repeat steps 3 and 4 until all reference points are recorded. Typically 11 data points are used

6. Perform least-squares regression and statistical values to compare linearity criteria

As per 40 CFR Part 1065.307 [68], 11 data points were recorded. These points spanned across the full range the sensor was expected to measure. Furthermore, 1065.307 explains how to measure all data points for the listed sensors in Table 12 from above.

Performing linear verification is similar for most of the sensors with differences being that of a measured signal with a frequency (e.g. engine speed) or that of one without a frequency (e.g. temperature). The following shows the linearity verification for the "Radiator Left 1" temperature sensor. This sensor is a K-type thermocouple from Omega ${ }^{\mathrm{TM}}$ Engineering. Reference measurement of temperature sensors were performed with an Omega ${ }^{\text {TM }}$ CL3515R calibrator/thermometer, compliant to NIST monograph 175 . This sensor measures between $55^{\circ} \mathrm{F}$ and $95^{\circ} \mathrm{F}$ and as such an appropriate 
range to measure verification for would be just outside of this range at $50^{\circ} \mathrm{F}$ to $100^{\circ} \mathrm{F}$. Table 16 shows the reference and reading values for this sensor.

Table 16 - Radiator Left 1 thermocouple linearity values

\begin{tabular}{|c|c|c|}
\hline \multicolumn{3}{|c|}{ Rad L1 } \\
\hline PTS & $\begin{array}{c}\text { Reference } \\
{\left[{ }^{\circ} \text { F }\right]}\end{array}$ & $\begin{array}{c}\text { Reading } \\
{\left[{ }^{\circ} \mathbf{F}\right]}\end{array}$ \\
\hline 1 & 50.0 & 54.3 \\
\hline 2 & 55.0 & 59.2 \\
\hline 3 & 60.0 & 64.2 \\
\hline 5 & 70.0 & 74.3 \\
\hline 6 & 75.0 & 79.2 \\
\hline 7 & 80.0 & 84.2 \\
\hline 8 & 85.0 & 89.2 \\
\hline 9 & 90.0 & 94.3 \\
\hline 10 & 95.0 & 99.3 \\
\hline 11 & 100.0 & 104.2 \\
\hline
\end{tabular}

As per 40 CFR Part 1065.602 [70], statistical analysis was performed on the data to find the coefficients $\mathrm{r}^{2}, \overline{\mathrm{y}}, \mathrm{y}_{1}, \mathrm{a} 1$, and $\mathrm{a} 0$. Table 17 shows the corresponding statistical data from Table 16 .

Table 17 - Corresponding statistical data for Radiator Left 1 data

\begin{tabular}{|c|c|c|}
\hline Value & Reference & Reading \\
\hline $\mathbf{r}^{\mathbf{2}}$ & 1.00 & 1.00 \\
\hline $\mathbf{N}$ & 11.00 & 11.00 \\
\hline$\overline{\mathbf{y}}$ & 76.00 & 80.24 \\
\hline $\mathbf{y}_{\mathbf{1}}$ & 50.00 & 54.30 \\
\hline & 674.44 & 676.00 \\
\hline & 441.84 & 441.00 \\
\hline & 256.64 & 256.00 \\
\hline & 35.64 & 36.00 \\
\hline & 1.04 & 1.00 \\
\hline & 15.84 & 16.00 \\
\hline & 80.64 & 81.00 \\
\hline & 196.84 & 196.00 \\
\hline & 362.14 & 361.00 \\
\hline & 575.04 & 576.00 \\
\hline & 2640.10 & 2640.00 \\
\hline $\mathbf{a 1}$ & 1.00 & CRITERIA \\
\hline $\mathbf{a 0}$ & 4.237 & 1.04 \\
\hline & & 4.24 \\
\hline
\end{tabular}


It can be seen that the linearity for least-squares regression met the criteria of $\geq 0.998$ with an $r^{2}=1.00$. However, continuing the linearity statistical analysis showed that a 0 for the reading values did not meet the criteria where a 0 reference was less than a 0 reading and thus the sensor failed linearity.

In order to meet linearity, the scaling value for the temperature conversion needed to be changed (i.e. $9 / 5^{*} \mathrm{~T}\left[{ }^{\circ} \mathrm{C}\right]+32\left[{ }^{\circ} \mathrm{F}\right]$ ). Changing the value of $9 / 5$, or 1.8 , to a different value that scales the reading value to the reference value meets linearity. To do this, the reading values were converted to degrees Celsius, seen in Table 18, then statistical analysis performed on the data, Table 19, and finally the slope was found for " ${ }^{\circ} \mathrm{C}$ "ref"'" to find the new temperature coefficient as 1.79.

Table 18 - Recalculated reference values with updated temperature coefficient

\begin{tabular}{|c|c|}
\hline${ }^{\circ}$ C "ref" & Reading \\
\hline 12.38 & 50.0 \\
\hline 15.11 & 55.0 \\
\hline 17.88 & 60.0 \\
\hline 23.50 & 70.0 \\
\hline 26.22 & 75.0 \\
\hline 29.00 & 80.0 \\
\hline 31.77 & 85.0 \\
\hline 34.61 & 90.0 \\
\hline 37.38 & 95.0 \\
\hline 40.11 & 100.0 \\
\hline 26.80 & 76.0 \\
\hline
\end{tabular}

Table 19 - a1 coefficient values for recalculated data in Table 18

\begin{tabular}{|c|c|}
\hline${ }^{\circ} \mathbf{C}$ "ref" & Reading \\
\hline 374.69 & 207.68 \\
\hline 245.47 & 136.63 \\
\hline 142.58 & 79.41 \\
\hline 19.80 & 10.89 \\
\hline 0.58 & 0.33 \\
\hline 8.80 & 4.84 \\
\hline 44.80 & 24.78 \\
\hline 109.36 & 61.01 \\
\hline 201.19 & 112.12 \\
\hline 319.47 & 177.19 \\
\hline
\end{tabular}

After finding the new temperature coefficient and putting it into Scimitar, the data values were recalculated, Table 20, and statistical analysis performed to check linearity, Table 21. 
Table 20 - Updated reference values for temperature sensor "Radiator Left 1"

\begin{tabular}{|c|c|}
\hline $\begin{array}{c}\text { Reference } \\
{\left[{ }^{\circ} \mathbf{C}\right]}\end{array}$ & $\begin{array}{c}\text { Reading } \\
{\left[{ }^{\circ} \mathbf{F}\right]}\end{array}$ \\
\hline 12.39 & 50.06 \\
\hline 15.11 & 54.96 \\
\hline 17.89 & 59.96 \\
\hline 23.50 & 70.06 \\
\hline 26.22 & 74.96 \\
\hline 29.00 & 79.96 \\
\hline 31.78 & 84.96 \\
\hline 34.61 & 90.06 \\
\hline 37.39 & 95.06 \\
\hline 40.11 & 99.96 \\
\hline
\end{tabular}

Table 21 - Corresponding statistical analysis for updated values to temperature sensor

"Radiator Left 1"

\begin{tabular}{|c|c|c|}
\hline Value & Reference & Reading \\
\hline $\mathbf{r 2}$ & 1.00 & 1.00 \\
\hline $\mathbf{N}$ & 11.00 & 11.00 \\
\hline$\overline{\mathbf{y}}$ & 76.00 & 76.00 \\
\hline $\mathbf{y 1}$ & 50.00 & 50.06 \\
\hline $\mathbf{a 1}$ & 0.999 & 0.999 \\
\hline $\mathbf{a 0}$ & 0.001 & 0.00 \\
\hline SEE & 0.05 & 1.00 \\
\hline
\end{tabular}

It can be seen from Table 21 that the sensor "Radiator Left 1 " met the linearity criteria per 40 CFR Part 1065.307 [68].

After linearity verification and statistical analysis was performed for each sensor, the corresponding scaling factor for each sensor (temperature, pressure, engine parameter) was put into Scimitar in order for the sensor to meet the linearity criteria of 40 CFR Part 1065.307 [68].

\subsection{Design and Analysis of the Juniata Emissions Measurement System}

While the emissions measurement system has been in place at Juniata emissions lab for years, and provided data for Norfolk Southern, GE, EDM, and CAFEE, a full report showing how the system functions has not been provided. This thesis will show an analysis of the system's compliance to federal code.

As stated previously, the emissions measurement system utilizes a DAQ software system developed by emissions engineers at WVU's CAFEE named Scimitar. Scimitar collects data from 
atmospheric conditions such as intake, exhaust, and air temperatures around the locomotive as well as a locomotive's intakes, barometric air pressure, relative humidity, radiator temperatures, and the exhaust gas emissions collected by BG-3 particulate matter sampling system and MEXA exhaust gas analyzer and compiles this data into an excel spreadsheet output and corresponding preliminary data sheet. A partial data screenshot of the Scimitar excel sheet can be seen in Figure 32 and the final Switcher and Line-Haul emissions from the preliminary test data can be seen in Figure 33.

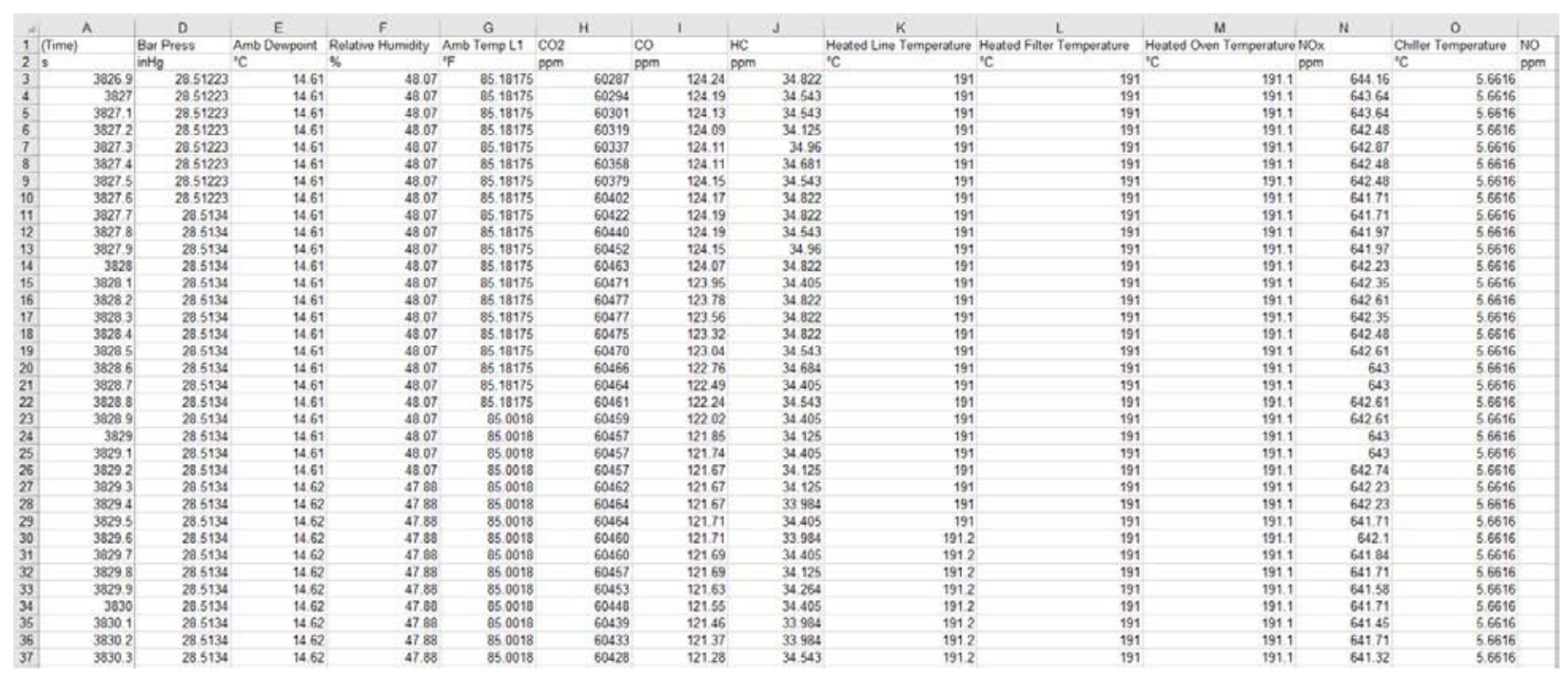

Figure 32 - Screenshot of some of Scimitar's data in Excel output for an EDM/JLS 2016 SD60E equipped with a model year 1990 engine Test ID: R0007-002-198 


\section{Locomotive Test Report R0007-002-198}

\section{Switcher Duty Cycle Weighted Results}

\begin{tabular}{|c|c|c|c|c|c|c|c|c|}
\hline Notch & Factor (\%) & Power (hp) & Fuel Rate (lb/hr) & $\mathrm{CO} 2$ (g/hr) & $\mathrm{HC}(\mathrm{g} / \mathrm{hr})$ & $\mathrm{CO}(\mathrm{g} / \mathrm{hr})$ & NOx $(g / h r)$ & PM (g/hr) \\
\hline Idle & 50.8 & 6.6 & 14.3 & 21577 & 24.4 & 23.7 & 444.5 & - \\
\hline DynBraking & 0.0 & 0.0 & 0.0 & 0 & 0.0 & 0.0 & 0.0 & \\
\hline Notch 1 & 124 & 27.4 & 11.7 & 17151 & 7.7 & 14.0 & 336.5 & \\
\hline Notch 2 & 123 & 54.9 & 20.7 & 30191 & 10.4 & 18.6 & 541.5 & \\
\hline Notch 3 & 5.8 & 57.4 & 20.5 & 29787 & 8.7 & 10.7 & 496.2 & \\
\hline Notch 4 & 3.6 & 56.0 & 18.5 & 28304 & 7.1 & 21.0 & 416.3 & \\
\hline Notch 5 & 3.6 & 73.7 & 25.8 & 37490 & 8.2 & 91.2 & 477.8 & \\
\hline Notch 6 & 1.5 & 36.5 & 12.8 & 18608 & 3.5 & 55.4 & 199.4 & \\
\hline Notch 7 & 0.2 & 7.4 & 2.5 & 3649 & 0.8 & 4.3 & 41.0 & \\
\hline Notch 8 & 0.8 & 35.5 & 12.2 & 17612 & 3.5 & 29.5 & 190.5 & \\
\hline $\begin{array}{r}\text { Sum } \\
\text { Brake Specific }\end{array}$ & 100.0 & 355.4 & $\begin{array}{l}140.1 \\
0.394\end{array}$ & $\begin{array}{r}204370 \\
575\end{array}$ & $\begin{array}{l}74.2 \\
0.209\end{array}$ & $\begin{array}{r}288.3 \\
0.75\end{array}$ & $\begin{array}{r}3143.6 \\
8.84\end{array}$ & \\
\hline
\end{tabular}

Line-Haul Duty Cycle Weighted Results

\begin{tabular}{rrrrrrrrr}
\hline Notch & Factor (\%) & Power (hp) & Fuel Rate (lb/hr) & CO2 (g/hr) & HC (g/hr) & CO (g/hr) & NOx (g/hr) & PM (g/hr) \\
\hline Idle & 38.0 & 4.2 & 9.1 & 13711 & 15.5 & 15.1 & 282.5 \\
DynBraking & 12.5 & 3.5 & 5.6 & 8468 & 8.5 & 10.8 & 132.9 & - \\
Notch 1 & 6.5 & 14.4 & 6.1 & 8991 & 4.0 & 7.3 & 176.4 & - \\
Notch 2 & 6.5 & 29.0 & 10.9 & 15955 & 5.5 & 9.8 & 286.2 & - \\
Notch 3 & 5.2 & 51.4 & 18.4 & 28706 & 7.8 & 9.6 & 444.8 & - \\
Notch 4 & 4.4 & 68.5 & 23.8 & 34593 & 8.7 & 25.7 & 508.8 & - \\
Notch 5 & 3.8 & 77.8 & 27.4 & 39573 & 8.7 & 96.2 & 504.3 & - \\
Notch 6 & 3.9 & 95.0 & 33.5 & 48381 & 9.1 & 144.1 & 518.5 & - \\
Notch 7 & 3.0 & 111.0 & 37.7 & 54733 & 11.4 & 63.9 & 614.7 & - \\
Notch 8 & 16.2 & 719.4 & 246.2 & 358649 & 71.7 & 597.2 & 3856.7 & - \\
Sum & 100.0 & 1174.2 & 418.8 & 607760 & 150.9 & 979.7 & 7325.7 & - \\
Brake Specific & & & 0.357 & 518 & 0.129 & 0.83 & -
\end{tabular}

Figure 33 - Screenshot of preliminary test report from Scimitar compiled data for an EDM/JLS 2016

SD60E equipped with a model year 1990 engine Test ID: R0007-002-198

As stated previously, the emissions measurement system at the Juniata emissions lab measures emissions through partial flow raw exhaust sampling and PM by partial flow dilution of exhaust gas. Title 40 CFR Part 1065.140 - Dilution for gaseous and PM constituents [71] outlines the procedures to condition and perform emissions measurement. This regulation outlines construction of the emissions measurement system (i.e. materials, piping, etc.), pressure of portioned exhaust gas, mixing of exhaust gas and dilution flow (setting dilution ratio between 5:1 to 7:1 for diluted exhaust gas to raw exhaust gas), preconditioning of the diluted exhaust, addressing condensation in exhaust gas, and meeting the requirements for partial flow dilution (PFD) such as temperature (for example, maintaining a sample temperature of $(47 \pm 5)^{\circ} \mathrm{C}$ measured $20 \mathrm{~cm}$ upstream or downstream of the PM filter).

Furthermore, 40 CFR Part 1065.650 [13] specifies the particular ways to determine the brakespecific emissions over a test interval which are:

1. "For any testing, you may calculate the total mass of emissions and divide it by the total work generated over the test interval [13]" 
2. "For discrete-mode steady-state testing, you may calculate the brake-specific emissions over a test interval using the ratio of emission mass rate to power [13]"

3. "For field testing, you may calculate the ratio of total mass to total work [13]"

The emissions measurement system in Altoona utilizes option 2. Since this method is used, it must follow 1033.501 paragraph (4) [4] which states, "Ifyou perform discrete-mode testing and use only one batch fuel measurement to determine your mean raw exhaust flow rate, you must target a constant sample flow rate over the mode. Verify proportional sampling as described in 40 CFR 1065.545 using the mean raw exhaust molar flow rate paired with each recorded sample flow rate."

In order to calculate the emissions and create the preliminary emissions data sheet, Scimitar utilizes the emissions calculations from 40 CFR Part 1033 Subpart F [34] and Part 1065 Subpart G [72]. After setup of a locomotive, and all checks and verifications of equipment is performed, an emissions test is completed. The data is collected by the Scimitar program and performs emissions calculations. Emissions reporting begins with 40 CFR Part 1065 Subpart G - Calculations and Data Requirements [72] which describes how to use the signals from an emissions test to calculate the brake-specific emissions of each measured exhaust constituent, perform calibrations and performance checks, and how to determine statistical values.

From 40 CFR Part 1065.655 - Chemical balances of fuel, intake air, and exhaust [38], "Chemical balances of fuel, intake air, and exhaust may be used to calculate flows, the amount of water in their flows, and the wet concentration of constituents in their flows." These chemical balances are used for calculating several factors, most importantly of which are the brake-specific emissions. To accomplish research goal (1), emissions calculations were performed and compared to Scimitar as a check. The results from the emissions calculations were used in proportional verification of exhaust flow. For this study, Idle and Notch 8 were chosen for evaluation as they had low and high fuel flow rates which were the extremes of the flows.

The procedures for determining the chemical balances involved a system of equations which required iteration to solve them. These iteration procedures from 1065.655 [38] were written into a MATLAB $^{\circledR}$ code (Appendix A3.1 - Carbon Balance for Test R0007-002-198) to solve for xdil/exh, $\mathrm{xH} 2 \mathrm{Oexh}$, and xCcombdry. The iteration equations for xdil/exh, xH2Oexh, and xCcombdry can be seen in the equations below. All calculations for emissions can be found in the MATLAB ${ }^{\circledR}$ code carbon balancer.

$$
\mathrm{x}_{\mathrm{dil} / \mathrm{exh}}=1-\frac{\mathrm{x}_{\mathrm{raw} / \mathrm{exhdry}}}{1+\mathrm{x}_{\mathrm{H} 2 \mathrm{eexhdry}}}
$$




$$
\begin{aligned}
& \mathrm{x}_{\mathrm{H} 2 \mathrm{Oexh}}=1-\frac{\mathrm{x}_{\mathrm{H} 2 \text { Oexhdry }}}{1+\mathrm{x}_{\mathrm{H} 2 \text { Oexhdry }}} \\
& \mathrm{x}_{\text {Ccombdry }}=x_{\text {CO2dry }}+x_{\text {COdry }}+x_{\text {THCdry }} \\
& -x_{\text {CO2dil }} * \mathrm{x}_{\text {dil/exhdry }}-x_{\text {CO2int }} * \mathrm{x}_{\text {int/exhdry }} \text { Eq. 3.2-3 (Eq. 1065.655-3) }
\end{aligned}
$$

The following constants were used for calculations:

$$
\begin{aligned}
& \mathrm{W}_{\mathrm{C}}=\text { carbon mass fraction of no. } 2 \text { diesel fuel }=0.8988[\mathrm{~g} / \mathrm{g}] \\
& \text { Using the molar fraction coefficients: } \\
& \alpha=1.8 \\
& \beta=0 \\
& \gamma=0 \\
& \delta=0 \\
& \text { Mc }=\text { molar mass of carbon }=12.0107[\mathrm{~g} / \mathrm{mol}] \\
& \mathrm{KH} 2 \mathrm{Ogas}=\text { water-gas reaction equilibrium coefficient }=3.5 \\
& \text { xdil/exh = between 0.75-0.95 } \\
& \mathrm{xH} 20 \mathrm{exh}=\text { twice the intake air humidity ( } 2 * \mathrm{xH} 2 \mathrm{Oint}) \\
& \mathrm{xCcombdry}=\mathrm{CO} 2+\mathrm{CO}+\mathrm{THC} \text { (wet to dry converted) } \\
& \mathrm{xH} 2 \mathrm{Oint}=\mathrm{xH} 2 \mathrm{Odil}
\end{aligned}
$$

The MATLAB ${ }^{\circledR}$ code used a "while" loop to continuously solve the iteration values and checked for convergence of the values to a $1 \%$ difference in iterations as seen in the equation below.

$$
\frac{x_{i}-x_{i-1}}{x_{i-1}}=0.01
$$

The iterative loop calculated xH2_dry, xintexh_dry, xH2Oexh_dry, xrawexh_dry, xH2O_exh, xTHC_dry, xCcomb_dry, xdilexh, then calculated the error for xH2Oexh, xTHCdry, xdil/exh, and $\mathrm{xCcombdry}$ with the above equation using the initial assumption values as $x_{i-1}$. If the error criteria was not met, the loop restarted with the iteration values updating the newly calculated values and proceeded with the iteration again. The iteration process continued until the convergence criteria was met.

The constituents (xCO_meas, xCO2_meas, xNOx_meas, xNO_meas, xNO2_meas, xTHC_meas) used for the iteration came from the averaged values of each recorded constituent by Scimitar. These values varied from notch to notch due to the locomotive's operating states. The constituent's 
xCO2dil_dry and xCO2int_dry were set at $375 \mu \mathrm{mol} / \mathrm{mol}$ as per 1065.655 paragraph (c)(3). Table 22, below, shows a comparison of data for MATLAB ${ }^{\circledR}$ and Scimitar for Notch 8 of Test ID: R0007-002198 (calculations can be found in Appendix A3.1 - Carbon Balance for Test R0007-002-198).

Table 22 - Comparison of iterated values from MATLAB ${ }^{\circledR}$ and Scimitar from Notch 8 of Test ID: R0007-002-198

\begin{tabular}{|c|c|c|c|c|}
\hline Factor & MATLAB & Scimitar & Unit & \%Difference \\
\hline xdilexh & 0.5641 & 0.5633 & $\mathrm{~mol} / \mathrm{mol}$ & 0.14 \\
\hline xCcomb_dry & 0.0624 & 0.0624 & $\mathrm{~mol} / \mathrm{mol}$ & 0.00 \\
\hline xH20_exh_dry & 0.0737 & - & $\mathrm{mol} / \mathrm{mol}$ & - \\
\hline Kh & 1.0048 & 1.0049 & - & 0.00 \\
\hline
\end{tabular}

As seen in Table 22, the iterated values xdilexh and xCcombdry are less than $1 \%$ of each other. As Scimitar does not show the iterated value xH2O_exh_dry, it was not compared but because that value used xdilexh in the iteration, a strong assumption was made that this value was also within $1 \%$ of Scimitar's value. This meant that the iteration that Scimitar performed followed 40 CFR Part 1065.655 (c)(4) code and further evaluation of the emissions measurement system continued.

Continuation for comparing values were that of emission concentrations. Table 23 shows the comparison of emission concentrations between MATLAB ${ }^{\circledR}$ and Scimitar.

Table 23 - Comparison of emissions concentrations from MATLAB ${ }^{\circledR}$ and Scimitar from Notch 8 of Test

ID: R0007-002-198

\begin{tabular}{|c|c|c|c|c|}
\hline $\begin{array}{c}\text { Emission } \\
\text { Concentrations }\end{array}$ & MATLAB $^{\circledR}$ & Scimitar & Unit & \% Difference \\
\hline xCO2_dry & 6.27 & 6.26 & $\%$ & 0.15 \\
\hline xCO_dry & 164.19 & 165 & $\begin{array}{c}\mathrm{ppm} \\
(\mathrm{mol} / \mathrm{mol})\end{array}$ & 0.49 \\
\hline xNOxcor & 644.98 & 644 & $\begin{array}{c}\mathrm{ppm} \\
(\mathrm{mol} / \mathrm{mol})\end{array}$ & 0.15 \\
\hline xTHC_dry & 38.11 & 37.2 & $\begin{array}{c}\mathrm{ppm} \\
(\mathrm{mol} / \mathrm{mol})\end{array}$ & 2.42 \\
\hline
\end{tabular}

As seen from the Table 23, the emissions concentration of $\mathrm{CO}, \mathrm{CO} 2$, and $\mathrm{NOx}$, between MATLAB $^{\circledR}$ and Scimitar were within $1 \%$ of each other while THC was within $2.5 \%$. It was determined the differences in the constituents occurred due to the temperature parameters used for humidity calculations which determine the factors to correct the emissions constituents to a dry basis. Once converted to a dry basis and carbon balance performed, the mass of emissions were calculated. The mass of emissions were calculated with the formula below. 
Mass of emission $=$

$$
\begin{aligned}
= & \text { Emission Concentration }[p p m] * 10^{-6}(p p m) * \text { Molar Mass }\left[\frac{g}{m o l}\right] \\
& * \text { Notch Duration }[s] * \text { Exhaust Molar Rate }\left[\frac{\text { mols }}{\mathrm{s}}\right]
\end{aligned}
$$

Emission concentration was the respective measured constituent (i.e. NOx, THC, CO, CO2). To convert to a percent basis, each constituent is divided by $10^{6}$, except $\mathrm{CO} 2$ as it was already on a percentage basis. The exhaust molar rate, nexh, is calculated through the equation below.

$$
\dot{\mathrm{n}}_{\mathrm{exh}}=\frac{\dot{\mathrm{m}}_{\mathrm{fuel}} * \mathrm{w}_{\mathrm{c}} *\left(1+\mathrm{x}_{\mathrm{H} 2 \mathrm{Oexhdry}}\right)}{\mathrm{M}_{\mathrm{c}} * \mathrm{x}_{\mathrm{Ccombdry}}}
$$

Where:

$$
\dot{\mathrm{m}}_{\text {fuel }}=\text { mass flow rate of fuel }
$$

To get the switcher and line-haul emissions, interval mass was multiplied by the weighting factors in 40 CFR Part 1033.530 [73], which can also be seen in Table 24.

Table 24 - Standard duty cycle weighting factors for calculating emission rates for locomotives from 40 CFR Part 1033.530 [73]

\begin{tabular}{|c|c|c|}
\hline Notch setting & $\begin{array}{c}\text { Line-haul } \\
\text { weighing } \\
\text { factor }\end{array}$ & $\begin{array}{c}\text { Switcher } \\
\text { weighing } \\
\text { factor }\end{array}$ \\
\hline Normal Idle & 0.38 & 0.598 \\
\hline Dynamic Brake & 0.125 & 0 \\
\hline Notch 1 & 0.065 & 0.124 \\
\hline Notch 2 & 0.065 & 0.123 \\
\hline Notch 3 & 0.052 & 0.058 \\
\hline Notch 4 & 0.044 & 0.036 \\
\hline Notch 5 & 0.038 & 0.036 \\
\hline Notch 6 & 0.039 & 0.015 \\
\hline Notch 7 & 0.03 & 0.002 \\
\hline Notch 8 & 0.162 & 0.008 \\
\hline
\end{tabular}

After calculating the line-haul and switcher emissions, the brake-specific emissions were calculated by dividing the sum of weighted emissions by the sum of weighted bhp's. These numbers were used to obtain the brake-specific emissions. The emissions calculated by Scimitar can be seen in 
Table 25 and the calculated emissions from MATLAB ${ }^{\circledR}$ (Appendix A3.1 - Carbon Balance for Test R0007-002-198) can be seen in Table 26.

Table 25 - Scimitar emission results from Notch 8 of Test ID: R0007-002-198

\begin{tabular}{|c|c|c|c|c|c|c|}
\hline \multirow{3}{*}{ Emission } & \multicolumn{7}{|c|}{ Scimitar } \\
\cline { 2 - 7 } & Mass & $\begin{array}{c}\text { Mass per } \\
\text { interval }\end{array}$ & $\begin{array}{c}\text { Switcher } \\
\text { weighted }\end{array}$ & $\begin{array}{c}\text { Line-Haul } \\
\text { weighted }\end{array}$ & $\begin{array}{c}\text { Brake- } \\
\text { Specific } \\
\text { (Switcher) }\end{array}$ & $\begin{array}{c}\text { Brake- } \\
\text { Specific } \\
\text { (Line-Haul) }\end{array}$ \\
\cline { 2 - 7 } & $\mathbf{g}$ & $\mathbf{g} / \mathbf{h r}$ & $\mathbf{g} / \mathbf{h r}$ & $\mathbf{g} / \mathbf{h r}$ & $\mathbf{g} / \mathbf{h p}-\mathbf{h r}$ & $\mathbf{g} / \mathbf{h p - h r}$ \\
\hline CO2 & 366923.1 & 2201538.0 & 17612.0 & 356649.0 & 496.1 & 495.8 \\
\hline CO & 614.4 & 3686.3 & 29.5 & 597.2 & 0.83 & 0.83 \\
\hline NOx & 3967.8 & 23806.8 & 190.5 & 3856.7 & 5.37 & 5.36 \\
\hline THC & 73.8 & 442.9 & 3.5 & 71.7 & 0.10 & 0.10 \\
\hline
\end{tabular}

Table 26 - MATLAB ${ }^{\circledR}$ emission results from Notch 8 of Test ID: R0007-002-198

\begin{tabular}{|c|c|c|c|c|c|c|}
\hline \multirow{2}{*}{ Emission } & \multicolumn{7}{|c|}{ MATLAB ${ }^{\circledR}$} \\
\cline { 2 - 7 } & Mass & $\begin{array}{c}\text { Mass per } \\
\text { interval }\end{array}$ & $\begin{array}{c}\text { Switcher } \\
\text { weighted }\end{array}$ & $\begin{array}{c}\text { Line-Haul } \\
\text { weighted }\end{array}$ & $\begin{array}{c}\text { Brake- } \\
\text { Specific } \\
\text { (Switcher) }\end{array}$ & $\begin{array}{c}\text { Brake- } \\
\text { Specific } \\
\text { (Line-Haul) }\end{array}$ \\
\cline { 2 - 7 } & $\mathbf{g}$ & $\mathbf{g} / \mathbf{h r}$ & $\mathbf{g} / \mathbf{h r}$ & $\mathbf{g} / \mathbf{h r}$ & $\mathbf{g} / \mathbf{h p - h r}$ & $\mathbf{g} / \mathbf{h p - h r}$ \\
\hline CO2 & 367370 & 2204220 & 17634 & 357080 & 496.7 & 496.4 \\
\hline CO & 612.4 & 3674.7 & 29.4 & 595.3 & 0.828 & 0.828 \\
\hline NOx & 3780.3 & 22682 & 181.5 & 3674.5 & 5.11 & 5.11 \\
\hline THC & 66.1 & 396.5 & 3.2 & 64.2 & 0.089 & 0.089 \\
\hline
\end{tabular}

The brake-specific emissions were calculated and the percent difference between each constituent were $0.12 \%, 0.24 \%, 4.96 \%$, and $11.60 \%$ for CO2, CO, NOx, and THC, respectively for Notch 8 carbon balance for Test ID: R0007-002-198. At Idle (Appendix C8 - Test ID: R0007-002-198 Idle Carbon Balance Results) the percent differences of the same respective constituents were $2.10 \%$, $0.00 \%, 2.25 \%, 3.86 \%$.

While the percent differences for NOx and THC were high in Notch 8, the percent differences for Idle were low (less than 5\%). It was concluded that Scimitar performed carbon balance compliant to 40 CFR Part 1065 even though there were differences between the two programs. However, it can be further concluded that, unless the numbers were exactly the same, like CO, the higher errors occurred due to the magnitude of the constituent. Compared to CO2, NOx and THC were small magnitude and the errors between Scimitar and MATLAB ${ }^{\circledR}$ were much larger for them, as seen above.

The BSFC was calculated similar to Switcher and Line-Haul emissions; divided the weighted constituent by the weighted bhp. Table 27 shows the fuel consumed by the locomotive over the emissions test (Test ID: R0007-002-198), and Table 28 shows the BSFC. 
Table 27 - Fuel burned over an emissions test for a 2016 SD60E equipped with a model year 1990 engine (data from Appendix C2 - Preliminary Test Data for Test ID: R0007-002-198)

\begin{tabular}{|c|c|c|c|c|c|}
\hline Notch & $\begin{array}{c}\text { Fuel } \\
\text { (lb.) }\end{array}$ & $\begin{array}{c}\text { Duration } \\
\text { (s) }\end{array}$ & $\begin{array}{c}\text { Flow } \\
\text { Rate } \\
\text { (lb./hr) }\end{array}$ & $\begin{array}{c}\text { Brake-specific Flow } \\
\text { Rate } \\
\text { Switcher } \\
\text { (lb/hr) }\end{array}$ & $\begin{array}{c}\text { Brake-specific Flow } \\
\text { Rate } \\
\text { Line-Haul } \\
\text { (lb/hr) }\end{array}$ \\
\hline Idle & 4.0 & 600 & 24.0 & 14.3 & 9.1 \\
\hline DynBraking & 3.7 & 300 & 44.4 & 0.0 & 5.6 \\
\hline Notch 1 & 7.9 & 300 & 94.8 & 11.7 & 6.1 \\
\hline Notch 2 & 14.0 & 300 & 168.0 & 20.7 & 10.9 \\
\hline Notch 3 & 29.4 & 300 & 352.8 & 20.5 & 18.4 \\
\hline Notch 4 & 45.1 & 300 & 541.2 & 19.5 & 23.8 \\
\hline Notch 5 & 60.0 & 300 & 720.0 & 25.9 & 27.4 \\
\hline Notch 6 & 71.6 & 300 & 859.2 & 12.9 & 33.5 \\
\hline Notch 7 & 104.9 & 300 & 1258.8 & 2.5 & 24.7 \\
\hline Notch 8 & 253.3 & 600 & 1519.8 & 12.2 & \\
\hline
\end{tabular}

Table 28 - Brake-specific fuel consumption for a 2016 SD60E equipped with a model year 1990 engine (data from Appendix C2 - Preliminary Test Data for Test ID: R0007-002-198)

\begin{tabular}{|c|c|}
\hline \multicolumn{2}{|c|}{$\begin{array}{c}\text { BSFC } \\
\text { (lb/hp-hr) }\end{array}$} \\
\hline Switcher & Line-Haul \\
\hline 0.394 & 0.357 \\
\hline
\end{tabular}

The total family emissions limits of each emissions constituent is found by dividing the sums of weighted constituents [g/hr] by the sum of weighted bhp. The locomotive from Test ID: R0007-002198 (Appendix C2 - Preliminary Test Data for Test ID: R0007-002-198) passes the emissions criteria for an engine with original year of manufacture between 1973-1992 according to 40 CFR Part 1033.101 [6] for the emission constituents CO, THC, and NOx.

The final criteria for emissions measurement comes from PM measurement. As previously stated in Section 3.1.2 Raw Exhaust and Particulate Emissions Sampling, particulate matter is sampled through the BG3 PFD PM sampling system. Figure 34 shows a simplified diagram of the BG3 PM sampling system [7]. 


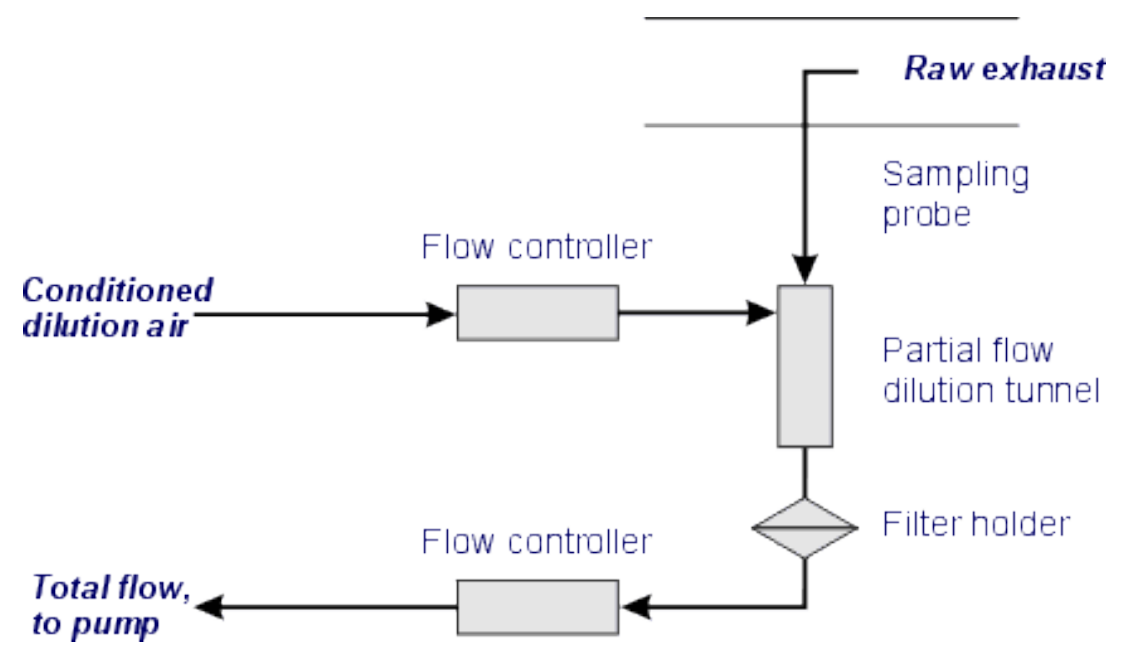

Figure 34 - Simplified diagram of BG3 PM sampling system [7]

As it can be seen from the figure, exhaust gas is partially sampled from the exhaust stack and diluted with ambient air and pulled through a PM filter by a vacuum. As previously mentioned, the sample flow temperature must be maintained at $(47 \pm 5){ }^{\circ} \mathrm{C}$ and measured $20 \mathrm{~cm}$ upstream or downstream of the PM filter. Furthermore, the dilution ratio of diluted exhaust gas to raw exhaust gas must be maintained between $5: 1$ to $7: 1$, but may also be set through engineering judgement by manufacturer-published literature. The filter is placed in the filter holder at the beginning of a notch and removed at the end. The filter is weighed and the post-weight of the filter minus the original filter weight provides the PM weight. The buoyancy-corrected tare mass of the PM filter minus its respective buoyancy-corrected mass is the net PM used for emissions reporting.

\subsection{Particulate Matter Filter Weighing}

TX40 $47 \mathrm{~mm}$ particulate matter filters are used in PM measurement at the Juniata emissions lab. The PM filters are pre-conditioned at the CAFEE laboratory located the Engines and Emissions Research Center (ERC). The ERC houses an ISO 14644-1 ISO 6, Class 1000, conditioning room per 40 CFR 1065.190 [74]. By design, and allowable per 1065.190, the PM stabilization environment and the weighing environment are the same room. The conditioning room is kept at an ambient temperature of $(22 \pm 1){ }^{\circ} \mathrm{C}$, maintains a target dewpoint temperature of $(9.5 \pm 1)^{\circ} \mathrm{C}$. Barometric pressure inside and outside of the conditioning environment is recorded as well and maintained $\pm 100 \mathrm{~Pa}$ outside of the weighing environment, per 1065.190 [74].

After conditioning the filters to the room for the minimum requirement of at least 60 minutes, they are weighed. The required number of filters is typically 10 (for Idle, Dynamic Braking, Notches 18), but vary based on the emissions test. The filters and their glass containers are gathered and identification stickers are placed on them. The filter weighing procedure is:

1. Gather the reference filters and desired filters to be weighed 
2. Connect grounding wire to your body

3. Sign into the filter weighing data base

4. Zero and span the balance

5. Scan the reference filter ID sticker

6. With tweezers, carefully remove the filter and hover over static eliminator

7. Open the Sartorius SE2-F Filter Microbalance lid and slowly place filter onto the weighing pad and close the lid

8. Allow at least 10 seconds for balance to stabilize and hit "record weight"

9. Carefully remove filter and place back into filter container

10. Hit the next filter button

11. Repeat steps 4-9 for the reference filters to ensure that the filters and balance are weighing correctly

Reference filters are used and must be weighed, per 40 CFR 1065.390 [75], within 80 hours of weighing, performing a test, and reweighing. At least two filters must remain in the conditioning room, but more may be used. Per 1065.390, reference filter weights may not vary more that $\pm 10 \mu \mathrm{g}$.

If the reference filters weighed were within their respective weights, continue to repeat steps 4-9 until all the filters are weighed. Figure 35 shows a picture of the Sartorius SE2-F Filter Microbalance, the static eliminator, and the balance output. 


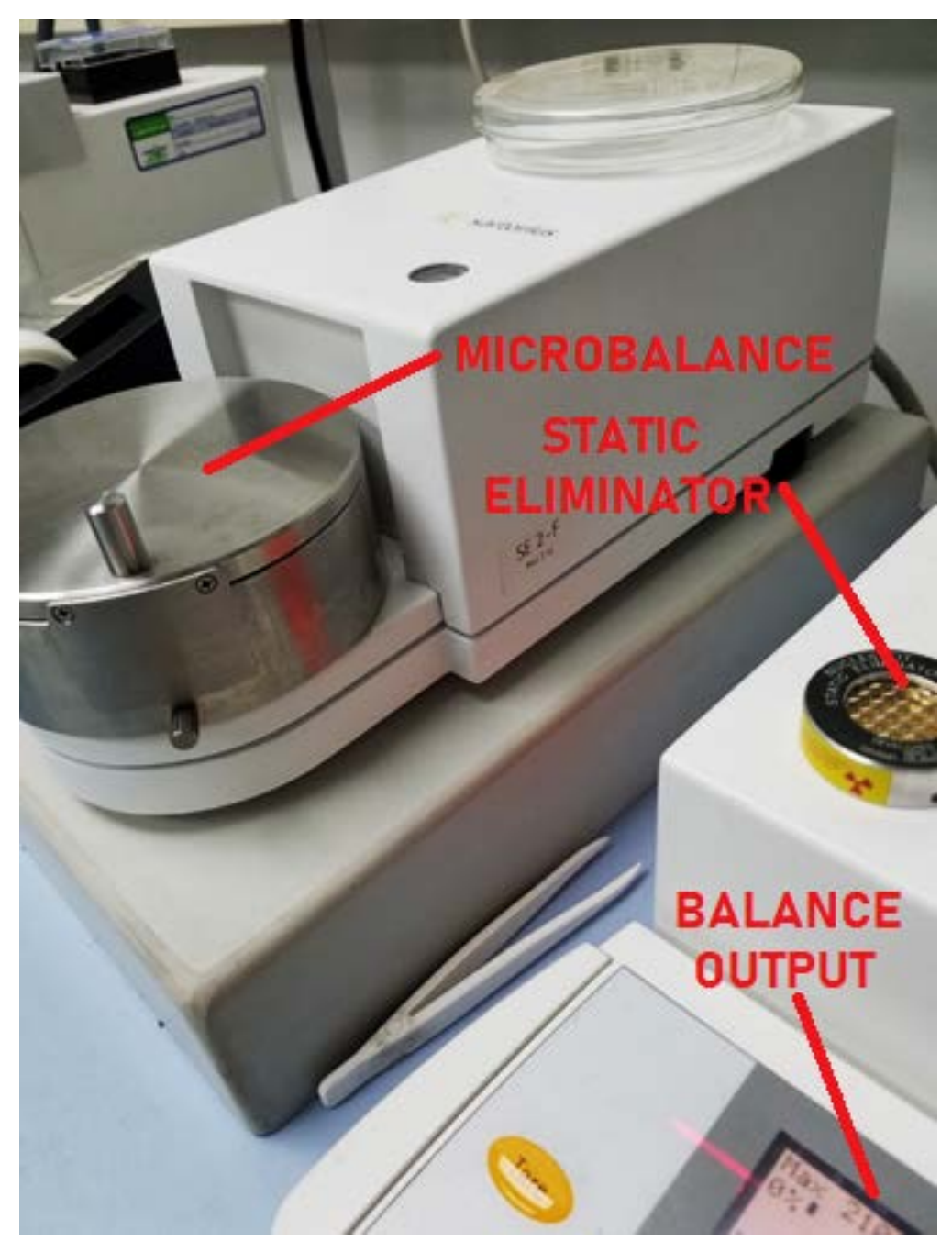

Figure 35 - Sartorius SE2-F Filter Microbalance in the CAFEE ERC controlled filter weighing room After the filters are weighed, they are placed into filter pucks and placed in bags for transporting them from the filter conditioning room to the emissions test site. These bags have the filter ID stickers placed on them and their respective filters placed into them.

After an emissions test is performed, the filters are reweighed using the same procedure above. The filter weights are used in the PM calculations, as described in Section 3.2 Design and Analysis of the Juniata Emissions Measurement System, to determine the amount of PM emissions. Figure 36 shows a picture of a particulate filter before and after an emissions test. 


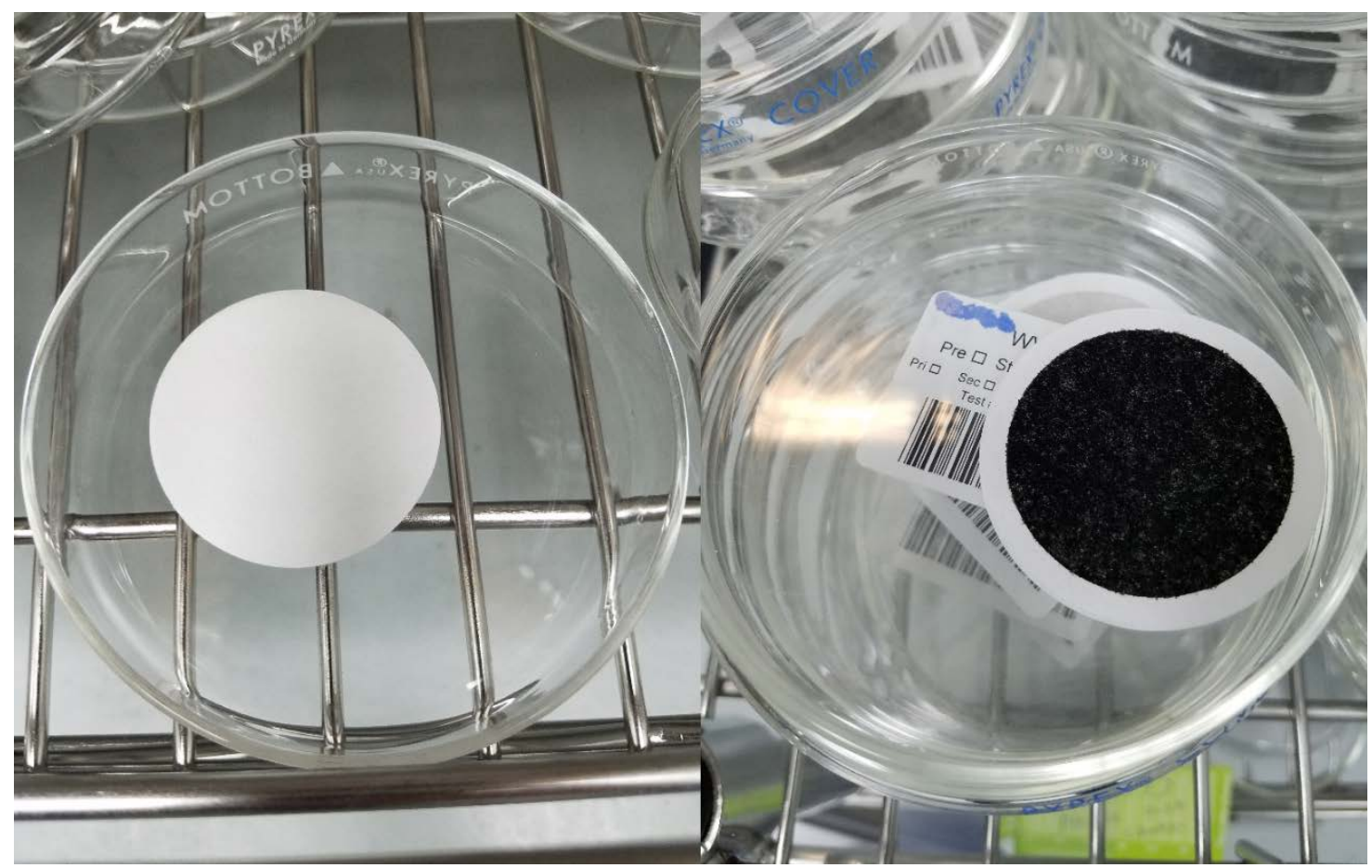

Figure 36 - Particulate matter filter before (left) and after (right) use in an emissions test

After an emissions test is performed, the filters are returned to the conditioning environment and conditioned for at least 60 minutes. The filters are reweighed through the same weighing procedures above. The post-test filter weight minus the pre-test filter weight is the PM sample weight without buoyancy corrections. PM buoyancy corrections are performed per 40 CFR Part 1065.690 and using equation 1065.690-1, below.

$$
m_{\text {cor }}=m_{\text {uncor }} *\left(\frac{1-\frac{\rho_{\text {air }}}{\rho_{\text {weight }}}}{1-\frac{\rho_{\text {air }}}{\rho_{\text {media }}}}\right)
$$

Where:

$$
\begin{aligned}
& \mathrm{m}_{\text {cor }}=\text { PM mass corrected for buoyancy } \\
& \mathrm{m}_{\text {uncor }}=\text { PM mass uncorrected for buoyancy } \\
& \rho_{\text {air }}=\text { density of air in balance environment } \\
& \rho_{\text {weight }}=\text { density of calibration weight used to span balance } \\
& \rho_{\text {media }}=\text { density of PM sample media }
\end{aligned}
$$

\subsection{Validation and Verification of Gravimetric Fuel Measurement}

The gravimetric fuel measurement system utilizes batch sampling, described by 40 CFR 1065.15 (c)(2)(ii) [76], and as such it must adhere to 40 CFR Part 1065.650 [13] via one of the three 
ways described in that section. As stated previously, brake-specific emissions are measured and calculated using option 2, discrete-mode steady-state testing. Due to this, it must follow 1033.501 paragraph (4) [4] which states that if discrete-mode steady-state testing is used with one batch fuel measurement then a target constant sample flow rate (of PM) must be met through proportional sampling of this flow as described in 40 CFR Part 1065.545 [12]. The CFR provides 2 options:

1. "For any pair of flow rates, use recorded sample and total flow rates, where total flow rate means the raw exhaust flow rate for raw exhaust sampling and the dilute exhaust flow rate for CVS sampling, or their $1 \mathrm{~Hz}$ means with the statistical calculations in $\$ 1065.602$. Determine the standard error of the estimate, SEE, of the sample flow rate versus the total flow rate. For each test interval, demonstrate that SEE was less than or equal to $3.5 \%$ of the mean sample flow rate"

2. "For any pair of flow rates, use recorded sample and total flow rates, where total flow rate means the raw exhaust flow rate for raw exhaust sampling and the dilute exhaust flow rate for CVS sampling, or their $1 \mathrm{~Hz}$ means to demonstrate that each flow rate was constant within $\pm 2.5 \%$ of its respective mean or target flow rate."

The gravimetric fuel consumption system utilizes option 1. As stated previously, a BG3 is used for PM sampling. Figure 37 shows the Dilution Flow Rate [SLPM], the Total PM Flow Rate [SLPM], and the Dilution Ratio from the BG3 during Notch 8 of Test ID: R0007-002-198.

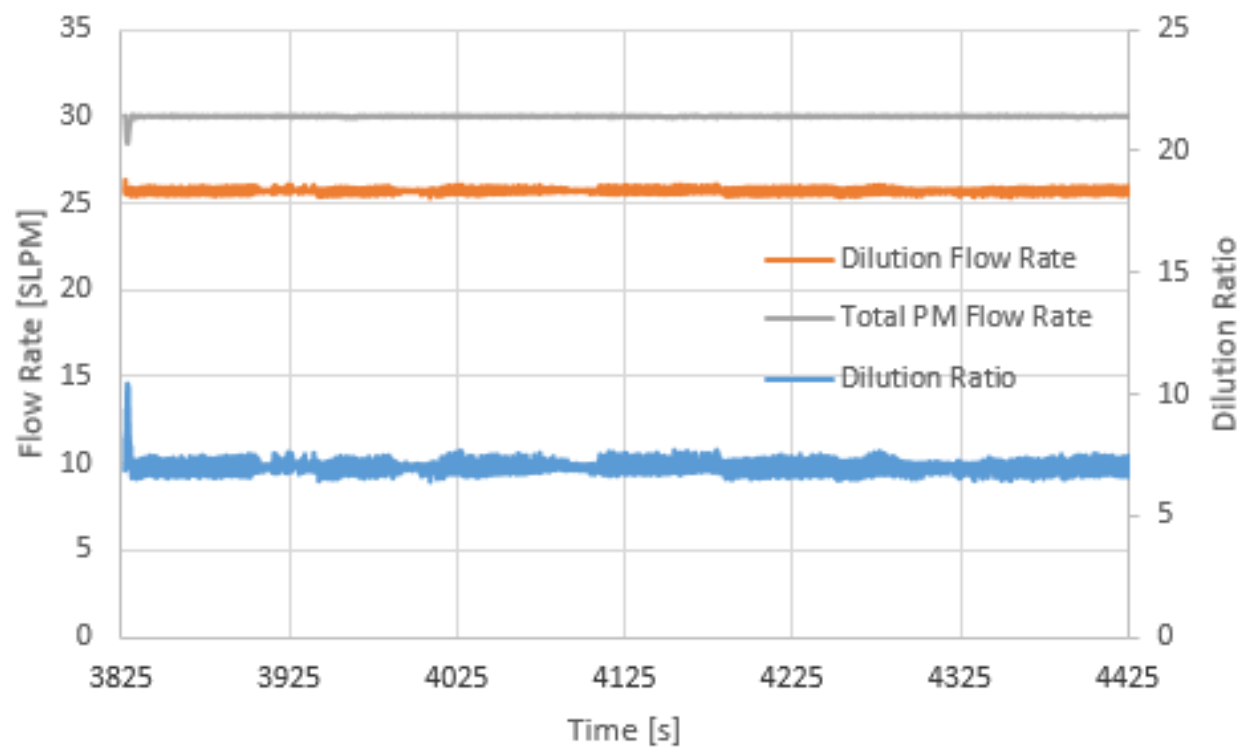

Figure 37 - Dilution Flow Rate [SLPM], Total PM Flow Rate [SLPM], and Dilution Ratio during Notch 8 of Test ID: R0007-002-198

At the start of the notch the engine is ramping up and the total flow rate and dilution ratio are changing, which can be seen from the figures above. However, while the dilution ratio change occurs at 
the beginning of the notch, the dilution air flow rate is constant over the interval. For the gravimetric fuel measurement system, and per the CFR, $5 \%$ of the total number of data points may be omitted as outliers. Figure 38 shows the updated data for Dilution Flow Rate [SLPM], Total PM Flow Rate [SLPM], and Dilution Ratio with the first $5 \%$ of the data points in Notch 8 omitted.

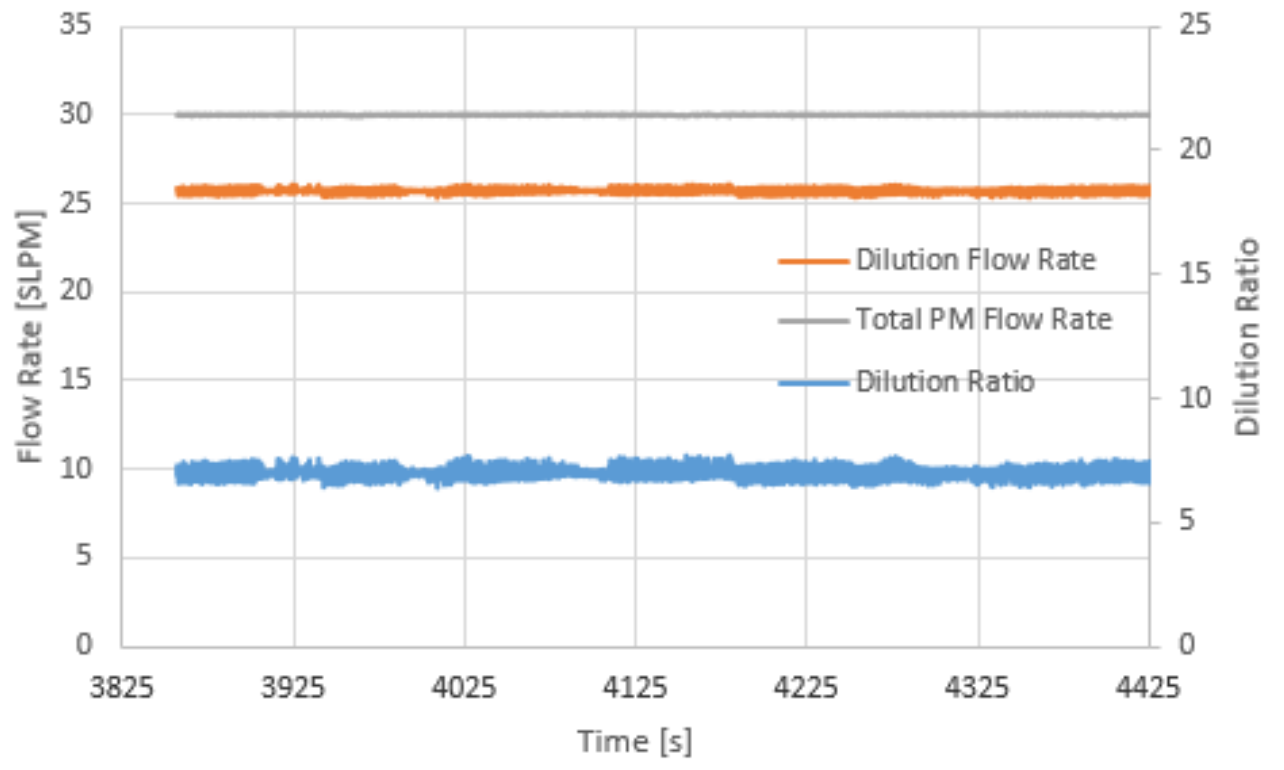

Figure 38 - Dilution Flow Rate [SLPM], Total PM Flow Rate [SLPM], and Dilution Ratio with first 5\% of data points omitted during Notch 8 of Test ID: R0007-002-198

It can be seen that the ramp up is no longer in the data due to the omission. To calculate the SEE, the diluted exhaust flow rate is compared to the total exhaust flow rate. Table 29 shows a portion of data used in the SEE calculation

Table 29 - Portion of data for SEE calculation of Dilution and PM flow rates during Notch 8 of Test ID: R0007-002-198

\begin{tabular}{|c|c|c|}
\hline Time & $\begin{array}{c}\text { Dilution } \\
\text { Flow Rate }\end{array}$ & PM Flow Rate \\
\hline [s] & [SLPM] & [SLPM] \\
\hline 4224.0 & 25.52 & 30.00 \\
\hline 4224.1 & 25.85 & 30.03 \\
\hline 4224.2 & 25.48 & 30.01 \\
\hline 4224.3 & 25.93 & 29.97 \\
\hline 4224.4 & 25.49 & 30.04 \\
\hline 4224.5 & 25.70 & 30.01 \\
\hline 4224.6 & 25.84 & 30.01 \\
\hline 4224.7 & 25.53 & 29.97 \\
\hline 4224.8 & 25.91 & 30.02 \\
\hline 4224.9 & 25.63 & 29.98 \\
\hline
\end{tabular}


With $5 \%$ of data points omitted, the standard error of the estimate (SEE) was calculated and compared to 40 CFR 1065.545 paragraph (a) criteria. Per 40 CFR Part 1065.602 [70], the SEE was calculated with the following equations.

$$
\begin{gathered}
a_{1 y}=\frac{\sum_{i=1}^{N}\left(\mathrm{y}_{i}-\bar{y}\right)\left(\mathrm{x}_{i}-\bar{x}\right)}{\sum_{i=1}^{N}\left(\mathrm{x}_{i}-\bar{x}\right)^{2}} \\
a_{0 y}=\bar{y}-\left(a_{1 y} * \bar{x}\right) \\
S E E_{y}=\sqrt{\frac{\sum_{i=1}^{N}\left[\mathrm{y}_{i}-a_{0 y}-\left(a_{1 y} * \mathrm{x}_{i}\right)\right]^{2}}{\mathrm{~N}-2}}
\end{gathered}
$$

Calculating the SEE was performed using Excel's "STEYX" function which executed the same calculations as the CFR SEE. Using the PM flow $\left(\mathrm{y}_{\mathrm{i}}\right)$ versus dilution flow rate $\left(\mathrm{x}_{\mathrm{i}}\right)$ and using the mean exhaust flow rate ( $\bar{y}$ ) calculated from the averaged fuel consumption (Eq. 3.4-4), the SEE was calculated to be $2.67 \%$ during Notch 8 for Test ID: R0007-002-198, which was below the 3.5\% requirement.

$$
\dot{\mathrm{n}}_{\mathrm{exh}}=\frac{\dot{\mathrm{m}}_{\text {fuel }} * \mathrm{~W}_{\mathrm{c}} *\left(1+\mathrm{x}_{\mathrm{H} 2 \text { Oexhdry }}\right)}{\mathrm{M}_{\mathrm{c}} * \mathrm{x}_{\text {Ccombdry }}}
$$

The same procedures were performed at Idle for the same locomotive. Figure 39 shows the same flow parameters that were evaluated at Notch 8. 


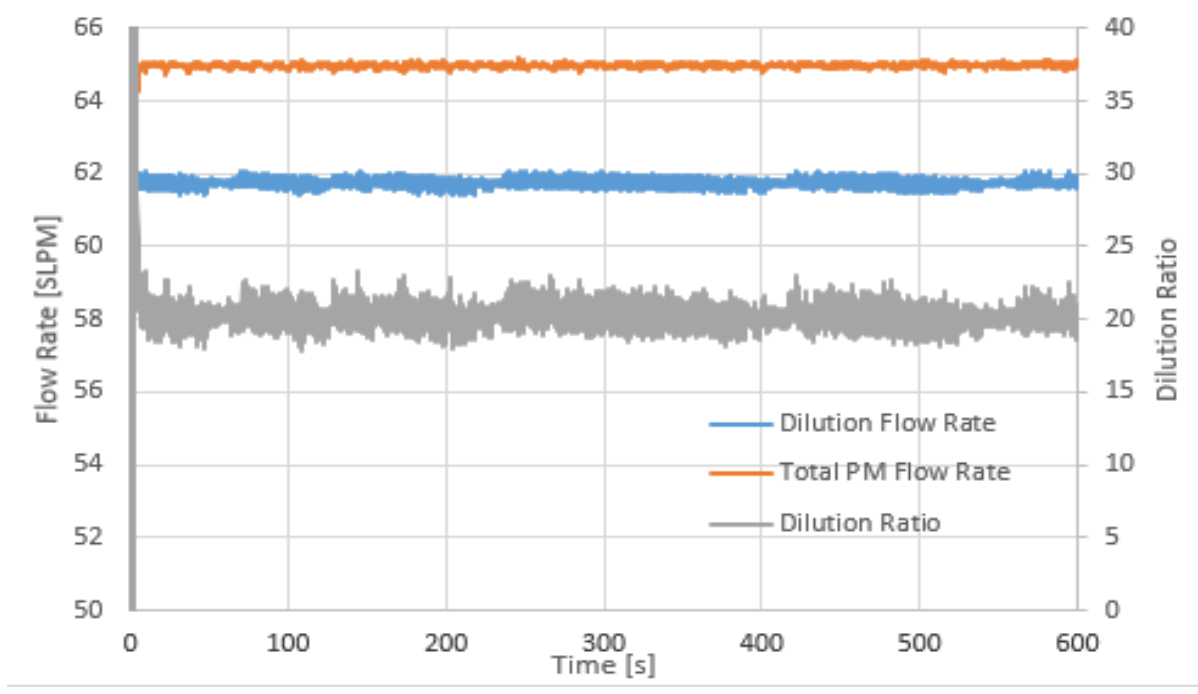

Figure 39 - Dilution Flow Rate [SLPM], Total PM Flow Rate [SLPM], and Dilution Ratio during Idle of Test ID: R0007-002-198

For SEE evaluation at Idle of Test ID: R0007-002-198, the first 5\% of data points were omitted similar to Notch 8 evaluation as there were no obvious outliers during the notch. Through this evaluation, the SEE was calculated at 5.31\%, which was outside of the allowable range of 3.5\% per 1065.545 .

The SEE at Idle may not have been met, however the evaluation used an omission of data for the first $5 \%$ of data. Better control techniques were used to evaluate the SEE. As seen from Figure 39, there were no obvious outliers during the notch. For this example, omitting $5 \%$ of the highest or lowest data points using a mean plus or minus one standard deviation (nexh $\pm \sigma$ ) outlier criteria resulted in an SEE of 3.17\%, which was compliant to 1065.545 . While there are several other outlier criteria methods that may be used, the mean plus or minus one standard deviation technique was satisfactory.

While better outlier criteria made the SEE compliant for this test, there are factors that can affect the exhaust flow rates. These factors could cause proportionality to not meet the 3.5\% SEE requirement which would provide inaccurate results of proportional verification of emissions. Some examples of these factors include auxiliary loads such as radiator fans cycling on mid-notch, or a turbo charger switching over mid-notch (e.g. EMD EUI engine Notch 6 engine speed increase where air-fuel ratio changes).

\subsection{Fuel Flow Measurement by Volumetric Flow Meter Technology}

As seen in Section 3.4 Validation and Verification of Gravimetric Fuel Measurement, for the emissions test performed (Test ID: R0007-002-198), the SEE was met for Notch 8 but not for Idle without better omission techniques. As discussed, there are several factors that could possibly cause proportional sampling validation to not be met even with extensive omission techniques. As per 
1065.545, "any pair of flow rates, use recorded sample and total flow rates" may be used in proportional verification. Since gravimetric fuel measurement cannot provide $1 \mathrm{~Hz}$ flow rates, instantaneous flow rates of mass flow of fuel can be used to provide $1 \mathrm{~Hz}$ exhaust flow rates to be used in proportional verification. As they were readily available from CAFEE, KRAL-USA volumeters were selected to be used to calculate instantaneous fuel flow rates.

\subsubsection{Installation of Volumetric Flow Meters}

KRAL-USA, Inc. is a leading manufacturer in volumetric flow meters, or volumeters. KRAL's flow meter's accuracy is projected at $\pm 0.1 \%$ of flow rate over a wide flow and viscosity range of various liquids $[77,78]$. The flow meters are positive displacement flow meters that utilize two screw spindles to measure flow rate. The volume flow rate is calculated from the known chamber volume between the screws and the spindle rotation speed [78]. KRAL-USA offers a solution for direct fuel flow measurement by a dual volumeter system, as seen in Figure 40 below.

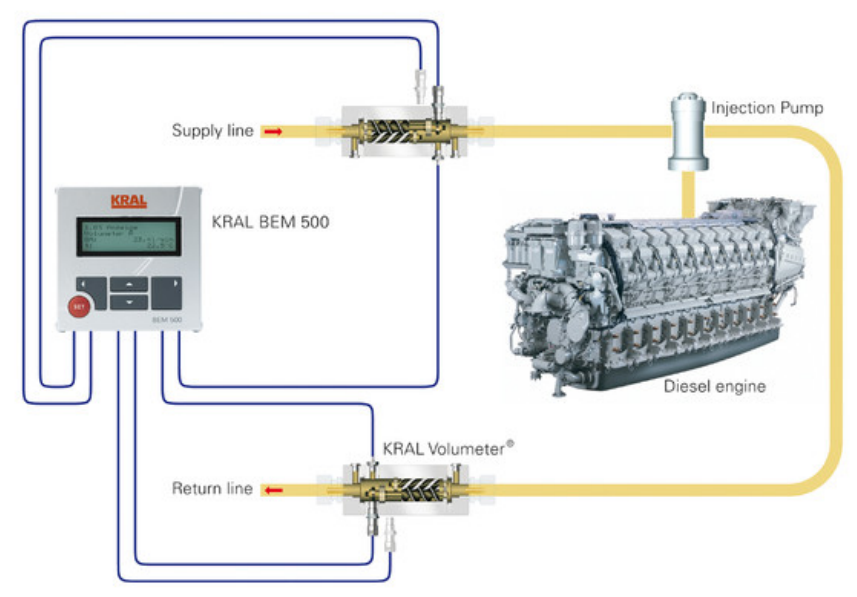

Figure 40 KRAL - USA, Inc. dual volumeter fuel flow measurement diagram [77]

Two KRAL volumeter's were plumbed into the gravimetric fuel system to determine the viability of using dual KRAL flow meters for replacement of gravimetric fuel flow measurement. One volumeter was connected into the fuel supply line to the locomotive right out of the fuel drum, the other into the fuel return line after the chiller as seen in Figure 41 and Figure 42, respectively, and a diagram of the updated system can be seen in Figure 43. 


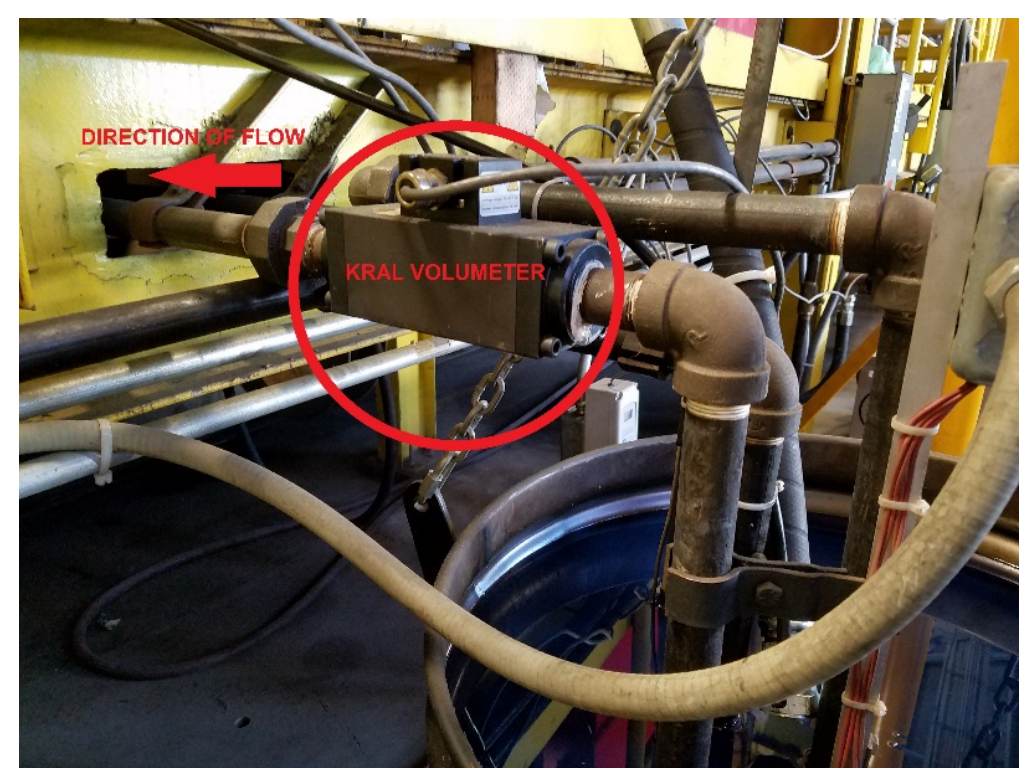

Figure 41 - Picture of KRAL volumeter placed in fuel supply line

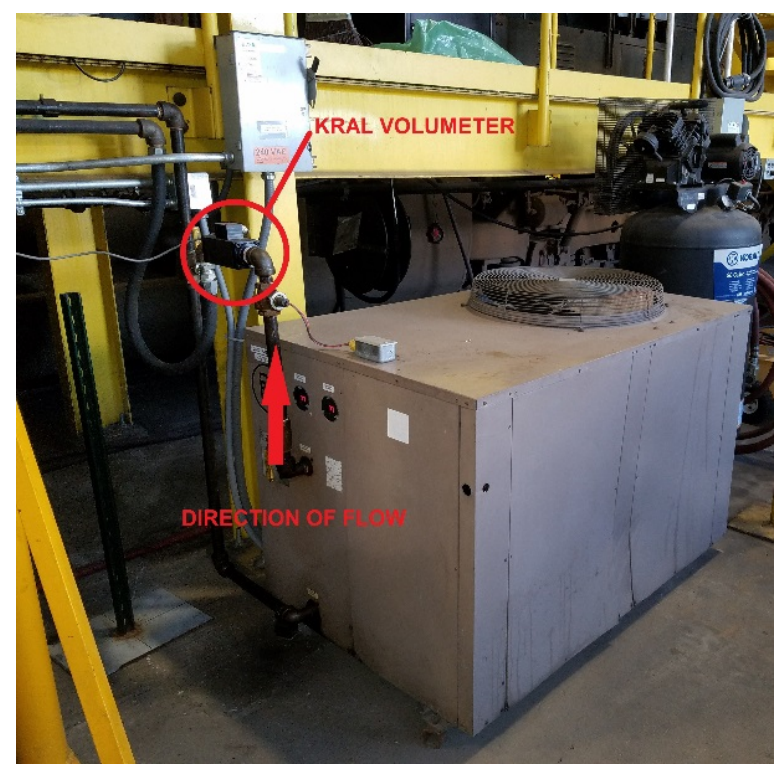

Figure 42 - Picture of KRAL volumeter placed in fuel return line 


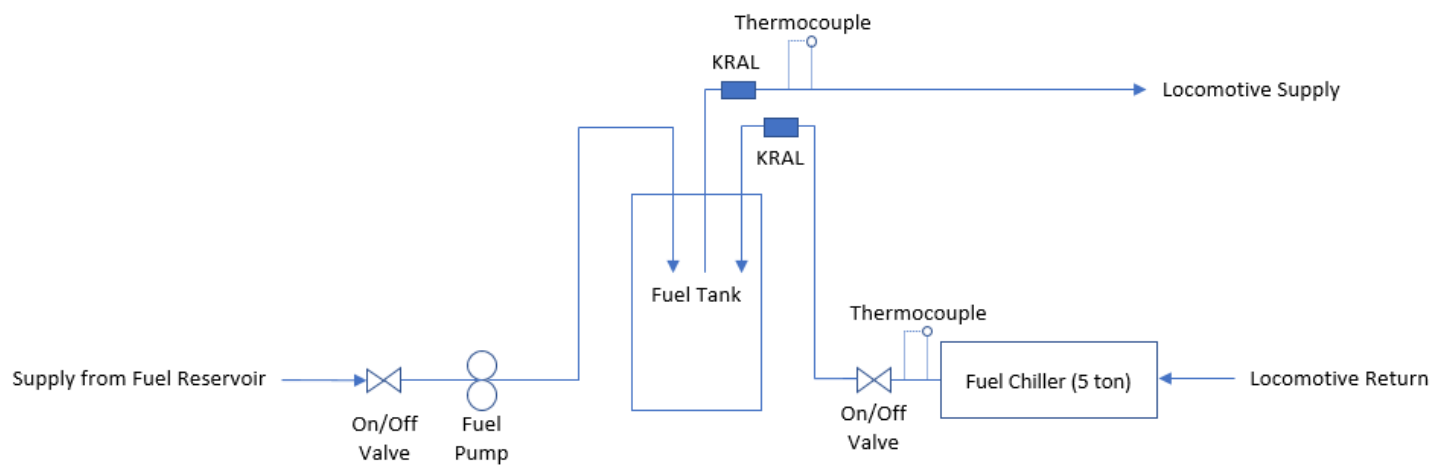

Figure 43 - Flow diagram of volumeters plumbed into fuel measurement system As the fuel cycles through the system, the fuel is heated by the onboard fuel heater and surrounding engine components. Placing the return volumeter after the chiller provides a known temperature controlled fuel stream through the volumeter and to the fuel drum. It is important to keep fuel conditioned before the volumeter's such that fuel properties (i.e. fuel temperature and density) can be used to accurately calculate the fuel flow rates.

\subsubsection{Calibration and Verification of KRAL Volumeters}

After installation of the KRAL volumeters, verification by gravimetric measurement was performed using the fuel drum weight measurement. Fuel was pumped through the $3 / 4 \mathrm{hp}$, 8GPM rated, Burks fuel pump and into the fuel drum. Scimitar was used to record the measurement data. The fuel flow temperature was measured at $57.8^{\circ} \mathrm{C}\left(14.3^{\circ} \mathrm{C}\right)$. As explained further below, density data was gathered from the Innovation, Science and Economic Development Canada (ISEDC) website. At $14.3^{\circ} \mathrm{C}$ the corresponding density was $840.50 \mathrm{~kg} / \mathrm{m}^{3}$. Post data processing provided the data tabulated in Table 30.

Table 30 - Tabulated data of KRAL calibration flow test

\begin{tabular}{|c|c|c|c|c|c|c|}
\hline Time & $\begin{array}{c}\text { Fuel } \\
\text { Weight }\end{array}$ & $\begin{array}{c}\text { Target } \\
\text { Flow } \\
\text { Rate }\end{array}$ & $\begin{array}{c}\text { Calculated } \\
\text { Flow Rate }\end{array}$ & $\begin{array}{c}\text { Measured } \\
\text { KRAL Flow } \\
\text { Rate }\end{array}$ & $\begin{array}{c}\text { KRAL Flow } \\
\text { Rate }\end{array}$ & $\begin{array}{c}\text { Error of } \\
\text { Flow }\end{array}$ \\
\hline$[\mathbf{s}]$ & {$[\mathrm{lb}]$} & {$[\mathrm{gpm}]$} & {$[\mathrm{gpm}]$} & {$[\mathrm{L} / \mathrm{hr}]$} & {$[\mathrm{gpm}]$} & {$[\%]$} \\
\hline 30 & 28.1 & 8.0 & 8.006 & 1817.17 & 8.001 & 0.06 \\
\hline
\end{tabular}


It can be seen from Table 30 that there was a $0.06 \%$ error of flow, which is better than KRAL USA's projected error of $0.1 \%[77,78]$ and meets the flow meter specifications of 40 CFR 1065.205 [79] which required $\pm 2 \%$ of reading.

\subsubsection{Analysis of Volumetric Fuel Measurement}

After installation, calibration, and verification of the KRAL volumeter's, an emissions test was performed per 40 CFR Part 1033 [34] and Part 1065 [35]. It should be noted that the test performed with the gravimetric system was also performed with the volumeters plumbed in. This was to check gravimetric fuel measurement to volumetric fuel measurement. Figure 44, below, shows a screenshot of some of Scimitar's compiled data for the KRAL volumeters in an Excel file.

\begin{tabular}{|c|c|c|c|c|c|c|c|c|c|c|}
\hline$\Delta$ & A & $\mathrm{CP}$ & $\mathrm{CQ}$ & $\mathrm{CR}$ & CS & CT & $\mathrm{CU}$ & $\mathrm{CV}$ & $\mathrm{CW}$ & $\mathrm{CX}$ \\
\hline 1 & (Time) & KRAL Net Flow & Supply Flow & Return Flow & Supply Temperature & Return Temperature & Net Volumetric Flow Calc & Notch Averaged Volume & & Drum Fuel Rate \\
\hline 2 & s & $\mathrm{L} / \mathrm{hr}$ & $\mathrm{L} / \mathrm{hr}$ & L/hr & ${ }^{\circ} \mathrm{C}$ & ${ }^{\circ} \mathrm{C}$ & & & & $g / s$ \\
\hline 3 & 3826.9 & 689.8 & 1610.7 & 920.9 & 22.1 & 19.2 & 692.1 & -685.9933954 & 685.9933954 & -1.648134574 \\
\hline 4 & 3827 & 693.1 & 1612.6 & 919.5 & 22.1 & 19.2 & 689.8 & -689.8 & 689.8 & -1 \\
\hline 5 & 3827.1 & 699.7 & 1616 & 916.4 & 22.1 & 19.2 & 693.1 & -1382.9 & 1382.9 & 136.0314 \\
\hline 6 & 3827.2 & 697.7 & 1610.3 & 916 & 22.1 & 19.2 & 699.6 & -1041.25 & 1041.25 & 158.7033 \\
\hline 7 & 3827.3 & 693.1 & 1610.3 & 917.2 & 22.1 & 19.2 & 694.3 & -925.6 & 925.6 & 166.2606 \\
\hline 8 & 3827.4 & 708.9 & 1620.5 & 914 & 22.1 & 19.2 & 693.1 & -867.475 & 867.475 & 158.7033 \\
\hline 9 & 3827.5 & 695.8 & 1618.2 & 922.4 & 22.1 & 19.2 & 706.5 & -835.28 & 835.28 & 136.0314 \\
\hline 10 & 3827.6 & 689.4 & 1613.1 & 923.6 & 22.1 & 19.2 & 695.8 & -812.0333333 & 812.0333333 & 166.2606 \\
\hline 11 & 3827.7 & 690.3 & 1614.9 & 924.6 & 22.1 & 19.2 & 689.5 & -794.5285714 & 794.5285714 & 168.4198286 \\
\hline 12 & 3827.8 & 701.8 & 1620.6 & 919.9 & 22 & 19.5 & 690.3 & -781.5 & 781.5 & 164.371275 \\
\hline 13 & 3827.9 & 692.5 & 1607.3 & 914.7 & 22 & 19.5 & 700.7 & -772.5222222 & 772.5222222 & 166.2606 \\
\hline 14 & 3828 & 695.1 & 1612.8 & 917.7 & 22 & 19.5 & 692.6 & -764.53 & 764.53 & 167.77206 \\
\hline 15 & 3828.1 & 703.7 & 1616.6 & 912.9 & 22 & 19.5 & 695.1 & -758.2181818 & 758.2181818 & 169.0087091 \\
\hline 16 & 3828.2 & 701.2 & 1617.5 & 916.3 & 22 & 19.5 & 703.7 & -753.675 & 753.675 & 154.92465 \\
\hline 17 & 3828.3 & 695 & 1607.1 & 912.1 & 22 & 19.5 & 701.2 & -749.6384615 & 749.6384615 & 167.4232615 \\
\hline 18 & 3828.4 & 697.4 & 1615.7 & 915.7 & 22 & 19.5 & 695 & -745.7357143 & 745.7357143 & 168.4198286 \\
\hline 19 & 3828.5 & 717.7 & 1619.9 & 902.2 & 22 & 19.5 & 700 & -742.6866667 & 742.6866667 & 169.28352 \\
\hline 20 & 3828.6 & 709.2 & 1609 & 899.8 & 22 & 19.5 & 717.7 & -741.125 & 741.125 & 170.03925 \\
\hline
\end{tabular}

Figure 44 - Screenshot of Scimitar's data output with KRAL volumeter's data for Notch 8 for test

$$
\text { R0007-002-198 }
$$

Per 1065.545 (a), proportional sampling is performed using total exhaust flow. As shown previously, exhaust flow was directly calculated by mass flow rate. The respective mass flow rates were calculated through the supply and return volumetric rates and corresponding temperatures. Figure 45 shows the volumetric flow rates from the Scimitar data. 


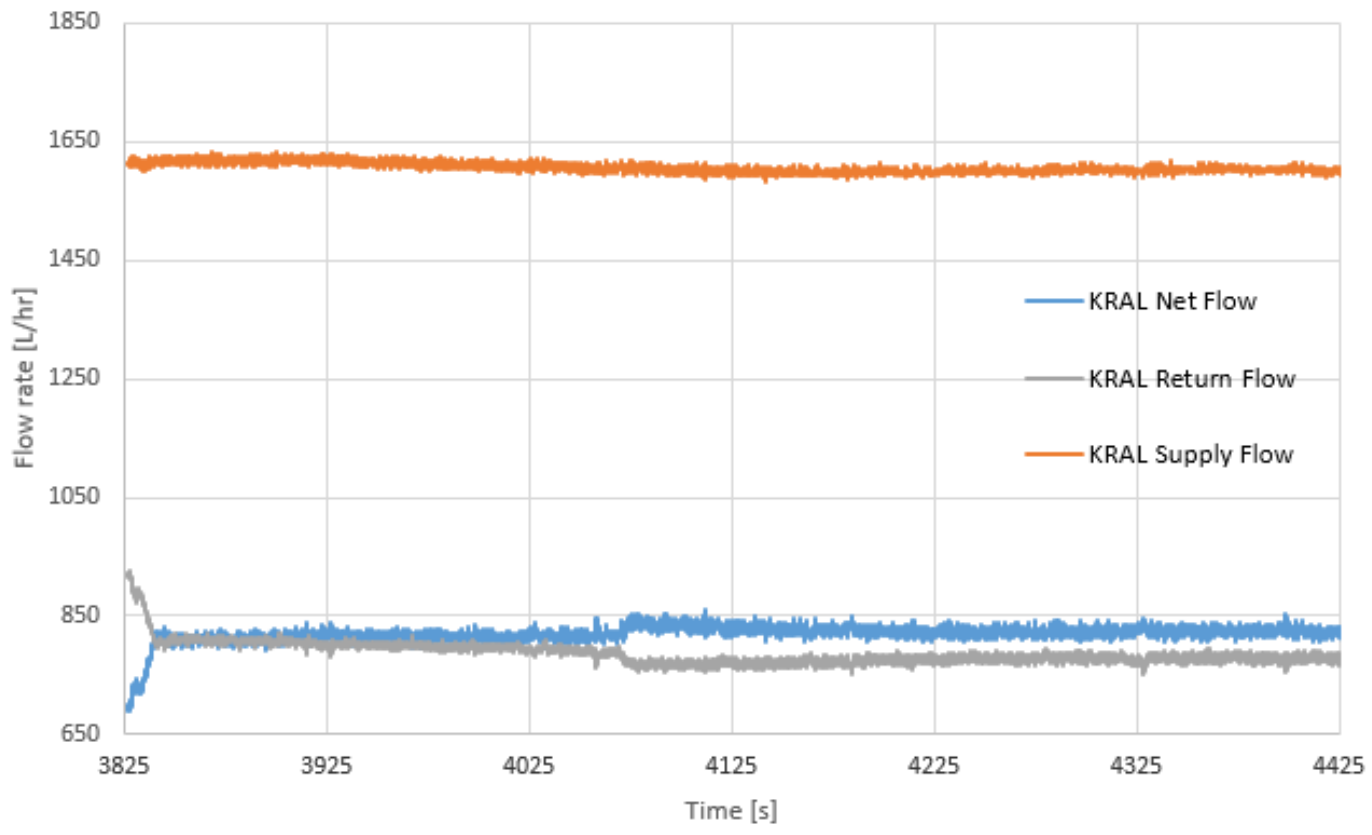

Figure 45 - KRAL volumetric fuel flow rate measurements at Notch 8 for test R0007-002-198

The mass flow rate was calculated by multiplying the volumetric flow rate by the density of the fluid. Since the temperature of the fluid was dynamic, the density was dynamic and needed to be calculated based on the temperature. The supply and return temperatures of the fuel was measured after the volumeter no further than 12 inches. Figure 46 shows the supply and return temperatures of the fuel during Notch 8 for Test ID: R007-002-198.

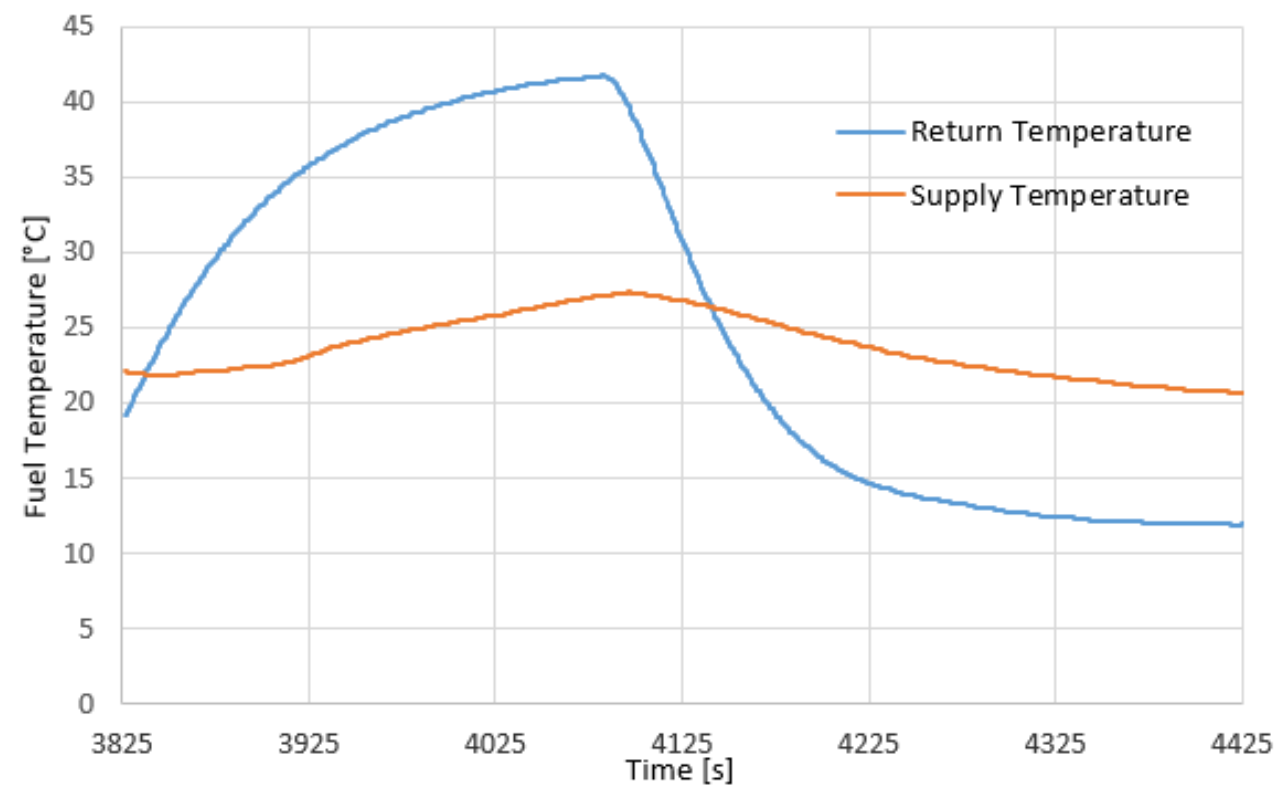

Figure 46 - Measured Supply and Return temperatures of the fuel in degree Celsius during Notch 8 for Test ID: R007-002-198 
It can be seen how the fuel temperature fluctuated widely with the gravimetric and volumetric fuel flow measurement system. For gravimetric measurement, the temperature fluctuations do not affect flow measurement as much as in the volumetric measurement which required temperature to calculate density.

As previously stated, to determine the density at each temperature point, the density of the diesel fuel was used from the ISEDC website [80] with data used from the API Standard 2540 (1980) Chapter 11.1 table $54 \mathrm{~B}$. The data used a reference density $840 \mathrm{~kg} / \mathrm{m}^{3}$ at $15^{\circ} \mathrm{C}$. This data was tabulated and input into excel. A graph of the data can be seen in Figure 47.

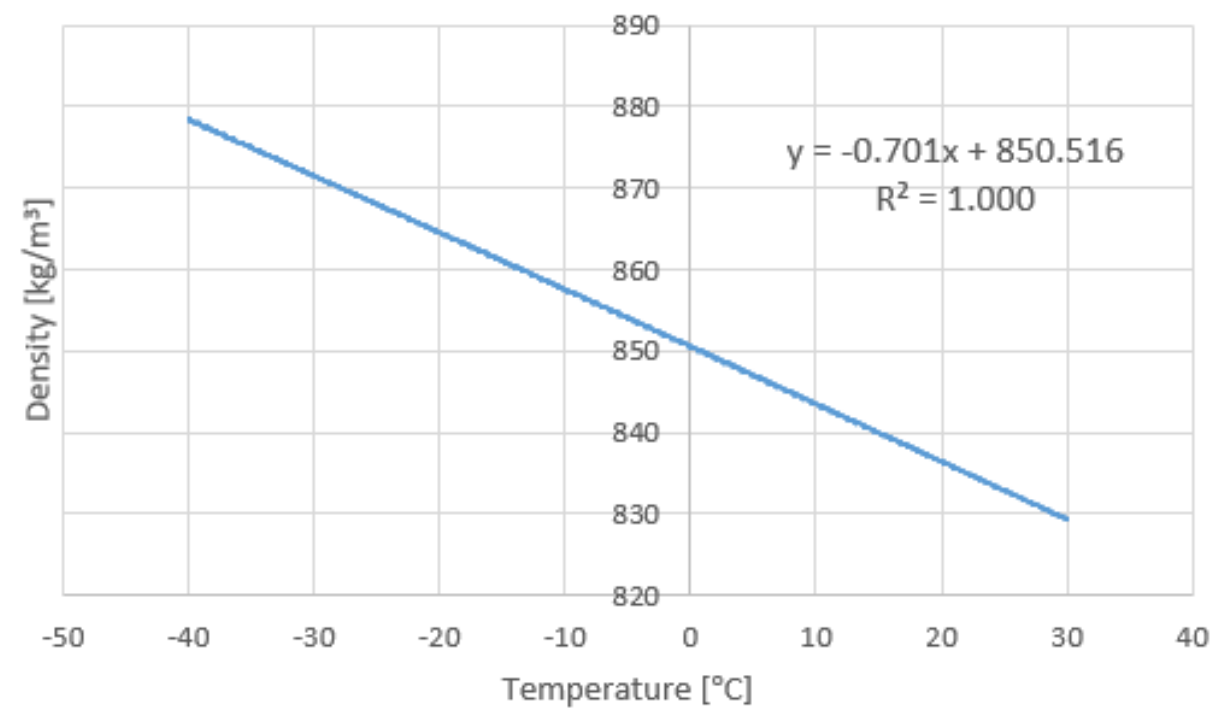

Figure 47 - Density of diesel fuel plotted against temperature (data from ISEDC) [80] Applying a linear trendline to the data showed the data set followed the equation:

$$
\text { Density }=850.516-0.701 * \mathrm{~T}\left[{ }^{\circ} \mathrm{C}\right]
$$

As seen from the trendline, this equation follows perfect linearity $\left(\mathrm{R}^{2}=1.000\right)$. This equation was used to calculate the volumetric flow rate at the flow rate's temperature, as seen in the following equation:

Volumetric Flow Rate $(\dot{V}) *$ Density $=$ Mass Flow Rate $(\dot{\mathrm{m}})$ 


$$
\frac{\dot{V}\left[\frac{L}{h r}\right] * 0.001\left[\frac{\mathrm{m}^{3}}{\mathrm{~L}}\right] *\left\{850.516-0.701 * T\left[{ }^{\circ} \mathrm{C}\right]\right\}\left[\frac{\mathrm{kg}}{\mathrm{m}^{3}}\right] * 1000\left[\frac{\mathrm{g}}{\mathrm{kg}}\right]}{3600\left[\frac{\mathrm{S}}{\mathrm{hr}}\right]}=\dot{\mathrm{m}}\left[\frac{\mathrm{g}}{\mathrm{S}}\right]
$$

Applying this equation to the Scimitar volumeter data from test R007-002-198 yielded the following data set for the mass flow rates as seen in Figure 48.

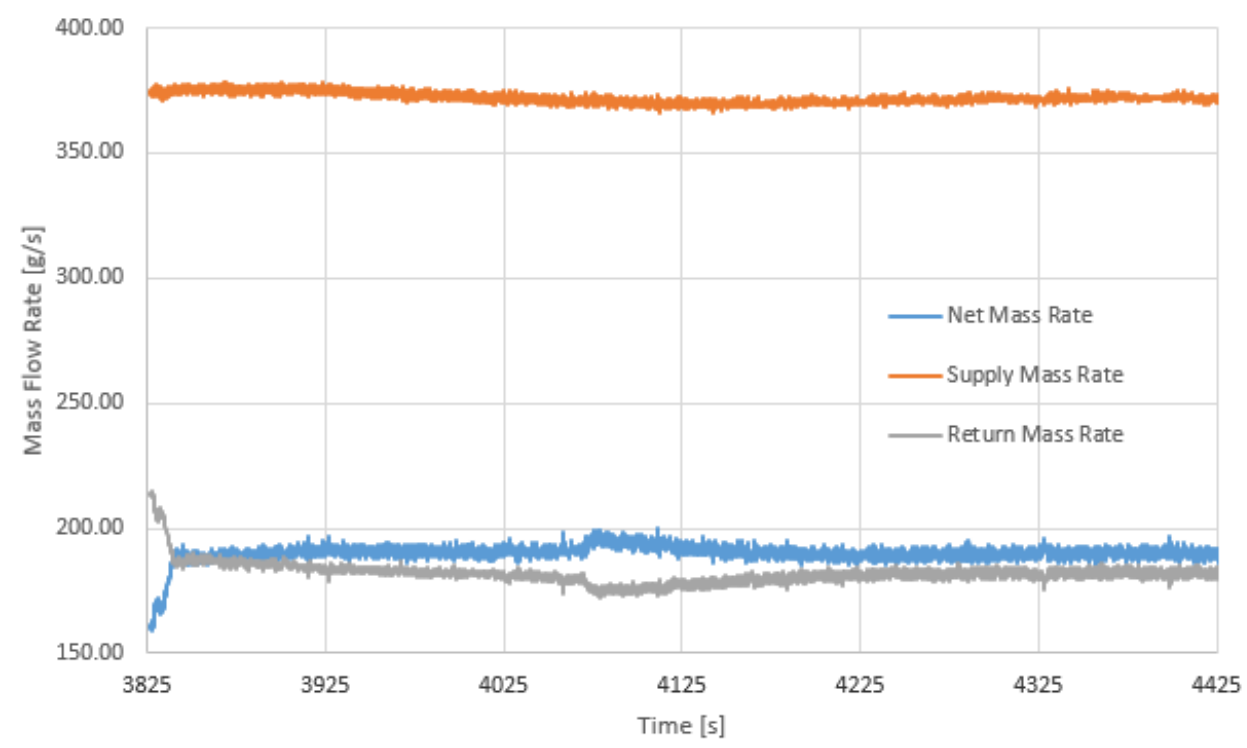

Figure 48 - Calculated mass flow rates from KRAL volumetric fuel flow rate measurements at Notch 8 for test R0007-002-198

The calculated net mass flow rate was used in Equation 3.4-4 (Eq. 1065.655-25) to calculate the instantaneous, $1 \mathrm{~Hz}$ exhaust flow rate. The calculated molar exhaust flow rate can be seen in Figure 49. 


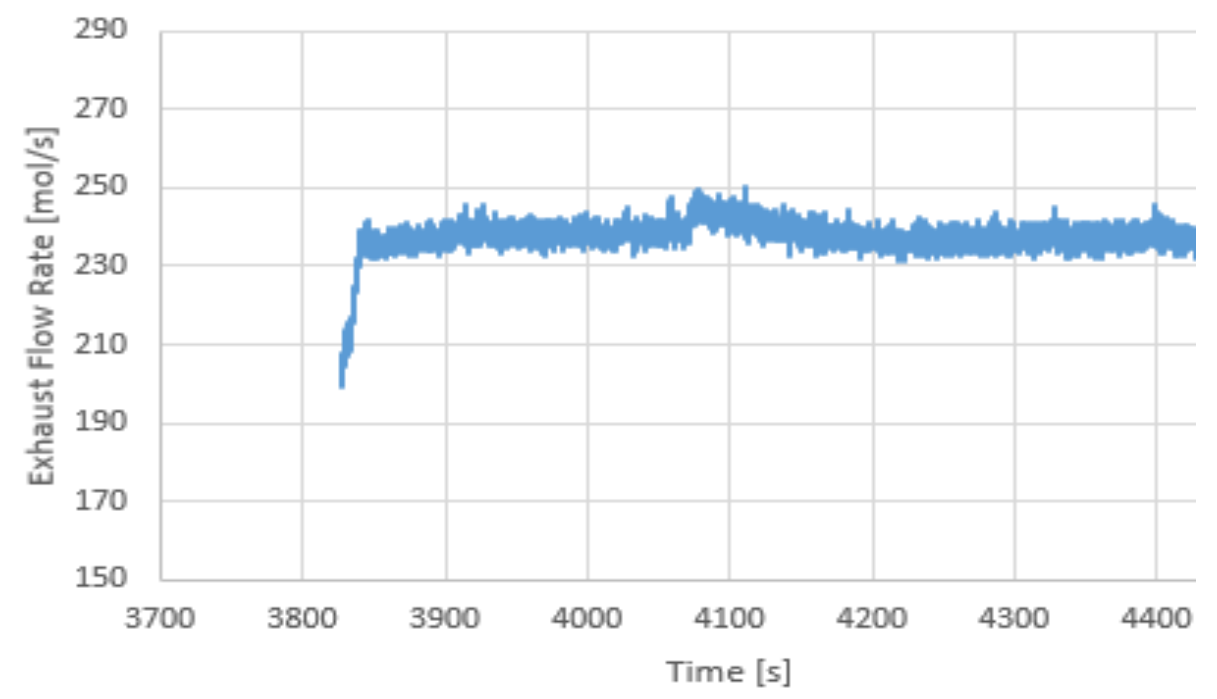

Figure 49 - Calculated exhaust molar flow rate from calculated KRAL mass flow for Notch 8 of Test ID: R0007-002-198

As previously performed, the calculated exhaust flow rate was used in the SEE for 1065.545 (a) [12]. Table 31 shows a portion of the sample flow and calculated exhaust flow rates for Notch 8 for Test ID: R0007-002-198.

Table 31 - Portion of data from time 3900 seconds to 3900.5 seconds of Notch 8 for Test ID: R0007-002-198

\begin{tabular}{|c|c|c|}
\hline $\begin{array}{c}\text { Time } \\
{[\mathbf{s}]}\end{array}$ & $\begin{array}{c}\text { Sample Flow Rate } \\
{[\mathbf{m o l} / \mathbf{s}]}\end{array}$ & $\begin{array}{c}\text { Calculated Exhaust } \\
\text { Flow Rate } \\
{[\mathbf{m o l} / \mathbf{s}]}\end{array}$ \\
\hline 3900 & 223.44 & 237.84 \\
\hline 3900.1 & 223.41 & 239.84 \\
\hline 3900.2 & 223.69 & 239.31 \\
\hline 3900.3 & 223.58 & 238.97 \\
\hline 3900.4 & 223.39 & 239.36 \\
\hline 3900.5 & 223.67 & 237.48 \\
\hline
\end{tabular}

Sample flow is stored by Scimitar in Standard Liters per Minute [SLPM]. To convert to moles per second [mol/s], the NIST unit conversion chart was used [81]. The conversion from [SLPM] to $[\mathrm{mol} / \mathrm{s}]$ is:

$$
1\left[\frac{\mathrm{mol}}{\mathrm{s}}\right]=[S L P M] * 1000 \frac{[S C C M]}{[S L P M]} * 7.45 e-7 \frac{[\mathrm{mol} / \mathrm{s}]}{[S C C M]}
$$

The SEE calculation using volumetric fuel flow measurement was performed using the calculated exhaust flow (y) versus sample flow rate (x). Per CFR SEE calculations, the SEE for Notch 8 
of Test ID: R0007-002-198 was 2.62\% when the first 5\% of data points were omitted which was less than the 3.5\% limit per 1065.545. This was consistent to Section 3.4 Validation and Verification of Gravimetric Fuel Measurement which calculated the SEE at 2.67\%.

However, for Idle, the SEE was $11.69 \%$ with the first $5 \%$ of data points omitted, which was outside the limit of the SEE. This large percentage was due to several factors which included large fluctuations in temperature change, but more so influenced due to the errors in the KRAL flow meters from the subtraction of two large numbers with similar numerical value. This can be more easily seen in Figure 50 which shows the KRAL volumetric flow rate [L/hr] during Idle for Test ID: R0007-002198. Figure 51 shows the calculated mass flow rate from temperature and density of the flow with the volumetric flow rates.

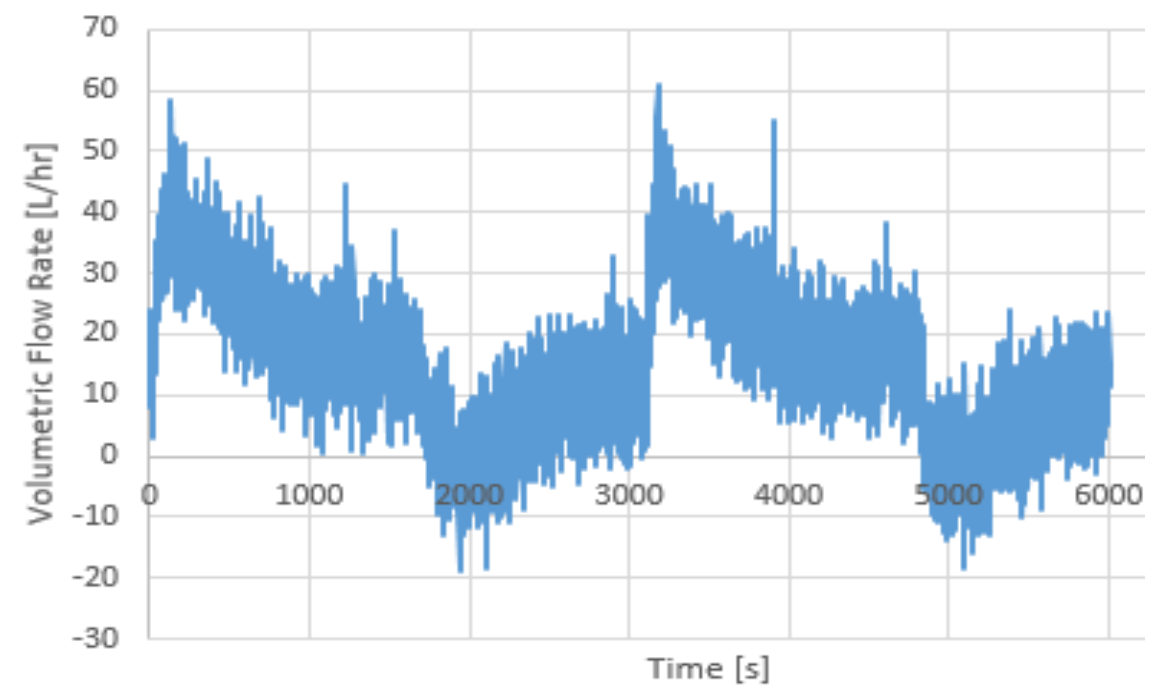

Figure 50 - KRAL net volumetric flow rate [L/hr] during Idle for Test ID: R0007-002-198 


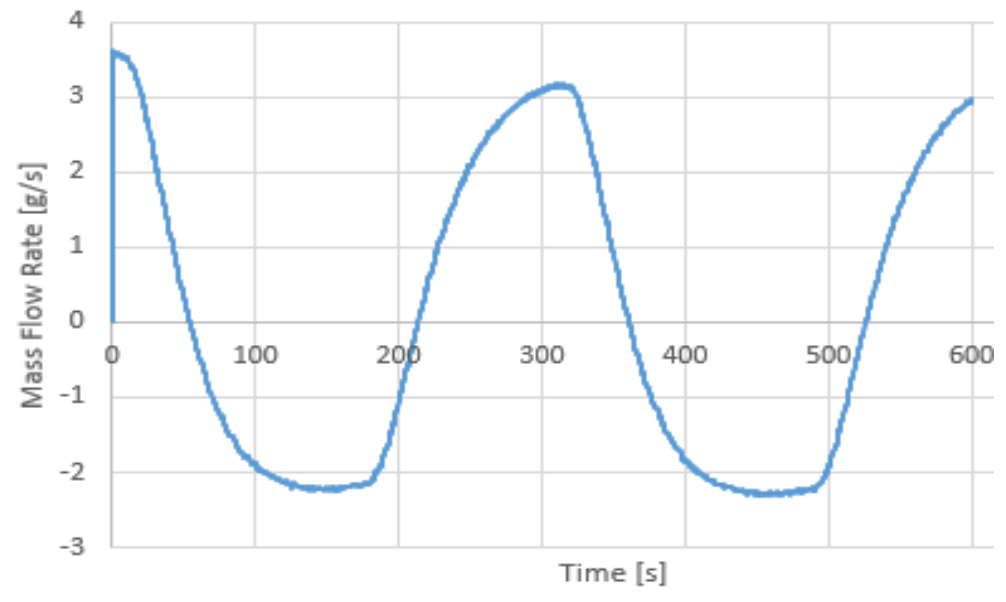

Figure 51 - Calculated net mass flow rate $[\mathrm{g} / \mathrm{s}]$ from KRAL net volumetric flow rate [L/hr] during Idle for Test ID: R0007-002-198

The errors due to the subtraction of numbers from the KRAL volumeters start to become more pronounced at lower engine speeds where there are smaller differences between high supply and return flow rates.

\subsection{3-1 Error Analysis of Volumetric Fuel Measurement}

The averaged fuel supply and return flows at Idle for Test ID: R0007-002-198 were 1606.22 [L/hr] and 1590.83 [L/hr]. The supply and return flows at Notch 8 were 1606.52 [L/hr] and 786.98 $[\mathrm{L} / \mathrm{hr}]$ respectively. The errors used in the error analysis used KRAL's accuracy of $0.1 \%$ as a worse-case scenario. Subtracting the supply and return flows for the respective notches provided the following:

$$
\begin{array}{r}
\text { Idle: }(1606.22 \pm 1.61)[\mathrm{L} / \mathrm{hr}]-(1590.83 \pm 1.59)[\mathrm{L} / \mathrm{hr}]=15.39 \pm 3.20[\mathrm{~L} / \mathrm{hr}] \\
\text { Notch 8: }(1606.52 \pm 1.61)[\mathrm{L} / \mathrm{hr}]-(786.98 \pm 0.78)[\mathrm{L} / \mathrm{hr}]=819.54 \pm 2.39[\mathrm{~L} / \mathrm{hr}]
\end{array}
$$

Subtraction or addition of numbers results in error addition. At these flows, the error was $20.8 \%$ (3.20 L/hr divided by $15.39 \mathrm{~L} / \mathrm{hr}$ ) for Idle whereas for Notch 8 the error was $0.29 \%$ (2.39 L/hr divided by $819.54 \mathrm{~L} / \mathrm{hr}$ ). Performing the same error analysis on the instantaneous data provided errors greater than $\pm 3200 \%$ at Idle and maximum errors of $\pm 0.38 \%$ for Notch 8 . The large error from Idle is why there were apparent negative fuel flows as seen in Figure 51. Due to the errors that propagate from the subtraction of two similar flows, a single measured flow system was desired. Furthermore, measuring mass flow directly instead of measuring temperature and calculating density for mass measurement was also preferred. 


\subsection{Development of a Fuel Mass Flow Measurement System}

The initial concept for a mass fuel flow measurement system was based on Southwest Research's mass flow measurement system, as seen previously in Section 2.7.1 SwRI - Progress Rail PR30 Locomotive SJVR3003 3000-Hour Emissions Test Report in Figure 7 - Schematic of SwRI Fuel Mass Flow Measurement System [41]. Fuel was pumped by a positive displacement pump through a flow meter at a high line pressure, reduced to near atmospheric by a control valve, and into a reservoir tank. Inside the reservoir tank was a level sensor that measures the fuel level. A PID controller added fuel to the reservoir by controlling the flow control valve to maintain a constant fuel level at a set point. The fuel pumped into the reservoir tank was measured by a Coriolis mass flow meter. The original flow diagram schematic for the new direct mass flow measurement system can be seen in Figure 52 . 


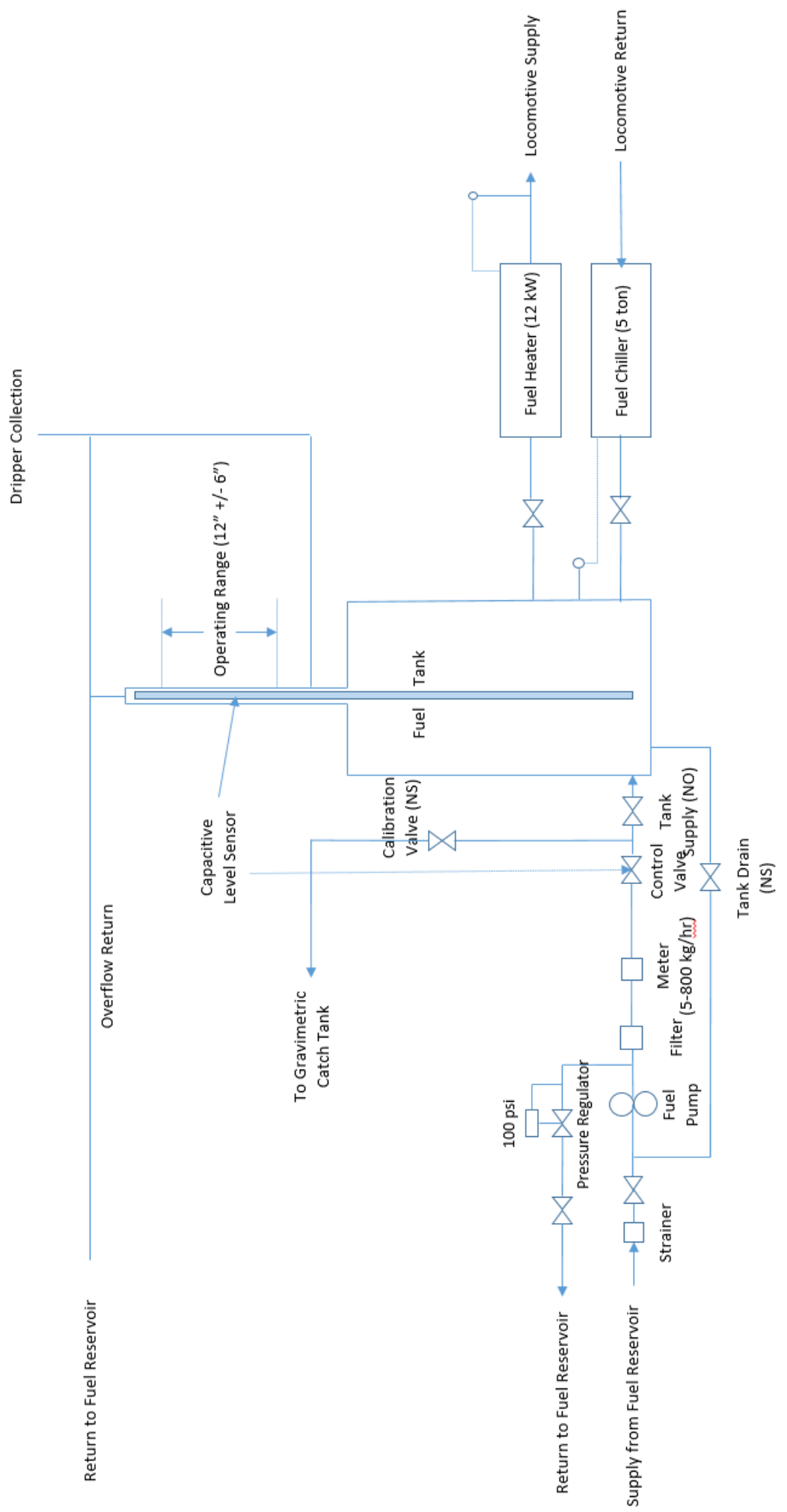

Figure 52 - Schematic diagram of the fuel mass flow measurement system 
In this system setup, if the level sensor read that fuel level in the reservoir tank was below the set point, the control valve opened to allow fuel from the certification tank into the reservoir tank. Once at the set point, the control valve closed and the pump continuously cycled fuel through the pressure relief valve back to the locomotive certification tank. A drop in fuel level occurred when fuel was consumed by the locomotive. Fuel from the reservoir tank was heated and sent to the locomotive. It should be noted this initial design changed for the new system which can be seen in Section 3.6.3 System Construction and Implementation. The unburned fuel was conditioned through a fuel cooler and returned to the level measured fuel reservoir tank. The returned, excess, conditioned, unburned fuel slightly raised the level in the reservoir tank but not to the set point, thus the control valve opened and returned fuel raised the level in the reservoir tank to the set point. With this system, the fuel needed to bring the fuel level back to set point was the fuel consumed by the locomotive. This is where the fuel flow measurement was made by the flow meter, which provided a direct mass flow measurement of the fuel that the locomotive consumed.

Several critical factors for designing the fuel mass flow measurement system included:

- Fuel is properly conditioned to accurately measure fuel flow

- The tube in which the level sensor is reading in has a small diameter to pick up small changes in level for the level sensor

- The flow range for the flow meter could match those of the locomotives tested by Norfolk Southern

- The fuel pump is a positive displacement pump that can supply adequate flows

- Ensure high system response with no more than 2 seconds from system disturbance to system stability

- Ensure system meets applicable Title 40 CFR Part 1033 and 1065 regulations as discussed later

- And several other sensor accuracy and equipment requirements as discussed later

\subsubsection{System Equipment and Sensors Selection}

The new fuel system was proposed to be built around the mass flow meter, level sensor, and flow controller. The level sensor and flow controller would work in unison with each other to keep the level in the fuel tank at a set point. Replenished fuel to the tank would provide instantaneous fuel mass flow measurement from the Coriolis flow meter which would improve the accuracy of emissions calculations.

Several factors were considered during the selection of parts for the system which included:

- Manufacturer of parts (i.e. price and availability) 
- Accuracy of flow meter and other system parts (e.g. pressure transducer, flow controller, level sensor)

- Type of material for parts (e.g. black iron steel, stainless steel, flexible steel braided lines)

- Fuel conditioning (i.e. heating and cooling)

- Validation of flow control (i.e. ensuring the system is working properly and can be properly reported back to NIST calibration)

\subsection{1-1 Mass Flow Meter Selection}

Typically, fuel supply flow in Tier 0 , Tier 1 , and Tier 2 locomotives ranges from 0 to 3.5 gallons per minute (gpm), while Tier 3 and Tier 4 locomotives fuel supply flow can reach nearly $7 \mathrm{gpm}$. Since the Juniata emissions lab typically tests the lower three tiers of locomotives, a mass flow rate range of 0 to $\sim 700$ kilograms per hour (kg/hr) ( 0 to $\sim 4 \mathrm{gpm}$ ) was used as an initial selection basis for choosing an appropriate mass flow meter. However, the final design for the mass flow measurement system would allow for a larger fuel pump and mass flow meter to be switched out such that Tiers 3 and 4 locomotives could be tested if desired. A Coriolis mass flow meter was chosen for several reasons:

- It is compatible to measure No. 2 diesel fuel

- It has high accuracy and repeatability

- It has no mechanically moving parts (i.e. gears or spindles) that small impurities or debris could create a blockage in the system which would require maintenance that was not routine

- Direct mass flow rate given without density corrections (versus a volumetric flow meter)

Several flow meters were compared to determine a suitable flow meter for the new fuel measurement system. OMEGA ${ }^{\mathrm{TM}}$ Engineering, Siemens, and Emerson are three top manufacturers of mass flow meters in the U.S. Initial consideration of each company started with their mass flow meter accuracy capabilities. Table 32 shows comparisons for flow and density accuracies for each company.

Table 32 - Initial overview comparison of mass flow and density accuracies for OMEGA ${ }^{\mathrm{TM}}$, Siemens, and Emerson mass flow meters (info used from company websites)

\begin{tabular}{|c|c|c|}
\hline Meter & Flow Accuracy & Density Accuracy \\
\hline OMEGA & $\pm 0.05 \%-0.5 \%$ & $\pm 0.002 \mathrm{~g} / \mathrm{cc}$ \\
\hline Siemens & $\pm 0.1 \%$ & - \\
\hline Emerson & $\pm 0.1 \%-0.05 \%$ & $\pm 0.0005-0.0002 \mathrm{~g} / \mathrm{cc}$ \\
\hline
\end{tabular}


As per CFR 1065.205 [79], the measurement system "as a whole must meet all calibrations, verifications, and test-validation criteria" as specified outside section 1065.205 [79] for laboratory or field testing, when applicable. Table 1 in section 1065.205 [79], as seen in Table 33 [79] below, shows the fuel flow meter performance specifications required for emissions testing.

Table 33 - 1065.205 Recommended performance specifications for measurement instruments [79]

\begin{tabular}{|c|c|c|c|c|c|c|}
\hline Measurement instrument & $\begin{array}{l}\text { Measured } \\
\text { quantity } \\
\text { symbol }\end{array}$ & $\begin{array}{l}\text { Complete system } \\
\text { rise time }\left(t_{10-90}\right) \text { and } \\
\text { fall time }\left(t_{90-10}\right)^{a}\end{array}$ & $\begin{array}{l}\text { Recording } \\
\text { update } \\
\text { frequency }\end{array}$ & Accuracy ${ }^{\mathbf{b}}$ & Repeatability $\mathbf{b}$ & Noise $^{b}$ \\
\hline $\begin{array}{l}\text { Fuel flow meter }{ }^{c} \text { (Fuel } \\
\text { totalizer) }\end{array}$ & $\dot{m}$ & $\begin{array}{l}5 \mathrm{~s} \\
(-)\end{array}$ & $\mid \begin{array}{l}1 \mathrm{~Hz} \\
(-)\end{array}$ & $\begin{array}{l}2 \% \text { of pt. or } \\
1.5 \% \text { of } \\
\max \end{array}$ & $\begin{array}{l}1 \% \text { of pt. or } \\
0.75 \% \text { of } \max \end{array}$ & $\begin{array}{l}0.5 \% \\
\text { of } \\
\max .\end{array}$ \\
\hline
\end{tabular}

According to the requirements listed from Table 33 [79], the fuel flow meters flow accuracy error must not exceed $2 \%$ of the flow reading at any point or $1.5 \%$ of the flow meters max flow rate. As seen in Table 32, the initial flow accuracies meet this requirement.

While the initial accuracies were within specification, flow accuracies for each flow meter needed to be calculated for the flow ranges that the meters would need to measure. This would narrow down selection to a final flow meter. Each company was consulted in order to determine the required flow meter model and flow meter characteristics (i.e. line pressure, pressure drop, flow accuracy, flow range, density of fluid) required to meet the specifications of 1065.205. Table 34 to Table 36 show the flow characteristics of each mass flow meter.

Table 34 - Omega $^{\mathrm{TM}}$ flow meter specifications for Coriolis flow meter at various flow rates (full data sheet in Appendix C3 - Omega ${ }^{\mathrm{TM}}$ Engineering FMC-5000 Coriolis Mass Flow Meter Specifications)

\begin{tabular}{|c|c|c|c|c|c|}
\hline & $\begin{array}{c}\text { Normal } \\
\text { Flow Range } \\
\text { for } \\
\text { Allowable } \\
\text { Flow } \\
\text { Range }\end{array}$ & $\begin{array}{c}\text { Accuracy } \\
\mathbf{0 . 1 \%}\end{array}$ & $\begin{array}{c}\text { Normal Flow } \\
\text { Range for } \\
\text { Accuracy 0.2\% }\end{array}$ & $\begin{array}{c}\text { Normal } \\
\text { Flow Range } \\
\text { for Accuracy } \\
\mathbf{0 . 5 \%}\end{array}$ & $\begin{array}{c}\text { Projected } \\
\text { Accuracy for 5 } \\
\text { kg/hr Flow Rate }\end{array}$ \\
\hline $\mathbf{( m m )}$ & {$[\mathbf{k g} / \mathbf{h r}]$} & {$[\mathbf{k g} / \mathbf{h r}]$} & {$[\mathrm{kg} / \mathbf{h r}]$} & {$[\mathbf{k g} / \mathbf{h r}]$} & {$[\%]$} \\
\hline 15 & $20-3000$ & $200-3000$ & $150-3000$ & $100-3000$ & 2.26 \\
\hline
\end{tabular}

It should be noted that the Omega ${ }^{\mathrm{TM}}$ flow meter did not come with a table of calculations to show the accuracy. Due to this, a projected accuracy through a logarithmic trendline was performed 
to evaluate whether the flow rate could be met while maintaining the required $2 \%$ accuracy of the CFR. The projected data can be seen in Figure 53, below.

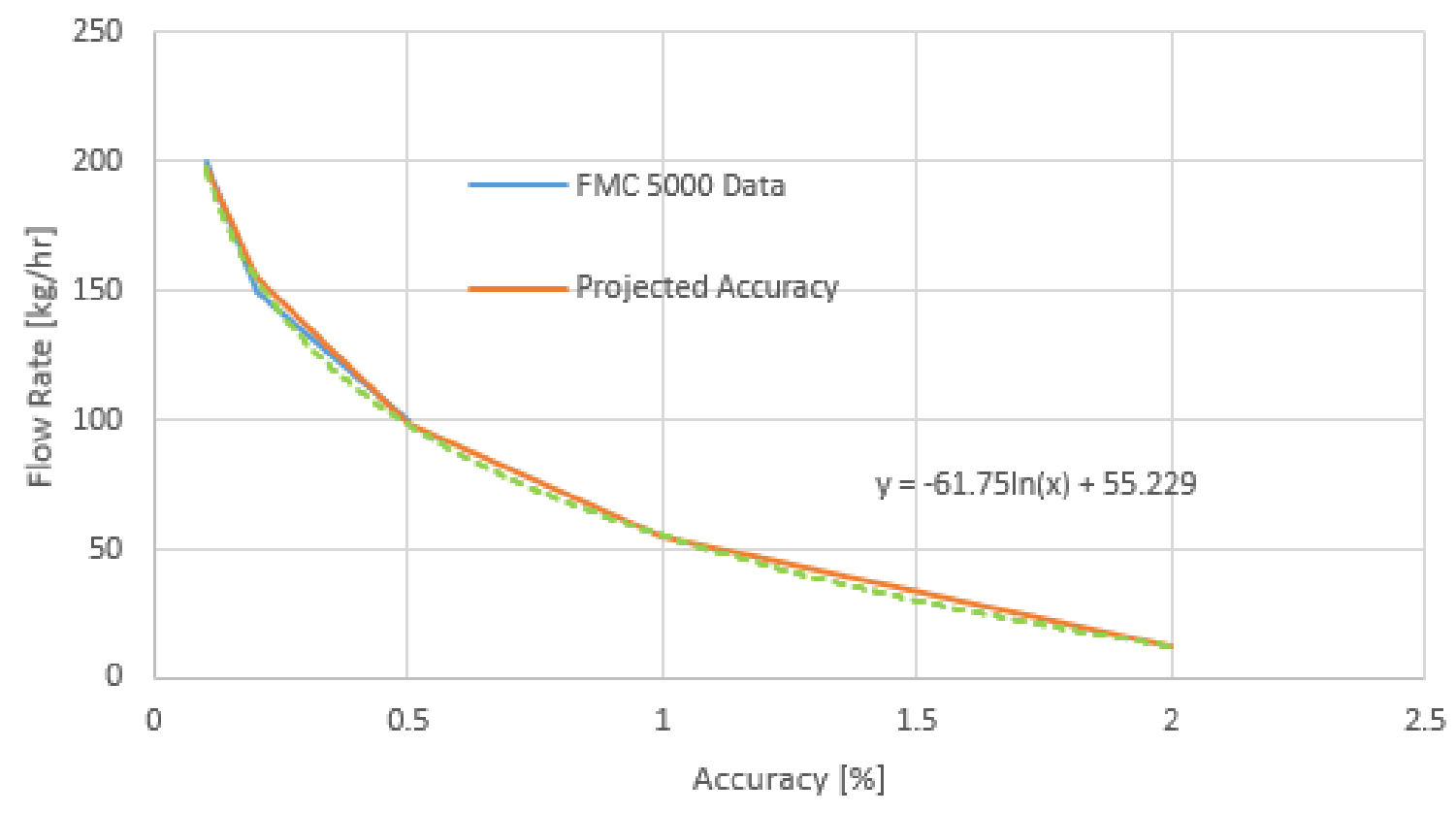

Figure 53 - Projected Accuracy of FMC 5000 Coriolis Mass Flow Meter

Table 35 - Siemens flow meter specifications for FCS400 DN 15 Coriolis flow meter at various flow rates at $840 \mathrm{~kg} / \mathrm{m}^{3}$ (full data sheet in Appendix C4 - Siemens FCS400 DN 15 sensor flow meter calculations)

\begin{tabular}{|c|c|c|c|c|}
\hline $\begin{array}{c}\text { Flowrate } \\
{[\mathbf{k g} / \mathbf{h r}]}\end{array}$ & $\begin{array}{c}\text { Pressure } \\
\text { drop } \\
{[\text { bar] }}\end{array}$ & $\begin{array}{c}\text { Flow } \\
\text { velocity } \\
{[\mathbf{m} / \mathbf{s}]}\end{array}$ & $\begin{array}{c}\text { Reynold } \\
\text { No } \\
{[\mathbf{R e}]}\end{array}$ & $\begin{array}{c}\text { Max error } \\
{[\mathbf{\pm \%} \text { of Flowrate] }}\end{array}$ \\
\hline 5.00 & 0.00018 & 0.02 & 12 & 4.00 \\
\hline 77.27 & 0.0027 & 0.29 & 182 & 0.28 \\
\hline 149.55 & 0.0053 & 0.56 & 353 & 0.17 \\
\hline 221.82 & 0.0078 & 0.83 & 523 & 0.13 \\
\hline 294.09 & 0.01 & 1.10 & 693 & 0.12 \\
\hline 366.36 & 0.013 & 1.37 & 864 & 0.11 \\
\hline 438.64 & 0.015 & 1.64 & 1,034 & 0.11 \\
\hline 510.91 & 0.018 & 1.91 & 1,205 & 0.11 \\
\hline 583.18 & 0.02 & 2.18 & 1,375 & 0.11 \\
\hline 655.45 & 0.023 & 2.45 & 1,545 & 0.10 \\
\hline 727.73 & 0.026 & 2.72 & 1,716 & 0.10 \\
\hline 800.00 & 0.028 & 2.99 & 1,886 & 0.10 \\
\hline
\end{tabular}


Table 36 - Emerson's Micro Motion flow meter specifications for CMFS040 Coriolis flow meter at various flow rates at $840 \mathrm{~kg} / \mathrm{m}^{3}$ and 100 psig line pressure (full data sheet in Appendix C5 - Micro

Motion CMFS040M calculation summ
\begin{tabular}{|c|c|}
\hline $\begin{array}{c}\text { Flow Rate } \\
{[\mathbf{k g} / \mathbf{h r}]}\end{array}$ & $\begin{array}{c}\text { Mass Flow } \\
\text { Accuracy } \\
\mathbf{\mathbf { 1 } \% \text { of Rate }}\end{array}$ \\
\hline 800.000 & 0.100 \\
\hline 720.360 & 0.100 \\
\hline 640.720 & 0.100 \\
\hline 561.080 & 0.100 \\
\hline 481.440 & 0.100 \\
\hline 401.800 & 0.100 \\
\hline 322.160 & 0.100 \\
\hline 242.520 & 0.100 \\
\hline 162.880 & 0.100 \\
\hline 100.000 & 0.100 \\
\hline 3.600 & 1.966 \\
\hline
\end{tabular}

It can be seen from highlighted data in the tables that the Omega ${ }^{\mathrm{TM}}$ and Siemens flow meters did not meet the $2 \%$ of reading accuracy that is required by the CFR as seen in Table 33 under "Accuracy". This ruled out those flow meters for the system design. However, as seen in Table 36, for all flow rates above $3.6 \mathrm{~kg} / \mathrm{hr}$, at line pressure of $100 \mathrm{psi}$, the mass flow accuracy of the Micro Motion flow meter met the $2 \%$ of reading criteria. This meant that for all flow rates $(5-800 \mathrm{~kg} / \mathrm{hr})$ that will be initially tested, the Micro Motion Coriolis flow meter would meet the accuracy targets required. Thus, the Micro Motion flow meter was selected as the flow meter to be used for the new fuel measurement system.

\subsection{1-2 Fuel Pump Selection}

For a fuel pump, a PD pump was desired as it supplies a known constant volume of fuel as well as being self-priming. Paragon Pumps is an aftermarket supplier of PD pumps that are already used on some Norfolk Southern locomotives. The 5.5 gpm, 120 psi, 230/460 VAC diesel fuel pump was selected to supply fuel through the fuel system. This pump met the supply fuel flow rate and pressure needed for the system and flow meter to respond appropriately. The fuel pump could also be wired using outside electrical supply so that the pump's electrical load would not interfere with the locomotive's emissions. This was due to parasitic electrical loads creating more load on the engine. However, due to lead times on the pump, the $7 \mathrm{gpm}, 120$ psi, 74 VDC fuel pump was supplied as an alternative pump until the AC pump was delivered. This pump was wired into the locomotives electrical supply and used until the AC pump arrived. 


\subsection{1-3 Design of Fuel Tank Reservoir}

The design of the fuel tank reservoir was based on two criteria: (1) the tank needed to hold enough fuel such that at Notch 8 there would be enough fuel in case the fuel pump stopped working and no fuel would be able to be pumped back in (2) the tank was small enough such that a level sensor has adequate resolution of fuel change in the tank. Goals 1 and 2 were accomplished by using a large diameter base with a smaller diameter amplifier tube on top. Figure 54 shows the conceptual design.

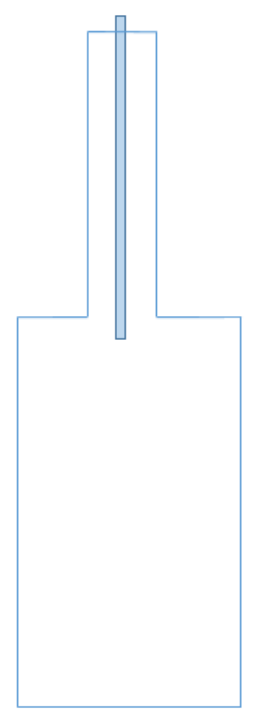

Figure 54 - Fuel drum conceptual design

In order to accomplish goal 1 for the fuel drum, the diameter of the drum needed to be calculated based on the fuel consumed during a Notch 8 power setting. For most Tier 0-2 locomotives, $300 \mathrm{lbs}$ of fuel over 300 seconds was sufficient to accomplish this as seen from Table 27 in Section 3.2 Design and Analysis of the Juniata Emissions Measurement System where a 2016 SD60E equipped with a model year 1990 engine consumed 253 lbs. of fuel in Notch 8 during an emissions test. Once the mass of fuel required was known, the density of fuel and the volume of a cylinder equation was used to determine a sufficient diameter and height for the drum.

A MATLAB ${ }^{\circledR}$ code was written (Appendix A2 - Fuel Drum Sizing Calculations) to quickly change the diameter and height of the fuel drum to find the fuel volume. Calculations for the mass of fuel were based on a fuel temperature of $70^{\circ} \mathrm{F}\left(15^{\circ} \mathrm{C}\right)$ with proportional fuel density $840 \mathrm{~kg} / \mathrm{m}^{3}$. Since density can be found by dividing mass by volume, the equivalent mass of fuel was found from the calculated volume and given density to calculate an approximate fuel weight of $300 \mathrm{lbs}$. In this case, a middle ground compromise was the best option as the drum should not be too large in the diameter nor too tall in height such that the drum can be maneuvered around during fabrication and 
afterwards for any teardown that may occur later on in the fuel measurement systems lifetime. An 18 inch diameter and 30 inch tall tank was the best setup for accomplishing goal 1.

Accomplishing goal 2 with the previously determined base diameter was not sufficient at 18 inches as the level sensor resolution would be greatly diminished. The MATLAB ${ }^{\circledR}$ code (Appendix A2 - Fuel Drum Sizing Calculations) was also written to determine how the fuel height would change based on a fuel temperature change of $0.1^{\circ} \mathrm{C}$ as temperature of fuel is measured to $\pm 0.1^{\circ} \mathrm{C}$ accuracy by the fuel temperature thermocouples. Temperature effects were analyzed to determine an appropriate amplifier tube diameter where a level sensor could read temperature effects that could later be calibrated out. Table 37 shows the change in height of fuel in a cylinder for $0.1^{\circ} \mathrm{C}$ change in temperature. Figure 55 shows the corresponding data.

Table 37 - Changes in height of fuel in fuel drum based on a fuel temperature change of $0.1^{\circ} \mathrm{C}$ for various fuel drum diameters

\begin{tabular}{|c|c|}
\hline $\begin{array}{c}\text { Diameter of } \\
\text { fuel drum } \\
\text { [in] }\end{array}$ & $\begin{array}{c}\text { Change in height of } \\
\text { fuel in drum } \\
\text { [in] }\end{array}$ \\
\hline 1.0 & 0.806 \\
\hline 2.0 & 0.202 \\
\hline 4.0 & 0.051 \\
\hline 6.0 & 0.023 \\
\hline 8.0 & 0.013 \\
\hline 10.0 & 0.009 \\
\hline 12.0 & 0.006 \\
\hline
\end{tabular}

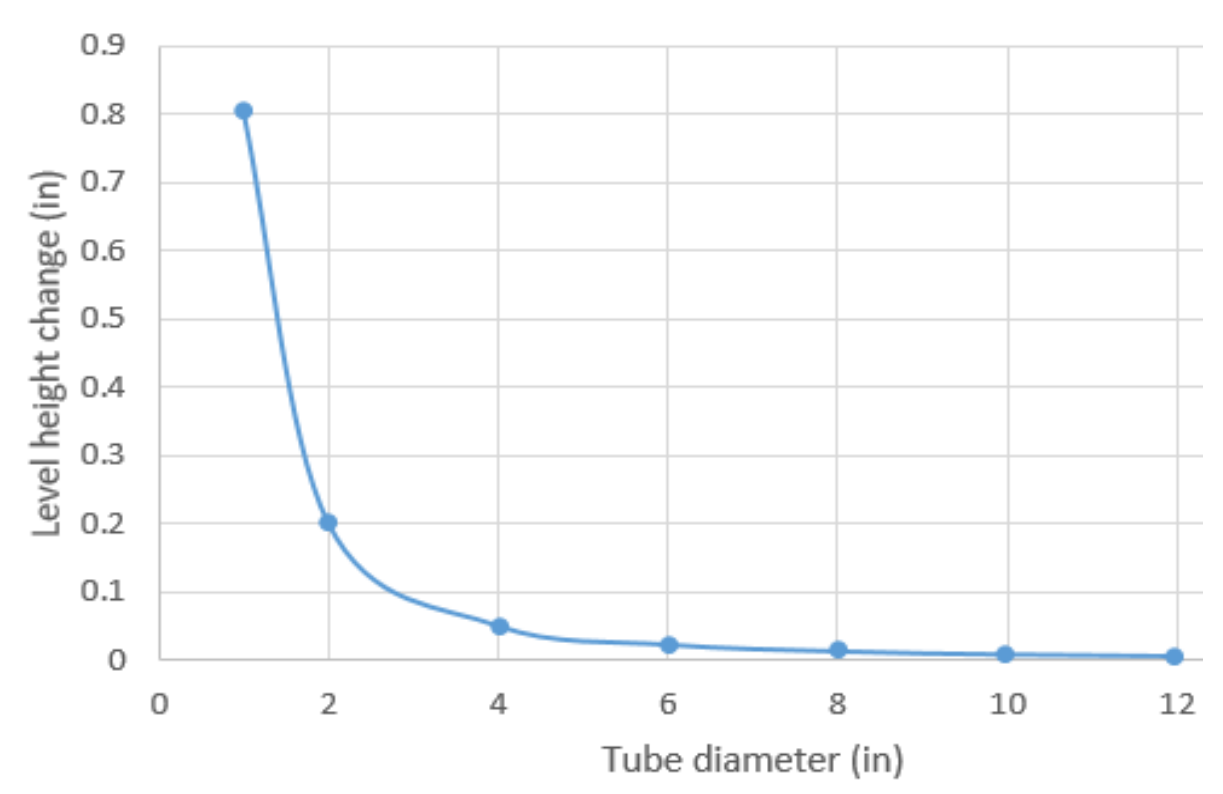

Figure 55 - Changes in height of fuel in fuel drum based on a fuel temperature change of $0.1^{\circ} \mathrm{C}$ for various fuel drum diameters (data from Table 37) 
It can be seen in Figure 55 how the fuel level change varied for different amplifier tube diameters. Smaller diameters created a larger displacement which would provide a better resolution. Choosing the proper amplifier tube diameter required knowing how much resolution a fuel level sensor would have. Expanded on in the next section, Section 3.6.1-4 Fuel Level Sensor, the fuel level sensor chosen would accurately measure a level change of at least \pm 0.15 inches. This level change corresponded to a fuel drum diameter of approximately 3 inches. This meant that a small diameter tube on top of a large diameter tube would accomplish goal 2 which is what the conceptual design from Figure 54 shows. A 4" diameter amplifier tube was chosen as 4" schedule 40 pipe was readily available in stainless construction. A standard 4 inch diameter schedule 40 pipe has an approximate inner pipe diameter of 4.026 inches which calculated a change in height of 0.050 inches for $0.1^{\circ} \mathrm{C}$ of fuel temperature change from $15^{\circ} \mathrm{C}$ to $15.1^{\circ} \mathrm{C}$. This was less than the level sensor would read of 0.15 inches. This meant that this pipe diameter was sufficient in providing enough resolution for the fuel level sensor to read a change in level due to a fuel temperature fluctuation of $0.1^{\circ} \mathrm{C}$.

\subsection{1-4 Fuel Level Sensor Selection}

Initial selection for a fuel level sensor started with a wide range of possible types of level sensors that could have been used; submersible, float, radar, and ultrasonic. After conversing with technical engineers, several criteria were formulated to narrow down the type of level sensor to use. The criteria were as follows:

- How large is the tank that the level sensor will be measuring?

- The range in height that the level sensor will measure?

- Accuracy of the level sensor?

- Type of liquid being measured?

- Output communication protocol of level sensor (i.e. is it compatible with 4-20mA)?

- Operation temperature of the liquid being measured?

To meet this criteria, the level sensor would need to:

- $\quad$ Fit inside a 4 inch diameter tube

- Measure through a level range no larger than 15 inches

- Be accurate enough to read a level change of at least 0.15 inches

- Measure No. 2 diesel fuel

- Be compatible with 4-20mA communication protocol

- Can operate with fuel temperatures between $30^{\circ} \mathrm{F}$ to $150^{\circ} \mathrm{F}$

A submersible, capacitance type level measurement sensor was chosen as it met all the criteria needed for the level sensor. The float level measurement sensor would not provide enough resolution 
required based on the calculations performed from Section 3.6.1-3 Design of Fuel Tank Reservoir. The radar and ultrasonic level measurement sensors would not properly function in a small diameter tube as the walls of the 4 inch diameter tube would be too close together and interfere with the feedback response waves.

An LTX60 capacitance level sensor was selected for level measurement. The LTX60 can measure No. 2 diesel fuel, it has high accuracy ( $\pm 1 \%$ of full span) and repeatability $( \pm 0.1 \%$ of full span), provides 4-20 mA communication output which works well with the Scimitar DAQ software, and can operate between $-40^{\circ} \mathrm{F}$ to $158^{\circ} \mathrm{F}\left(-40^{\circ} \mathrm{C}\right.$ to $\left.70^{\circ} \mathrm{C}\right)$ which is more than the required fuel temperature range. Figure 56 shows the LTX60 specification sheet below.

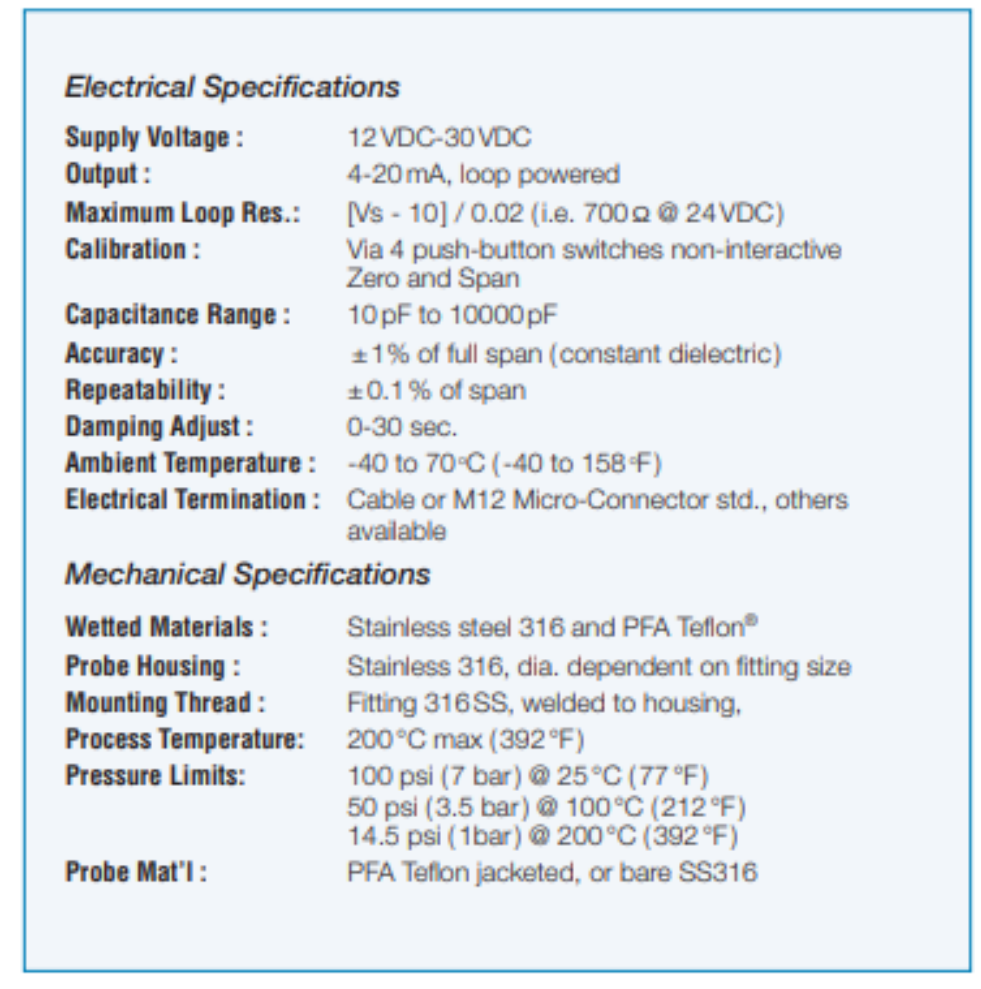

Figure 56 - LTX60 capacitance level sensor specifications sheet (specifications via Instrumart.com)

While the CFR has no performance criteria for level sensors, most other sensors from $40 \mathrm{CFR}$ Part 1065.205 [79] have a $0.5 \%$ to $2 \%$ of max reading accuracy requirement. The LTX60 accuracy of $\pm 1 \%$ full span is within this specification and would be a good use of engineering judgement for justifying using this sensor. From the maximum loop resolution specification, the resolution for the LTX60 capacitance level sensor would read 0.15 inches across 15 inches with a 12 VDC supply.

\subsection{1-5 Fuel Cooler Selection for Fuel Conditioning}

Selection of a fuel cooler started with the fuel cooler already in the Juniata emissions lab. A MATLAB ${ }^{\circledR}$ code was written to test several cooling requirements to determine if the cooler unit was 
sufficient. The code can be found in Appendix A1 - Chiller Calculations. The code asks for user input for temperature in $\left[{ }^{\circ} \mathrm{F}\right]$ and temperature out $\left[{ }^{\circ} \mathrm{F}\right]$, and the flow rate $[\mathrm{gal} / \mathrm{min}]$, then performs chiller calculations based on the following equation.

$$
\begin{gathered}
H=\frac{c_{p} * \rho_{T^{*}} \dot{Q} *\left(T_{i n}-T_{\text {out }}\right)}{12,000 \mathrm{Btu} / \mathrm{hr}} \\
\mathrm{H}=\text { required cooling load [tons] } \\
\left.\mathrm{c}_{\mathrm{p}}=\text { specific heat of fluid [Btu/lb.- }{ }^{\circ} \mathrm{F}\right] \\
\rho_{\mathrm{T}}=\text { density of fluid }[\mathrm{lb} / \mathrm{gal}] \\
\dot{Q}=\text { flow rate of fluid [gal/sec] }
\end{gathered}
$$

The conversions for each factor can be seen in Appendix A1 - Chiller Calculations to calculate the required cooling tonnage for diesel fuel. From the data in Appendix C2 - Preliminary Test Data for Test ID: R0007-002-198 the highest fuel temperature read approximately $110^{\circ} \mathrm{F}$ and the coldest fuel temperature read approximately $68^{\circ} \mathrm{F}$. In order to calculate the largest required cooling tonnage, slightly out of range numbers were selected as target cooling numbers to ensure that proper cooling would be met during testing. An inlet temperature of $120^{\circ} \mathrm{F}$, an outlet temperature of $65^{\circ} \mathrm{F}$, and a flow rate of $5 \mathrm{gpm}$ (higher flow rate than a Tier 2 locomotive) were selected as target flow parameters. The required cooling tonnage was 3.57 tons. Since the fuel cooler at the Juniata emissions lab is capable of 5 tons, the fuel cooler would be sufficient for the required cooling needed in conditioning the heated fuel returning from the locomotive to the fuel reservoir tank. It is important to note, for future work, a larger fuel cooler would be required in order to meet the temperature specifications for Tier 3 and 4 locomotives which have return flow rates up to $12 \mathrm{gpm}$. The required cooling tonnage would be upwards of 8.5 tons.

\subsection{1-6 Fuel Heater Selection for Fuel Conditioning}

Initially, the fuel heater needed to meet fuel conditioning needs of heating fuel from $70^{\circ} \mathrm{F}$ to $120^{\circ} \mathrm{F}$ at a $3.5 \mathrm{gpm}$ flow rate. This initial criteria is what was used to select the fuel heater. A Warren Electric 13kW, 208V, 3 phase fuel heater was selected because it met the required heating criteria as well as having an already designed PID controller for temperature control which measured temperature with a resistance temperature detector (RTD). The PID controller only needed to be connected to a power source and the set point temperature input in order to perform fuel heating conditioning. However, the fuel conditioning criteria changed, as discussed in Section 
3.6.2 Mass Flow Measurement System CAD Design, to heat the fuel from approximately $65^{\circ} \mathrm{F}$ to $75^{\circ} \mathrm{F}$. Since the flow rate would remain the same but the required temperature was much lower, the fuel heater was still adequate for the fuel conditioning required.

\subsection{1-7 Flow Controller Selection}

Flow controller selection began with fluid flow specifications. The new fuel measurement system would operate at 100 psig with a mass flow rate range between $5 \mathrm{~kg} / \mathrm{hr}$ and $800 \mathrm{~kg} / \mathrm{hr}$, with No. 2 diesel fuel at fuel temperature of $15^{\circ} \mathrm{C}$. The flow controller would be used to keep the 100 psig pressure between the pump, through the mass flow meter, and the flow controller. The controller would need to allow fuel to flow out of it at a much lower pressure but still allow enough flow rate to fill the reservoir tank fast enough to replenish fuel at a Notch 8 fuel consumption.

After conversing with technical engineers from Omega ${ }^{\mathrm{TM}}$ Engineering, Siemens Engineering and Emerson Process Management, the Emerson Baumann ${ }^{\mathrm{TM}}$ 24000SVF stainless steel flanged control valve with Fisher FIELDVUE ${ }^{\mathrm{TM}}$ digital valve controller was selected as the control valve for the new mass flow measurement system.

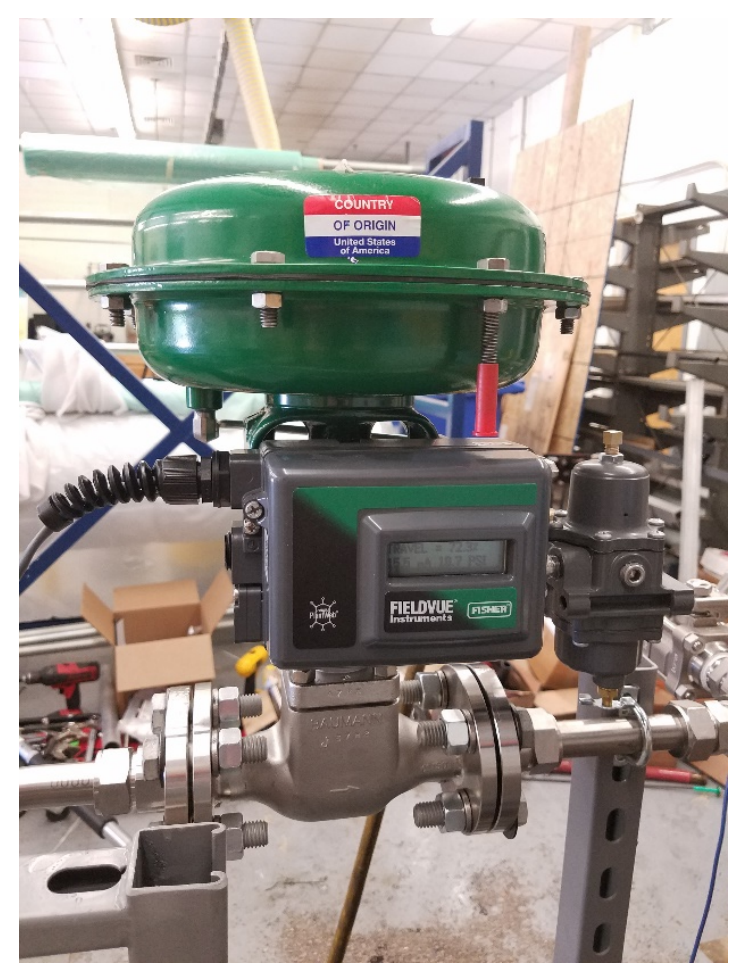

Figure 57 - Emerson's Baumann ${ }^{\mathrm{TM}}$ 24000SVF stainless steel flanged control valve with Fisher

FIELDVUE ${ }^{\mathrm{TM}}$ digital valve controller plumbed into mass flow measurement system

The Emerson's control valve was selected for several reasons:

- Compatible with No. 2 diesel fuel

- Comes with flange connection option 
- Met the pressure requirements of flow

- Emerson's extensive and thorough technical assistance which helped in sizing and selection of control valve

\subsection{1-8 Pressure Relief Valve Selection}

An Emerson MR98H pressure relief valve was selected as a relief valve for several reasons:

- It had the required pressure relief capability to meet 100 psig

- Compatible with No. 2 diesel fuel

- Comes with flange connection option

- Emerson's extensive and thorough technical assistance which helped in sizing and selection of relief valve

The MR98H pressure relief valve has a 15 to 200 psig pressure control capability. It is adjusted by a set screw and operates with a metal spring and diaphragm as seen in Appendix C6 Emerson MR98H Series Operational Schematics. The relief valve can be seen in Figure 58.

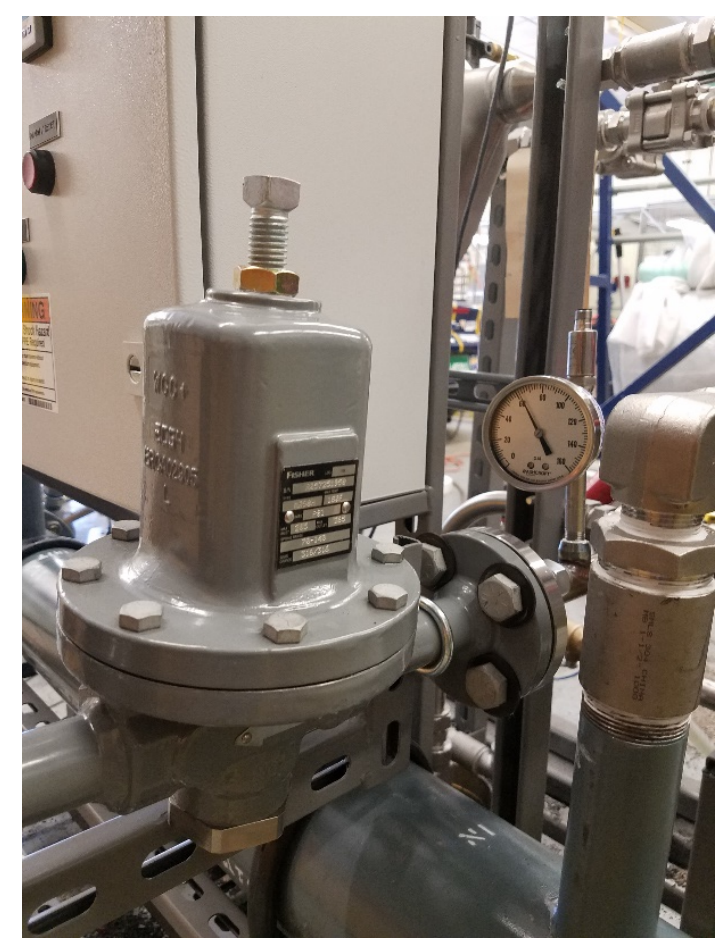

Figure 58 - Emerson MR98H pressure relief valve plumbed into the mass flow measurement system

\subsection{1-9 Pressure Gage Selection}

An Ashcroft 2-1/2 inch analog pressure gage with 0-160 psi range was selected as a visual pressure gage to quickly set the pressure relief valve pressure. It has a $\pm 1 \%$ of scale accuracy $( \pm 1.6$ psig). In order to fine tune line pressure to set it as close as possible to the required 100 psig for 
the mass flow meter, a ProSense SPTD25-20-0200H (0 to 200 psig) pressure gage was chosen. It has a $\pm 0.5 \%$ of full scale accuracy ( $\pm 1 \mathrm{psig}$ ) and a projected $\pm 0.1 \%$ best fit of straight line linearity. Figure 59 shows a photo of the two pressure gages plumbed into the mass flow measurement system.

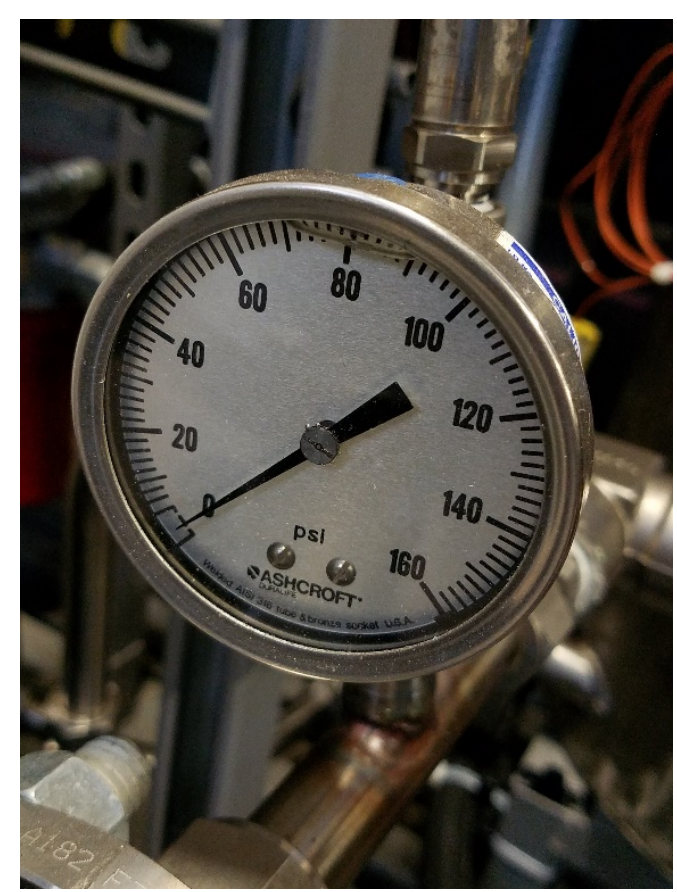

Figure 59 - Photo of Ashcroft analog (front) and ProSense digital (behind) pressure gages plumbed into mass fuel measurement system

\subsubsection{Mass Flow Measurement System CAD Design}

After finalizing part selections, the 3D parametric model of the fuel system was designed using the CAD files provided by the parts manufacturers. SolidWorks ${ }^{\mathrm{TM}}$ 3D modeling software was used to assemble the parametric model. Figure 60 and Figure 61 show the top (annotated) and isometric views of the CAD model, respectively. 


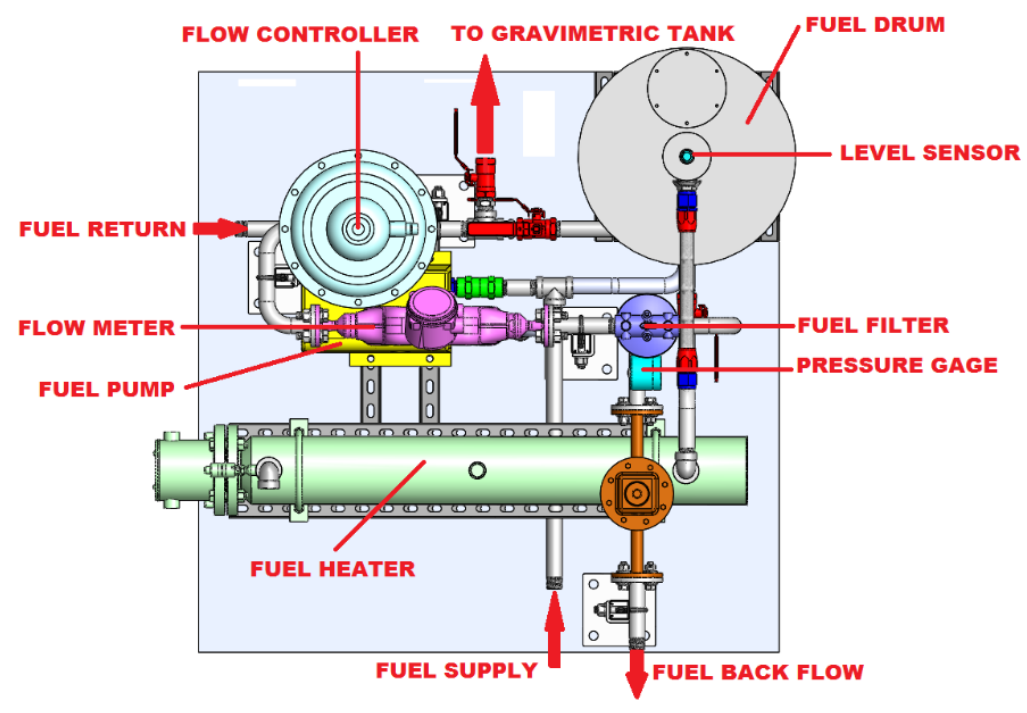

Figure 60 - Top view of annotated mass flow measurement system CAD model on 48 inch x 48 inch

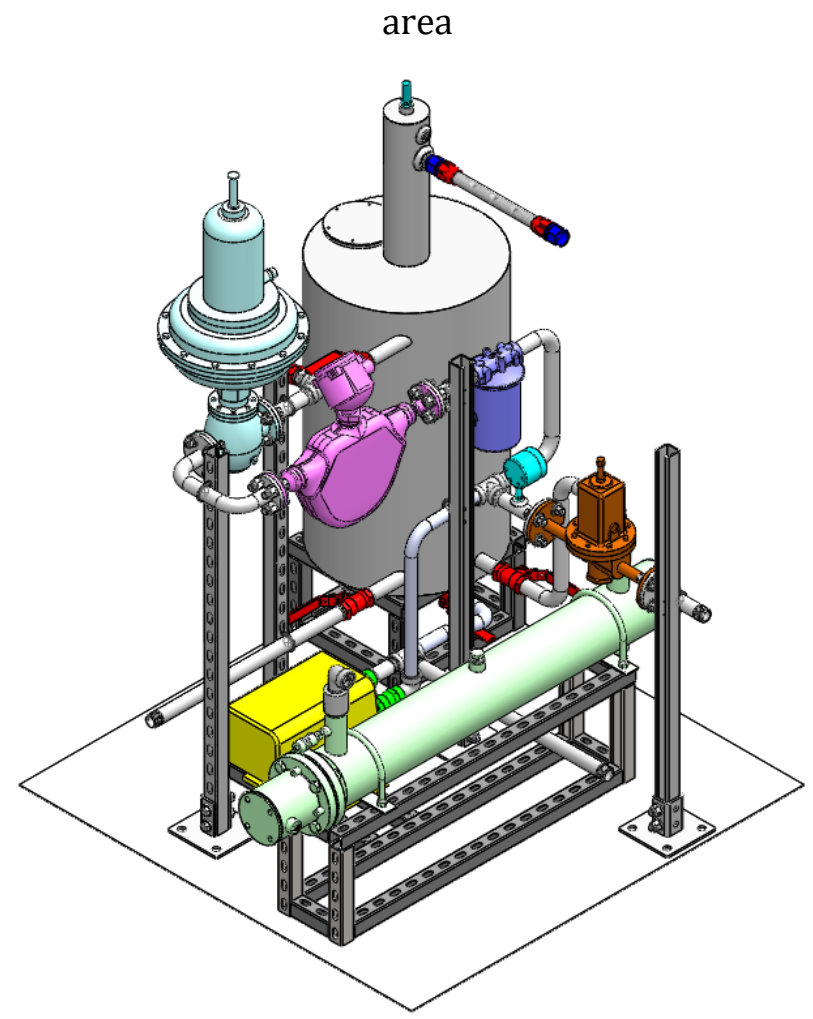

Figure 61 - Left isometric view of mass flow measurement system CAD model on 48 inch x 48 inch area 


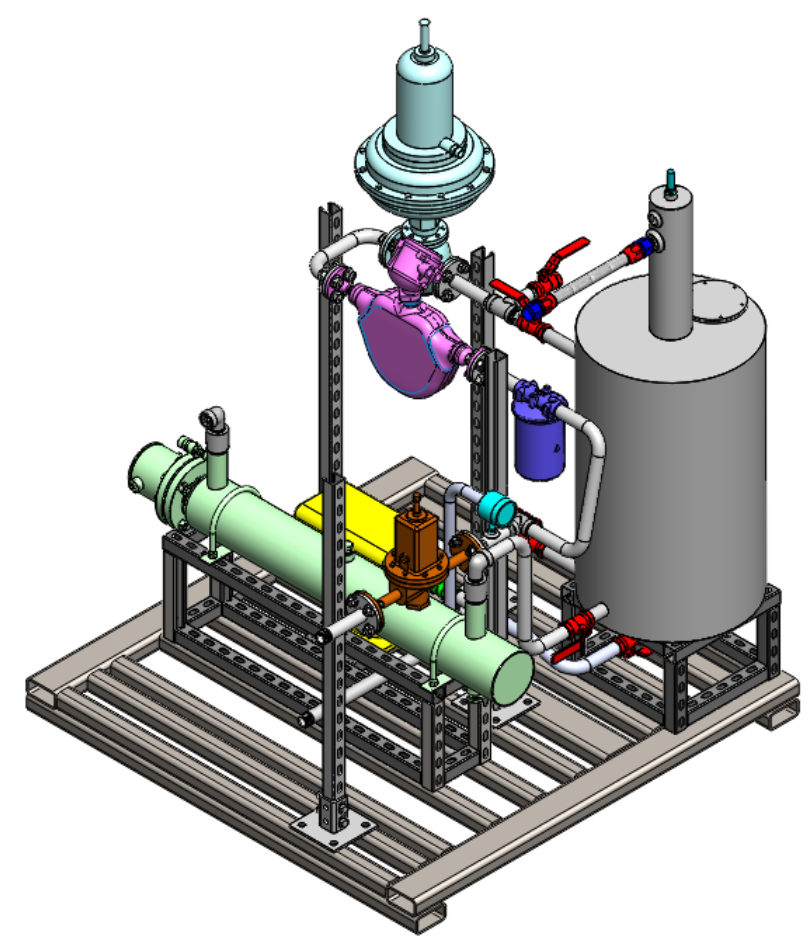

Figure 62 - Right isometric view of mass flow measurement system CAD model on designed 52 inch $\mathrm{x}$ 52 inch steel pallet

Figure 60 and Figure 61 show the arrangement of the components. The system was designed to be mounted to a 52 inch $\times 52$ inch transportable steel pallet as seen in Figure 62 . The plumbing consisted of 1 inch stainless steel tube for the fuel lines and stainless steel construction for the fuel reservoir to prevent corrosion which could contaminate the fuel being delivered to the locomotive. Flanges were used at sensor connections as they provide more robust connections over tapered national pipe threading (NPT). The stainless hardlines were supported at the flanged connections and the supporting structure. U-bolts were used to clamp the tubes to the vertical unistruts that were bolted to the pallet.

\subsubsection{System Construction and Implementation}

During initial design, the fuel was to be conditioned by heating it before it went to the locomotive. However, it was more important that fuel was conditioned in the fuel measurement tank to minimize the level fluctuation due to fuel volume changes from density changes from fuel temperature. Thus, the flow diagram was revised as seen in Figure 63, below. 


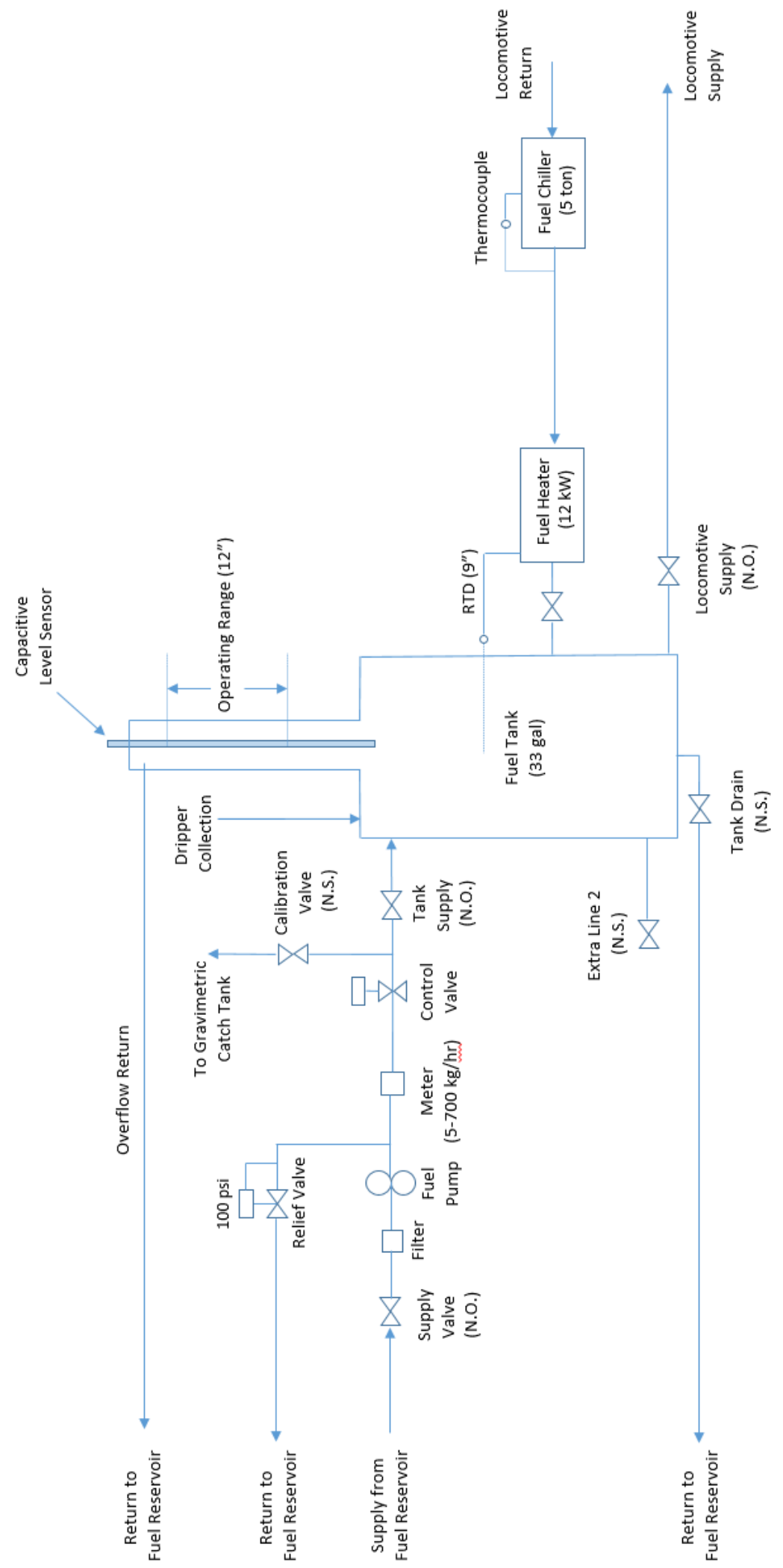

Figure 63 - Revised schematic diagram of the mass flow measurement system 
Similar to the first schematic, the only changes made were placement of the fuel heater, and a dripper line collection port. The fuel heater was placed after the fuel chiller and controlled by an RTD placed inside the fuel tank to measure the fuel reservoir tank temperature. Since the fuel heater had the capability to heat fuel from $70^{\circ} \mathrm{F}$ to $120^{\circ} \mathrm{F}$ (calculated from Section 3.6.1-5 Fuel Cooler Selection for Fuel Conditioning), the fuel heating required for the revised system was adequate.

Once the mass fuel measurement system was assembled at WVU's Engineering Science Building, it was transported to the Juniata emissions lab for tuning, calibration and validation. Figure 64 to Figure 66 show top, left isometric, and right isometric views, respectively, of the new fuel mass flow measurement system in place at the Juniata emissions lab.

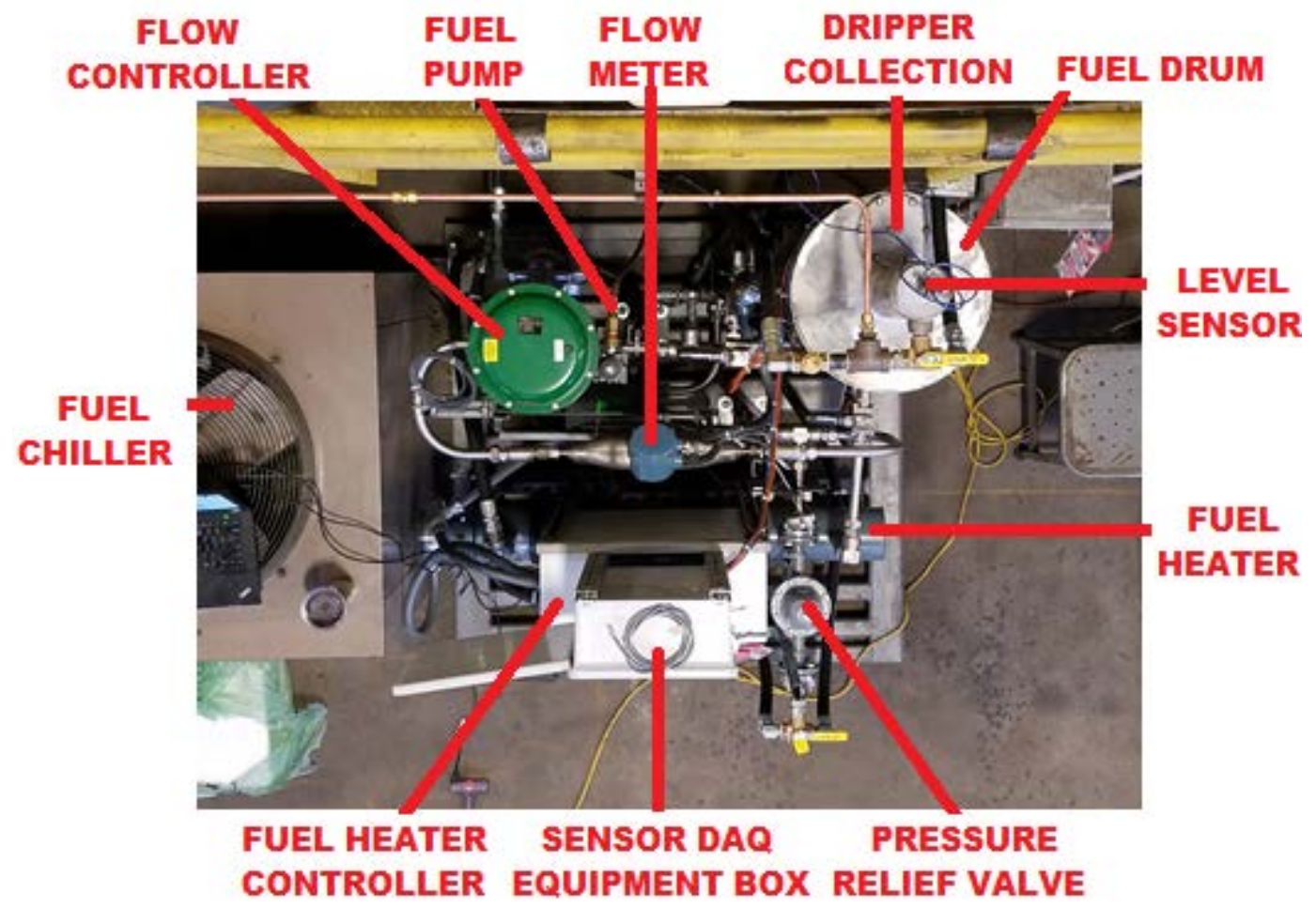

Figure 64 - Top view annotated picture of mass flow measurement system in place at Juniata emissions lab 


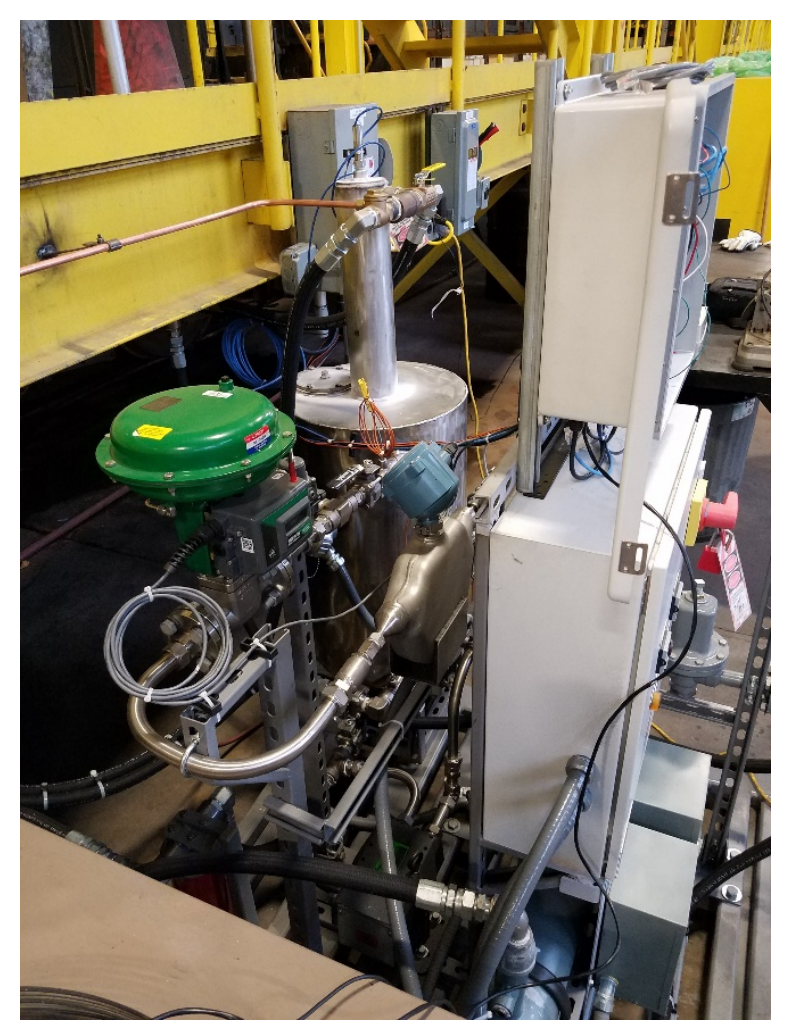

Figure 65 - Left isometric picture of mass flow measurement system in place at Juniata emissions lab

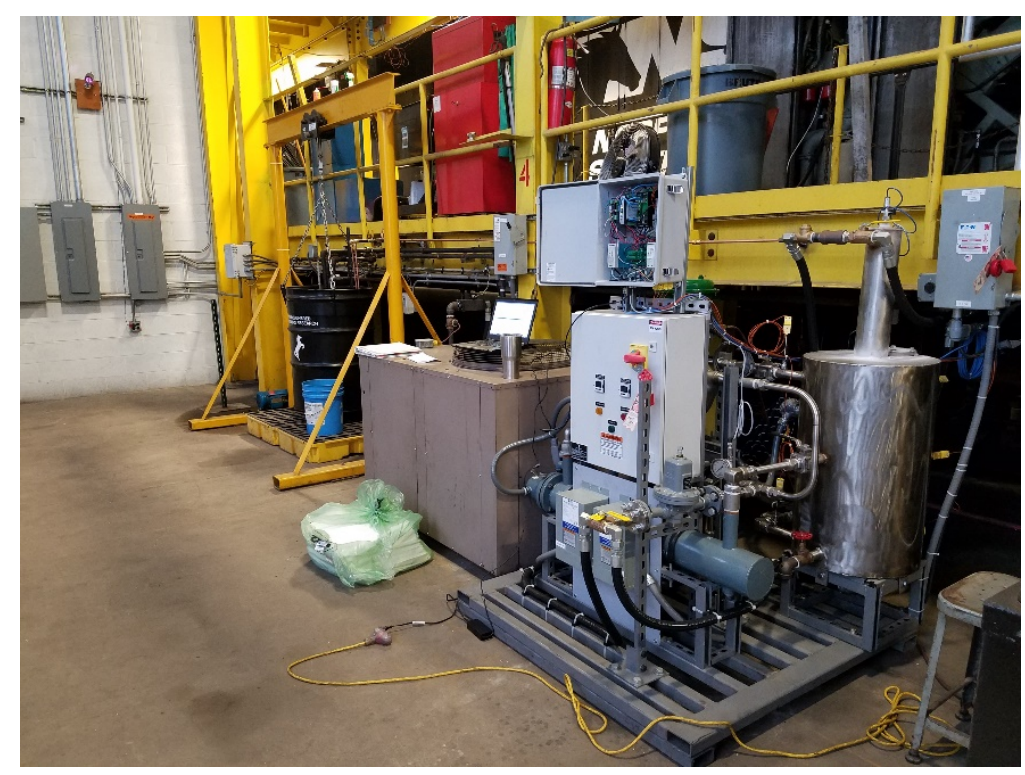

Figure 66 - Right isometric picture of mass flow measurement system in place at Juniata emissions lab beside gravimetric fuel measurement system

The laboratory was plumbed to enable either the gravimetric system or the mass system to be used. The final flow diagram of the dual system can be seen in Figure 67. 


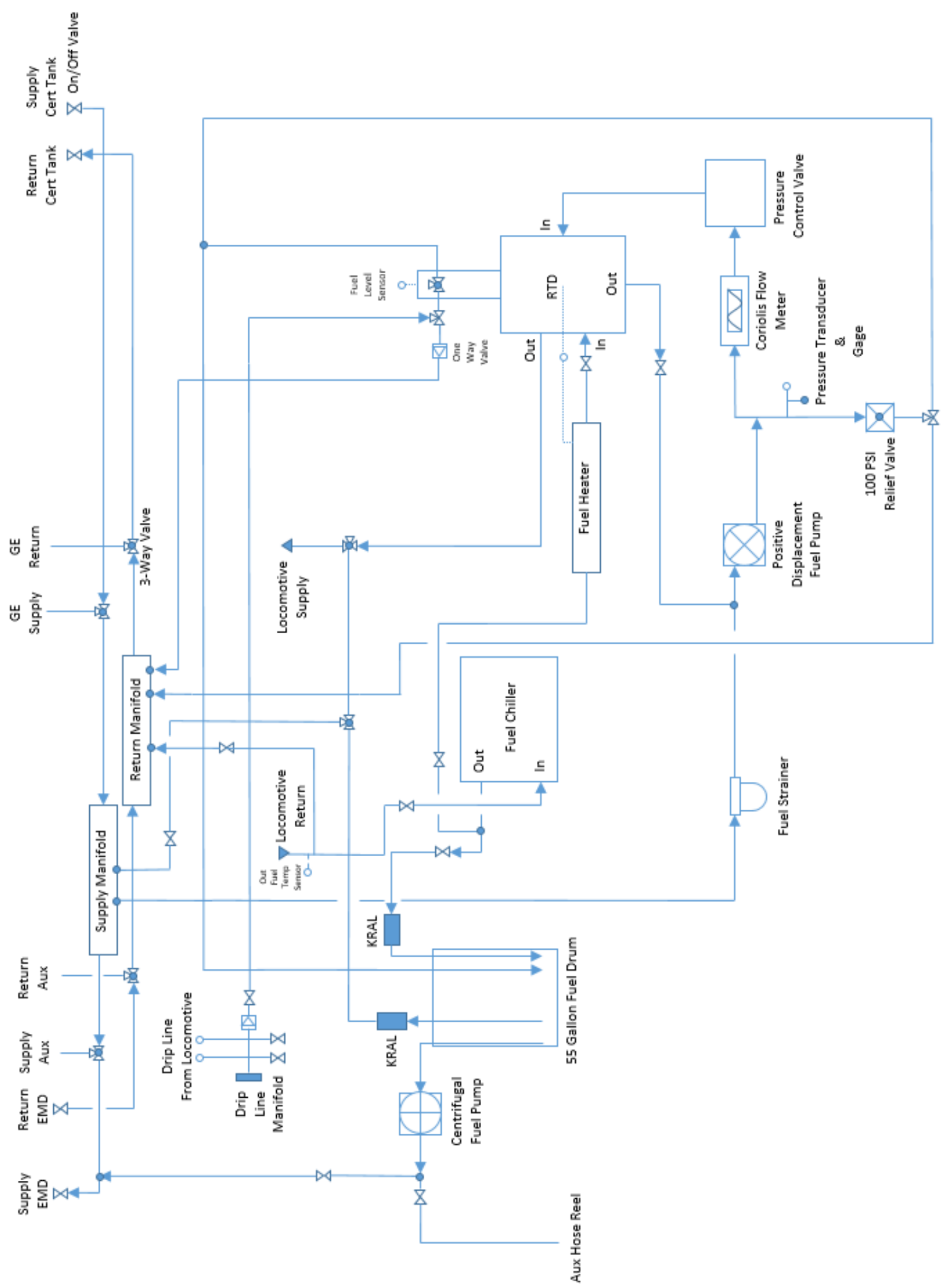

Figure 67 - Final fuel flow diagram for the gravimetric and mass flow measurement systems 


\subsection{System Calibration}

\subsubsection{Level Sensor Calibration}

The LTX60 capacitance level sensor was calibrated by draining specified amounts of fuel into a container, and recording the weight of the fuel and the fuel level in the amplifier tube. A $500 \mathrm{ml}$

graduated cylinder was used as a fuel container which was placed on a Salter-Brecknell ESA-6000 Digital Balance for reading the weight of the fuel. The setup can be seen in Figure 68. The fuel level was recorded through Scimitar's output from the LTX60. The measurement process was as follows:

1. Fill amplifier tube until level sensor read above 7.00"

2. Drain fuel until level sensor read 7.00"

3. Place empty graduated cylinder on digital scale, tare, and place under draining nozzle as shown in Figure 68 - Fuel Calibration Drain and Fuel Weight Measurement Setup

4. Slowly open needle valve until fuel started to drain

5. Drain fuel until level sensor read desired calibration level and close valve

6. Record fuel weight and fuel level

7. Repeat steps 4-6 until level read 6.00"

8. Empty graduated cylinder and repeat step 3

9. Repeat steps 4-6 until level read 5.00"

10. Empty graduated cylinder and repeat steps 1-10 using different desired level drops 


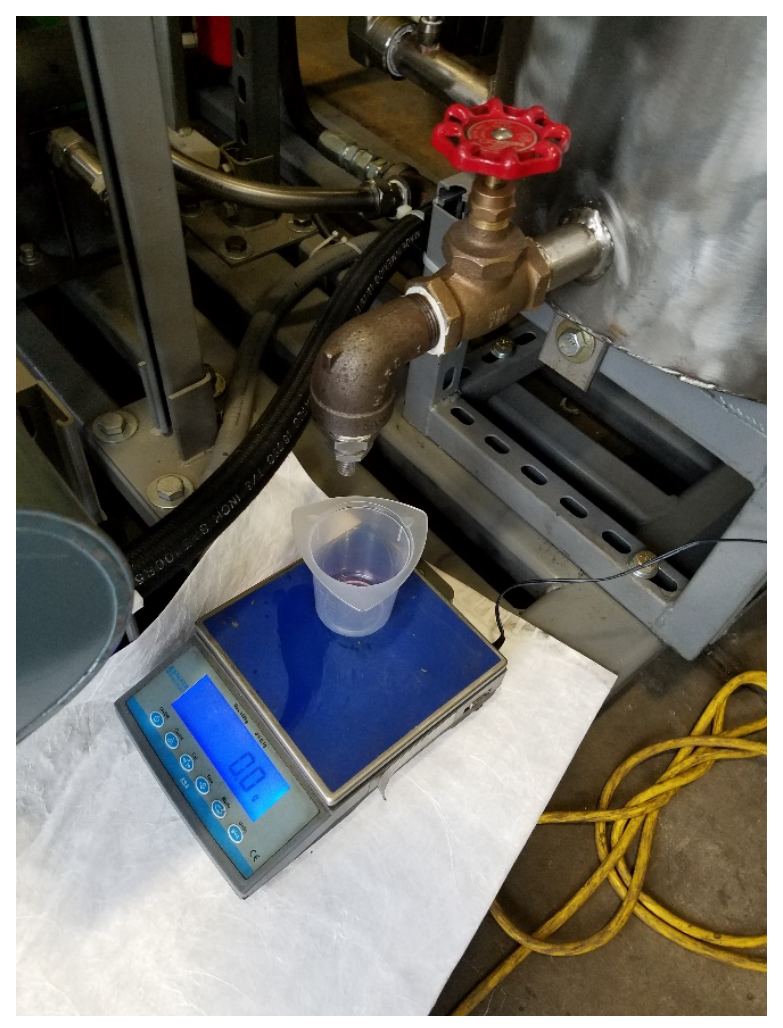

Figure 68 - Fuel Calibration Drain and Fuel Weight Measurement Setup

The set point for the level sensor was 6.00 " as this height gave sufficient room from the top and bottom of the amplifier tube to allow for large fluctuations in fuel flow. The fuel level measurement range was selected between 5.00" to 7.00" reading on the level sensor as initial testing showed that the fuel fluctuated between 0.25 " in either direction. 1.00" fluid fluctuation would provide sufficient level height measurement to allow for any unsuspected fluctuations.

The ESA-6000 Digital Balance was calibrated and verified using a Troemner stainless steel calibration weight set. The 14 calibration weights were tested and certified to the NIST Test Number 684/289871-17 and calibrated to ASTM 617-13 Class 7 tolerances. The Traceable Certificate can be found in Appendix B2 - Troemner, LLC Traceable Certificate for Calibration Weights.

The balance was calibrated using the 2000 gram calibration setting that is standard to the balance programming and verification was performed using all 14 calibration weights. Each weight weighed exactly the amount they were specified for as seen in Table 38 below which shows the Nominal Mass Value with the Weight Uncertainty and the Measured Weight of the calibration weights. 
Table 38 - Troemner Calibration Weights Measurement

\begin{tabular}{|c|c|c|}
\hline $\begin{array}{c}\text { Nominal } \\
\text { Mass } \\
\text { Value }\end{array}$ & Uncertainty & $\begin{array}{c}\text { ESA-6000 } \\
\text { Measured } \\
\text { Weight }\end{array}$ \\
\hline [g] & [mg] & [g] \\
\hline 2000 & 75 & 2000.0 \\
\hline 1000 & 50 & 1000.0 \\
\hline 500 & 30 & 500.0 \\
\hline 200 & 16 & 200.0 \\
\hline 200 & 16 & 200.0 \\
\hline 100 & 10 & 100.0 \\
\hline 50 & 6 & 50.0 \\
\hline 20 & 3 & 20.0 \\
\hline 20 & 3 & 20.0 \\
\hline 10 & 2 & 10.0 \\
\hline 5 & 1.3 & 5.0 \\
\hline 2 & 0.7 & 2.0 \\
\hline 2 & 0.7 & 2.0 \\
\hline 1 & 0.5 & 1.0 \\
\hline
\end{tabular}

After calibration and verification of the ESA-6000 Digital Balance, amplifier tube measurement was performed via the 10 step process described above. Figure 69 shows the measured data and linear relationship of grams of fuel per inch drop in the amplifier tube.

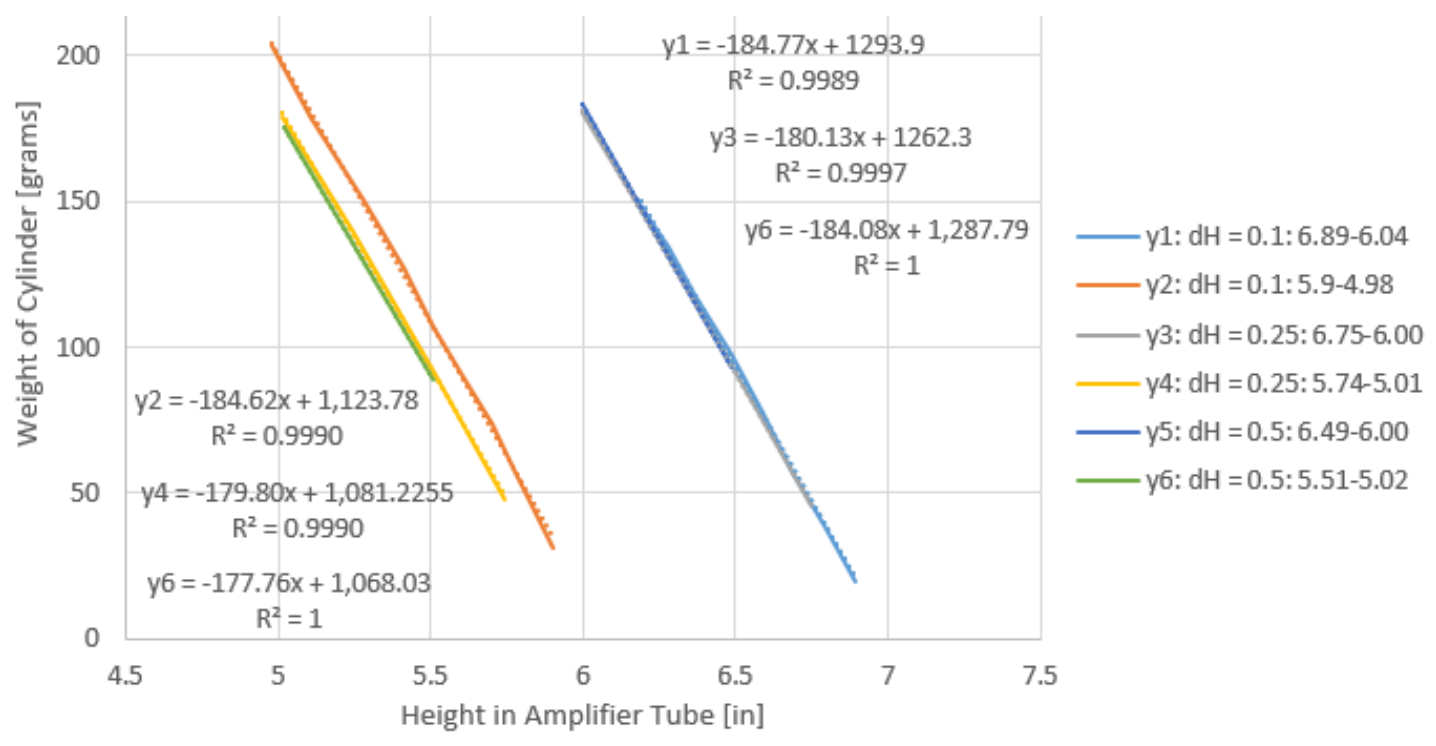

Figure 69 - Level measurement in grams of fuel per inch drop in the amplifier tube 
As seen in Figure 69, several changes in height were performed to analyze how the LTX60 level sensor measures different changes in height. Fuel was drained in three separate height change increments from 6 inches to 5 inches. The increments were drops in $0.1 \mathrm{inch}, 0.25 \mathrm{inch}$, and $0.5 \mathrm{inch}$. Each data set was input into an Excel spreadsheet with a linear regression line shown to determine the change in mass of fuel per inch. Using linear regression lines with an $\mathrm{r}^{2}$ greater than 0.999 , the average change in mass per change in height was 181.9 grams per inch. Theoretically, the level change in inch should follow the equation:

$$
M_{f}=\rho_{f @ T e m p} * A_{p}
$$

Where:

$$
\begin{gathered}
M_{f}-\text { mass of fuel per inch } \\
\rho_{f}-\text { density of fuel at measured fuel temperature } \\
A_{p}-\text { inside area of amplifier tube }
\end{gathered}
$$

Using the RTD in the fuel drum, the temperature of the fuel was measured at $29.72{ }^{\circ} \mathrm{F}$. Using the data for the density of No. 2 diesel fuel [80] and interpolating to this temperature gave the density of fuel at $851.48 \mathrm{~kg} / \mathrm{m}^{3}$. A telescoping gauge was used to find the inner diameter of the amplifier tube. The average diameter of the amplifier tube between 3 and 8 inches up the amplifier tube measured at 4.056 inches, which was slightly larger than the averaged specifications of 4.026 inches. Substituting these numbers into the equation above yielded:

$$
M_{f}=851.48 \frac{\mathrm{kg}}{\mathrm{m}^{3}} * \pi * \frac{(4.056 \mathrm{inch})^{2}}{4} *\left(0.0254 \frac{\mathrm{m}}{\mathrm{inch}}\right)^{3} * 1000 \frac{\mathrm{g}}{\mathrm{kg}}=180.3 \frac{\mathrm{grams}}{\mathrm{inch}}
$$

Comparing the theoretical to measured values with $\mathrm{r}^{2}$ greater than 0.999 yielded a less than $1 \%$ difference between the measured (average $181.9 \mathrm{~g} / \mathrm{in}$ ) and theoretical value. It was determined that the level sensor was within accuracy specifications determined in Section 3.6.1-4 Fuel Level Sensor Selection.

\subsubsection{Micro Motion Coriolis Flow Meter Calibration}

The Micro Motion Coriolis flow meter was calibrated by Micro Motion technicians and was traceable to National Metrology Institutes: NIM-China, NIST-USA, and VSL - The Netherlands. The flow meter was calibrated twice on February 22, 2018 with water at a flow rate range between $1.133 \mathrm{~kg} / \mathrm{min}$ (68 kg/hr) and $13.3 \mathrm{~kg} / \mathrm{min}(800 \mathrm{~kg} / \mathrm{hr}$.) Table 39 and Table 40 show the flow meter's flow calibration trends. As seen from Table 39 and Table 40, the flow meter meets 40 CFR Part 1065.205 [79] accuracy specifications which read less than $2 \%$ of flow. The full calibration certificate sheets can be found in Appendix B1 - Micro Motion, Inc. Coriolis Mass Flow Meter Calibration Certificate Sheet. 
Table 39 - Micro Motion, Inc. mass flow meter calibration trends for test 12154968 (Appendix B1.1 Calibration Sheet for Test 12154968)

\begin{tabular}{|c|c|c|c|c|c|}
\hline $\begin{array}{c}\text { Flow } \\
{[\%]}\end{array}$ & $\begin{array}{c}\text { Flow } \\
\text { Rate } \\
{[\mathbf{k g} / \mathbf{m i n}]}\end{array}$ & $\begin{array}{c}\text { Meter } \\
\text { total } \\
{[\mathbf{k g}]}\end{array}$ & $\begin{array}{c}\text { Reference } \\
\text { total } \\
{[\mathbf{k g}]}\end{array}$ & $\begin{array}{c}\text { Error } \\
{[\%]}\end{array}$ & $\begin{array}{c}\text { Specification } \\
{[\mathbf{\pm \%}]}\end{array}$ \\
\hline 100.0 & 13.333 & 13.685 & 13.686 & -0.003 & 0.100 \\
\hline 70.0 & 9.333 & 9.455 & 9.456 & -0.005 & 0.100 \\
\hline 50.0 & 6.667 & 6.709 & 6.710 & -0.005 & 0.100 \\
\hline 40.0 & 5.333 & 5.401 & 5.401 & 0.001 & 0.100 \\
\hline 20.0 & 2.667 & 1.361 & 1.362 & -0.049 & 0.100 \\
\hline 8.50 & 1.133 & 1.147 & 1.147 & 0.025 & 0.100 \\
\hline
\end{tabular}

Table 40 - Micro Motion, Inc. mass flow meter calibration trends for test 12154969 (Appendix B1.2 Calibration Sheet for Test 12154969)

\begin{tabular}{|c|c|c|c|c|c|}
\hline $\begin{array}{c}\text { Flow } \\
{[\%]}\end{array}$ & $\begin{array}{c}\text { Flow } \\
\text { Rate } \\
{[\mathbf{k g} / \mathbf{m i n}]}\end{array}$ & $\begin{array}{c}\text { Meter } \\
\text { total } \\
{[\mathbf{k g}]}\end{array}$ & $\begin{array}{c}\text { Reference } \\
\text { total } \\
{[\mathbf{k g}]}\end{array}$ & $\begin{array}{c}\text { Error } \\
{[\%]}\end{array}$ & $\begin{array}{c}\text { Specification } \\
{[\mathbf{\mathbf { \pm } \% ]}}\end{array}$ \\
\hline 100.0 & 13.333 & 13.710 & 13.709 & 0.002 & 0.100 \\
\hline 70.0 & 9.333 & 9.453 & 9.453 & 0.000 & 0.100 \\
\hline 50.0 & 6.667 & 6.697 & 6.697 & -0.005 & 0.100 \\
\hline 40.0 & 5.333 & 5.384 & 5.383 & 0.010 & 0.100 \\
\hline 20.0 & 2.667 & 1.361 & 1.361 & -0.008 & 0.100 \\
\hline 8.50 & 1.133 & 1.150 & 1.149 & 0.060 & 0.100 \\
\hline
\end{tabular}

\subsubsection{Pressure Relief Valve Setting}

In order to meet the accuracy requirements of 40 CFR Part 1065.205 [79], a line pressure of $100 \mathrm{psi}$ is required for proper Coriolis flow meter function. As stated from Section 3.6.1-9 Pressure Gage Selection, an Ashcroft analog 160 psi pressure gauge was used for rough visual setting of the relief valve and fined tuned using a ProSense SPTD25-20-0200H pressure transducer. Setting the relief valve pressure required loosening the set nut on top and adjusting the set screw until the pressure gauges read 100 psi then retightening the set nut. Figure 70 shows the pressure relief valve, pressure gauge, and pressure transducer plumbed and operating at 60 psi line pressure during preliminary testing before transporting the system to the emissions lab. 


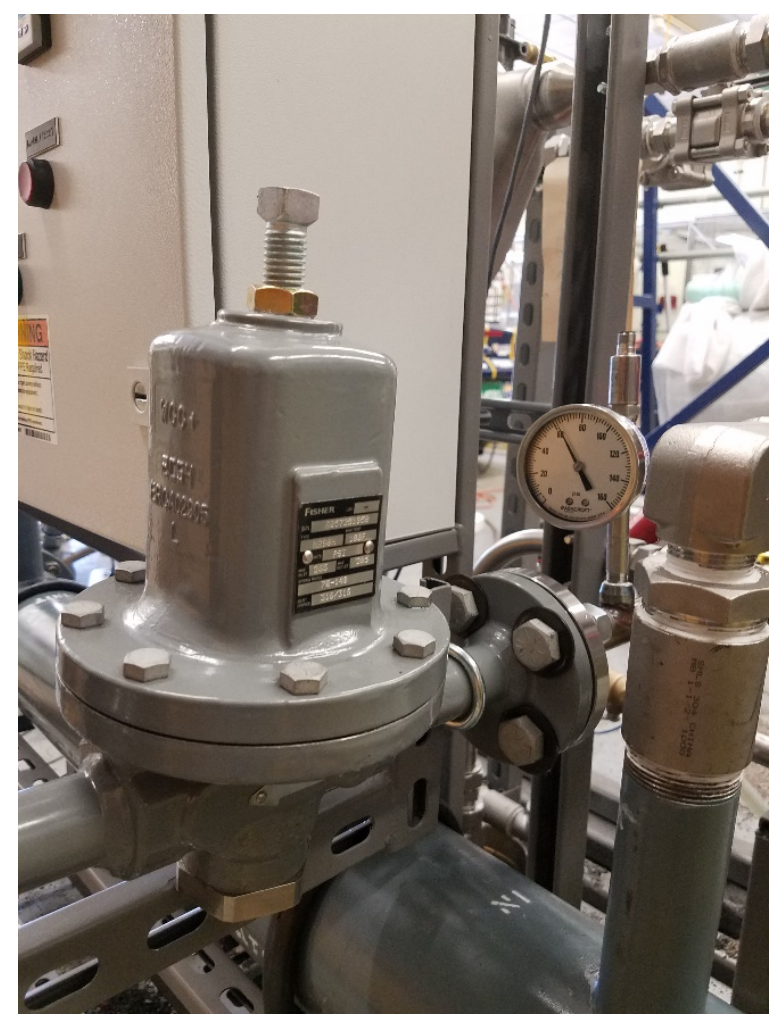

Figure 70 - Picture of pressure relief valve, pressure gauge, and pressure transducer plumbed into mass flow measurement system and operating at 60psig line pressure

\subsubsection{Controller Box}

The PID controller, Coriolis meter data logger, control valve data logger, and the thermocouple's temperature data channels were packaged together in a removable front panel, sealable, controller box. The PID controller and controller box was designed and built by supervisory engineer, Mr. David McKain. Figure 71 shows a picture of the controller box opened. 


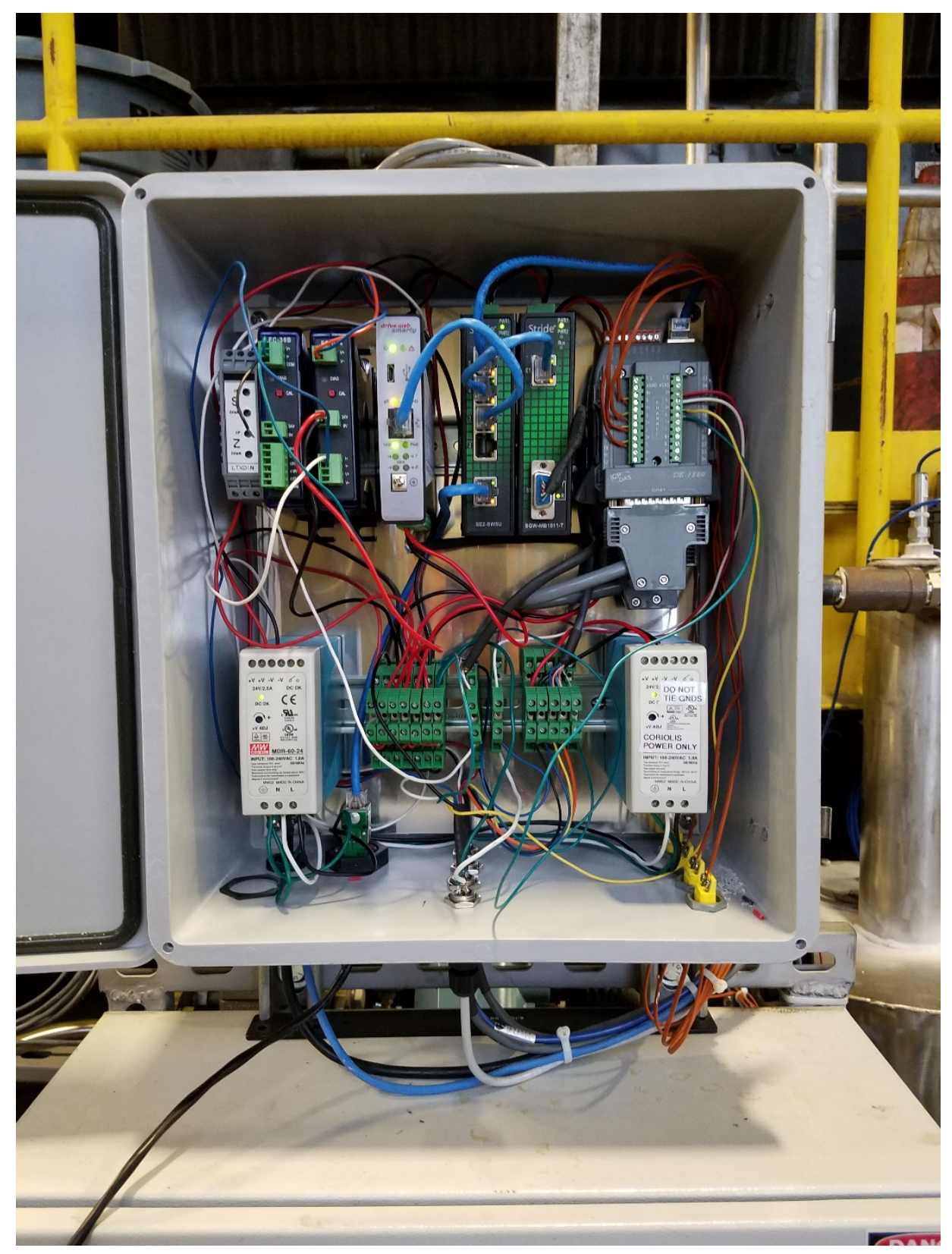

Figure 71 - Controller box

A drive.web ${ }^{\circledR}$ smarty ${ }^{\circledR}$ controller was used for the PID controller which uses savvy ${ }^{\circledR}$ control software. The controller is an internet-accessible controller for machine or process controls. It works well with remote input/output (I/O) devices and connects through Ethernet cables [82]. Figure 72 shows a PID block diagram from the drive.web ${ }^{\circledR}$ website. 


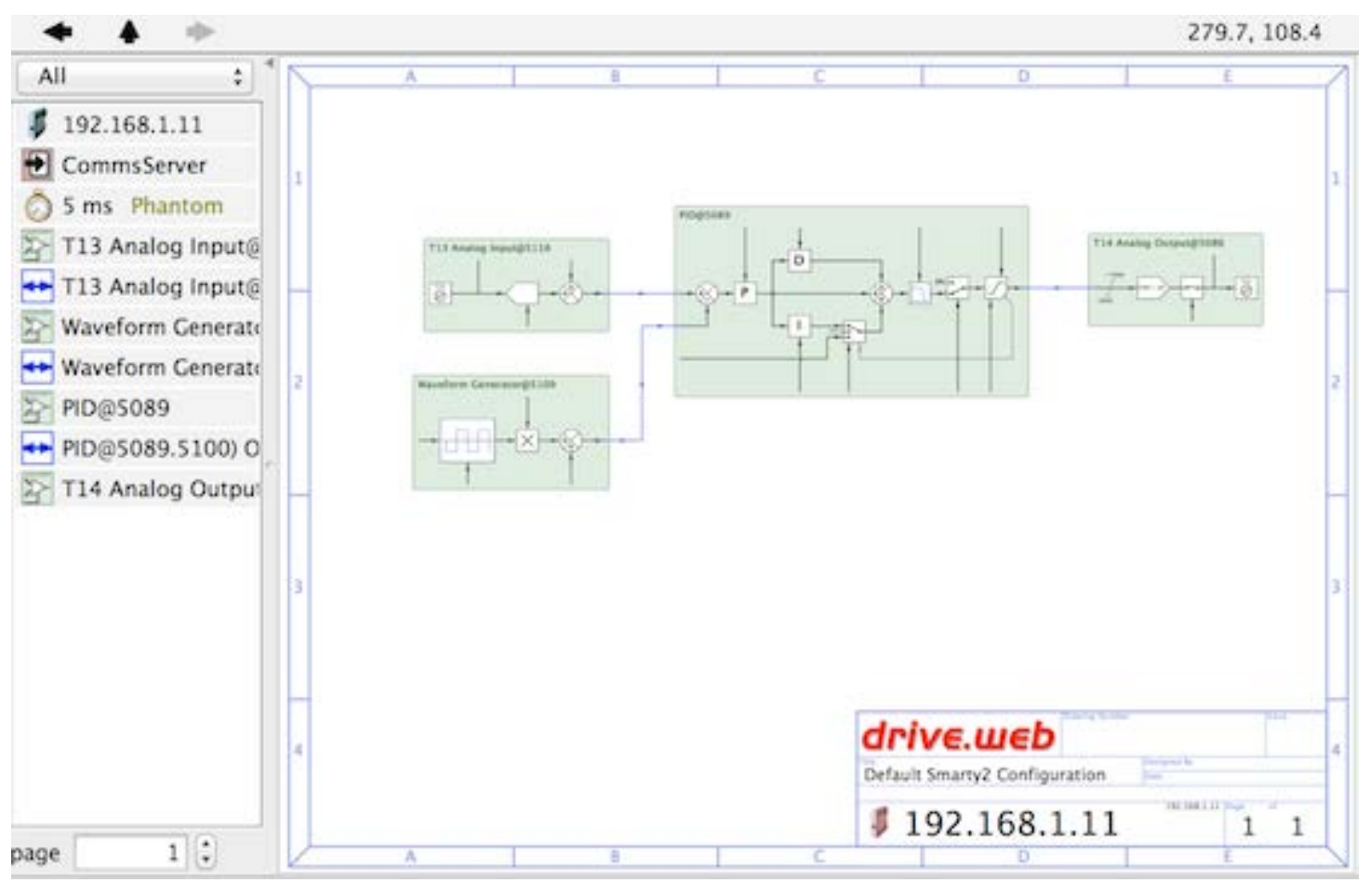

Figure 72 - drive.web ${ }^{\circledR}$ Smarty ${ }^{\circledR}$ PID controller block diagram (available driveweb.com)

The thermocouple data channel controller is an ICP DAS DB-1820 Ethernet I/O module with 10 channel thermocouple input capability. The controller is compatible with Modbus TCP/UDP communication protocol which is compatible with Scimitar's communication protocol.

A Stride ${ }^{\circledR}$ SE2-SW5U RJ45 5 port Ethernet switch was used for communicating the data from the communication ports of the control valve, level sensor, Coriolis meter, and thermocouples to Scimitar.

\section{ANALYSIS OF MASS FLOW MEASUREMENT BY CORIOLIS TECHNOLOGY}

After installation, setup, and tuning the mass fuel flow measurement system in the Juniata emissions lab, an emissions test was performed to determine how the measurement system performed.

\subsection{Analysis of the Mass Flow Measurement System}

A 2003 EMD SD70M (Test ID: R0007-002-264) with a model year 2003 engine was tested using the mass fuel flow measurement system. Particulate matter data was not available for this test, however the test provided useful data for the new mass flow measurement system. During this test, the proportional and integral terms for the PI controller were set to 5. The fuel level set point was 6.29 inches up the level sensor during Notch 8 for Test ID: R0007-002-264. Figure 73 shows the Coriolis mass flow rate measurement $[\mathrm{g} / \mathrm{s}]$. Figure 74 shows the fuel level reading in the amplifier tube along the fuel level sensor. Figure 75 shows the control valve position during Notch 8 for Test ID: R0007-002264. 


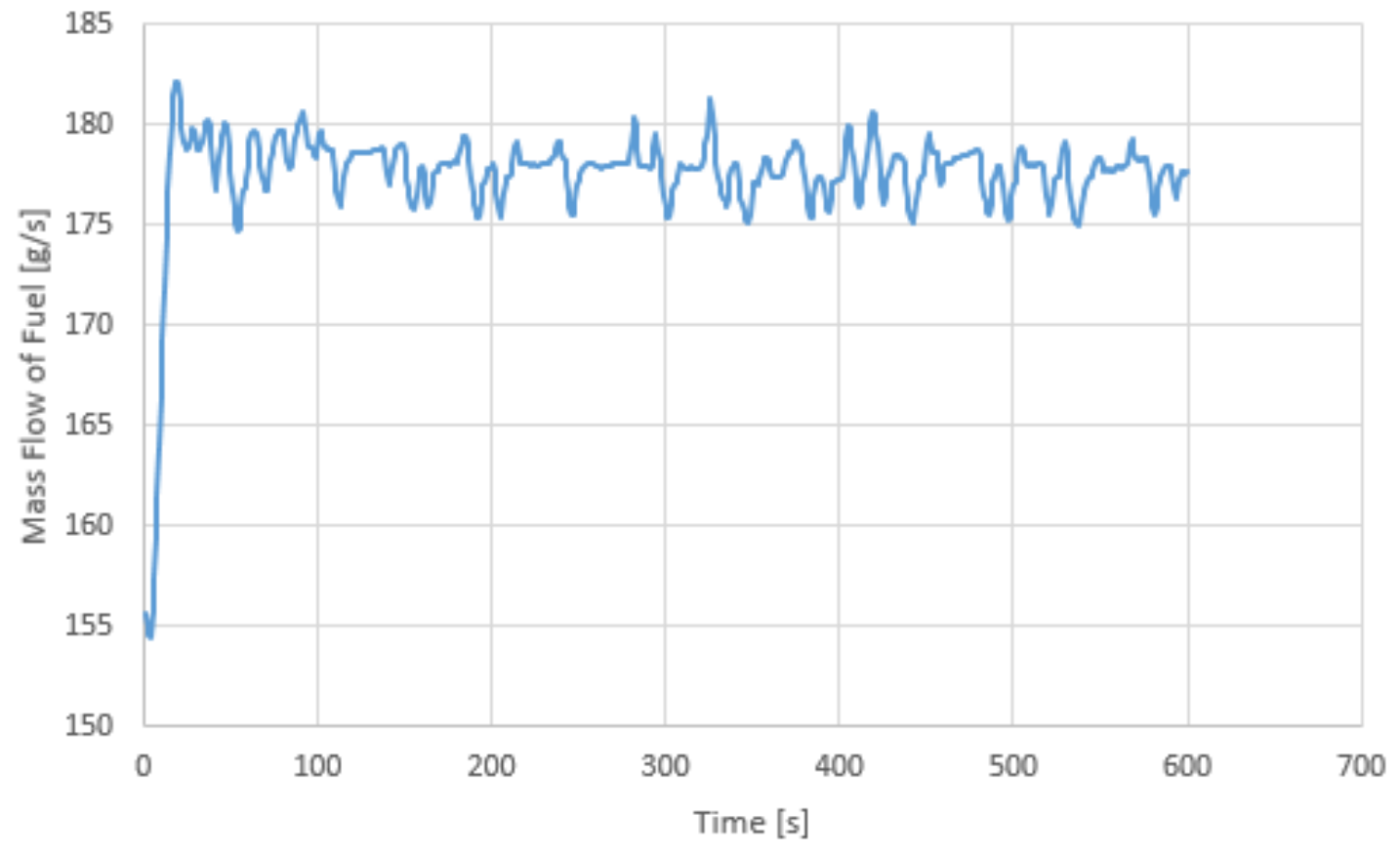

Figure 73 - Mass rate $[\mathrm{g} / \mathrm{s}]$ of fuel flow measured through Coriolis flow meter during Notch 8 for Test ID: R0007-002-264

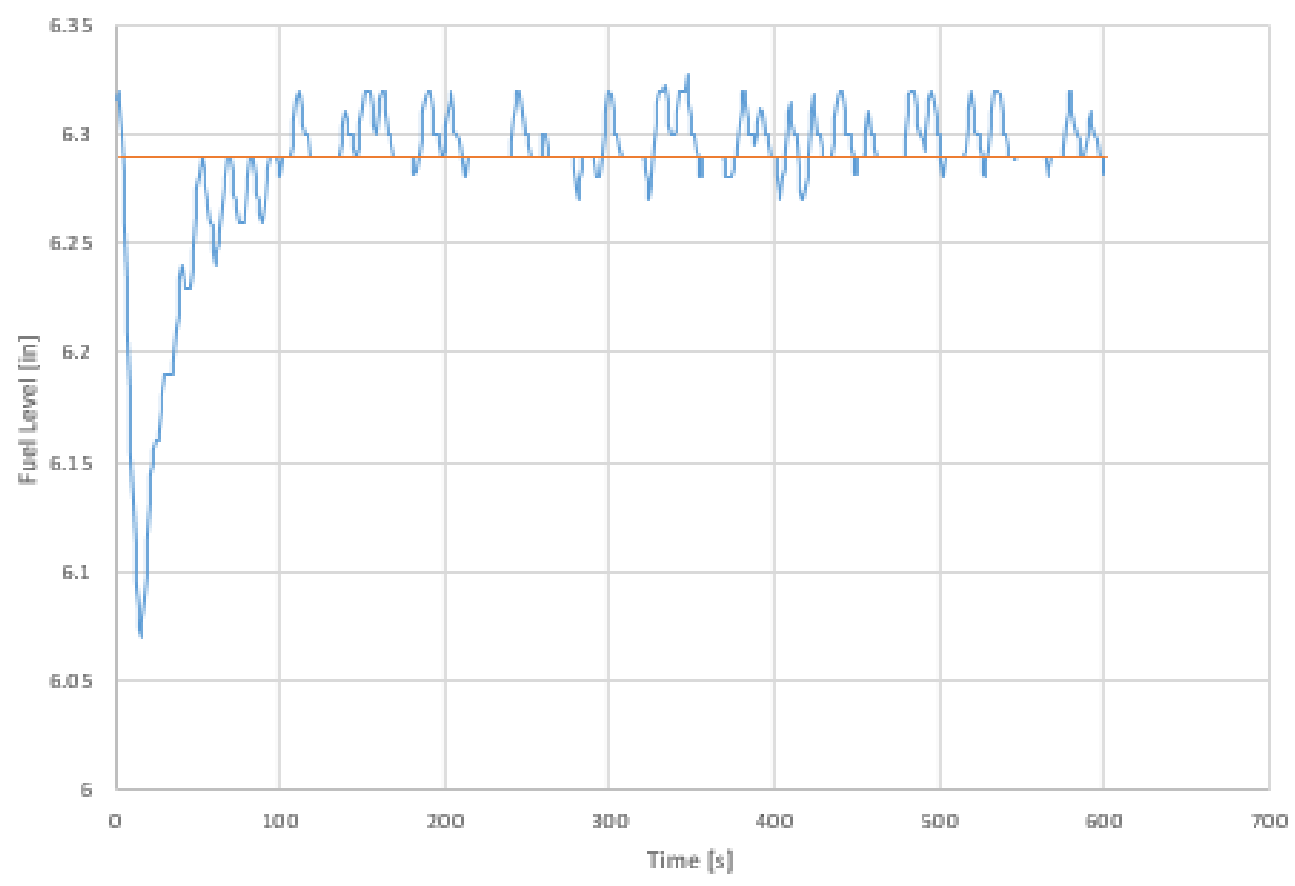

Figure 74 - Fuel level reading from the bottom of the fuel level sensor during Notch 8 for Test ID: R0007-002-264 


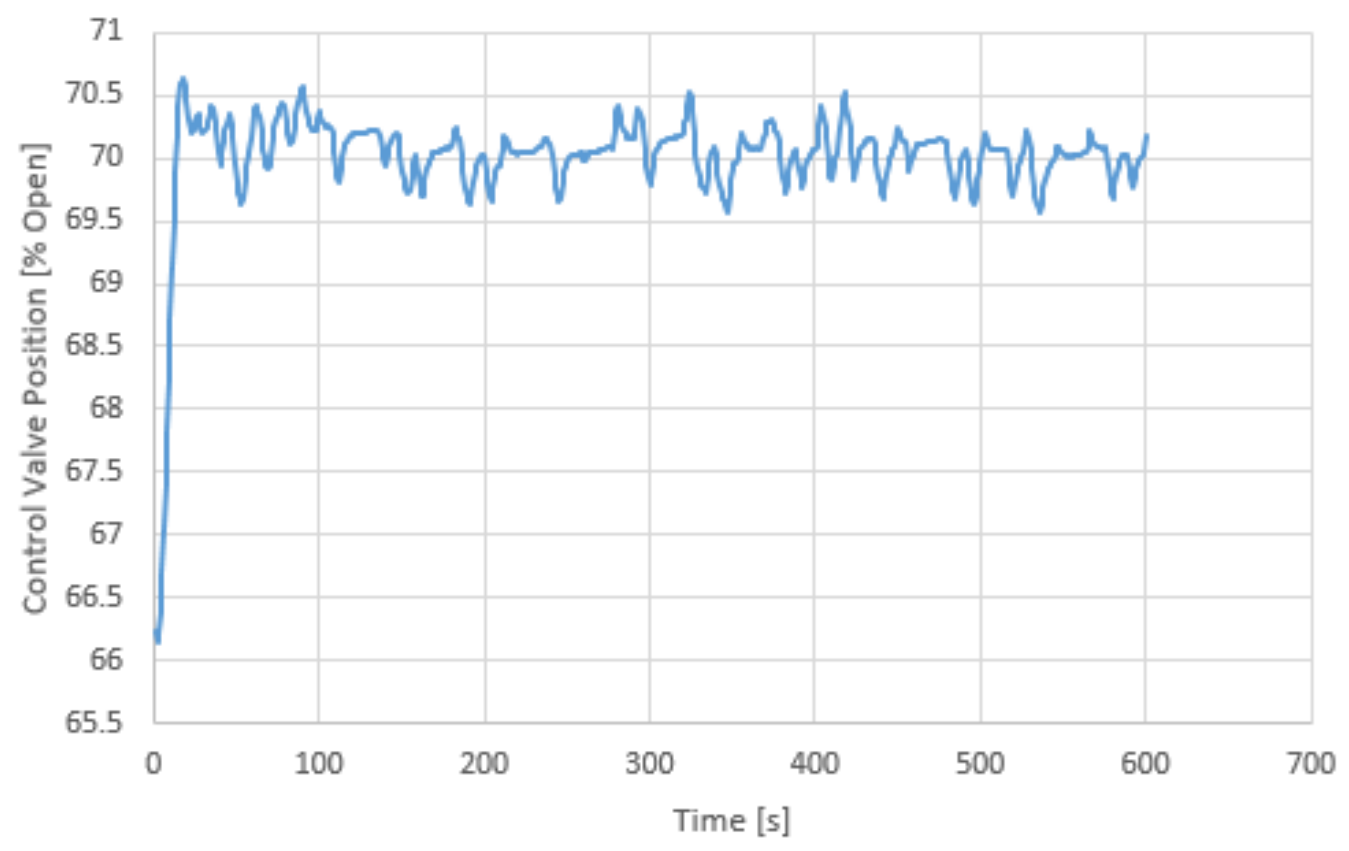

Figure 75 - Control valve percentage of open during Notch 8 for Test ID: R0007-002-264

It can be seen from the figures that there is a long rise time at the start of the notch of approximately 19 seconds. This is due to the valve adjusting for the new fuel flow, while also trying to maintain the 6.29 inch level set point. Figure 75 shows how the PI controller functions due to fuel flow which maintains fuel level fluctuation to \pm 0.025 inch.

Unlike in volumetric measurement, the Coriolis flow meter measures mass directly through the sine waves produced by the motion of fluid through the meter. Due to this, fuel temperature measurement for density correction is not an issue. However, temperature in the mass flow measurement system is still important for fluctuations in level height due to expansion effects. Minimizing the temperature effects in the fuel reservoir tank minimized the height fluctuations. Figure 76 shows how the fuel temperature fluctuated in the fuel reservoir and Figure 77 shows temperature of the fuel returning into the fuel reservoir after being conditioned by the fuel chiller and fuel heater during Notch 8 for Test ID: R0007-002-264. 


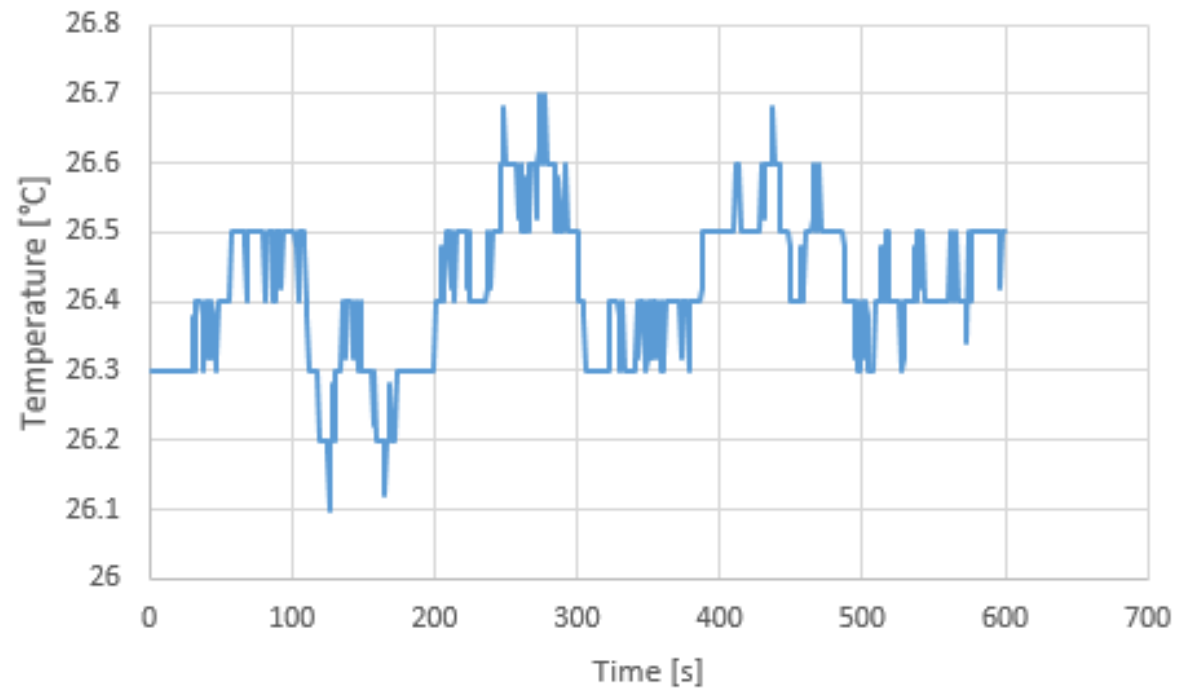

Figure 76 - Fuel reservoir temperature $\left[{ }^{\circ} \mathrm{C}\right]$ during Notch 8 for Test ID: R0007-002-264

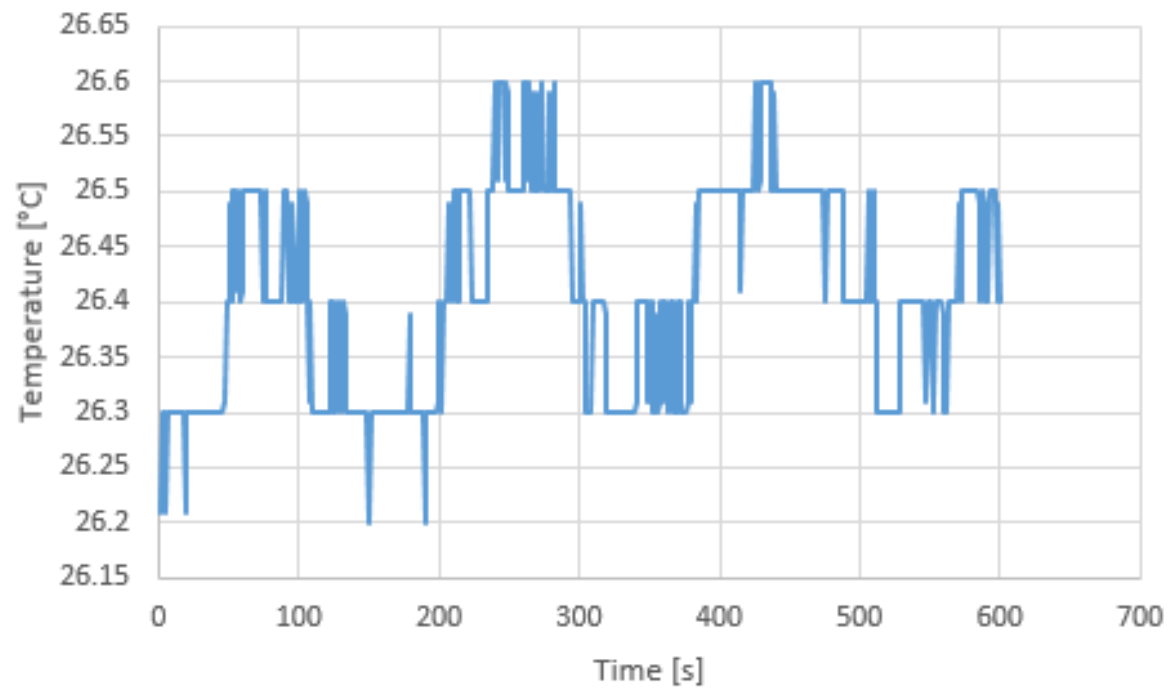

Figure 77 - Fuel return temperature $\left[{ }^{\circ} \mathrm{C}\right]$ during Notch 8 for Test ID: R0007-002-264

It can be seen from Figure 76 and Figure 77 that the fuel temperature fluctuated $\pm 0.3^{\circ} \mathrm{C}$ in the fuel reservoir and $\pm 0.2^{\circ} \mathrm{C}$ when conditioned and returned to the fuel reservoir. It is reasonable that these temperature fluctuations are sufficient in providing constant fuel temperatures for mass flow and level measurement as they are less than a $1^{\circ} \mathrm{C}$ temperature fluctuation. Since the fuel temperatures had $\pm 0.5^{\circ} \mathrm{C}$ fluctuations from their averages, the fuel level height would have small fluctuations due to density changes which would need to be calibrated out.

The carbon balance for this test can be found in Appendix A3.2 - Carbon Balance for Test R0007-002-264. Table 41 shows the emissions results from the MATLAB ${ }^{\circledR}$ carbon balance for Notch 8 of Test ID: R007-002-264. 
Table 41 - MATLAB $^{\circledR}$ emission results from Notch 8 of Test ID: R0007-002-264

\begin{tabular}{|c|c|c|c|c|}
\hline \multirow{2}{*}{ Emission } & \multicolumn{4}{|c|}{ MATLAB $^{\circledR}$} \\
\cline { 2 - 5 } & Mass & $\begin{array}{c}\text { Mass } \\
\text { per } \\
\text { interval }\end{array}$ & $\begin{array}{c}\text { Switcher } \\
\text { weighted }\end{array}$ & $\begin{array}{c}\text { Line- } \\
\text { Haul } \\
\text { weighted }\end{array}$ \\
\cline { 2 - 5 } & $\mathbf{g}$ & $\mathbf{g} / \mathbf{h r}$ & $\mathbf{g} / \mathbf{h r}$ & $\mathbf{g} / \mathbf{h r}$ \\
\hline CO2 & 367070 & 2202400 & 17619 & 356790 \\
\hline CO & 319.26 & 1915.5 & 15.32 & 310.32 \\
\hline NOx & 4187.2 & 25123 & 200.98 & 4070.0 \\
\hline THC & 62.94 & 377.63 & 3.02 & 61.18 \\
\hline
\end{tabular}

The Coriolis measured mass flow rate and the carbon balance constituents (xH2Oexhdry and xCcombdry) were used in Eq. 1065.655-25 to calculate the molar exhaust flow rate. From the MATLAB ${ }^{\circledR}$ code (Appendix A3.2 - Carbon Balance for Test R0007-002-264), xCcombdry was 0.0507 [mol/mol], and $\mathrm{xH} 2 \mathrm{Oexhdry}$ was 0.0737 . Figure 78 shows the calculated molar exhaust flow rate [mol/s].

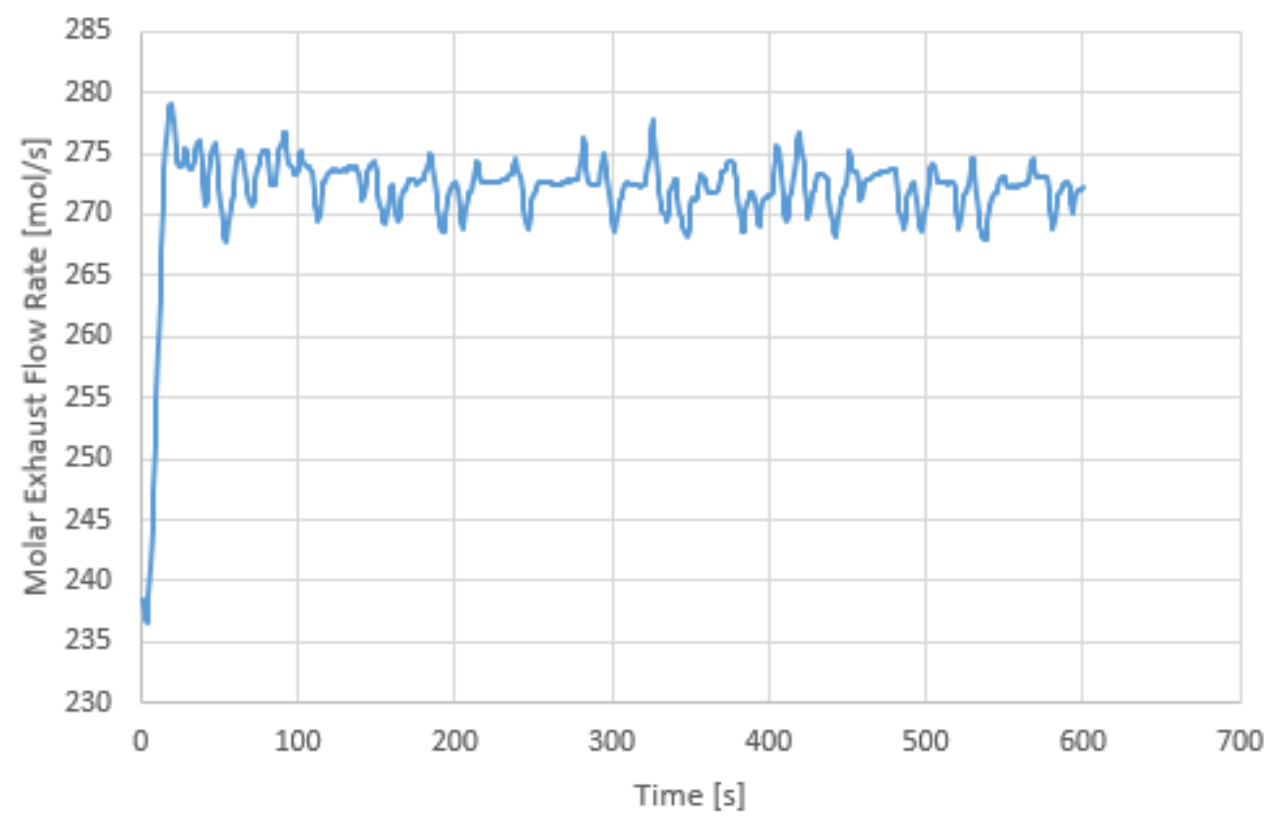

Figure 78 - Molar Exhaust Flow Rate [mol/s] calculated through mass fuel flow measured by Coriolis flow meter during Notch 8 for Test ID: R0007-002-264

The calculated molar exhaust flow rate was used for proportional verification per 40 CFR 1065.545 [12]. Table 42 shows a portion of data from Notch 8 for Test ID: R0007-002-264 that was used to calculate the SEE. 
Table 42 - Portion of data between 100 seconds to 110 seconds of Sample Flow Rate [mol/s] versus Calculated Exhaust Flow Rate [mol/s] during Notch 8 for Test ID: R0007-002-264

\begin{tabular}{|c|c|c|}
\hline Time & $\begin{array}{c}\text { Sample } \\
\text { Flow Rate }\end{array}$ & $\begin{array}{c}\text { Calculated } \\
\text { Exhaust } \\
\text { Flow Rate }\end{array}$ \\
\hline$[\mathbf{s}]$ & {$[\mathrm{mol} / \mathbf{s}]$} & {$[\mathbf{m o l} / \mathbf{s}]$} \\
\hline 100.0 & 275.08 & 179.57 \\
\hline 101.0 & 275.20 & 179.65 \\
\hline 102.0 & 274.57 & 179.24 \\
\hline 103.0 & 274.11 & 178.94 \\
\hline 104.0 & 274.00 & 178.87 \\
\hline 105.0 & 273.90 & 178.80 \\
\hline 106.0 & 273.88 & 178.79 \\
\hline 107.0 & 273.74 & 178.70 \\
\hline 108.0 & 273.48 & 178.53 \\
\hline 109.0 & 271.90 & 177.50 \\
\hline 110.0 & 270.76 & 176.75 \\
\hline
\end{tabular}

From the exhaust flow rates, and with $5 \%$ of data point outliers that were greater than or less than the average flow plus the standard deviation (average nexh $\pm \sigma$ ) omitted, the SEE of exhaust flow and sample flow rates was 1.4\% during Notch 8 for Test ID: R0007-002-264.

As previously deliberated, high fuel consumption rates (e.g. Notch 8) provided better data for fuel consumption analysis over low fuel consumption rates (e.g. Idle). For this system, overshoot in level set point can cause fuel flow rates that are not representative of the actual fuel consumption of the locomotive. This is because if overshoot occurs, the level can only return to the set point as fast as the locomotive is consuming fuel. This is not as pronounced in higher notches as it is in lower notches. Figure 79 shows the fuel level reading and Figure 80 shows the mass flow measurement during Idle for Test ID: R0007-002-264. 


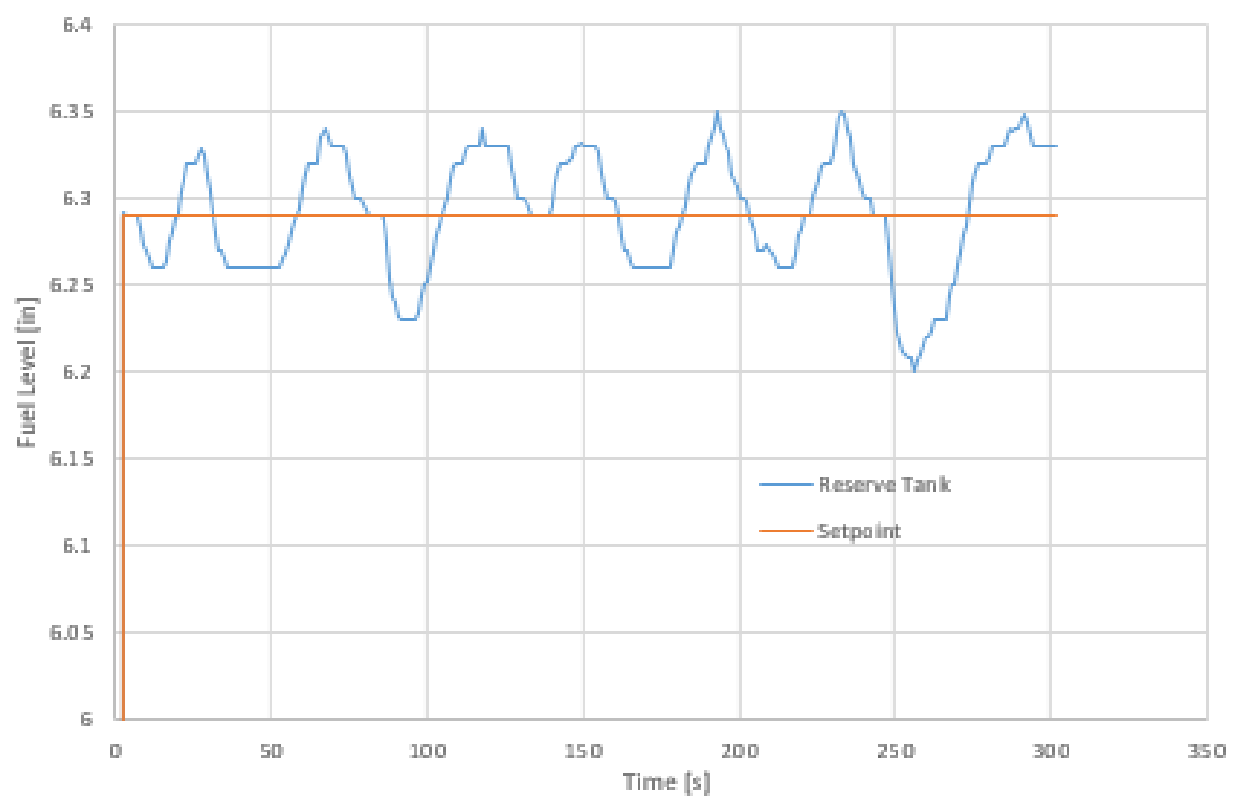

Figure 79 - Fuel level reading during Idle for Test ID: R0007-002-264

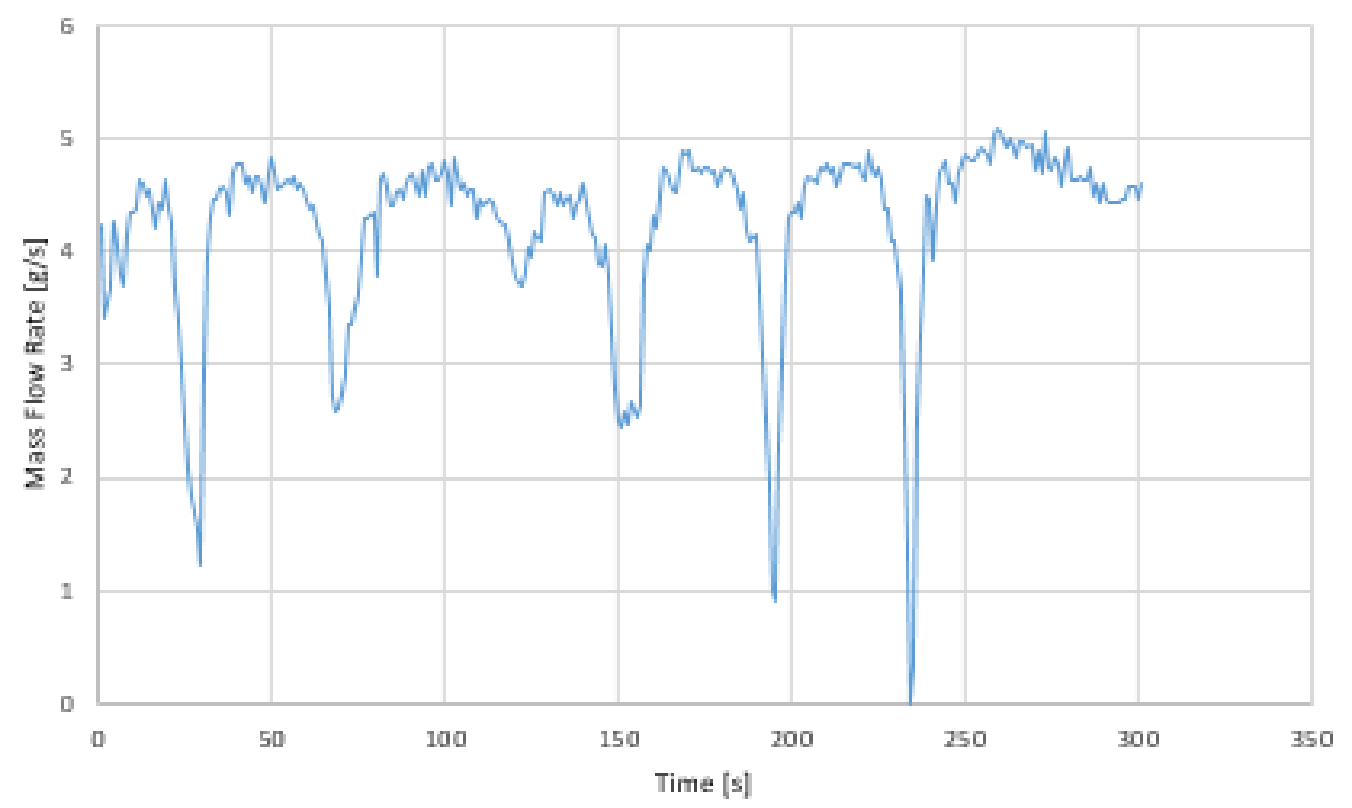

Figure 80 - Mass flow rate measurement during Idle for Test ID: R0007-002-264

By design of the mass flow measurement system, as fuel level drops from fuel consumption of the locomotive the control valve opens and fuel flows into the reservoir tank. As by nature of PID control, overshoot can occur depending on the PID terms. As seen in Notch 8 (Figure 74) and in Idle (Figure 79), there is overshoot of the set point level. As previously mentioned, at Notch 8, the overshoot was less of a concern in fuel flow measurement because the locomotive was consuming large amounts of fuel. However, due to low fuel consumption at Idle, overshoot started to pose problems in mass flow 
measurement. The problem became that fuel level could only drop in the amplifier tube due to fuel consumption. The expected level drop rate was determined by dividing the fuel consumption rate by the mass of fuel per inch (Eq. 3.7-1, Section 3.7.1 Level Sensor Calibration). At Notch 8, for a 4" amplifier tube, the expected level drop rate was approximately 1 inch per second and 0.025 inch per second at Idle. However, the Notch 8 level drop rate was approximately 0.0025 inch per second and the Idle level drop rate was approximately 0.001 inch per second.

While the fuel level was returning to the set point, the control valve was shutting and fuel flow rates slowed down. This can be seen in Figure 80, where the mass flow rates started approaching 0 which caused inaccurate representation of exhaust flow rates.

Calculations for Idle were performed using the Idle carbon balance code (Appendix A3.2 Carbon Balance for Test R0007-002-264) producing xCcombdry equal to 0.0070 [mol/mol] and xH2Oexhdry equal to 0.0273 [mol/mol]. Table 43 shows the emissions results and Figure 81 shows the calculated molar exhaust flow rate [mol/s] during Idle for Test ID: R0007-002-264.

Table 43 - MATLAB ${ }^{\circledR}$ emission results from Notch 1 of Test ID: R0007-002-264

\begin{tabular}{|c|c|c|c|c|}
\hline \multirow{2}{*}{ Emission } & \multicolumn{4}{|c|}{ MATLAB ${ }^{\circledR}$} \\
\cline { 2 - 5 } & Mass & $\begin{array}{c}\text { Mass } \\
\text { per } \\
\text { interval }\end{array}$ & $\begin{array}{c}\text { Switcher } \\
\text { weighted }\end{array}$ & $\begin{array}{c}\text { Line- } \\
\text { Haul } \\
\text { weighted }\end{array}$ \\
\cline { 2 - 5 } & $\mathbf{g}$ & $\mathbf{g} / \mathbf{h r}$ & $\mathbf{g} / \mathbf{h r}$ & $\mathbf{g} / \mathbf{h r}$ \\
\hline CO2 & 8621.9 & 103460 & 827.7 & 16761 \\
\hline CO & 14.21 & 170.55 & 1.36 & 27.63 \\
\hline NOx & 132.56 & 1590.8 & 12.73 & 257.7 \\
\hline THC & 8.26 & 99.17 & 0.79 & 16.07 \\
\hline
\end{tabular}




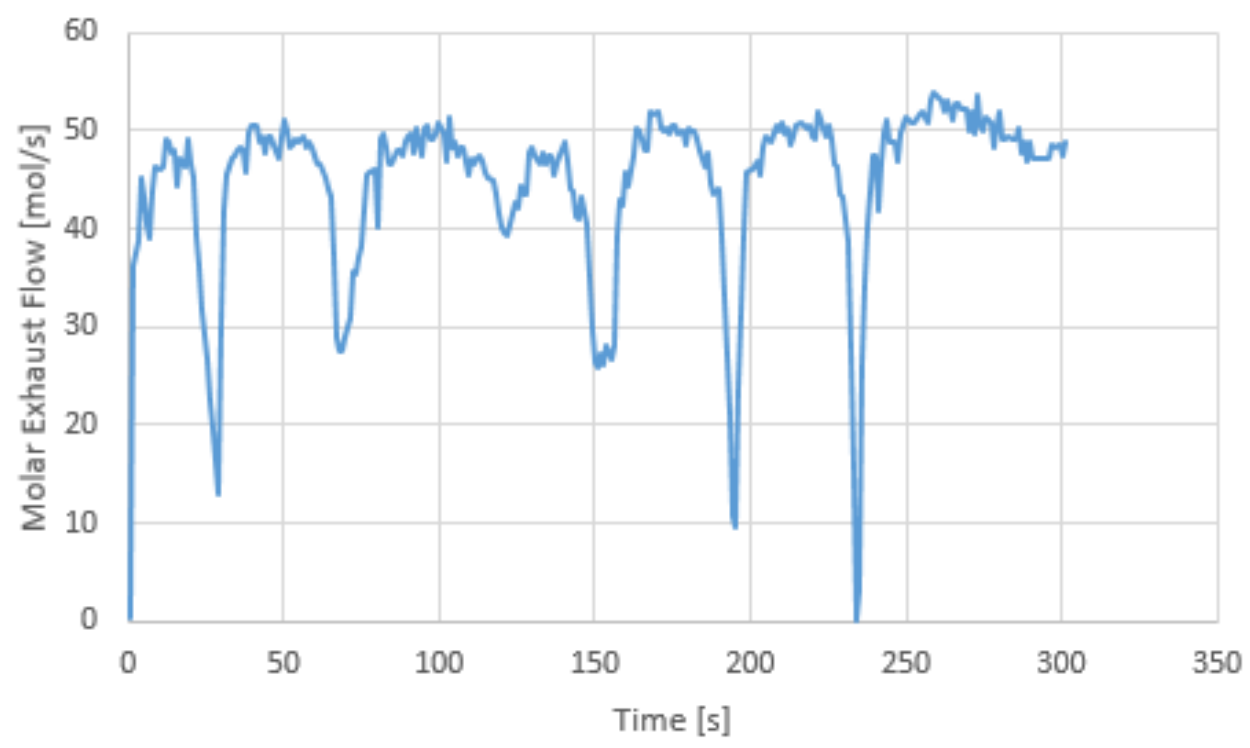

Figure 81 - Calculated molar exhaust flow rate [mol/s] during Idle for Test ID: R0007-002-264

As seen in Figure 81, there were large drops in exhaust flow rate, some even became 0, which was not representative of the true molar exhaust flow rate. Removing $5 \%$ of the largest outliers, the calculated SEE was 39.9\% for Idle during Test ID: R0007-002-264 which is significantly outside of the range of regulation 1065.545. Table 44 shows the SEE for all notches for Test ID: R0007-002-264 with and without $5 \%$ of data points removed.

Table 44 - SEE with and without $5 \%$ omission of data points for all notches for

Test ID: R0007-002-264

\begin{tabular}{|c|c|c|}
\hline Notch & $\begin{array}{c}\text { SEE \% } \\
\mathbf{5 \%} \\
\text { omission }\end{array}$ & SEE \% \\
\hline Idle & 39.9 & 39.9 \\
\hline Dyn Brake & 37.4 & 38.5 \\
\hline Notch 1 & 35.2 & 37.7 \\
\hline Notch 2 & 29.8 & 33.5 \\
\hline Notch 3 & 10.5 & 12.2 \\
\hline Notch 4 & 3.7 & 6.1 \\
\hline Notch 5 & 3.1 & 5.5 \\
\hline Notch 6 & 2.9 & 5.6 \\
\hline Notch 7 & 2.6 & 5.0 \\
\hline Notch 8 & 1.4 & 3.6 \\
\hline
\end{tabular}

It can be seen the SEE can be corrected to meet the 3.5\% SEE criteria in higher notches. This meant the PI controller was, albeit coincidental, tuned for higher level notches. While the SEE was met for Notch 8 for this locomotive, Idle was not when using a mean plus a single standard deviation outlier 
omission criteria. It was determined that other omission techniques could not meet the SEE either due to the large fluctuations in fuel flow due to poor PID control. Future tests will require better PID control in order to minimize overshoot of level set point such as through software controlled techniques.

\section{SUMMARY, CONCLUSIONS AND RECOMMENDATIONS}

There were two research goals of this project:

1. Verify that the emissions measurement system used at the Juniata emissions lab was compliant to 40 CFR Parts 1033 and 1065 specifically that verification of proportional sampling can be performed and met using gravimetric fuel measurement

2. Detail the design and implement an instantaneous fuel mass flow measurement system for use in verification of locomotive emissions.

Per goal (1), it was determined that, providing steady-state engine parameters were met such as no additional electrical loads applied to the engine (e.g. radiator fans cycling on) nor engine speed changes, the gravimetric system at the Juniata emissions lab was compliant to 40 CFR Parts 1033 and 1065. However steady-state engine parameters are not representative of most locomotives during every day operation, gravimetric fuel consumption measurement was not desirable for verification of locomotive exhaust flow rates.

Per goal (2), a new system that utilized mass flow measurement through Coriolis technology was designed and implemented at the Juniata lab. The mass flow measurement system used PID control with a flow control valve to maintain the level of fuel in a reservoir tank. Level drops in the tank opened the control valve which allowed fuel to flow into the tank. The fuel flowing into the tank was measured which provided direct fuel consumption of the locomotive. In this study, the PID controller was tuned for PI control using the same terms $(\mathrm{P}=\mathrm{I}=5)$.

It was observed that the PI controller was better suited for controlling higher locomotive power notches. The measured mass fuel flow and corresponding calculated exhaust flow used to determine the SEE met CFR proportional verification criteria in higher notches but not in lower notches. For this study, further PID tuning could not be performed as Norfolk Southern had emissions testing deadlines to meet which halted progress on further research and development.

\subsection{Future Work and Recommendations}

As the PID controller only used proportional and integral terms to control fuel level in the reservoir tank, overshoot and undershoot occurred in level set point which caused unrepresented exhaust flow rates. Due to this, the SEE was not able to be met even with extensive omission techniques. This was especially apparent in lower flows and it was concluded the controller was 
tuned better to meet the higher flow rates in fuel consumption. It is recommended the PID control utilize all three proportional-integral-derivative terms to minimize overshoot and undershoot.

Fuel consumption response can be recorded and analyzed before an emissions test in order determine suitable PID terms. Since a plant function is not known through this method, a PID controller can be designed using the MATLAB ${ }^{\circledR}$ pidTuner function to estimate PID terms based on notch requirements. With this method, input and output from system response can be used to determine a plant function for use in calculating PID controller terms. The input response would correspond to a notch switch from the operator. In this case, this represents a step input response from 0 to 1 . The output would be the fuel consumption system response. Figure 82 shows an example output and input system response in the $\mathrm{MATLAB}^{\circledR}$ pidTuner application.
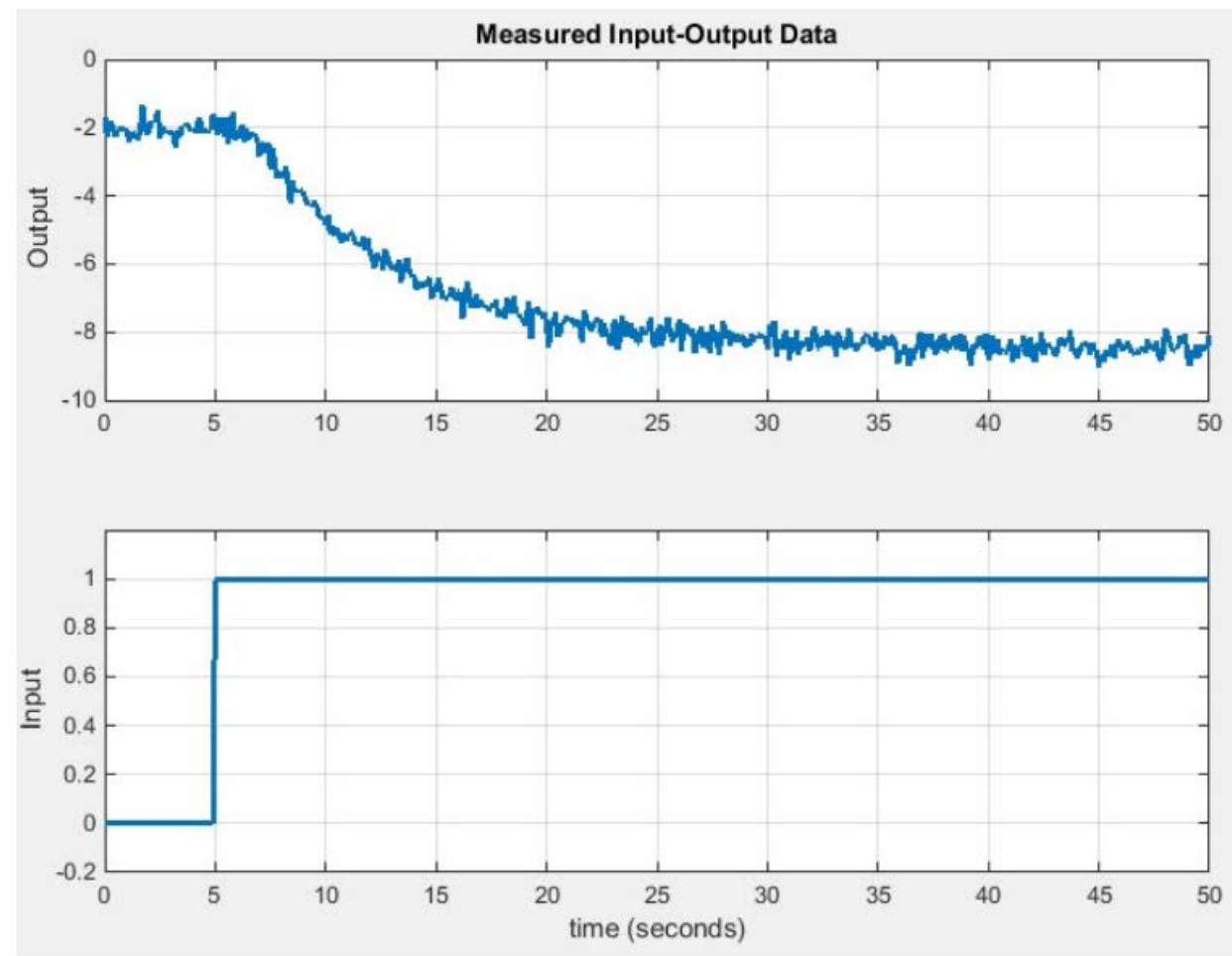

Figure 82 - Example output and input system response in the MATLAB ${ }^{\circledR}$ pidTuner application [83]

As an example, engine speed response at Notch 8 during Test ID: R0007-002-264 was used to determine a plant function and corresponding PID terms that could be used as initial terms in the PID controller. Once imported in the pidTuner, the data was manipulated to determine the plant function. Figure 83 shows the imported data into the pidTuner. 


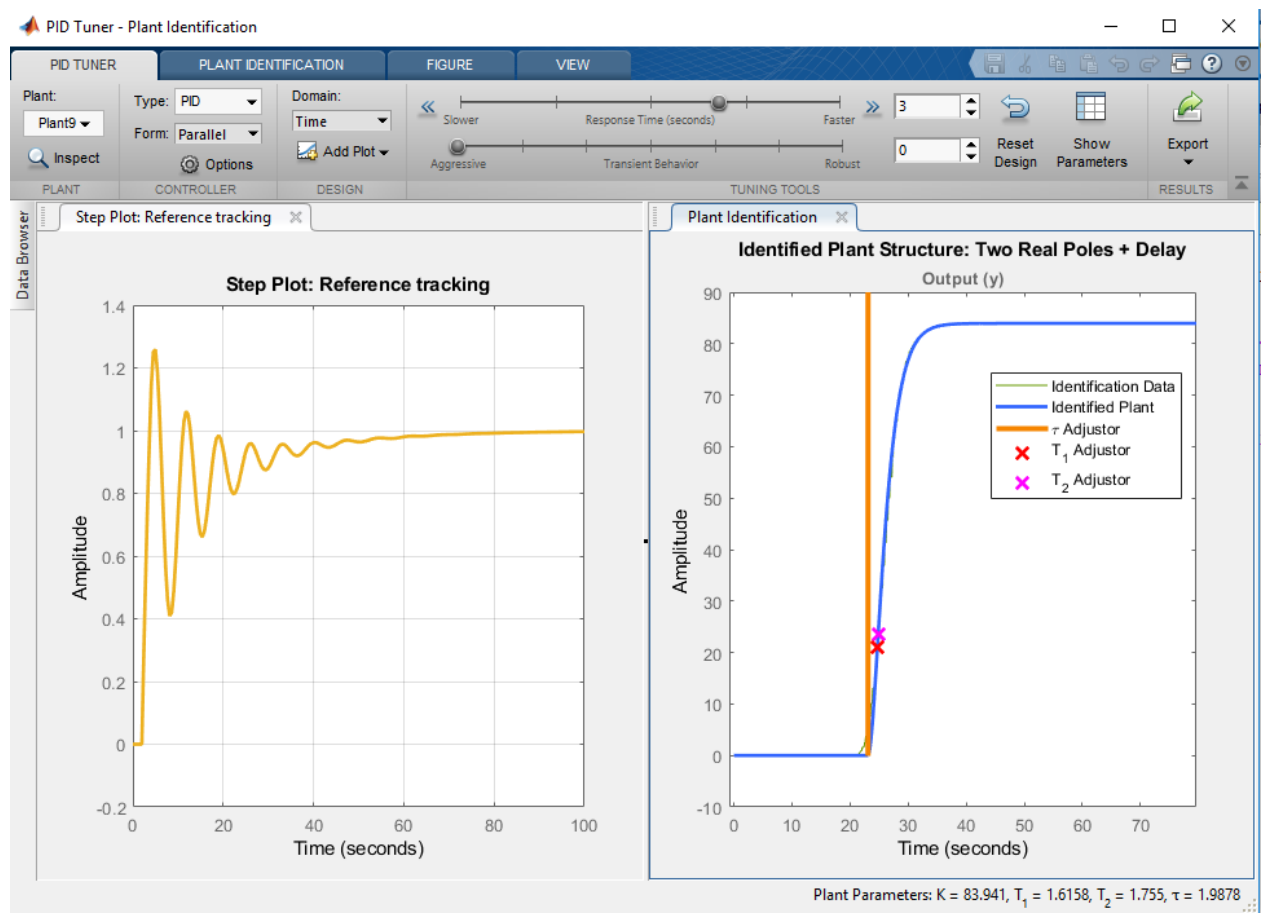

Figure 83 - Notch 8 engine speed transition from Test ID: R0007-002-264 in MATLAB ${ }^{\circledR}$ pidTuner application

To create a system plant function, the plant function data (Figure 83 left graph - Identified Plant) was manipulated to closely match the imported output (Figure 83 left graph - Identification Data). The output data in this case was able to be met with plant function data. System response was set at 3 seconds, because any response that was less cause system instability. The transient behavior was set to 0 which the pidTuner defined as aggressive. Exporting this data provided the following plant function:

$$
\begin{gathered}
\mathrm{C}=\mathrm{Kp}+\mathrm{Ki} * \frac{1}{\mathrm{~s}}+\mathrm{Kd} * \mathrm{~s} \\
\mathrm{Kp}=0.0232 \\
\mathrm{Ki}=0.00145 \\
\mathrm{Kd}=0.0239
\end{gathered}
$$

While this controller was an example, it may be used and tuned further to create better system response from the PID controller. Furthermore, the PID controller for this study used the same PI terms for all notches during the emissions test. Future testing should use different PID terms in order to meet the individual notch requirements. 


\section{BIBLIOGRAPHY}

[1] Title 40 - Chapter I - Subchapter U - Part 1033, E. P. Agency 1033, 2019. Available: https://www.ecfr.gov/cgi-bin/text-

$\underline{\text { idx?SID=29d8b9c8b5cb19d96e187804a2340fd8\&tpl=/ecfrbrowse/Title40/40cfr1033 main }}$ 02.tpl.

[2] Title 40 Chapter I Subchapter U Part 1065, E. P. Agency 1065, 2019. Available: https://www.ecfr.gov/cgi-bin/text-

$\underline{\mathrm{idx}}$ ?SID=17875739fd3d2cefe24dc18384b7e116\&mc=true\&node=pt40.37.1065\&rgn=div5.

[3] Overview, E. P. Agency 1065.501. Available: https://www.ecfr.gov/cgi-bin/text$\underline{\mathrm{idx}}$ ?SID=8dcd1fa62d04175fea8de9d20b38f749\&mc=true\&node=pt40.37.1065\&rgn=div5\#se 40.37.1065 1501.

[4] General provisions, E. P. Agency 1033.501, 2018. Available: https://www.ecfr.gov/cgi-bin/text$\underline{\mathrm{idx}}$ ?SID=692d8b2300dd280937d7f1e57d93eef $1 \& \mathrm{mc}=$ true \&node=se40.36.1033 1501\&rgn= $\underline{\operatorname{div} 8 .}$

[5] Engine-Testing Procedures, E. P. Agency 1065, 2018. Available: https://www.ecfr.gov/cgibin/text-idx?tpl=/ecfrbrowse/Title40/40cfr1065 main 02.tpl.

[6] Exhaust emissions standars, E. P. Agency 1033.101, 2018. Available: https://www.ecfr.gov/cgibin/text-

$\underline{\mathrm{idx}}$ ?SID=159ba6f126272ea1995c71a43b7af309\&mc=true\&node=pt40.36.1033\&rgn=div5\#s e40.36.1033 1101.

[7] H. Burtscher and W. A. Majewski. (2016). Exhaust Gas Sampling and Conditioning. Available: https://www.dieselnet.com/tech/measure sample.php

[8] G. Ninawe, "Review of Vehicle Emission Measurement and Sampling System," International Journal of Innovative Research in Science, Engineering and Technology, vol. 4, no. 8, 2015.

[9] CVS concept of exhaust gas sampling system, E. P. Agency 90.420, 2011. Available: https://www.govinfo.gov/content/pkg/CFR-2011-title40-vol20/pdf/CFR-2011-title40vol20-sec90-420.pdf.

[10] J. Zactruba. (2019). Isokinetic Sampling Method Using a Probe: Overview. Available: https://www.brighthubengineering.com/power-plants/98903-what-is-isokinetic-sampling/

[11] Subpart C - Measurement Instruments, E. P. Agency 1065, 2019. Available: https://www.ecfr.gov/cgi-bin/text-

$\underline{\mathrm{idx}}$ ?SID=8dcd1fa62d04175fea8de9d20b38f749\&mc=true \&node=pt40.37.1065\&rgn=div5\#sp 40.37.1065.c. 
[12] Verification of proportional flow control for batch sampling., E. P. Agency 1065.545, 2018. Available: $\quad$ https://www.ecfr.gov/cgi-bin/text$\underline{\mathrm{idx}}$ ?SID=f87cf229242b6a1c1f31bddd0fc8ea0f\&mc=true\&node=se40.37.1065 1545\&rgn=div $\underline{8}$.

[13] Emissions Calculations, E. P. Agency 650.1065, 2018. Available: https://www.ecfr.gov/cgi$\underline{\text { bin/text- }}$

$\underline{\mathrm{idx}}$ ?SID=8dcd1fa62d04175fea8de9d20b38f749\&mc=true\&node=pt40.37.1065\&rgn=div5\#se 40.37.1065 1650.

[14] Deterioration Factors, E. P. Agency 245, 2018. Available: https://www.ecfr.gov/cgi-bin/text$\underline{\mathrm{idx}}$ ?SID=419d5feaa489e546f6970112778dbf55\&mc=true \&node=pt40.36.1033\&rgn=div5\#s e40.36.1033 1245.

[15] (2017, December 10, 2017). Our Missions and What We Do. Available: https://www.epa.gov/aboutepa/our-mission-and-what-we-do

[16] N. C. f. E. Economics, Guidelines for Preparing Economic Analyses. 2014.

[17] A. o. A. Railroads, "Class I Railroad Statistics," May 1, 2017 2017, Available: https://www.aar.org/Documents/Railroad-Statistics.pdf, Accessed on: January 10, 2018.

[18] S. Lawrence, "Freight Railroad Backgrounds," April 24, 20152015.

[19] A. o. A. Railroads, "Railroads and Coal," Available: https://www.aar.org/wpcontent/uploads/2018/05/AAR-Railroads-Coal.pdf

[20] F. R. Administration. (2010, January 11, 2018). National Rail Plan Progress Report. Available: https://www.fra.dot.gov/eLib/Details/L02696

[21] "Locomotive Options," August 8, 20092009.

[22] K. Nice. (December 8, 2017). How Diesel Locomotives Work. Available: https://science.howstuffworks.com/transport/engines-equipment/diesel-locomotive10.htm

[23] S. Electrical. (2016). How Diesel Locomotives Work. Available: http://www.studyelectrical.com/2014/05/how-diesel-locomotives-work.html

[24] M.-C. R. Museum, "What makes a diesel locomotive work?," 2018.

[25] American-Rails.com. (January 14, 2018). Dynamic Braking. Available: https://www.americanrails.com/dynamic-braking.html

[26] R. S. McGonigal. (2006). Dynamic Braking. Available: http://trn.trains.com/railroads/abcs-ofrailroading/2006/05/dynamic-braking 
[27] (2017). Regulations for Emissions from Locomotives. Available: https://www.epa.gov/regulations-emissions-vehicles-and-engines/regulations-emissionslocomotives

[28] (2017, November 14, 2017). EPA's Report on the Environment (Roe) (2008 Final Report). Available: https://cfpub.epa.gov/ncea/risk/recordisplay.cfm?deid=190806

[29] M. S. Bergin, "Locomotive Emission Inventories for the United States from ERTAC Rail," Available: https://www3.epa.gov/ttnchie1/conference/ei20/session8/mbergin.pdf.

[30] P. Michelle Bergin, M. Harrel, and M. Janssen, "Locomotive Emission Inventories for the United States from ERTAC Rail," presented at the 2012 International Emissions Inventory Conference, Tampa, FL, $2012 . \quad$ Available: https://www3.epa.gov/ttnchie1/conference/ei20/session8/mbergin pres.pdf

[31] "Technical Highlights Emission Factors for Locomotives," Environmental Protection Agency2009, Available: https://nepis.epa.gov/Exe/ZyPDF.cgi/P100500B.PDF?Dockey=P100500B.PDF.

[32] U. S. N. A. a. R. Administration. (2018). About the Code of Federal Regulations. Available: https://www.archives.gov/federal-register/cfr/about.html

[33] U. S. G. P. Office. (2018). Code of Federal Regulations (CFR), 1996 to Present. Available: https://www.govinfo.gov/help/cfr

[34] Subpart F - Test Procedures, E. P. Agency 1033.Subpart F, 2018. Available: https://www.ecfr.gov/cgi-bin/text$\underline{\mathrm{idx}}$ ?SID=bc8a4d5e0e9202b6ae4a7eb809957e01\&mc=true\&node=sp40.36.1033.f\&rgn=div6.

[35] Part 1065 - Engine-Testing Procedures, E. P. Agency 1065, 2018. Available: https://www.ecfr.gov/cgi-bin/text$\underline{\mathrm{idx}}$ ?SID=bc8a4d5e0e9202b6ae4a7eb809957e01\&mc=true \&node=pt40.37.1065\&rgn=div5.

[36] Subpart H - Engine Fluids, Test Fuels, Analytical Gases and Other Calibration Standards, E. P. Agency, $\quad 2018 . \quad$ Available: https://www.ecfr.gov/cgi-bin/text-

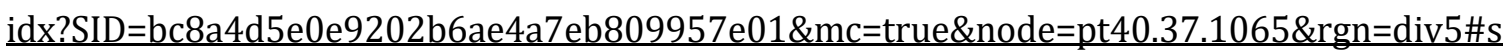
p40.37.1065.h.

[37] Discrete-mode steady-state emission tests of locomotives and locomotive engines, E. P. Agency 1033.515, 2018. Available: https://www.ecfr.gov/cgi-bin/text$\underline{\mathrm{idx}}$ ?SID=419d5feaa489e546f6970112778dbf55\&mc=true\&node=pt40.36.1033\&rgn=div5\#s e40.36.1033 1515. 
[38] Chemical balances of fuel, intake air, and exhaust., E. P. Agency 1065.655, 2019. Available: https://www.ecfr.gov/cgi-

bin/retrieveECFR?gp $=\& S I D=0$ be543e70fa055925c51393f9e1 eb898\&mc=true $\& n=p t 40.37 .10$ 65\&r=PART\&ty=HTML\#se40.37.1065 1655.

[39] S. R. Institute. (2018). History. Available: https://www.swri.org/who-we-are/history

[40] S. R. Institute. (2018). Who Are We. Available: https://www.swri.org/content/who-we-are

[41] (2016). SwRI 03.19533, Progress Rail PR30 Locomotive SJVR3003 3000-Hour Emissions Test Report.

[42] C. Yoder. (2017). Gravimetric Analysis. Available: http://www.wiredchemist.com/chemistry/instructional/laboratory-tutorials/gravimetricanalysis

[43] P. D. Shyamal Goswami. (2016, September 7, 2017). IC Engines \& Gas Turbine. Available: http://slideplayer.com/slide/10353056

[44] C. H. Joe Henggeler, Nicholas Kenny, Measuring Diesel Fuel Consumption to Estimate Engine Efficiency

[45] V. Ganesan, Internal Combustion Engines, 4th ed. New Delhi: Tata McGraw-Hill, 2013.

[46] (2017). Positive Displacement Flowmeter Technology. Available: http://www.flowmeters.com/positive-displacement-technology

[47] P. D. Jesse Yoder. (2011). Coriolis Effect Flow Meters... All You Need to Know. Available: https://www.flowcontrolnetwork.com/the-coriolis-effect

[48] (2017, August 10, 2017). Coriolis Mass Flowmeter Technology. Available: http://www.flowmeters.com/coriolis-mass-technology

[49] (2017, August 10, 2017). Coriolis Flow Meter. Available: http://www.keyence.com/ss/products/process/flowknowledge/types/coriolis.jsp

[50] Coriolis mass flow meter advantages and disadvantages. Available: http://www.metern.net/blog-metern-in-the-flow/coriolis-mass-flow-meter-advantages-anddisadvantages-8.html

[51] E. Guillot. (2014). Mass flow measurement and calibration procedures. Available: https://www.researchgate.net/figure/Advantages-and-disadvantages-of-Coriolisflowmeters-Advantages-Disadvantages tbl3 312293789

[52] L. Payne, "The Modern Industrial Workhorse: PID Controllers," Available: https://www.techbriefs.com/component/content/article/tb/features/articles/20013 
[53] T. Agarwal, "The Working Principle of a PID Controller for Beginners," Available: https://www.elprocus.com/the-working-of-a-pid-controller/

[54] I. The MathWorks. (2019). Rise time, settling time, and other step-response characteristics. Available: https://www.mathworks.com/help/control/ref/stepinfo.html

[55] "PID Controller," Available: http://engineering.ju.edu.jo/Laboratories/07PID\%20Controller.pdf

[56] N. Instruments, "PID Theory Explained," Available: http://www.ni.com/whitepaper/3782/en/

[57] J. Smuts. (2019). Quarter Amplitude Damping. Available: http://blog.opticontrols.com/archives/1066

[58] "PID Controller," Available: https://en.wikipedia.org/wiki/PID controller

[59] K. H. Ang, G. C. Y. Chong, and Y. Li, "PID control system analysis, design, and technology," IEEE TRANSACTIONS ON CONTROL SYSTEMS TECHNOLOGY, vol. 13, no. 4, p. 560, 2007.

[60] J. G. Ziegler and N. B. Nichols, "Optimum Settings for Automatic Controllers," 1942.

[61] I. Microstar Laboratories. (2019). Ziegler-Nichols Tuning. Available: http://www.mstarlabs.com/control/znrule.html

[62] J. Smuts, "Cohen-Coon Tuning Rules," ed, 2019.

[63] BIPM, International vocabulary of metrology - Basic and general concepts and associated terms (VIM), 3rD ed. 2008, p. 108.

[64] S. C. Inc. (January 16, 2018). NIST Traceable Calibration. Available: http://www.surecontrols.com/nist-traceable-calibration/

[65] NIST. (January 16, 2018). NIST Policy on Traceability. Available: https://www.nist.gov/nistpolicy-traceability

[66] 1033.505 Ambient Conditions, E. P. Agency 1033.505, 2018. Available: https://www.ecfr.gov/cgi-

bin/retrieveECFR?gp=\&SID=bc8a4d5e0e9202b6ae4a7eb809957e01\&mc=true\&n=pt40.36.1 033\&r=PART\&ty=HTML\#se40.36.1033 1505.

[67] R. Johnson. (2004). SD60. Available: http://sooline.org/Publications/Drawings/locomotive SD60.shtml

[68] Linearity Verification, E. P. Agency 1065.307, 2019. Available: https://www.ecfr.gov/cgibin/text-

$\underline{\mathrm{idx}}$ ?SID=1f7186adce591d4c0189717473d44c06\&mc=true\&node=se40.37.1065 1307\&rgn= $\underline{\operatorname{div} 8 .}$ 
[69] Summary of Required Calibration and Verifications, E. P. Agency 1065.303, 2019. Available: https://www.ecfr.gov/cgi-

bin/retrieveECFR?gp=\&SID=1f7186adce591d4c0189717473d44c06\&mc=true \&n=pt40.37.1 065\&r=PART\&ty=HTML\#se40.37.1065 1303.

[70] Statistics, E. P. Agency 1065.602, 2019. Available: https://www.ecfr.gov/cgi-

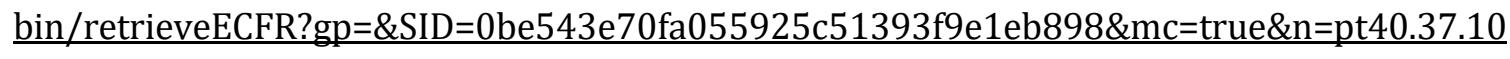
65\&r=PART\&ty=HTML\#se40.37.1065 1602.

[71] Dilution for gaseous and PM constituents, E. P. Agency 1065.140, 2019. Available: https://www.ecfr.gov/cgi-bin/text-

$\underline{\mathrm{idx}}$ ?SID=b5fe0a85a7ca37c15e31bbf847e613a6\&mc=true \&node=pt40.37.1065\&rgn=div5\#se $\underline{40.37 .1065 \quad 1140 .}$.

[72] Subpart G - Calculations and Data Requirements, E. P. Agency 1065, 2019. Available: https://www.ecfr.gov/cgi-

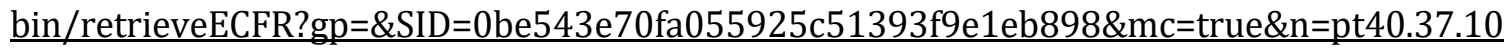
65\&r=PART\&ty=HTML\#sp40.37.1065.g.

[73] Duty cycles and calculations, E. P. Agency 1033.530, 2019. Available: https://www.ecfr.gov/cgi$\underline{\mathrm{bin} / \text { text- }}$

$\underline{\mathrm{idx}}$ ?SID=d9872224eb1447eb44e0ce900934d407\&mc=true\&node=se40.36.1033 1530\&rgn= $\underline{\operatorname{div} 8 .}$

[74] PM-stabilization and weighing environments for gravimetric analysis, E. P. Agency 1065.190, 2019. Available: https://www.ecfr.gov/cgi-bin/text$\underline{\mathrm{idx}}$ ?SID=89687c40a2122de9538bf52c71451bdf\&mc=true\&node=pt40.37.1065\&rgn=div5\#s $\underline{\mathrm{e} 40.37 .10651190 .}$.

[75] PM balance verifications and weighing process verification, E. P. Agency 1065.390, 2019. Available: $\quad$ https://www.ecfr.gov/cgi-bin/text-

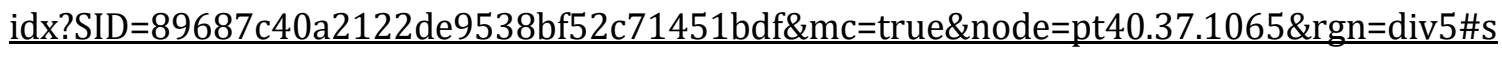
e40.37.1065 1390.

[76] Overview of preocedures for laboratory and field testing, E. P. Agency 1065.15, 2019.

[77] I. KRAL - USA. (2018). Fuel Consumption Measurement for Diesel Engines. Available: https://www.kral-usa.com/flow-measurement/fuel-consumption-measurement/

[78] (2018). Robust and precise. KRAL Volumeter for Flow Measurement. Available: https://www.kral-usa.com/flow-measurement/ 
[79] Performance specifications for measurement instruments, E. P. Agency 1065.205, 2018. Available: $\quad$ https://www.ecfr.gov/cgi-bin/text-

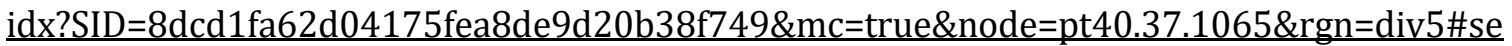
40.37.1065 1205.

[80] G. o. Canada. (2018). Volume correction factors-diesel, bio-diesel and diesel blends. Available: https://www.ic.gc.ca/eic/site/mc-mc.nsf/eng/lm00127.html

[81] J. E. Ricker and J. H. Hendricks. (2017). Unit Conversions. Available: https://www.nist.gov/pml/div685/grp01/unit conversions

[82] drive.web. (2018). Getting Started. Available: https://driveweb.com/support/manuals/driveweb/en start savvy.html

[83] A. Turevskiy, "Tuning a PID Controller When a Plant Model Is Not Available," Technical Articles and Newsletters, Available: https://www.mathworks.com/company/newsletters/articles/tuning-a-pid-controller-whena-plant-model-is-not-available.html 


\section{LIST OF APPENDICES}

APPENDIX A - MATLAB® CODES

Appendix A1 - Chiller Calculations

Appendix A2 - Fuel Drum Sizing Calculations

Appendix A3 - Carbon Balancer for Test R0007-002-198

Appendix A3.1 - Carbon Balance for Test R0007-002-198

Appendix A3.2 - Carbon Balance for Test R0007-002-264

APPENDIX B - CERTIFICATION CALIBRATION DATA SHEETS

Appendix B1 - Micro Motion, Inc. Coriolis Mass Flow Meter Calibration Certificate Sheets Appendix B1.1 - Calibration Sheet for Test 12154968

Appendix B1.2 - Calibration Sheet for Test 12154969

Appendix B2 - Troemner, LLC Traceable Certificate for Calibration Weights

APPENDIX C - ADDITIONAL FIGURES AND TABLES

Appendix C1 - Projected Future Emission Factors Complete Tables

Appendix C2 - Preliminary Test Data for Test ID: R0007-002-198

Appendix C3 - Omega ${ }^{\mathrm{TM}}$ Engineering FMC-5000 Coriolis Mass Flow Meter Specifications

Appendix C4 - Siemens FCS400 DN 15 sensor flow meter calculations

Appendix C5 - Micro Motion CMFS040M calculation summary

Appendix C6 - Emerson MR98H Series Operational Schematics

Appendix C7 - Test ID: R0007-002-198 Emissions Analyzer Data

Appendix C7.1 - Test ID: R0007-002-198 Notch 8 Emissions Analyzer Data

Appendix C7.2 - Test ID: R0007-002-198 Idle Emissions Analyzer Data

Appendix C8 - Test ID: R0007-002-198 Idle Carbon Balance Results

Appendix C9 - Mass Flow Rate Measurements during Test ID: R0007-002-264 


\section{APPENDIX A - MATLAB® CODES}

\section{Appendix A1 - Chiller Calculations}

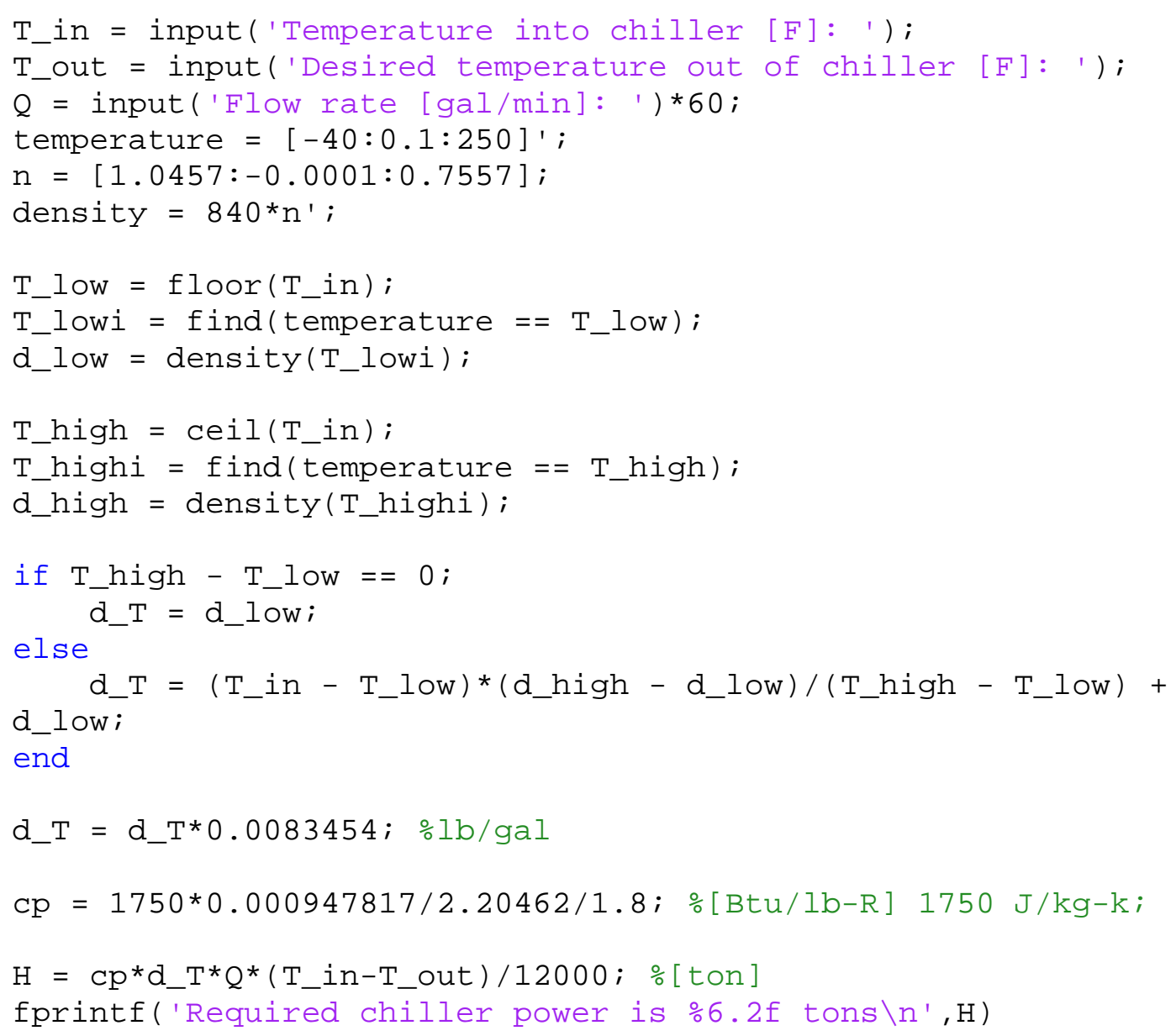

\section{Appendix A2 - Fuel Drum Sizing Calculations}

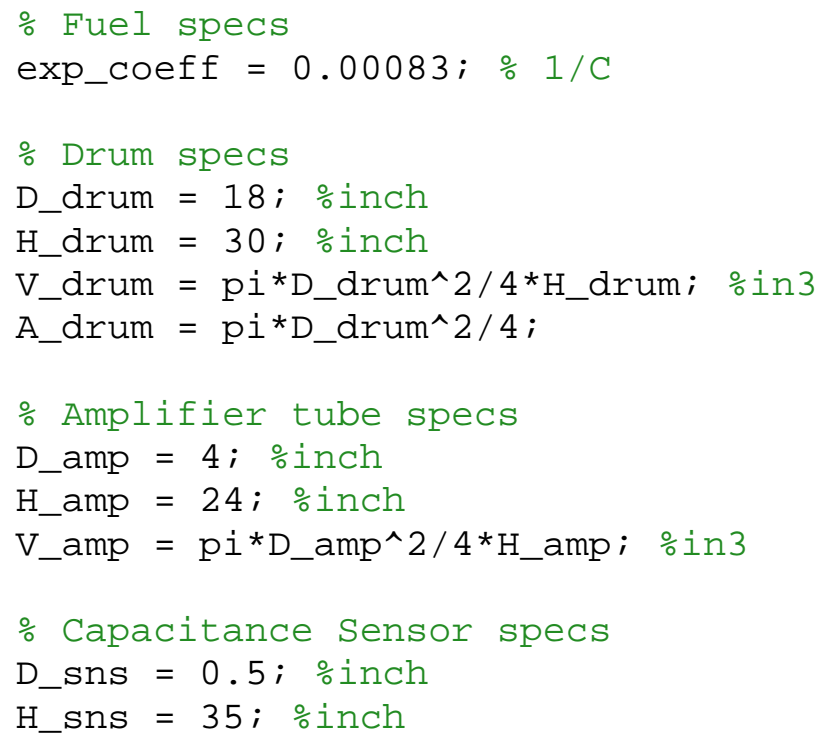




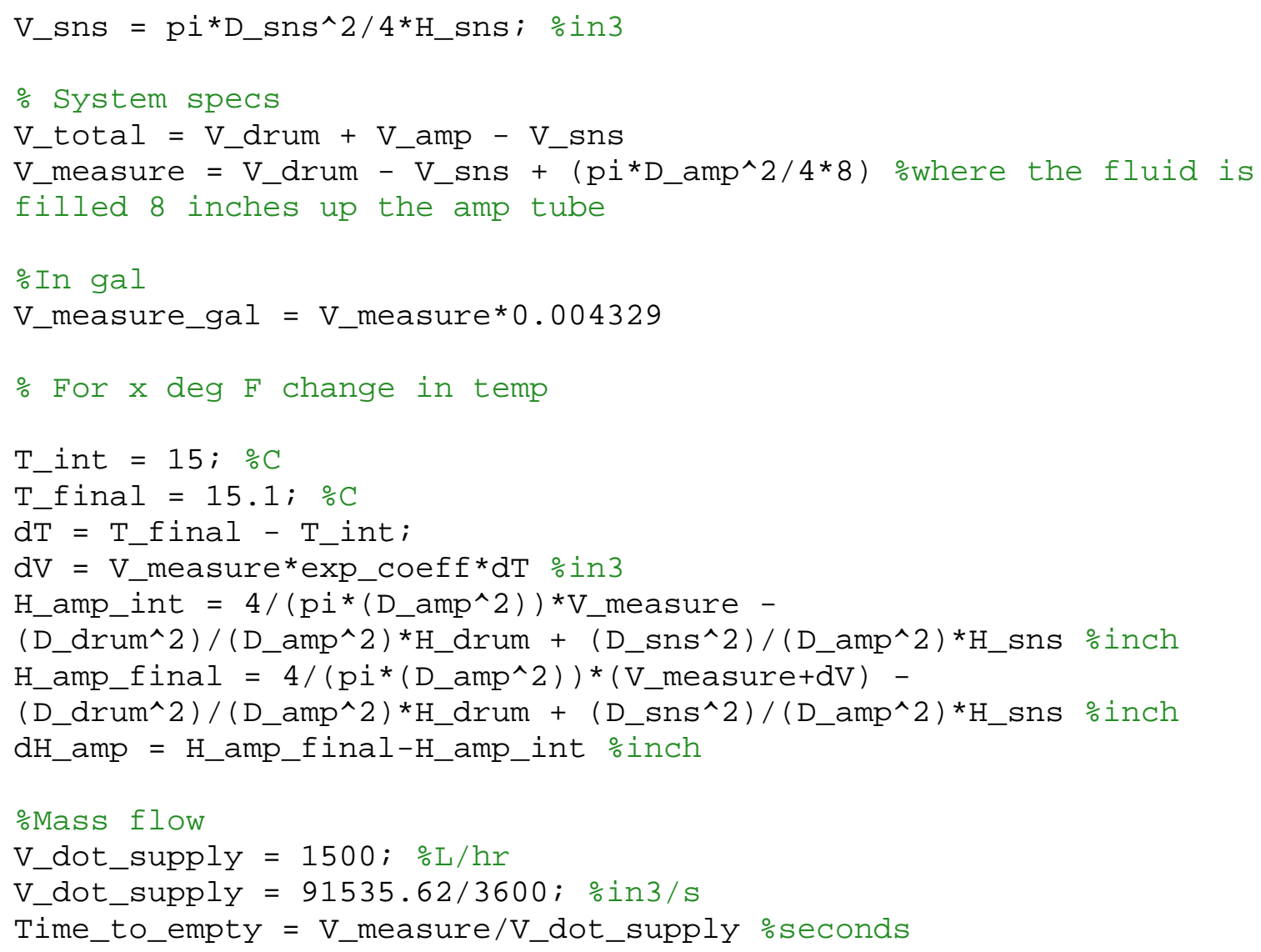

\section{Appendix A3 - Carbon Balancers}

\section{Appendix A3.1 - Carbon Balance for Test R0007-002-198}

\%\% Test R०००7-002-198 Notch 8

clc

clear all

close all

\% Iteration values for Diesel \#2 from Table 1 1065.655

alpha $=1.8$;

beta $=0$;

gamma $=0$;

del = 0 ;

Mc $=12.0107 ; \%[\mathrm{~g} / \mathrm{mol}]$ Molar Mass of Carbon

KH20gas $=3.5 ; \% 1065.655$ paragraph (c) section (3)

\% Carbon mass fraction Diesel \#2

WC $=$

Mc/ (Mc+alpha*1.00794+beta*15.9994+gamma*32.065+del*14.0067);\%[g/g] eq . $1065.655-19$

\% Humidity Calculation

Tdew_amb $=14.747 ; \%[\operatorname{deg} \mathrm{c}]$ *average

Tdew_chiller $=5.661 ; \%[$ deg $\mathrm{C}]$ *average 


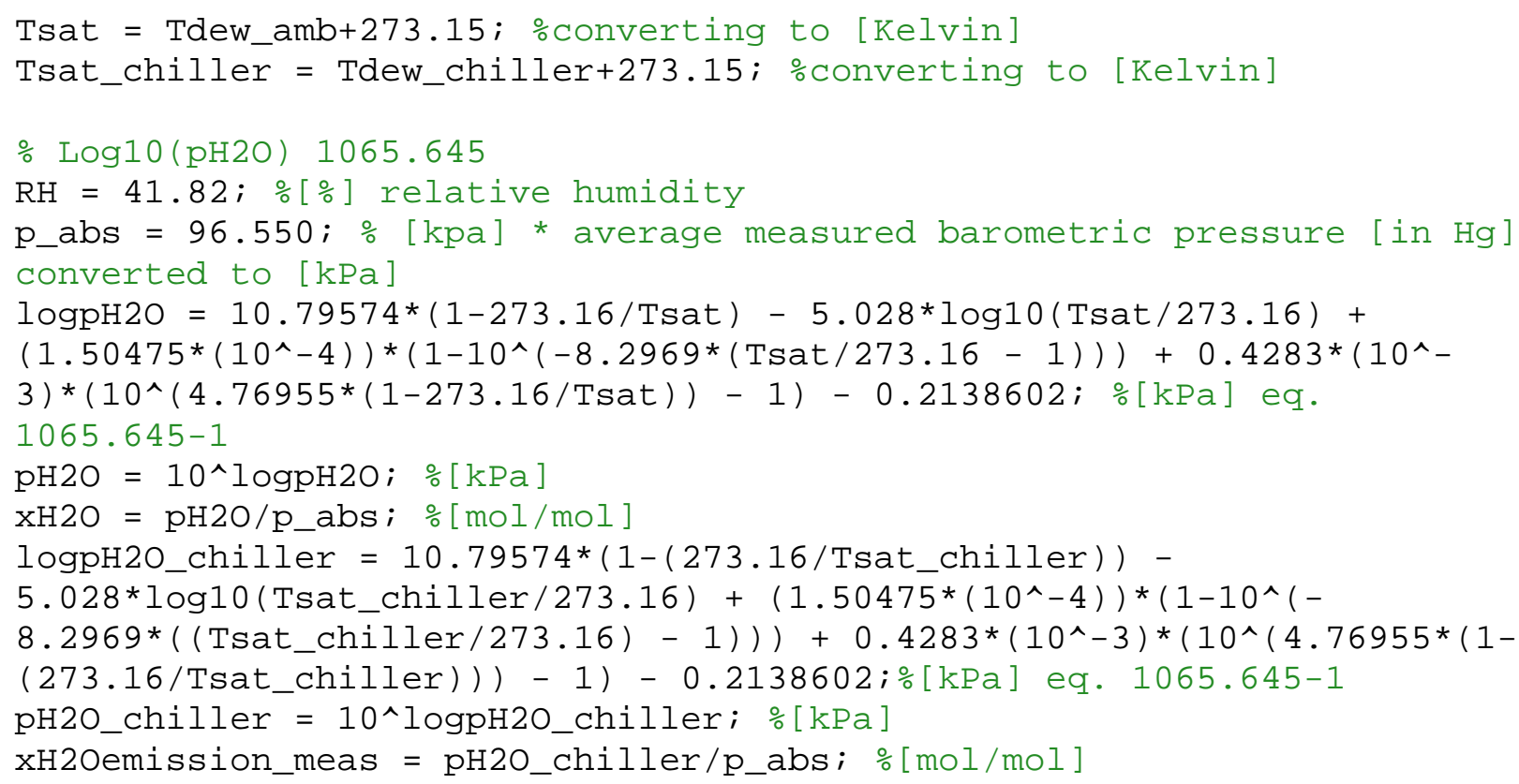

xH2Odil $=$ xH20; $\quad \% \log p($ H2O $) @ d i l$ air dewpoint xH2Oint $=$ xH2Odil; \% log p(H2O) @dil air dewpoint xH20int_dry $=$ xH20int/(1-xH20int);\%eq.1065.655-11 xH20dil_dry $=x H 20 d i l /(1-x H 20 d i l) ; \% e q .1065 .655-13$ xC02dil $=$ xC02dil_dry $/\left(1+x H 20 d i l \_d r y\right) ; \% e q \cdot 1065.655-12$ xC02int $=x$ C02int_dry $/(1+x H 20$ int_dry $) ; \%$ eq $\cdot 1065.655-10$ x02int $=(0.209820-x$ C02int_dry $) /(1+x H 20$ int_dry $) ; \%$ eq. $1065.655-9$ xdilexh $=0.8 ; \%$ initial guess from engineering judgement $\mathrm{xH} 20 \mathrm{exh}=2^{*} \mathrm{xH20int; \% eq} \mathrm{1065.655-2}$ 


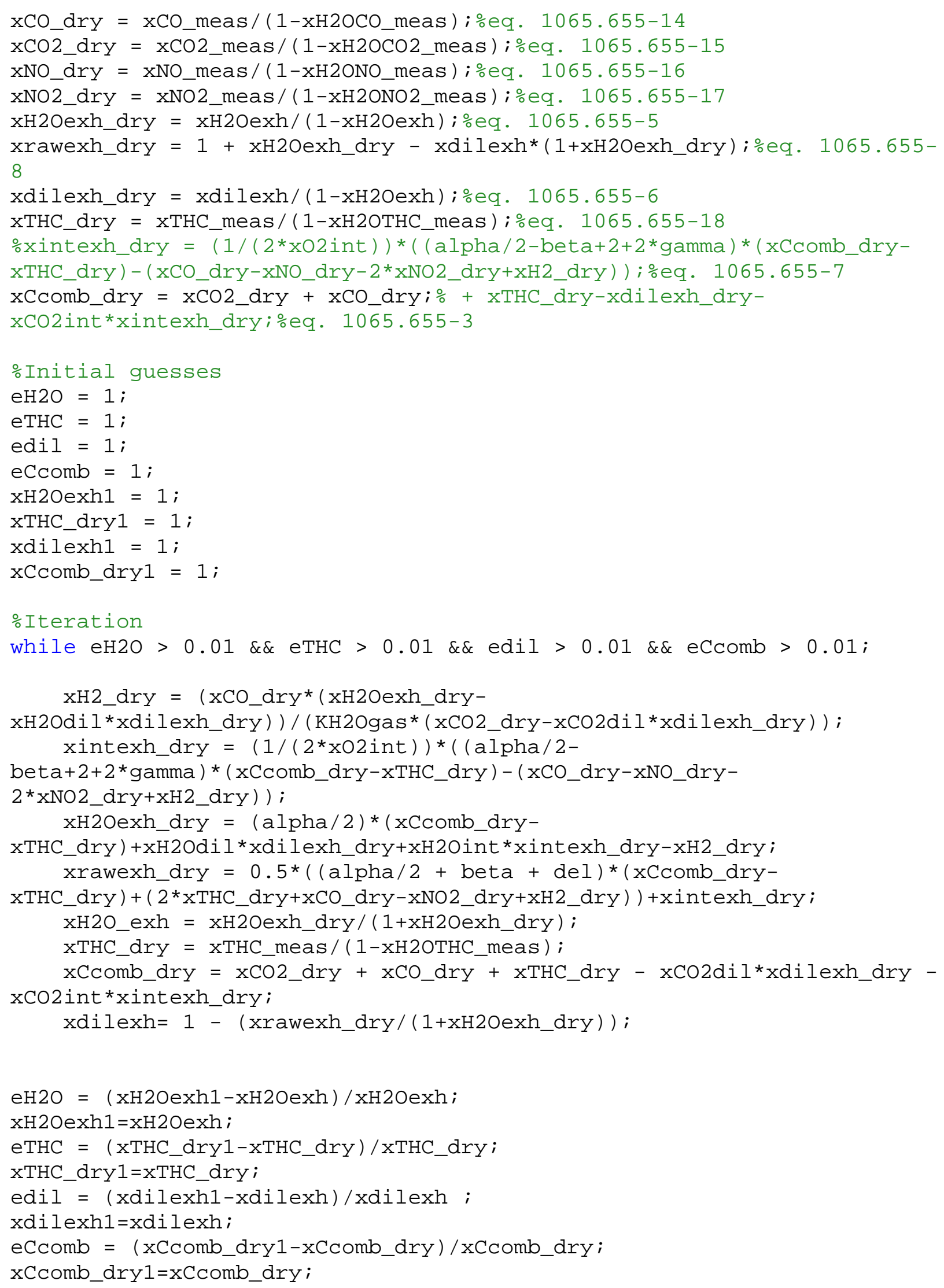


end

xH20exh1 \%[mol/mol]

xH20exh_dry \%[mol/mol]

xdilexh \%[mol/mol]

xCcomb_dry \%[mol/mol]

$x$ CO_dry $=x C 0 \_d r y * 1000000 \%[\mathrm{ppm}]$

xNOx_dry $=\left(x \mathrm{NO} 2 \_d r y+x N 0 \_d r y\right) * 1000000 ; \%[p p m]$

$x$ C02_dry $=x$ C02_dry* $100 \%[\mathrm{ppm}]$

$x T H C \_d r y=x T H C \_d r y * 1000000 \%[p p m]$

\%1065.670 N0x intake-air humidity and temperature corrections

xNOxuncor $=$ xNO_meas + xNO2_meas;

$x$ NOxcor $=$ xNOxuncor ${ }^{*}\left(9.953^{*} \times \mathrm{H} 20+0.832\right) * 1000000 \%[\mathrm{ppm}] \mathrm{eq} \cdot 1065.670-1$

$\mathrm{Kh}=\left(9.953^{*} \times \mathrm{H} 20+0.832\right) \% \mathrm{NO} \times$ correction factor eq. 1065.670-1

\%Measured and Compared Dilution Flow Rates

ndot_dexh $=29.993 * 1000 * 7.4 \mathrm{e}-07 * 10000 \%[\mathrm{~mol} / \mathrm{s}]$ *average converted

where $1[\mathrm{sccm}]=7.45 \mathrm{e}-07[\mathrm{mols} / \mathrm{s}]$

ndot_exh_mass $=191.483^{*} \mathrm{wc}^{*}\left(1+x \mathrm{H} 20 \mathrm{exh}\right.$ (dry) $/\left(\mathrm{Mc}{ }^{*} \mathrm{xCcomb} \_\mathrm{dry}\right) \%[\mathrm{~mol} / \mathrm{s}]$

ndot_exh_mass $2=190.5 *$ wc* $(1+x H 20 e x h) /\left(M c * x C c o m b \_d r y\right) \%[\mathrm{~mol} / \mathrm{s}]$

\%KRAL volumeters

mdot_avg $=190.6 ; \% *$ average mass flow rate $190.549[\mathrm{~g} / \mathrm{s}]$

ndot_exh_mdot $=$ mdot_avg*Wc* $\left(1+x H 20 e x h \_d r y\right) /\left(M c^{*} x C\right.$ comb_dry $) \%[m o l s / s]$

eq. $1065.655-25$

ndot_int $=$ ndot_exh_mdot* $(1+((x$ intexh_dry -

xrawexh_dry)/(1+xH20exh_dry )) )

\%Mass of Emissions

NOX $=x$ NOxCor ${ }^{*} 10^{\wedge}-6 * 44.013^{*}$ ndot_dexh*600

CO $=x C 0 \_d r y * 10 \wedge-6 * 28.01 *$ ndot_dexh*600

$\mathrm{HC}=\mathrm{xTHC} \_\mathrm{dry}{ }^{*} 10 \wedge-6 * 13.02 *$ ndot_dexh*600

$\mathrm{CO} 2=x \mathrm{C0} 2 \_\mathrm{dry}{ }^{*} 10^{\wedge}-2 * 44.01^{*}$ ndot_dexh*600

\%Mass of Emissions per Interval

$\mathrm{NO} \times \mathrm{p}=\mathrm{NOx} * 3600 / 600$

$\mathrm{cop}=\mathrm{co} * 3600 / 600$

$\mathrm{HCp}=\mathrm{HC} * 3600 / 600$

$\mathrm{CO} 2 \mathrm{p}=\mathrm{CO} 2 * 3600 / 600$

\%Switcher Emissions

NOXS $=$ NOxp*०.008

$\operatorname{COS}=\operatorname{COp}{ }^{*} \odot .008$

$\mathrm{HCS}=\mathrm{HCp}{ }^{\star} \odot .0 \odot 8$

$\mathrm{CO2S}=\mathrm{C02} \mathrm{p}{ }^{*} \odot .008$

NOXSBSFC $=$ NOXS $/ 4441 / 0.008$

$\operatorname{COSBSFC}=\operatorname{COS} / 4441 / 0.008$ 


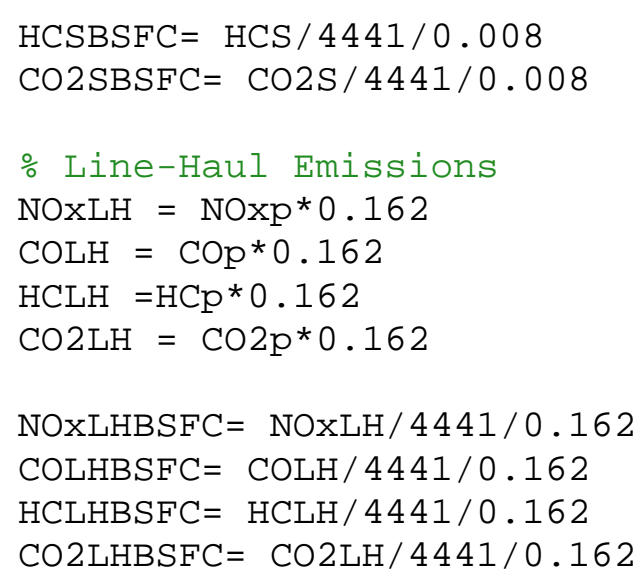


$8.2969 *\left(\left(\right.\right.$ Tsat_chiller/273.16) - 1) ) $+0.4283^{*}(10 \wedge-3) *\left(10 \wedge\left(4.76955^{*}(1-\right.\right.$ $(273.16 /$ Tsat_chiller )) -1$)-0.2138602 ; \%[\mathrm{kPa}]$ eq. 1065.645-1

pH20_chiller $=10^{\wedge} \operatorname{logpH} 20 \_c h i l l e r ; \%[\mathrm{kPa}]$

xH20emission_meas $=$ pH20_chiller $/ \mathrm{p} \_a b s ; \%[\mathrm{~mol} / \mathrm{mol}]$

\% From emissions analyzers

xC02dil_dry = 375/1000000; \%background bag conc. may use 375 $[\mathrm{mmol} / \mathrm{mol}]$

xC02int_dry $=375 / 1000000 ;$ \%background bag conc. may use 375 $[\mu \mathrm{mol} / \mathrm{mol}]$

xCo_meas $=12.587 / 1000000 ; \%[\mathrm{ppm}]$ *average

$\mathrm{xC0} 2$ meas $=7427.222 / 1000000 ; \%[\mathrm{ppm}]$ *average

xNOx_meas $=147.90 / 1000000 ; \%[\mathrm{ppm}]$ *average

xNO_meas $=0.887 / 1000000 ; \%[\mathrm{ppm}]$ *average

$\mathrm{xNO} 2$ meas $=\mathrm{xNO}$ __meas $-\mathrm{xNO} \_$meas $; \%[\mathrm{ppm}]$ *average

xTHC_meas $=26.782 / 1000000 ; \%[\mathrm{ppm}]$ *average

xH20C0_meas $=$ xH20emission_meas;

xH20C02_meas $=$ xH20emission_meas;

xH2ONO_meas $=$ xH2Oemission_meas;

xH2ONO2_meas $=$ xH20emission_meas;

xH20THC_meas $=$ xH20emission_meas;

xH2Odil $=$ xH20; $\% \log p($ H2O $) @ d i l$ air dewpoint

xH20int $=$ xH2Odil; \% log p(H20) @dil air dewpoint

xH20int_dry $=$ xH20int $/(1-x H 20$ int $) ; \%$ eq. 1065.655-11

xH20dil_dry $=x H 20 d i l /(1-x H 20 d i l) ; \% e q \cdot 1065.655-13$

$\mathrm{xC02dil}=\mathrm{xC02dil}$ dry $/\left(1+x H 20 d i 1 \_d r y\right) ; \% e q \cdot 1065.655-12$

xC02int $=$ xC02int_dry $/(1+x H 20$ int_dry $) ; \%$ eq $\cdot 1065.655-10$

x02int $=(0.209820-x$ C02int_dry $) /(1+x H 20$ int_dry $) ; \%$ eq. $1065.655-9$

xdilexh $=0.8 ; \%$ initial guess from engineering judgement

xH20exh $=2{ }^{*}$ xH20int; $\%$ eq 1065.655-2

xC0_dry $=$ xC0_meas $/(1-x H 20$ Co_meas $) ; \%$ eq $\cdot 1065.655-14$

$\mathrm{xC0} 2 \_\mathrm{dry}=\mathrm{xC0} 2 \_\mathrm{meas} /\left(1-\mathrm{xH} 20 \mathrm{C} 02 \_\right.$meas $) ; \% \mathrm{eq} \cdot 1065.655-15$

xNO_dry $=$ xNO_meas $/\left(1-x H 20 N O \_m e a s\right) ; \% e q \cdot 1065.655-16$

xNO2_dry $=x N 02 \_m e a s /\left(1-x H 20 N 02 \_m e a s\right) ; \%$ eq. 1065.655-17

xH20exh_dry $=$ xH20exh $/(1-x H 20$ exh $) ; \%$ eq. 1065.655-5

xrawexh_dry $=1+x H 20$ exh_dry - xdilexh*(1+xH20exh_dry);\%eq. 1065.6558

xdilexh_dry $=x d i l e x h /(1-x H 20 e x h) ; \% e q \cdot 1065.655-6$

xTHC_dry $=$ xTHC_meas $/\left(1-x H 20 T H C \_m e a s\right) ; \% e q .1065 .655-18$

$\% x i n t e x h \_d r y=(1 /(2 * x 02$ int $)) *\left(\left(\right.\right.$ alpha $/ 2-$ beta $+2+2{ }^{*}$ gamma $) *(x$ Ccomb_dry xTHC_dry) - (xCO_dry-xNO_dry-2*xNO2_dry+xH2_dry ) );\%eq. 1065.655-7

$x C c o m b \_d r y=x C 02 \_d r y+x C 0 \_d r y ; \%+x T H C \_d r y-x d i l e x h \_d r y-$

xc02int*xintexh_dry;\%eq. 1065.655-3

\%Initial guesses 


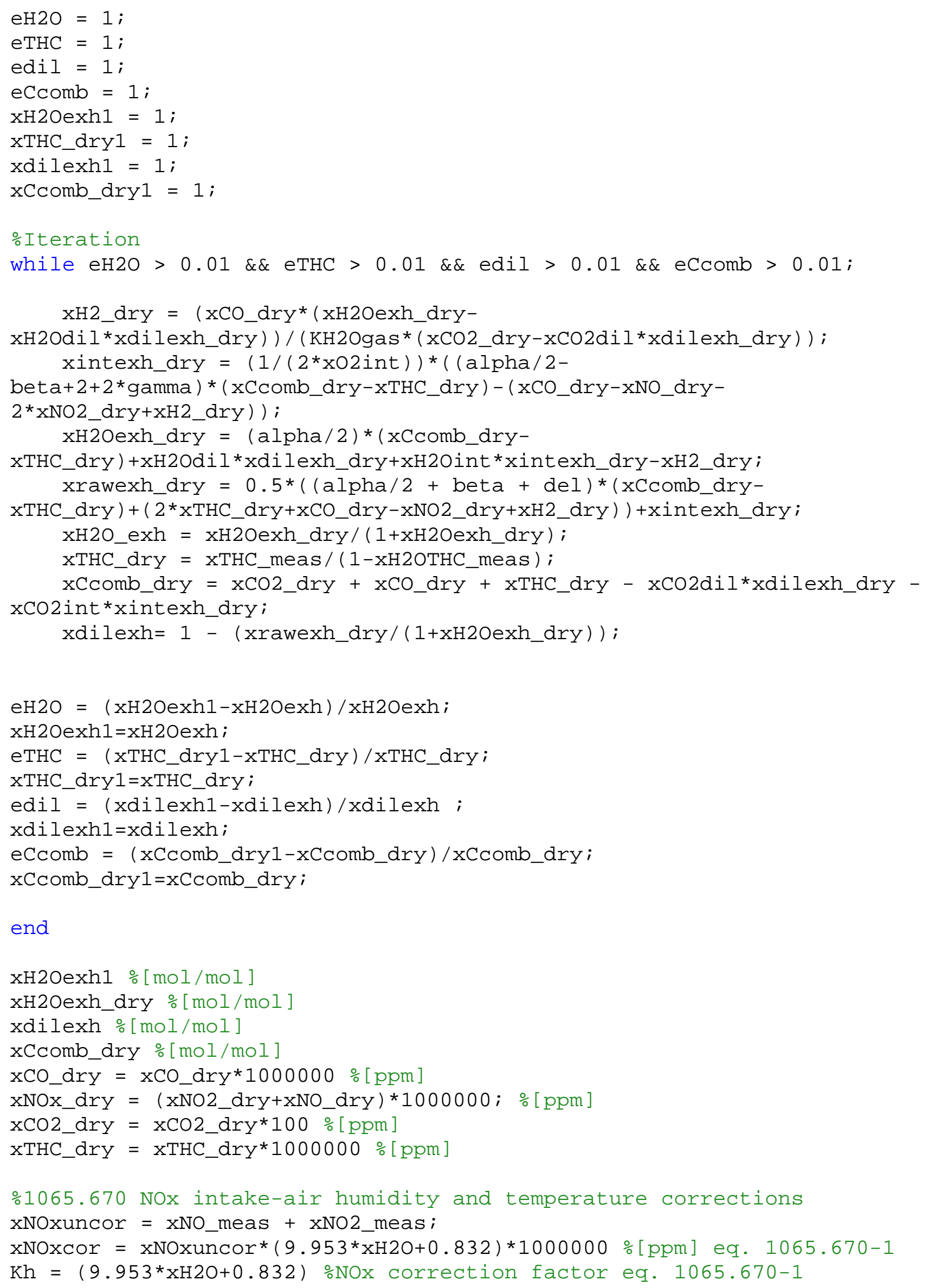


\%Measured and Compared Dilution Flow Rates

ndot_dexh $=65.078 * 1000 * 7.4 \mathrm{e}-07 * 10000 \%[\mathrm{~mol} / \mathrm{s}]$ *average converted where $1[\mathrm{sccm}]=7.45 \mathrm{e}-07[\mathrm{mols} / \mathrm{s}]$

ndot_exh_mass $=15.397^{*} \mathrm{WC}^{*}(1+\mathrm{xH} 20 \mathrm{exh}$-dry $) /\left(\mathrm{Mc}{ }^{*} \times \mathrm{Ccomb}\right.$ dry $) \%[\mathrm{~mol} / \mathrm{s}]$

\%KRAL volumeters

mdot_avg $=190.6 ; \%{ }^{*}$ average mass flow rate $190.549[\mathrm{~g} / \mathrm{s}]$

ndot_exh_mdot $=$ mdot_avg ${ }^{*} w c^{*}\left(1+x H 20 e x h \_d r y\right) /\left(M c * x C c o m b \_d r y\right) \%[m o l s / s]$

eq. 1065.655-25

ndot_int $=$ ndot_exh_mdot* $(1+((x$ intexh_dry -

xrawexh_dry $) /(1+x H 20$ exh_dry $)))$

\section{Appendix A3.2 - Carbon Balance for Test R0007-002-264}

$\%$ Test R0007-002-264 Notch 8

clc

clear all

close all

\% Iteration values for Diesel \#2 from Table 1 1065.655

alpha $=1.8$;

beta $=0$;

gamma $=0$;

del $=0$;

Mc $=12.0107 ; \%[\mathrm{~g} / \mathrm{mol}]$ Molar Mass of Carbon

KH20gas $=3.5 ; \% 1065.655$ paragraph $(\mathrm{c})$ section (3)

\% Carbon mass fraction Diesel \#2

WC $=$

Mc/(Mc+alpha*1.00794+beta*15.9994+gamma*32.065+del*14.0067);\%[g/g] eq . $1065.655-19$

\% Humidity Calculation

Tdew_amb $=19.68 ; \%[$ deg $\mathrm{C}]$ *average

Tdew_chiller $=4.257 ; \%[$ deg $\mathrm{C}]$ *average

Tsat $=$ Tdew_amb+273.15; \%converting to [Kelvin]

Tsat_chiller $=$ Tdew_chiller+273.15; \%converting to [Kelvin]

$\% \log 10(\mathrm{pH} 20) 1065.645$

$\mathrm{RH}=56.543 ; \%[\%]$ relative humidity

p_abs $=97.890 ; \%[\mathrm{kpa}]$ * average measured barometric pressure [in $\mathrm{Hg}]$ converted to $[\mathrm{kPa}]$

$\operatorname{logpH} 20=10.79574 *(1-273.16 /$ Tsat $)-5.028^{*} \log 10($ Tsat $/ 273.16)+$ $\left(1.50475^{*}(10 \wedge-4)\right) *\left(1-10 \wedge\left(-8.2969^{*}(\right.\right.$ Tsat $\left.\left./ 273.16-1)\right)\right)+0.4283^{*}(10 \wedge-$ $3)^{*}\left(10 \wedge\left(4.76955^{*}(1-273.16 /\right.\right.$ Tsat $\left.\left.)\right)-1\right)-0.2138602 ; \%[\mathrm{kPa}] \mathrm{eq}$. $1065.645-1$

$\mathrm{pH} 20=10 \wedge \log \mathrm{pH} 20 ; \%[\mathrm{kPa}]$

$\mathrm{xH} 20=\mathrm{pH} 20 / \mathrm{p} \_$abs; $\%[\mathrm{~mol} / \mathrm{mol}]$

logpH20_chiller $=10.79574^{*}(1-(273.16 /$ Tsat_chiller $))$ -

$5.028^{*} \log 10($ Tsat_chiller $/ 273.16)+\left(1.50475^{*}(10 \wedge-4)\right)^{*}\left(1-10^{\wedge}(-\right.$ 
$8.2969 *\left(\left(\right.\right.$ Tsat_chiller/273.16) - 1) ) $+0.4283^{*}(10 \wedge-3) *\left(10 \wedge\left(4.76955^{*}(1-\right.\right.$ $(273.16 /$ Tsat_chiller )) -1$)-0.2138602 ; \%[\mathrm{kPa}]$ eq. 1065.645-1

pH20_chiller $=10^{\wedge} \operatorname{logpH} 20 \_c h i l l e r ; \%[\mathrm{kPa}]$

xH20emission_meas $=$ pH20_chiller $/ \mathrm{p} \_a b s ; \%[\mathrm{~mol} / \mathrm{mol}]$

\% From emissions analyzers

xC02dil_dry = 375/1000000; \%background bag conc. may use 375 $[\mathrm{mmol} / \mathrm{mol}]$

xC02int_dry $=375 / 1000000 ;$ \%background bag conc. may use 375 $[\mu \mathrm{mol} / \mathrm{mol}]$

xCO_meas $=69.171 / 1000000 ; \%[\mathrm{ppm}] *$ average

xC02_meas $=50616.306 / 1000000 ; \%[\mathrm{ppm}]$ *average

$x$ NOX_meas $=546.762 / 1000000 ; \%[\mathrm{ppm}]$ *average

xNO_meas $=1.476 / 1000000 ; \%[\mathrm{ppm}]$ *average

$\mathrm{xNO} 2$ meas $=\mathrm{xNO}$ __meas $-\mathrm{xNO} \_$meas $; \%[\mathrm{ppm}]$ *average

xTHC_meas $=29.336 / 1000000 ; \%[\mathrm{ppm}]$ *average

xH20C0_meas $=$ xH20emission_meas;

xH20C02_meas $=$ xH20emission_meas;

xH2ONO_meas $=$ xH2Oemission_meas;

xH2ONO2_meas $=$ xH20emission_meas;

xH20THC_meas $=$ xH20emission_meas;

xH2Odil $=$ xH20; $\% \log p($ H2O $) @ d i l$ air dewpoint

xH20int $=$ xH2Odil; \% log p(H20) @dil air dewpoint

xH20int_dry $=$ xH20int $/(1-x H 20$ int $) ; \%$ eq. 1065.655-11

xH20dil_dry $=x H 20 d i l /(1-x H 20 d i l) ; \% e q \cdot 1065.655-13$

$\mathrm{xC02dil}=\mathrm{xC02dil}$ dry $/\left(1+x H 20 d i 1 \_d r y\right) ; \% e q \cdot 1065.655-12$

xC02int $=$ xC02int_dry $/(1+x H 20$ int_dry $) ; \%$ eq $\cdot 1065.655-10$

x02int $=(0.209820-x$ C02int_dry $) /(1+x H 20$ int_dry $) ; \%$ eq. $1065.655-9$

xdilexh $=0.8 ; \%$ initial guess from engineering judgement

xH20exh $=2{ }^{*}$ xH20int; $\%$ eq 1065.655-2

xC0_dry $=$ xC0_meas $/(1-x H 20$ Co_meas $) ; \%$ eq $\cdot 1065.655-14$

$\mathrm{xC0} 2 \_\mathrm{dry}=\mathrm{xC0} 2 \_\mathrm{meas} /\left(1-\mathrm{xH} 20 \mathrm{C} 02 \_\right.$meas $) ; \% \mathrm{eq} \cdot 1065.655-15$

xNO_dry $=$ xNO_meas $/\left(1-x H 20 N O \_m e a s\right) ; \% e q \cdot 1065.655-16$

xNO2_dry $=x N 02 \_m e a s /\left(1-x H 20 N 02 \_m e a s\right) ; \%$ eq. 1065.655-17

xH20exh_dry $=$ xH20exh $/(1-x H 20$ exh $) ; \%$ eq. 1065.655-5

xrawexh_dry $=1+x H 20$ exh_dry - xdilexh*(1+xH20exh_dry);\%eq. 1065.6558

xdilexh_dry $=x d i l e x h /(1-x H 20 e x h) ; \% e q \cdot 1065.655-6$

xTHC_dry $=$ xTHC_meas $/\left(1-x H 20 T H C \_m e a s\right) ; \% e q .1065 .655-18$

$\% x i n t e x h \_d r y=(1 /(2 * x 02$ int $)) *\left(\left(\right.\right.$ alpha $/ 2-$ beta $+2+2{ }^{*}$ gamma $) *(x$ Ccomb_dry xTHC_dry) - (xCO_dry-xNO_dry-2*xNO2_dry+xH2_dry ) );\%eq. 1065.655-7

$x C c o m b \_d r y=x C 02 \_d r y+x C 0 \_d r y ; \%+x T H C \_d r y-x d i l e x h \_d r y-$

xc02int*xintexh_dry;\%eq. 1065.655-3

\%Initial guesses 


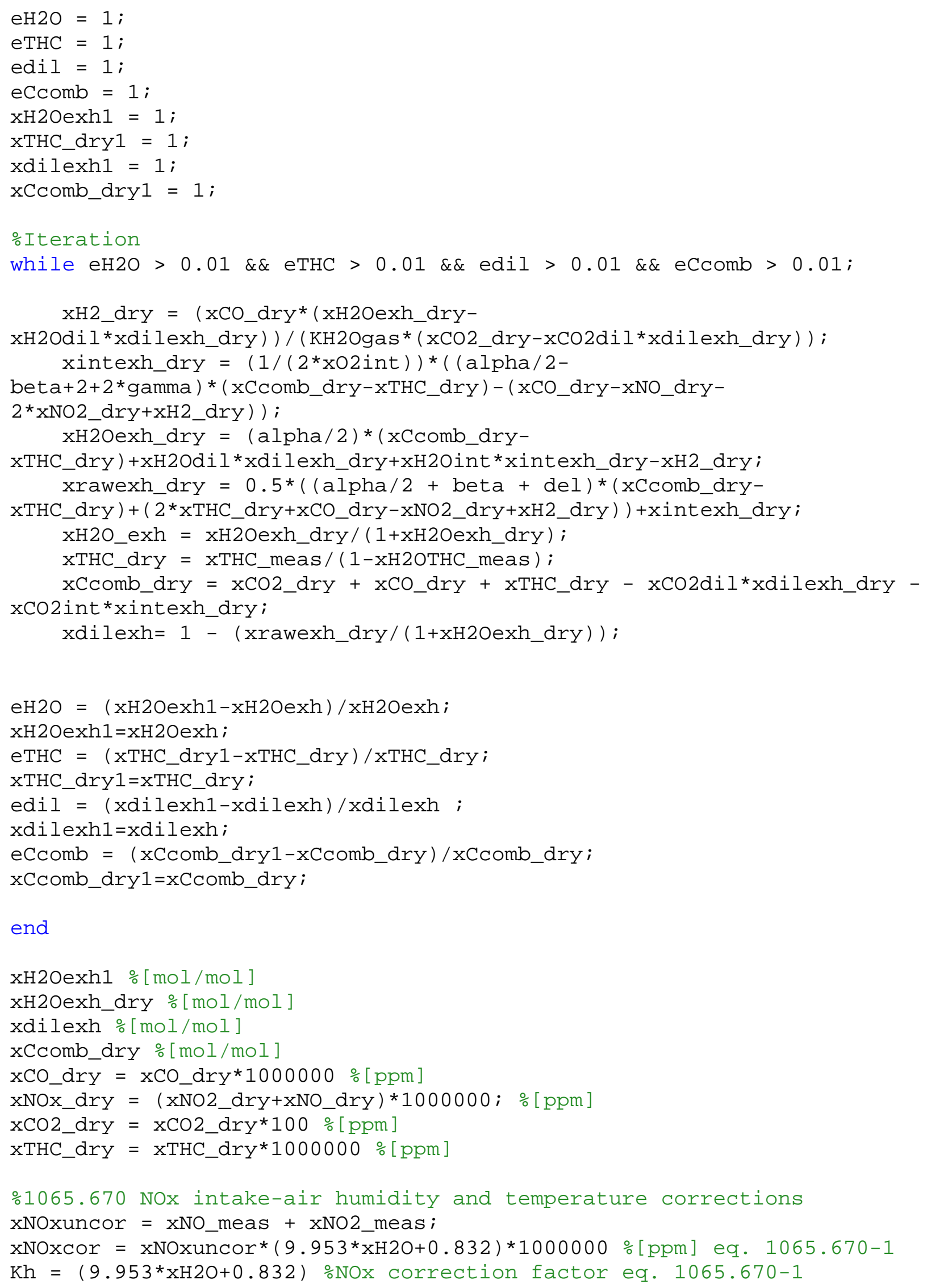




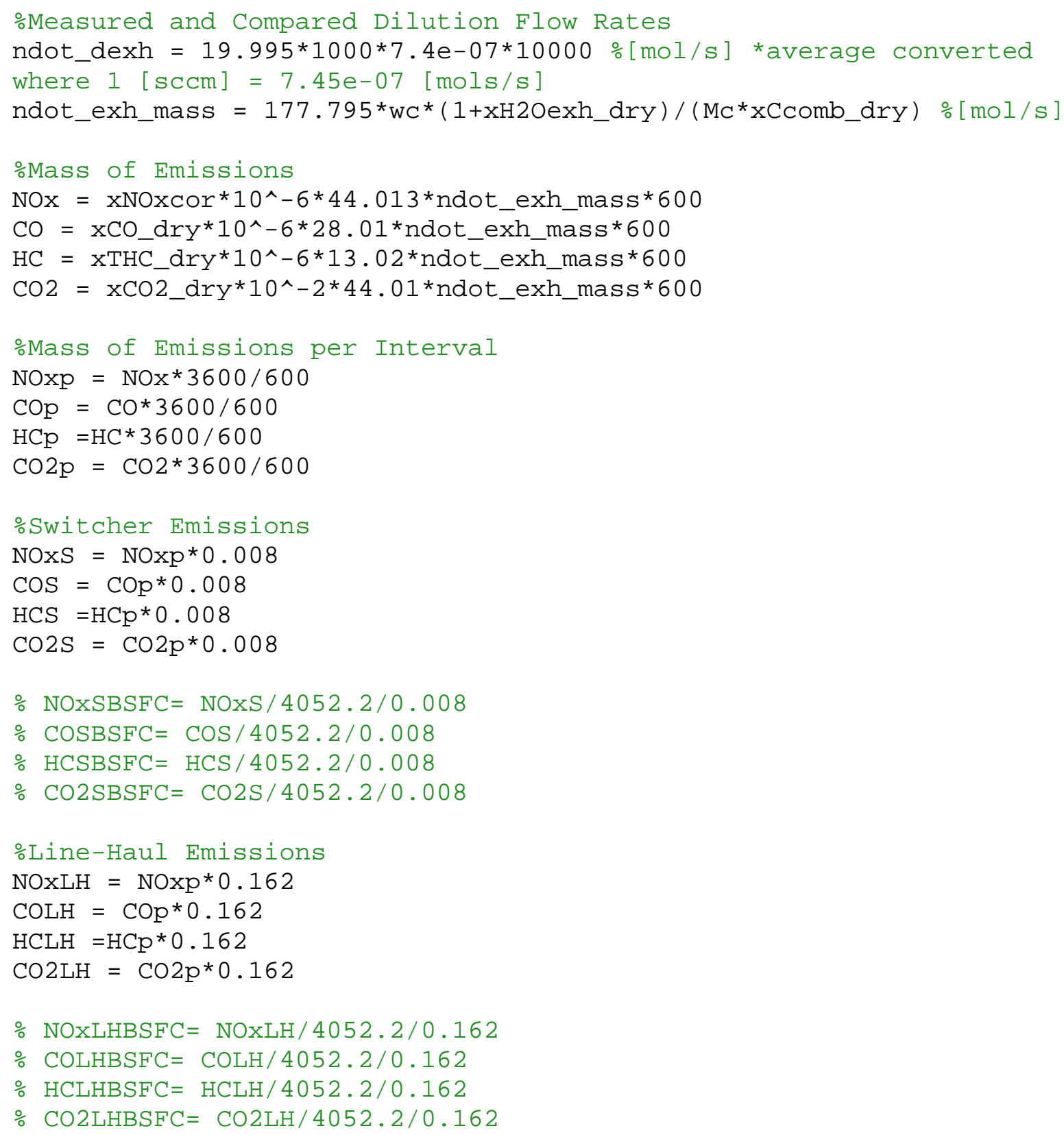


Mc $=12.0107 ; \%[\mathrm{~g} / \mathrm{mol}]$ Molar Mass of Carbon

KH20gas $=3.5 ; \% 1065.655$ paragraph $(\mathrm{c})$ section (3)

\% Carbon mass fraction Diesel \#2

wC $=$

Mc/ (Mc+alpha*1.00794+beta*15.9994+gamma*32.065+del*14.0067);\%[g/g] eq . 1065. 655-19

\% Humidity Calculation

Tdew_amb $=19.867 ; \%[$ deg $C]$ *average

Tdew_chiller $=4.257 ; \%[$ deg $\mathrm{C}]$ *average

Tsat $=$ Tdew_amb+273.15; \%converting to [Kelvin]

Tsat_chiller $=$ Tdew_chiller+273.15; \%converting to [Kelvin]

$\% \log 10(\mathrm{pH} 20) 1065.645$

$\mathrm{RH}=76.699 ; \%[\%]$ relative humidity

p_abs $=97.914 ; \%[\mathrm{kpa}]$ * average measured barometric pressure [in Hg] converted to $[\mathrm{kPa}]$

$\operatorname{logpH} 20=10.79574^{*}(1-273.16 /$ Tsat $)-5.028^{*} \log 10($ Tsat $/ 273.16)+$ $\left(1.50475^{*}(10 \wedge-4)\right) *(1-10 \wedge(-8.2969 *($ Tsat $/ 273.16-1)))+0.4283^{*}(10 \wedge-$ $3)^{*}\left(10 \wedge\left(4.76955^{*}(1-273.16 /\right.\right.$ Tsat $\left.\left.)\right)-1\right)-0.2138602 ; \%[\mathrm{kPa}] \mathrm{eq}$. $1065.645-1$

$\mathrm{pH} 20=10 \wedge \log \mathrm{pH} 20 ; \%[\mathrm{kPa}]$

$\mathrm{xH} 20=\mathrm{pH} 20 / \mathrm{p} \_a b s ; \%[\mathrm{~mol} / \mathrm{mol}]$

logpH20_chiller $=10.79574 *(1-(273.16 /$ Tsat_chiller $))$ -

$5.028 * \log 10($ Tsat_chiller $/ 273.16)+\left(1.50475^{*}(10 \wedge-4)\right) *(1-10 \wedge(-$

$8.2969 *\left(\left(\right.\right.$ Tsat_chiller/273.16) - 1) ) $+0.4283^{*}(10 \wedge-3) *\left(10 \wedge\left(4.76955^{*}(1-\right.\right.$ $(273.16 /$ Tsat_chiller )) -1$)-0.2138602 ; \%[\mathrm{kPa}] \mathrm{eq} \cdot 1065.645-1$

pH20_chiller $=10^{\wedge} \operatorname{logpH} 20 \_c h i l l e r ; \%[\mathrm{kPa}]$

xH20emission_meas $=$ pH20_chiller $/$ p_abs; $\%[\mathrm{~mol} / \mathrm{mol}]$

$\%$ From emissions analyzers

xC02dil_dry = 375/1000000; \%background bag conc. may use 375 $[\mathrm{\mu mol} / \mathrm{mol}]$

xC02int_dry $=375 / 1000000 ;$ \%background bag conc. may use 375 $[\mu \mathrm{mol} / \mathrm{mol}]$

xCo_meas $=18.581 / 1000000 ; \%[\mathrm{ppm}]$ *average

$\mathrm{xC02}$ meas $=7173.828 / 1000000 ; \%[\mathrm{ppm}]$ *average

xNOx_meas $=104.187 / 1000000 ; \%[\mathrm{ppm}]$ *average

xNO_meas $=0.742 / 1000000 ; \%[\mathrm{ppm}]$ *average

$\mathrm{xNO} 2$ meas $=\mathrm{xNOx} \_$meas $-\mathrm{xNO} \_$meas $; \%[\mathrm{ppm}]$ *average

$\mathrm{xTHC} \_$meas $=23.243 / 1000000 ; \%[\mathrm{ppm}]$ *average

xH20Co_meas $=$ xH20emission_meas;

xH20C02_meas $=$ xH20emission_meas;

xH2ONO_meas $=$ xH20emission_meas;

xH2ONO2_meas $=$ xH20emission_meas;

xH20THC_meas $=$ xH20emission_meas; 


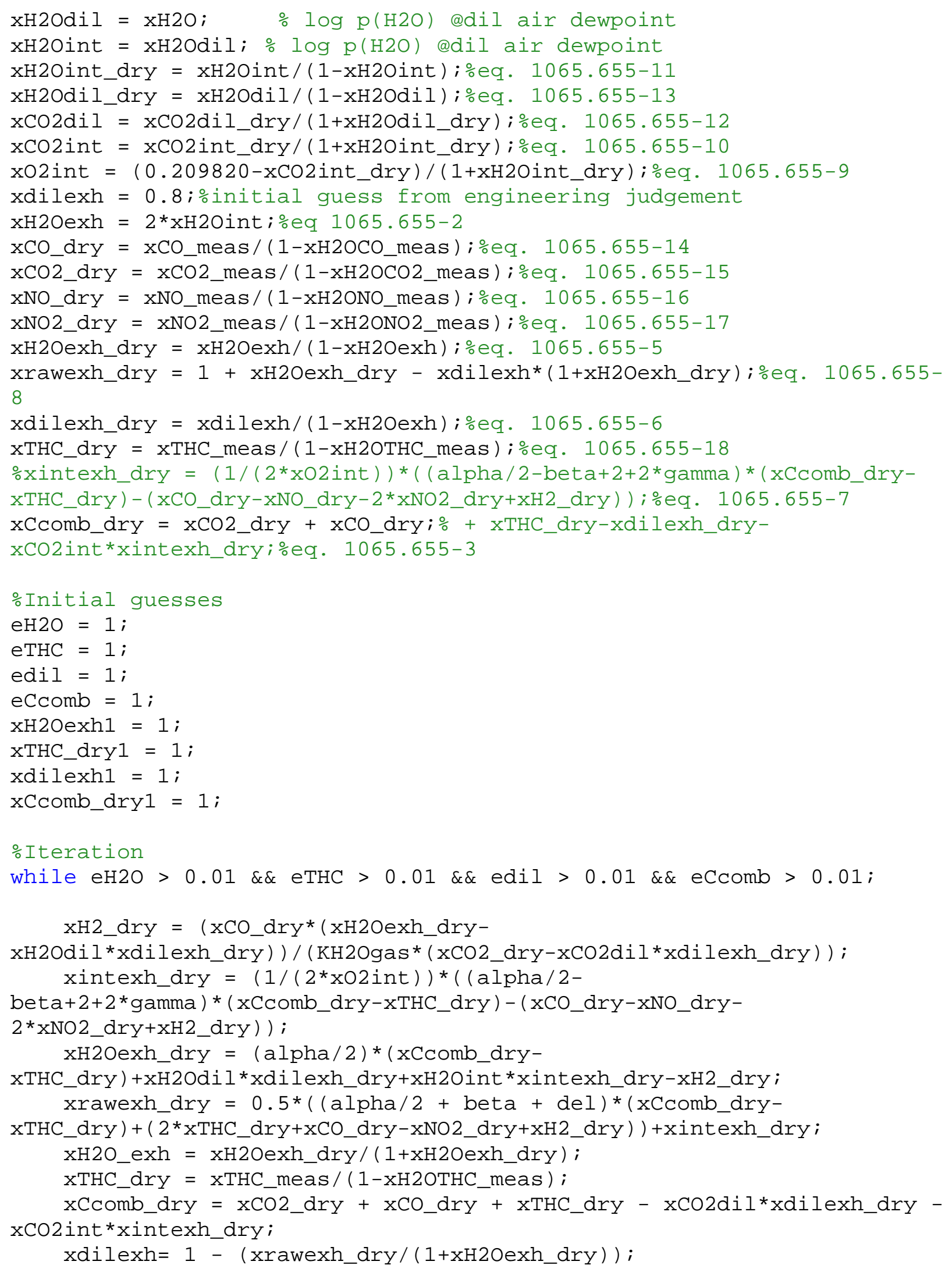




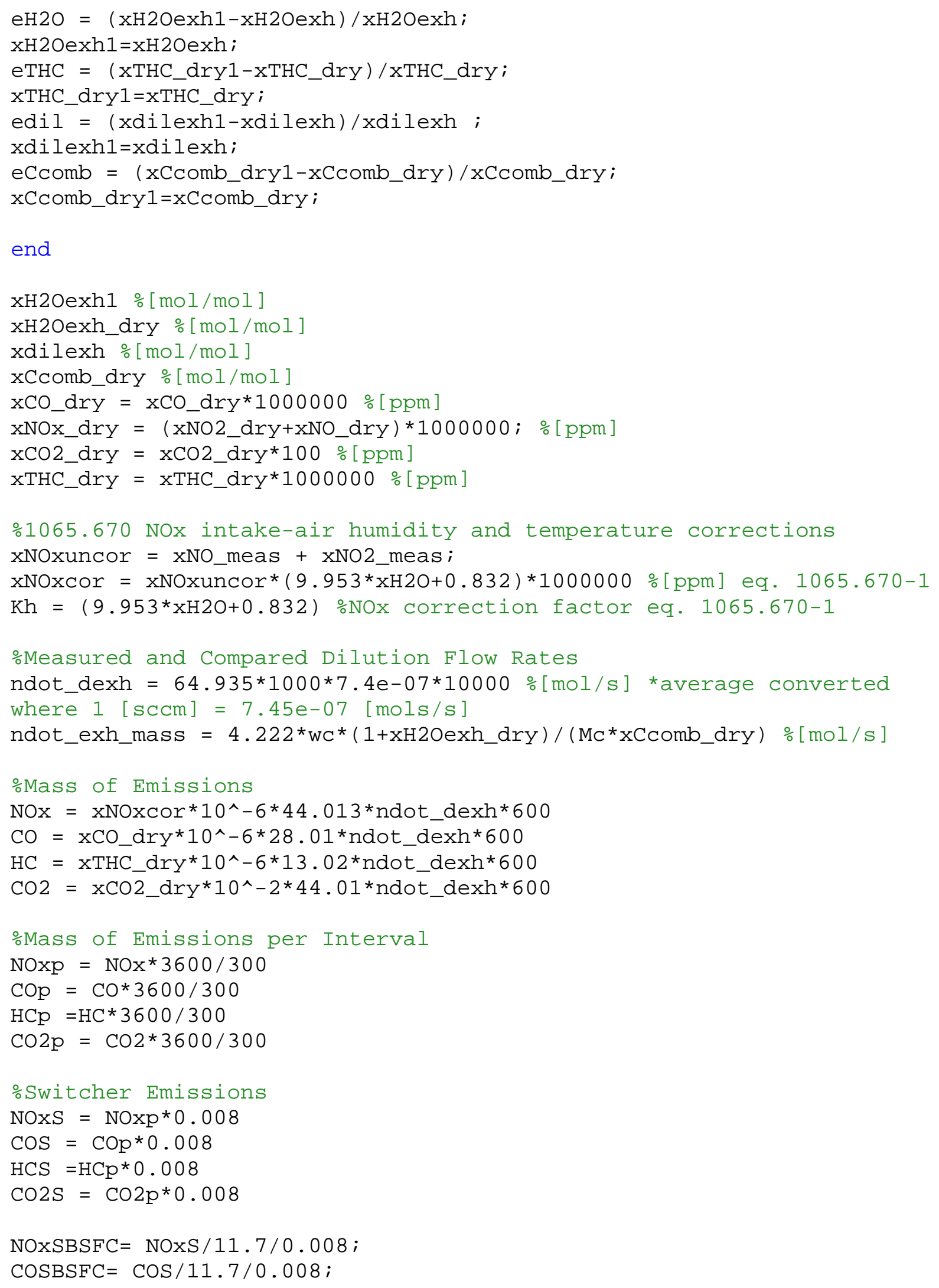


$\mathrm{HCSBSFC}=\mathrm{HCS} / 11.7 / 0.008$;

$\mathrm{C02SBSFC}=\mathrm{C} 02 \mathrm{~S} / 11.7 / 0.008$;

\% Line-Haul Emissions

NOXLH $=$ NOxp* 0.162

COLH $=$ COp*๑.162

$\mathrm{HCLH}=\mathrm{HCp}^{\star} \odot .162$

$\mathrm{CO} 2 \mathrm{LH}=\mathrm{CO} 2 \mathrm{p} * 0.162$

NOXLHBSFC $=$ NOXLH/11.7/0.162;

COLHBSFC $=\mathrm{COLH} / 11.7 / 0.162$;

$\mathrm{HCLHBSFC}=\mathrm{HCLH} / 11.7 / 0.162$;

C02LHBSFC $=$ C02LH/11.7/0.162; 


\section{APPENDIX B - CERTIFICATION CALIBRATION DATA SHEETS}

Appendix B1 - Micro Motion, Inc. Coriolis Mass Flow Meter Calibration Certificate Sheets Appendix B1.1 - Calibration Sheet for Test 12154968

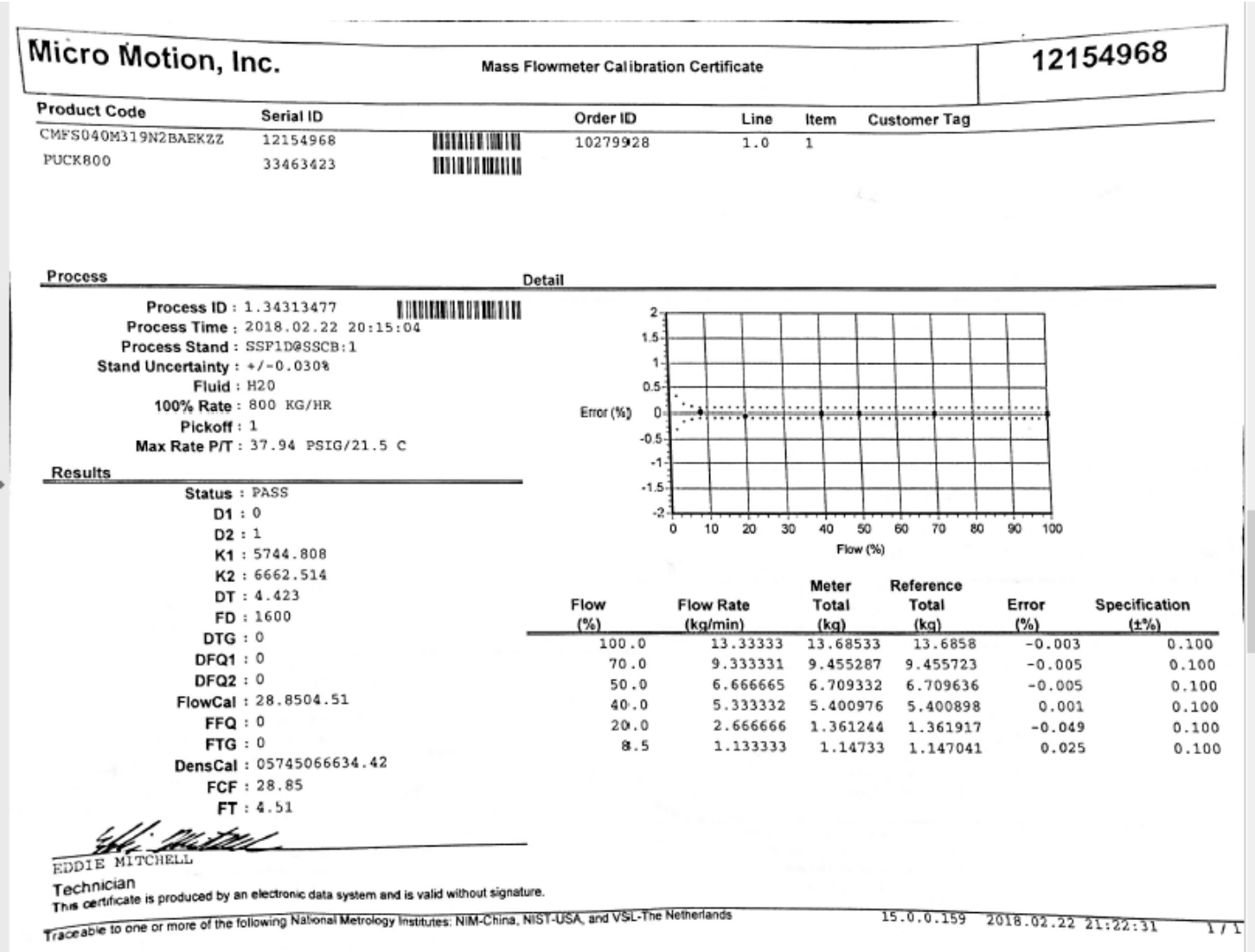




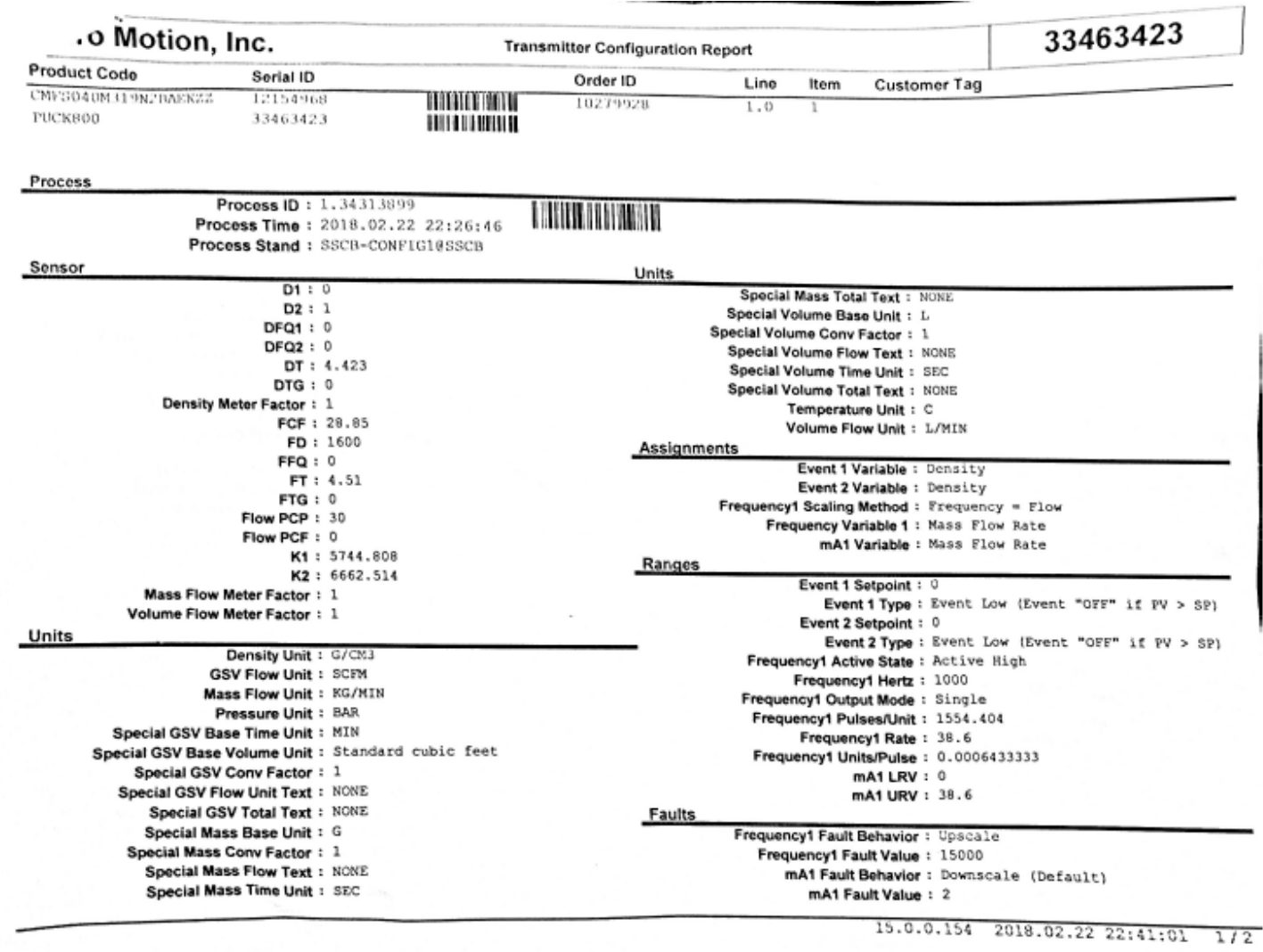

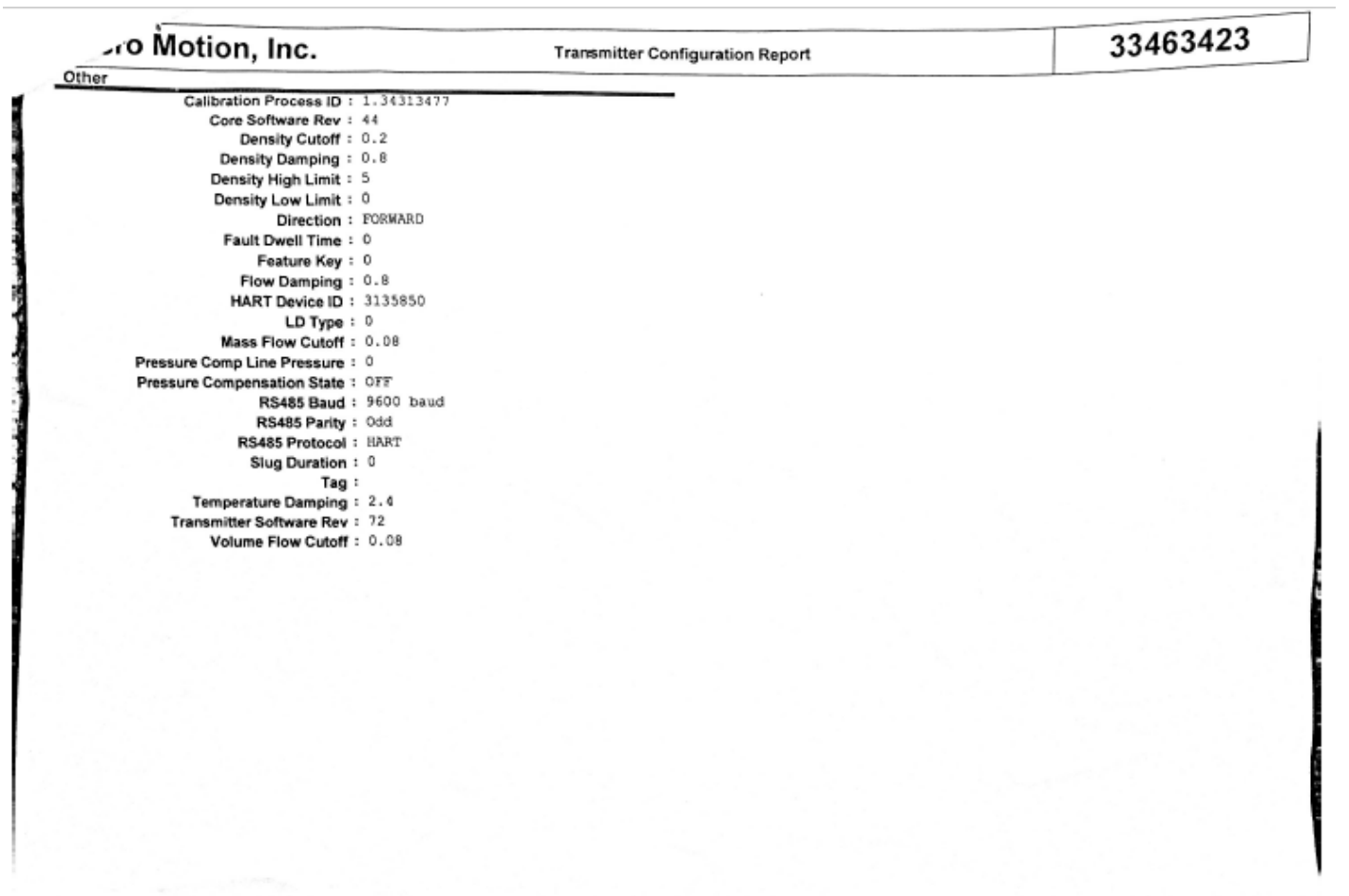




\section{Appendix B1.2 - Calibration Sheet for Test 12154969}

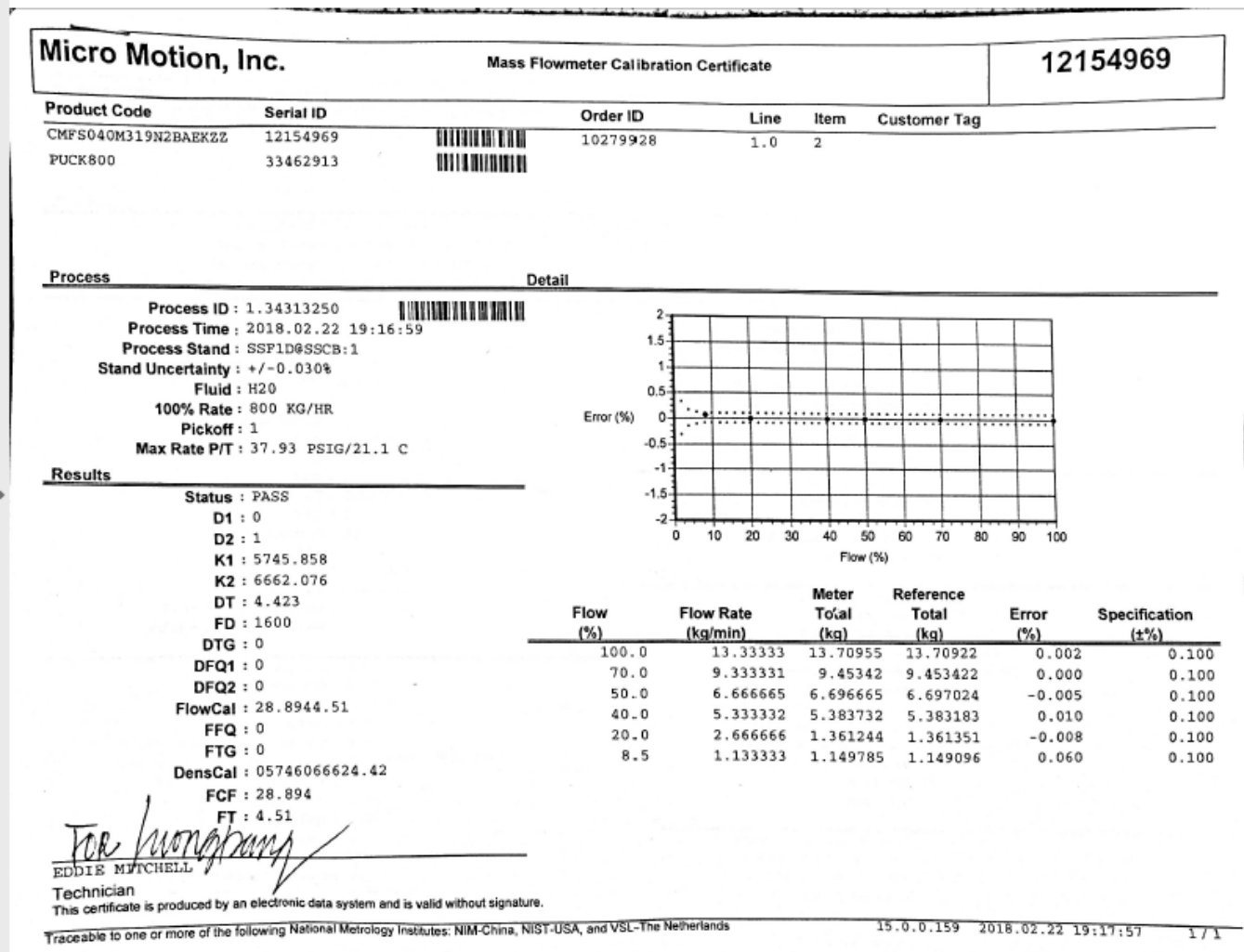

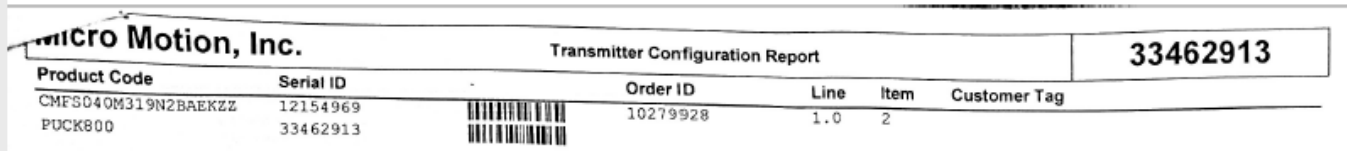

Process

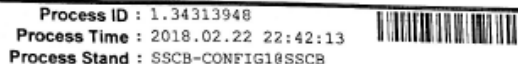

Sensor

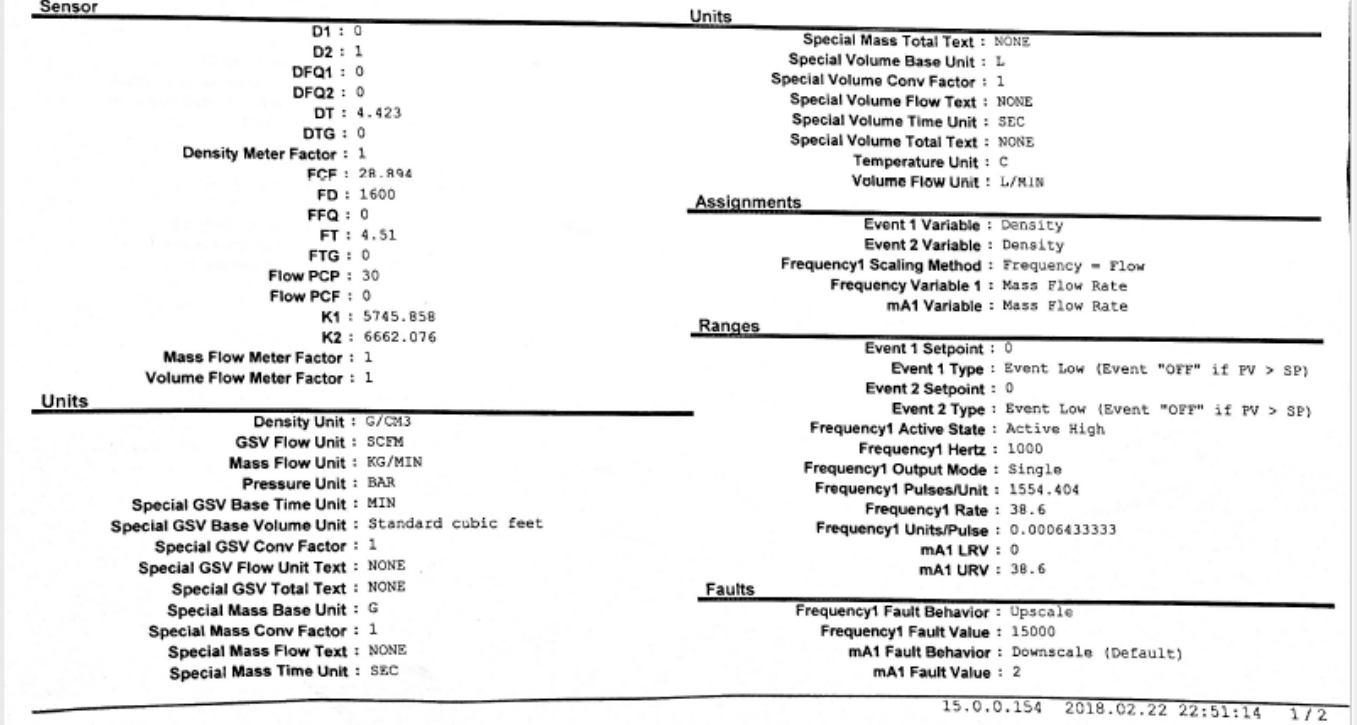




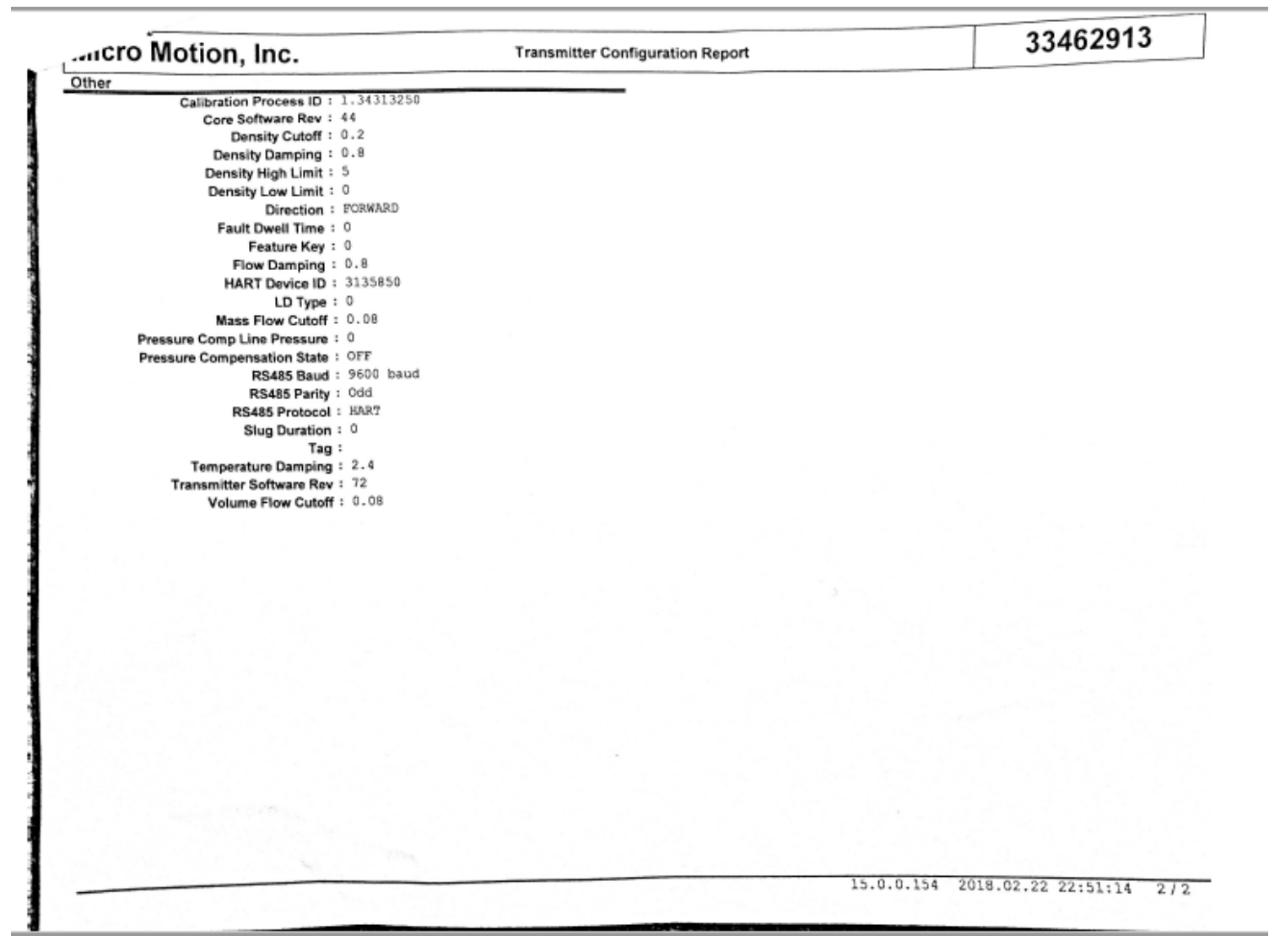




\section{$\perp$ TROEMNER}

Troemner, LLC

\section{Traceable Certificate}

201 Wolf Drive • P.O. Box 87• Thorofare, NJ 08086-0087• Phone: 856-686-1600• Fax: 856-686-1601• wuw.troemner.com• e-mail: troemnenatroemner.com Page 1 of 1 Pages

Weight

McMaster Carr Supply Co. (IL)

600 N. County Line Road

Elmhurst, IL 60126-2081
Serial Number Order Number Certificate Number Date of Calibration Calibration Due Date
7313

AE-33203890

$01020048 \mathrm{C}$

06-JUL-2018

Description of Weights: Economical Weight Set

\section{Material}

Stainless Steel

\section{Assumed Density at $20^{\circ} \mathrm{C}$}

$$
7.85 \mathrm{~g} / \mathrm{cm} 3
$$

\section{$\underline{\text { Range }}$}

$$
2 \mathrm{~kg}-1 \mathrm{~g}
$$

Tested with Reference Standards Traceable to the National Institute of Standards \& Technology through NIST Test Number 684/289871-17.

We certify that the weights listed are calibrated to ASTM E617-13 Class 7 tolerances.

The calibration of these weights is based on apparent mass vs material of density $8.0 \mathrm{~g} / \mathrm{cm}^{3}$.

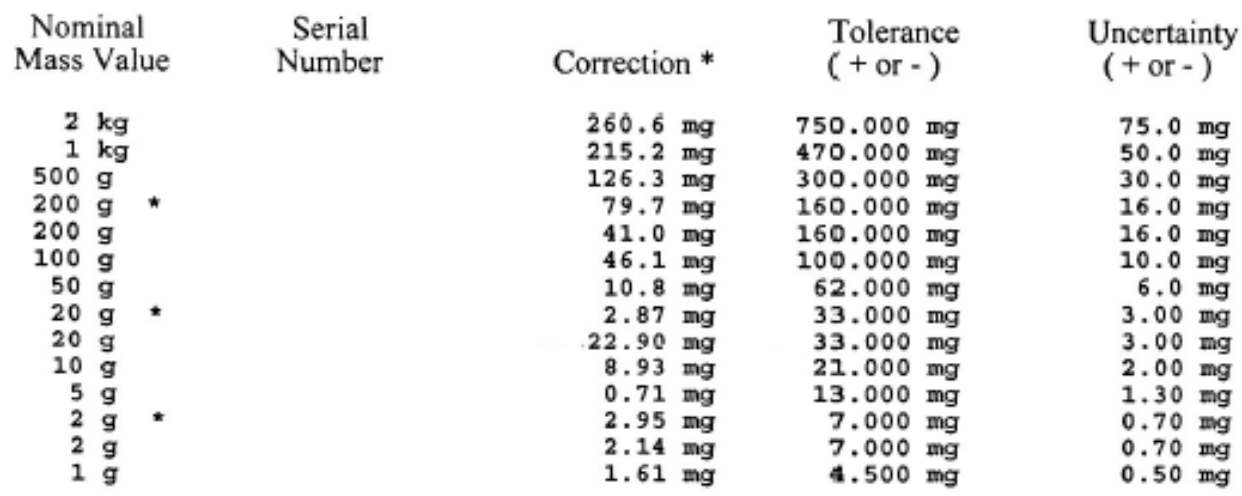

- Correction is defined as the difference between the mass value of a weight and its nominal value. A positive correction indicates that the mass value is greater than the nominal value by the amount of the correction.

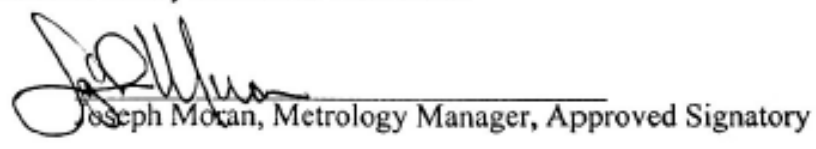

- Denotes weight is marked with a dot 
APPENDIX C - ADDITIONAL FIGURES AND TABLES

Appendix C1 - Projected Future Emission Factors Complete Tables [31]

Table 45 - NOx Emission Factors (g/gal)

\begin{tabular}{|c|c|c|c|c|c|}
\hline Calendar & Large Line- & Large & Small & & Overall \\
\hline Year & haul & Switch & Railroads & Passenger/Commuter & Average \\
\hline 2006 & 180 & 250 & 242 & 244 & 188 \\
\hline 2007 & 175 & 249 & 242 & 229 & 183 \\
\hline 2008 & 169 & 243 & 242 & 214 & 177 \\
\hline 2009 & 165 & 241 & 242 & 200 & 172 \\
\hline 2010 & 157 & 236 & 242 & 183 & 165 \\
\hline 2011 & 149 & 235 & 242 & 167 & 157 \\
\hline 2012 & 144 & 227 & 242 & 157 & 152 \\
\hline 2013 & 139 & 225 & 242 & 147 & 147 \\
\hline 2014 & 135 & 217 & 242 & 138 & 143 \\
\hline 2015 & 129 & 215 & 240 & 131 & 137 \\
\hline 2016 & 121 & 208 & 239 & 119 & 129 \\
\hline 2017 & 114 & 206 & 237 & 112 & 122 \\
\hline 2018 & 108 & 202 & 236 & 105 & 117 \\
\hline 2019 & 103 & 200 & 233 & 98 & 112 \\
\hline 2020 & 99 & 187 & 231 & 93 & 107 \\
\hline 2021 & 94 & 185 & 228 & 88 & 102 \\
\hline 2022 & 89 & 177 & 225 & 83 & 97 \\
\hline 2023 & 84 & 172 & 223 & 78 & 92 \\
\hline 2024 & 79 & 162 & 220 & 73 & 87 \\
\hline 2025 & 74 & 150 & 217 & 68 & 81 \\
\hline 2026 & 69 & 144 & 215 & 64 & 77 \\
\hline 2027 & 65 & 138 & 212 & 60 & 72 \\
\hline 2028 & 61 & 132 & 209 & 56 & 68 \\
\hline 2029 & 57 & 126 & 206 & 52 & 64 \\
\hline 2030 & 53 & 119 & 203 & 49 & 60 \\
\hline 2031 & 49 & 112 & 200 & 46 & 56 \\
\hline 2032 & 46 & 105 & 197 & 42 & 52 \\
\hline 2033 & 43 & 98 & 193 & 39 & 49 \\
\hline 2034 & 40 & 91 & 190 & 36 & 46 \\
\hline 2035 & 37 & 84 & 187 & 33 & 43 \\
\hline 2036 & 35 & 77 & 184 & 30 & 40 \\
\hline 2037 & 33 & 71 & 180 & 28 & 38 \\
\hline 2038 & 31 & 67 & 177 & 26 & 36 \\
\hline 2039 & 29 & 63 & 174 & 24 & 34 \\
\hline 2040 & 28 & 60 & 171 & 23 & 32 \\
\hline
\end{tabular}


Table 46 - PM Emission Factors (g/gal)

\begin{tabular}{|c|c|c|c|c|c|}
\hline Calendar & Large Line- & Large & Small & & Overall \\
\hline Year & haul & Switch & Railroads & Passenger/Commuter & Average \\
\hline 2006 & 6.4 & 6.5 & 6.5 & 6.5 & 6.4 \\
\hline 2007 & 6,3 & 6.5 & 6.5 & 6.4 & 6,3 \\
\hline 2008 & 5.1 & 5.5 & 5.7 & 5.1 & 5.1 \\
\hline 2009 & 4.9 & 5.5 & 5.7 & 5.0 & 4.9 \\
\hline 2010 & 4.7 & 5.4 & 5.7 & 4.8 & 4.7 \\
\hline 2011 & 4,4 & 5,3 & 5.7 & 4,5 & 4.5 \\
\hline 2012 & 4.1 & 5.1 & 5.7 & 4.2 & 4.2 \\
\hline 2013 & 3.8 & 5.0 & 5.6 & 3.9 & 3.9 \\
\hline 2014 & 3.6 & 4.8 & 5,6 & 3.6 & 3.7 \\
\hline 2015 & 3.4 & 4.8 & 5.5 & 3.4 & 3.5 \\
\hline 2016 & 3.1 & 4.6 & 5.5 & 3.1 & 3.3 \\
\hline 2017 & 2.9 & 4.5 & 5.4 & 2.8 & 3.0 \\
\hline 2018 & 2.7 & 4.4 & 5.4 & 2.6 & 2.8 \\
\hline 2019 & 2.5 & 4.4 & 5.4 & 2.3 & 2.6 \\
\hline 2020 & 2.3 & 4.1 & 5.3 & 2.1 & 2.5 \\
\hline 2021 & 2.2 & 4.0 & 5.3 & 2.0 & 2.4 \\
\hline 2022 & 2,0 & 3.9 & 5.3 & 1.8 & 2.2 \\
\hline 2023 & 1.9 & 3.7 & 5.2 & 1.7 & 2.1 \\
\hline 2024 & 1.7 & 3.5 & 5.2 & 1.5 & 1.9 \\
\hline 2025 & 1.6 & 3.2 & 5.1 & 1.4 & 1.8 \\
\hline 2026 & 1.5 & 3.1 & 5.1 & 1.2 & 1.6 \\
\hline 2027 & 1.4 & 3.0 & 5.1 & 1.1 & 1.5 \\
\hline 2028 & 1.3 & 2.8 & 5.0 & 1.0 & 1.4 \\
\hline 2029 & 1.1 & 2.7 & 5.0 & 0.9 & 1.3 \\
\hline 2030 & 1.0 & 2.5 & 4.9 & 0.8 & 1.2 \\
\hline 2031 & 1.0 & 2.4 & 4.8 & 0.7 & 1.1 \\
\hline 2032 & 0.9 & 2.2 & 4.8 & 0.7 & 1.0 \\
\hline 2033 & 0.8 & 2. 1 & 4.7 & 0.6 & 0.9 \\
\hline 2034 & 0.7 & 1.9 & 4.6 & 0.6 & 0.9 \\
\hline 2035 & 0.7 & 1.7 & 4.6 & 0.5 & 0.8 \\
\hline 2036 & 0.6 & 1.6 & 4.5 & 0.5 & 0.7 \\
\hline 2037 & 0.6 & 1.5 & 4.4 & 0.4 & 0.7 \\
\hline 2038 & 0.5 & 1.4 & 4.4 & 0.4 & 0.6 \\
\hline 2039 & 0.5 & 1.3 & 4.3 & 0.4 & 0.6 \\
\hline 2040 & 0.4 & 1.2 & 4.2 & 0.3 & 0.5 \\
\hline
\end{tabular}




\section{Table 47 - HC Emission Factors (g/gal)}

\begin{tabular}{|c|c|c|c|c|c|}
\hline Calendar & Large Line- & Large & Small & & Overall \\
\hline Year & haul & Switch & Railroads & Passenger/Commuter & Average \\
\hline 2006 & 9.5 & 15.0 & 11.7 & 9.7 & 10.0 \\
\hline 2007 & 9.3 & 150 & 11.7 & 9.5 & 9.8 \\
\hline 2008 & 9.0 & 14.5 & 11.7 & 9.3 & 9.5 \\
\hline 2009 & 8.7 & 14.5 & 11.7 & 9.1 & 9.1 \\
\hline 2010 & 8.3 & 14.1 & 11.7 & 8.6 & 8.8 \\
\hline 2011 & 7.7 & 14,0 & 11.7 & 8.1 & 8.2 \\
\hline 2012 & 7.1 & 13.3 & 11.7 & 7.5 & 7.6 \\
\hline 2013 & 6.5 & 13.3 & 11.7 & 6.9 & 7.1 \\
\hline 2014 & 6.1 & 12.7 & 11.7 & 6,3 & 6.7 \\
\hline 2015 & 5.7 & 12.6 & 11.7 & 5.8 & 6.3 \\
\hline 2016 & 5.1 & 12.0 & 11.7 & 5.2 & 5.7 \\
\hline 2017 & 4.6 & 11.8 & 11.7 & 4.6 & 5.2 \\
\hline 2018 & 4.2 & 11.5 & 11.7 & 4,1 & 4.8 \\
\hline 2019 & 3.9 & 11.4 & 11.7 & 3.5 & 4.5 \\
\hline 2020 & 3.6 & 10.5 & 11.7 & 3.1 & 4.2 \\
\hline 2021 & 3.4 & 10.4 & 11.7 & 2.9 & 4.0 \\
\hline 2022 & 3.2 & 9.8 & 11.7 & 2.7 & 3.8 \\
\hline 2023 & 3.0 & 9.5 & 11.7 & 2.4 & 3.6 \\
\hline 2024 & 2.8 & 8.9 & 11.7 & 2.2 & 3.4 \\
\hline 2025 & 2.6 & 8.0 & 11.7 & 2,0 & 3.1 \\
\hline 2026 & 2.5 & 7.6 & 11.7 & 1.8 & 2.9 \\
\hline 2027 & 2.3 & 7.3 & 11.7 & 1.6 & 2.8 \\
\hline 2028 & 2.1 & 6.9 & 11.7 & 1.5 & 2.6 \\
\hline 2029 & 2.0 & 6.5 & 11.7 & 1.3 & 2.4 \\
\hline 2030 & 1.9 & 6.2 & 11.7 & 1.2 & 2.3 \\
\hline 2031 & 1.7 & 5.8 & 11.7 & 1.1 & 2.2 \\
\hline 2032 & 1.6 & 5.5 & 11.7 & 1.0 & 2.0 \\
\hline 2033 & 1.5 & 5.1 & 11.7 & 0.9 & 1.9 \\
\hline 2034 & 1.4 & 4.7 & 11.7 & 0.8 & 1.8 \\
\hline 2035 & 1.3 & 4.4 & 11.7 & 0.7 & 1.7 \\
\hline 2036 & 1.2 & 4.0 & 11.7 & 0.7 & 1.6 \\
\hline 2037 & 1.2 & 3.7 & 11.7 & 0.6 & 1.5 \\
\hline 2038 & 1.1 & 3.6 & 11.7 & 0.6 & 1.4 \\
\hline 2039 & 1.1 & 3.4 & 11.7 & 0.5 & 1.4 \\
\hline 2040 & 1.0 & 3.2 & 11.7 & 0.5 & 1.3 \\
\hline
\end{tabular}


Appendix C2 - Preliminary Test Data for Test ID: R0007-002-198

Locomotive Test Report R0007-002-198

\section{Test Information}

Test ID: R0007-002-198

Perfomed: 04/27/17 11:13:31

\section{Locomotive}

\begin{tabular}{lr}
\hline & \\
\hline & \\
\hline Monulacturer: & EMDIJLS \\
Modet: & SD60E \\
Model Year: & 2016 \\
Cumulative Mwhr: & $6.6 \mathrm{MWhr}$ \\
Dynamic Brake Equipped: & Yes \\
$100 \%$ Self Load Equipped: & Yes \\
Low ldle Equipped: & No \\
Notch 7.8 Equipped: & No
\end{tabular}

Nominal Mechanical Load

Traction Motor Blower. 1500 None

Unloaded Compressor: 17.0 None

Single Fan: $\quad 40.3$ None

Inertial Separator: 126 None

Design Weight: $\quad 398000$ los $\quad 39000$ gas

Fuel Capacity. $\quad 48000$ gal

Centification Tier: Tier $\mathrm{O}_{+}$

Switch NOx FEL: $\quad 11.8 \mathrm{~g}$ thph-hr

Line Haul NOx FEL: $\quad 8.0$ gbho-tr

Switch CO FEL- $\quad 8.0 \mathrm{~g}$ bhohr

Line Haul CO FEL: $\quad 5.0$ gbho-tr

Switch PM FEL- $\quad 0.28 \mathrm{~g} / \mathrm{bhp}-\mathrm{hr}$

\section{Engine}

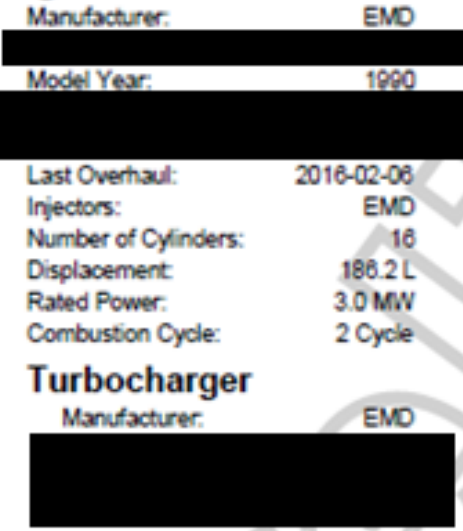

Rated Speed:

905.0 RPM 


\begin{tabular}{lr}
\hline Fuel & \\
\hline Type: & Number 2 Diesel \\
ID: & NS 7033 \\
Alpha: & 1.800000 \\
Beta: & 0.000000 \\
Gamma: & 0.000000 \\
Delta: & 0.000000 \\
Carbon Mass Fraction: & 0.869000
\end{tabular}

Intermediate Result

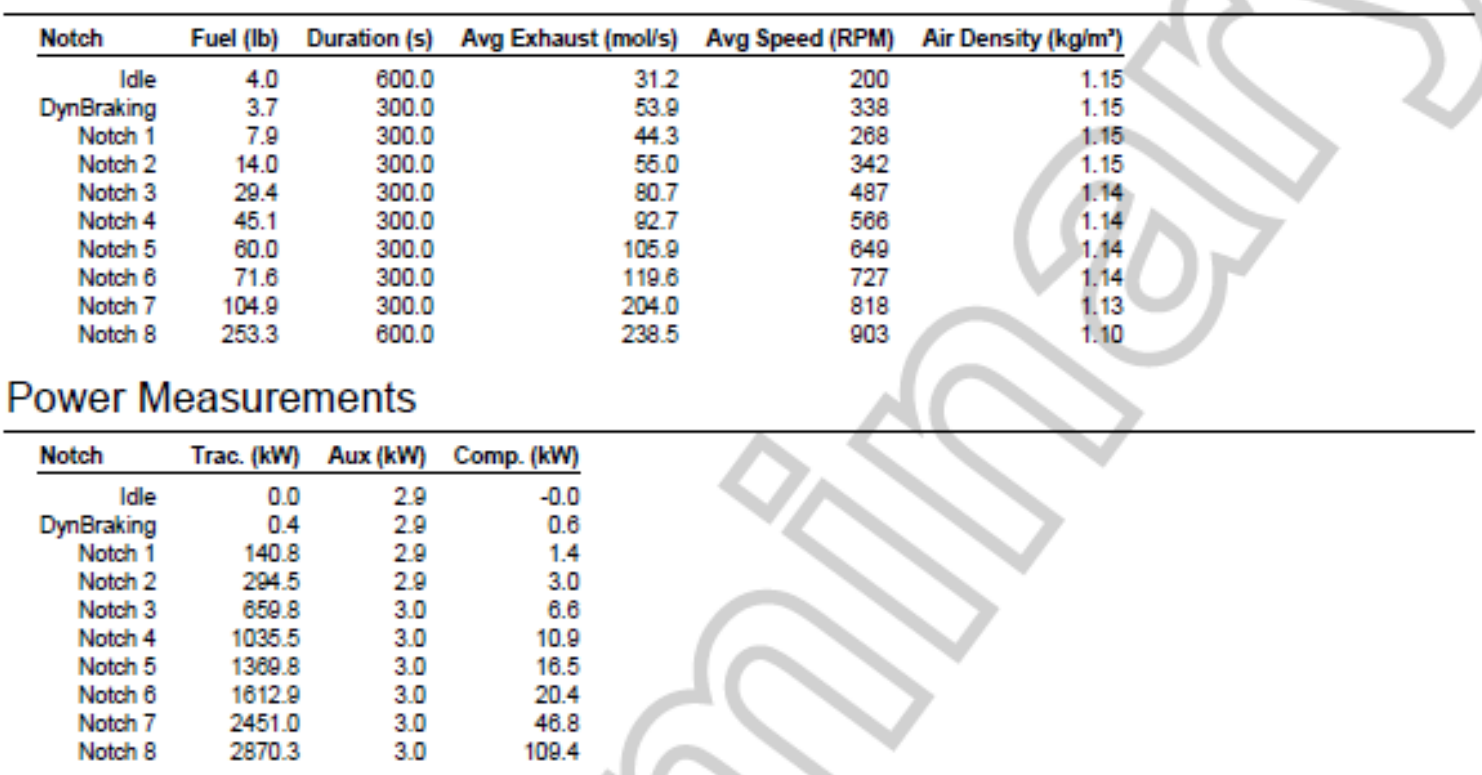

\section{Estimated Power}

\begin{tabular}{rrrrrrrr}
\multicolumn{1}{l}{ Notch } & Fans On & Fans (hp) & Compressor (hp) & Split Cool Fan (hp) & TM Blower (hp) & Total Acc (hp) & Total (hp) \\
\hline Idle & 0 & 0.0 & 3.8 & 0.1 & 1.6 & 9.5 & 9.5 \\
DynBraking & 0 & 0.0 & 6.3 & 0.6 & 7.6 & 18.6 & 19.2 \\
Notch 1 & 0 & 0.0 & 5.0 & 0.3 & 3.8 & 13.1 & 214.6 \\
Notch 2 & 1 & 2.1 & 6.4 & 0.7 & 7.8 & 21.0 & 442.4 \\
Notch 3 & 1 & 6.1 & 9.1 & 1.9 & 22.5 & 43.6 & 987.9 \\
Notch 4 & 2 & 19.1 & 10.6 & 3.0 & 35.5 & 72.3 & 1554.2 \\
Notch 5 & 3 & 43.2 & 12.2 & 4.5 & 53.6 & 117.4 & 2077.9 \\
Notch 6 & 3 & 60.5 & 13.7 & 6.3 & 75.1 & 159.6 & 2468.0 \\
Notch 7 & 3 & 85.2 & 15.4 & 8.9 & 105.8 & 219.2 & 3727.1 \\
Notch 8 & 3 & 111.6 & 17.0 & 11.6 & 138.4 & 282.6 & 4390.8
\end{tabular}

Uncorrected Emissions

\begin{tabular}{|c|c|c|c|c|}
\hline Notch & Uncorrected CO2 (g) & Uncorrected HC (g) & Uncorrected CO (g) & Uncorrected NOx (g) \\
\hline & 6012.8 & 6.9 & 6.5 & 125.0 \\
\hline Sraking & 5644.5 & 5.8 & 7.1 & 89.6 \\
\hline Notch 1 & 11525.9 & 5.3 & 9.3 & 226.8 \\
\hline Notch 2 & 20454.0 & 7.2 & 12.5 & 367.8 \\
\hline Notch 3 & 42796.4 & 12.6 & 15.3 & 714.1 \\
\hline & 65516.7 & 16.7 & 48.4 & 964.8 \\
\hline Notch & 86781.5 & 19.2 & 210.7 & 1107.5 \\
\hline Notch 6 & 103377.9 & 19.7 & 307.4 & 1109.6 \\
\hline Notch 7 & 152035.0 & 32.1 & 176.8 & 1710.7 \\
\hline & 368918.6 & 74.9 & 613.1 & 3975.1 \\
\hline
\end{tabular}




\section{Drift Check Data}

\begin{tabular}{lrrrr}
\multicolumn{1}{l}{ Drift data used for all notches is as follows: } & & \\
Analyzer & Zero Reading & Span Reading & Span Concentration & Unit \\
\hline CO2 & 8.0 & 100268.3 & 99890.0 & $\mathrm{ppm}$ \\
$\mathrm{CO}$ & -0.4 & 1503.4 & 1502.0 & $\mathrm{ppm}$ \\
$\mathrm{HC}$ & 1.3 & 300.9 & 300.3 & $\mathrm{ppm}$ \\
NOx & 3.0 & 1999.7 & 1993.0 & $\mathrm{ppm}$ \\
NO & -0.2 & -0.3 & 1895.0 & $\mathrm{ppm}$ \\
$\mathrm{CH} 4$ & -34.5 & -34.5 & 100.0 & $\mathrm{ppm}$
\end{tabular}

\section{Drift}

\begin{tabular}{rrrrr} 
Notch & CO2 Drift (\%) & HC Drift (\%) & CO Drift (\%) & NOx Drift (\%) \\
\hline Idle & -0.0 & 2.1 & -1.9 & 0.9 \\
DynBraking & -0.0 & 2.1 & -1.5 & 1.1 \\
Notch 1 & -0.0 & 1.9 & -1.0 & 0.3 \\
Notch 2 & -0.0 & 1.8 & -0.9 & 0.2 \\
Notch 3 & -0.0 & 1.4 & -1.0 & 0.2 \\
Notch 4 & -0.0 & 1.2 & -0.4 & 0.1 \\
Notch 5 & -0.0 & 1.2 & -0.2 & 0.1 \\
Notch 6 & -0.0 & 1.4 & -0.1 & 0.2 \\
Notch 7 & -0.0 & 1.4 & -0.3 & 0.2 \\
Notch 8 & -0.0 & 1.4 & -0.2 & 0.2
\end{tabular}

Composite Drift Result

\begin{tabular}{rrrrr} 
Duty Cycle & CO2 (\%) & HC (\%) & CO (\%) & NOx (\%) \\
\hline Switcher & -0.0 & 1.7 & -0.5 & 0.3 \\
Line-Haul & -0.0 & 1.5 & -0.3 & 0.2
\end{tabular}

\section{Emission Concentrations}

\begin{tabular}{rrrrr}
\multicolumn{1}{l}{ Notch } & CO2 dry (avg) (\%) & HC wet (avg) (ppm) & CO dry (avg) (ppm) & NOx dry (avg) (ppm) \\
\hline Idle & 0.75 & 26.2 & 13 & 148 \\
DymBraking & 0.81 & 25.4 & 16 & 123 \\
Notch 1 & 2.07 & 28.1 & 26 & 387 \\
Notch 2 & 2.94 & 30.7 & 28 & 505 \\
Notch 3 & 4.25 & 37.0 & 24 & 676 \\
Notch 4 & 5.73 & 42.7 & 67 & 805 \\
Notch 5 & 6.69 & 43.1 & 256 & 815 \\
Notch 6 & 7.08 & 39.0 & 332 & 725 \\
Notch 7 & 6.07 & 37.2 & 113 & 650 \\
Notch 8 & 6.26 & 37.2 & 185 & 644
\end{tabular}

Correction Factors

\begin{tabular}{rrrrr}
\hline \multicolumn{1}{c}{ Notch } & CO2 rwc (avg) & CO rwc (avg) & NOx rwc (avg) & NOx cor. factor (avg) \\
\hline Idle & 0.9862 & 0.9862 & 0.9862 & 0.9989 \\
DynBraking & 0.9857 & 0.9857 & 0.9857 & 0.9989 \\
Notch 1 & 0.9748 & 0.9748 & 0.9748 & 0.9988 \\
Notch 2 & 0.9875 & 0.9675 & 0.9675 & 0.9989 \\
Notch 3 & 0.9565 & 0.9565 & 0.9585 & 0.9984 \\
Notch 4 & 0.9444 & 0.9444 & 0.9444 & 1.0001 \\
Notch 5 & 0.9368 & 0.9868 & 0.9366 & 1.0009 \\
Notch 6 & 0.9336 & 0.9336 & 0.9336 & 1.0010 \\
Notch 7 & 0.9416 & 0.9416 & 0.9416 & 1.0016 \\
Notch 8 & 0.9398 & 0.9398 & 0.9398 & 1.0049
\end{tabular}




\begin{tabular}{llr}
\hline \multicolumn{2}{l}{ PM FilterS } \\
\hline \multicolumn{1}{l}{ Notch } & Filter ID & PM Mass (mg) \\
\hline Idle & WVE26761 & - \\
DynBraking & WVE26762 & - \\
Notch 1 & WVE26763 & - \\
Notch 2 & WVE26784 & - \\
Notch 3 & WVE26785 & - \\
Notch 4 & WVE26786 & - \\
Notch 5 & WVE26767 & - \\
Notch 6 & WVE26768 & - \\
Notch 7 & WVE26769 & - \\
Notch 8 & WVE26770 & - \\
\end{tabular}

\section{Mass Emissions}

\begin{tabular}{rrrrrr}
\hline Notch & \multicolumn{1}{c}{ CO2 (g) } & HC $(\mathrm{g})$ & $\mathrm{CO}(\mathrm{g})$ & NOx $(\mathrm{g})$ & $\mathrm{PM}(\mathrm{g})$ \\
\hline Idle & 6013.8 & 6.8 & 6.6 & 123.9 & - \\
DymBraking & 5645.2 & 5.7 & 7.2 & 88.6 & - \\
Notch 1 & 11526.5 & 5.2 & 9.4 & 226.2 & - \\
Notch 2 & 20454.6 & 7.0 & 12.6 & 368.9 & - \\
Notch 3 & 42797.3 & 12.4 & 15.4 & 712.9 & - \\
Notch 4 & 65517.6 & 16.5 & 48.6 & 963.6 & - \\
Notch 5 & 86782.4 & 19.0 & 211.0 & 1105.9 & - \\
Notch 6 & 103378.8 & 19.4 & 307.8 & 1107.9 & - \\
Notch 7 & 152037.0 & 31.6 & 177.4 & 1707.6 & - \\
Notch 8 & 366023.1 & 73.8 & 614.4 & 3967.8 & -
\end{tabular}

\section{Opacity Results}

\footnotetext{
Nomalized to 0.554 meters.
}

Notch $\quad$ Steady State (\%) 30 Second (\%) 3 Second (\%)

$\begin{array}{rl}\text { Idle } & 0.1 \\ \text { DynBraking } & 0.4 \\ \text { Notch 1 } & 0.6 \\ \text { Notch 2 } & 0.7 \\ \text { Notch 3 } & 0.8 \\ \text { Notch } 4 & 2.0 \\ \text { Notch } 5 & 4.6 \\ \text { Notch } 6 & 6.8 \\ \text { Notch } 7 & 1.1 \\ \text { Notch } 8 & 1.8\end{array}$

$\begin{array}{lll}0.1 & 0.2 & 0.3 \\ 0.4 & 0.4 & 0.5 \\ 0.6 & 0.7 & 0.8 \\ 0.7 & 0.9 & 1.0 \\ 0.8 & 0.9 & 1.0 \\ 2.0 & 2.1 & 2.3 \\ 4.6 & 5.0 & 5.5 \\ 6.8 & 7.5 & 8.3 \\ 1.1 & 6.7 & 11.3 \\ 1.9 & 3.3 & 3.5\end{array}$

\section{Reportable Results}

\begin{tabular}{|c|c|c|c|c|c|c|c|}
\hline Notch & Gross Power (hp) & Fuel Rate (lb/hr) & $\mathrm{CO} 2(\mathrm{~g} / \mathrm{hr})$ & $\mathrm{HC}(\mathrm{g} / \mathrm{hr})$ & $\mathrm{CO}(\mathrm{g} / \mathrm{hr})$ & Corr. NOx (g/hr) & $\mathrm{PM}(\mathrm{g} / \mathrm{hr})$ \\
\hline $\begin{array}{r}\text { Idle } \\
\text { DymBraking } \\
\text { Notch } 1 \\
\text { Notch } 2 \\
\text { Notch } 3 \\
\text { Notch } 4 \\
\text { Notch } 5 \\
\text { Notch } 6 \\
\text { Notch } 7 \\
\text { Notch } 8\end{array}$ & $\begin{array}{r}11.1 \\
28.0 \\
221.1 \\
445.9 \\
988.9 \\
1556.3 \\
2046.9 \\
2435.7 \\
3898.7 \\
4441.0\end{array}$ & $\begin{array}{r}23.8 \\
45.0 \\
94.3 \\
168.1 \\
352.8 \\
541.8 \\
720.1 \\
858.8 \\
1258.3 \\
1519.9\end{array}$ & $\begin{array}{r}36083 \\
67742 \\
138318 \\
245456 \\
513587 \\
786211 \\
1041389 \\
1240546 \\
1824444 \\
2201538\end{array}$ & $\begin{array}{r}40.8 \\
68.3 \\
62.1 \\
84.3 \\
149.2 \\
197.6 \\
228.2 \\
233.1 \\
379.2 \\
442.9\end{array}$ & $\begin{array}{r}39.6 \\
86.7 \\
112.7 \\
151.2 \\
185.0 \\
583.1 \\
2532.4 \\
3694.3 \\
2128.5 \\
3686.3\end{array}$ & $\begin{array}{r}743.3 \\
1062.9 \\
2714.1 \\
4402.8 \\
8554.3 \\
11563.3 \\
13271.3 \\
13294.5 \\
20491.0 \\
23806.8\end{array}$ & $\begin{array}{l}- \\
- \\
- \\
- \\
- \\
- \\
- \\
-\end{array}$ \\
\hline
\end{tabular}


Switcher Duty Cycle Weighted Results

\begin{tabular}{|c|c|c|c|c|c|c|c|c|}
\hline Notch & Factor (\%) & Power (hp) & Fuel Rate (lb/hr) & $\mathrm{CO} 2$ (g/hr) & HC (g/hr) & $\mathrm{CO}(\mathrm{g} / \mathrm{hr})$ & NOx $(g / h r)$ & PM (g/hr) \\
\hline Idle & $5 e .8$ & 6.6 & 14.3 & 21577 & 24.4 & 23.7 & 444.5 & - \\
\hline DynBraking & 0.0 & 0.0 & 0.0 & 0 & 0.0 & 0.0 & 0.0 & \\
\hline Notch 1 & 12.4 & 27.4 & 11.7 & 17151 & 7.7 & 14.0 & 336.5 & \\
\hline Notch 2 & 123 & 54.8 & 20.7 & 30191 & 10.4 & 18.6 & 541.5 & \\
\hline Notch 3 & 5.8 & 57.4 & 20.5 & 29787 & 8.7 & 10.7 & 496.2 & \\
\hline Notch 4 & 3.6 & 56.0 & 18.5 & 28304 & 7.1 & 21.0 & 416.3 & - \\
\hline Notch 5 & 3.6 & 73.7 & 25.9 & 37490 & 8.2 & 91.2 & 477.8 & \\
\hline Notch 6 & 1.5 & 38.5 & 12.9 & 18608 & 3.5 & 55.4 & 199.4 & - \\
\hline Notch 7 & 0.2 & 7.4 & 2.5 & 3649 & 0.8 & 4.3 & 41.0 & \\
\hline Notch 8 & 0.8 & 35.5 & 12.2 & 17612 & 3.5 & 29.5 & 190.5 & - \\
\hline $\begin{array}{r}\text { Sum } \\
\text { Brake Specific }\end{array}$ & 100.0 & 355.4 & $\begin{array}{l}140.1 \\
0.304\end{array}$ & $\begin{array}{r}204370 \\
575\end{array}$ & $\begin{array}{l}74.2 \\
0.209\end{array}$ & $\begin{array}{r}288.3 \\
0.75\end{array}$ & $\begin{array}{r}3143.6 \\
8.84\end{array}$ & - \\
\hline
\end{tabular}

Line-Haul Duty Cycle Weighted Results

\begin{tabular}{|c|c|c|c|c|c|c|c|c|}
\hline Notch & Factor (\%) & Power (hp) & Fuel Rate (lb/hr) & $\mathrm{CO} 2(\mathrm{~g} / \mathrm{hr})$ & $\mathrm{HC}(g / \mathrm{hr})$ & $\mathrm{CO}(g / \mathrm{hr})$ & NOx $(g / h r)$ & PM (g/hr) \\
\hline Idle & 38.0 & 4.2 & 8.1 & 13711 & 15.5 & 15.1 & 282.5 & - \\
\hline DynBraking & 12.5 & 3.5 & 5.6 & 8488 & 8.5 & 10.8 & 132.8 & - \\
\hline Notch 1 & 6.5 & 14.4 & 6.1 & 8991 & 4.0 & 7.3 & 176.4 & - \\
\hline Notch 2 & 6.5 & 29.0 & 10.9 & 15955 & 5.5 & 9.8 & 286.2 & - \\
\hline Notch 3 & 5.2 & 51.4 & 18.4 & 28706 & 7.8 & 9.6 & 444.8 & - \\
\hline Notch 4 & 4.4 & 68.5 & 23.8 & 34593 & 8.7 & 25.7 & 508.8 & - \\
\hline Notch 5 & 3.8 & 77.8 & 27.4 & 39573 & 8.7 & 86.2 & 504.3 & - \\
\hline Notch 6 & 3.9 & 85.0 & 33.5 & 48381 & 8.1 & 144.1 & 518.5 & - \\
\hline Notch 7 & 3.0 & 111.0 & 37.7 & 54733 & 11.4 & 63.9 & 614.7 & - \\
\hline Notch 8 & 16.2 & 719.4 & 246.2 & 356649 & 71.7 & 597.2 & 3856.7 & - \\
\hline $\begin{array}{r}\text { Sum } \\
\text { Brake Specific }\end{array}$ & 100.0 & 1174.2 & $\begin{array}{l}418.8 \\
0.357\end{array}$ & $\begin{array}{r}607760 \\
518\end{array}$ & $\begin{array}{r}150.9 \\
0.12\end{array}$ & $\begin{array}{r}979.7 \\
0.83\end{array}$ & $\begin{array}{r}7325.7 \\
6.24\end{array}$ & - \\
\hline
\end{tabular}




\section{Appendix C3 - Omega ${ }^{\mathrm{TM}}$ Engineering FMC-5000 Coriolis Mass Flow Meter Specifications}

2.1.1 Flow Range

Table 3: Flow Range of Micro-bend type sensor (for Liquid)

\begin{tabular}{|c|c|c|c|c|c|}
\hline $\begin{array}{c}\text { DN } \\
(\mathrm{mm})\end{array}$ & $\begin{array}{c}\text { Allowable Flow } \\
\text { Range }(\mathrm{kg} / \mathrm{h})\end{array}$ & $\begin{array}{c}\text { Normal Flow } \\
\text { Range for } \\
\text { Accuracy 0.1\% } \\
(\mathrm{kg} / \mathrm{h})\end{array}$ & $\begin{array}{c}\text { Normal Flow } \\
\text { Range for } \\
\text { Accuracy 0.2\% } \\
(\mathrm{kg} / \mathrm{h})\end{array}$ & $\begin{array}{c}\text { Normal Flow } \\
\text { Range for } \\
\text { Accuracy 0.5\% } \\
(\mathrm{kg} / \mathrm{h})\end{array}$ & $\begin{array}{c}\text { Stability } \\
\text { of Zero } \\
\text { Point } \\
(\mathrm{kg} / \mathrm{h})\end{array}$ \\
\hline 15 & $20 \sim 3000$ & $200 \sim 3000$ & $150 \sim 3000$ & $100 \sim 3000$ & 0.09 \\
\hline 25 & $80 \sim 8000$ & $600 \sim 8000$ & $400 \sim 8000$ & $300 \sim 8000$ & 0.25 \\
\hline 40 & $240 \sim 24000$ & $2400 \sim 24000$ & $1200 \sim 24000$ & $1000 \sim 24000$ & 1 \\
\hline 50 & $500 \sim 45000$ & $5000 \sim 45000$ & $2500 \sim 45000$ & $2000 \sim 45000$ & 2 \\
\hline 80 & $800 \sim 120000$ & $8000 \sim 120000$ & $7000 \sim 120000$ & $6000 \sim 120000$ & 3.5 \\
\hline 100 & $1500 \sim 200000$ & $18000 \sim 200000$ & $12000 \sim 200000$ & $10000 \sim 200000$ & 7 \\
\hline 150 & $5000 \sim 500000$ & $50000 \sim 500000$ & $35000 \sim 500000$ & $30000 \sim 500000$ & 23 \\
\hline 200 & $10000 \sim$ & $100000 \sim$ & $70000 \sim$ & $50000 \sim$ & 45 \\
\hline
\end{tabular}




\section{Appendix C4 - Siemens FCS400 DN 15 sensor flow meter calculations}

\section{SIEMENS}

\section{Calculations on FCS400 DN 15 sensor}

\begin{tabular}{|r|r|r|r|r|}
\hline $\begin{array}{r}\text { Flowrate } \\
{[\mathrm{kg} / \mathrm{h}]}\end{array}$ & $\begin{array}{r}\text { Pressure drop } \\
{[\mathrm{bar}]}\end{array}$ & $\begin{array}{r}\text { Flow velocity } \\
{[\mathrm{m} / \mathrm{s}]}\end{array}$ & $\begin{array}{r}\text { Reynold No } \\
{[\mathrm{Re}]}\end{array}$ & $\begin{array}{r}\text { Max. error *) } \\
{[\% \text { of Flowrate] }}\end{array}$ \\
\hline 5.00 & 0.00018 & 0.02 & 12 & \pm 4.00 \\
77.27 & 0.0027 & 0.29 & 182 & \pm 0.28 \\
149.55 & 0.0053 & 0.56 & 353 & \pm 0.17 \\
221.82 & 0.0078 & 0.83 & 523 & \pm 0.13 \\
294.09 & 0.010 & 1.10 & 693 & \pm 0.12 \\
366.36 & 0.013 & 1.37 & 864 & \pm 0.11 \\
438.64 & 0.015 & 1.64 & 1.034 & \pm 0.11 \\
510.91 & 0.018 & 1.91 & 1.205 & \pm 0.11 \\
583.18 & 0.020 & 2.18 & 1.375 & \pm 0.11 \\
655.45 & 0.023 & 2.45 & 1.545 & \pm 0.10 \\
727.73 & 0.026 & 2.72 & 1.716 & \pm 0.10 \\
800.00 & 0.028 & 2.99 & 1.886 & \pm 0.10 \\
\hline
\end{tabular}

The following data are used for the pressure drop calculation:

Liquid Name: $\quad$ Diesiel Fuel No2 Density: $840 \mathrm{~kg} / \mathrm{m} 3$

Minimum flow rate: $5 \mathrm{~kg} / \mathrm{h} \quad$ Viscosity: $10 \mathrm{cP}\left(\mathrm{mPa}^{*} \mathrm{~s}\right)$

Maximum flow rate: $800 \mathrm{~kg} / \mathrm{h}$

The above pressure drop calculations are meant as guidelines only and if the pressure drop above the sensor is critical compared to the pump capacity. practical pressure drop measurements with the actual liquid must be made.

$\left.{ }^{*}\right)$ The error includes the combined effects of repeatability. linearity and hysteresis.

The results are based on reference conditions of water at $22^{\circ} \mathrm{C} \pm 5^{\circ} \mathrm{C}$ and at $1-2 \mathrm{bar}$. 


\section{Appendix C5 - Micro Motion CMFS040M calculation summary}

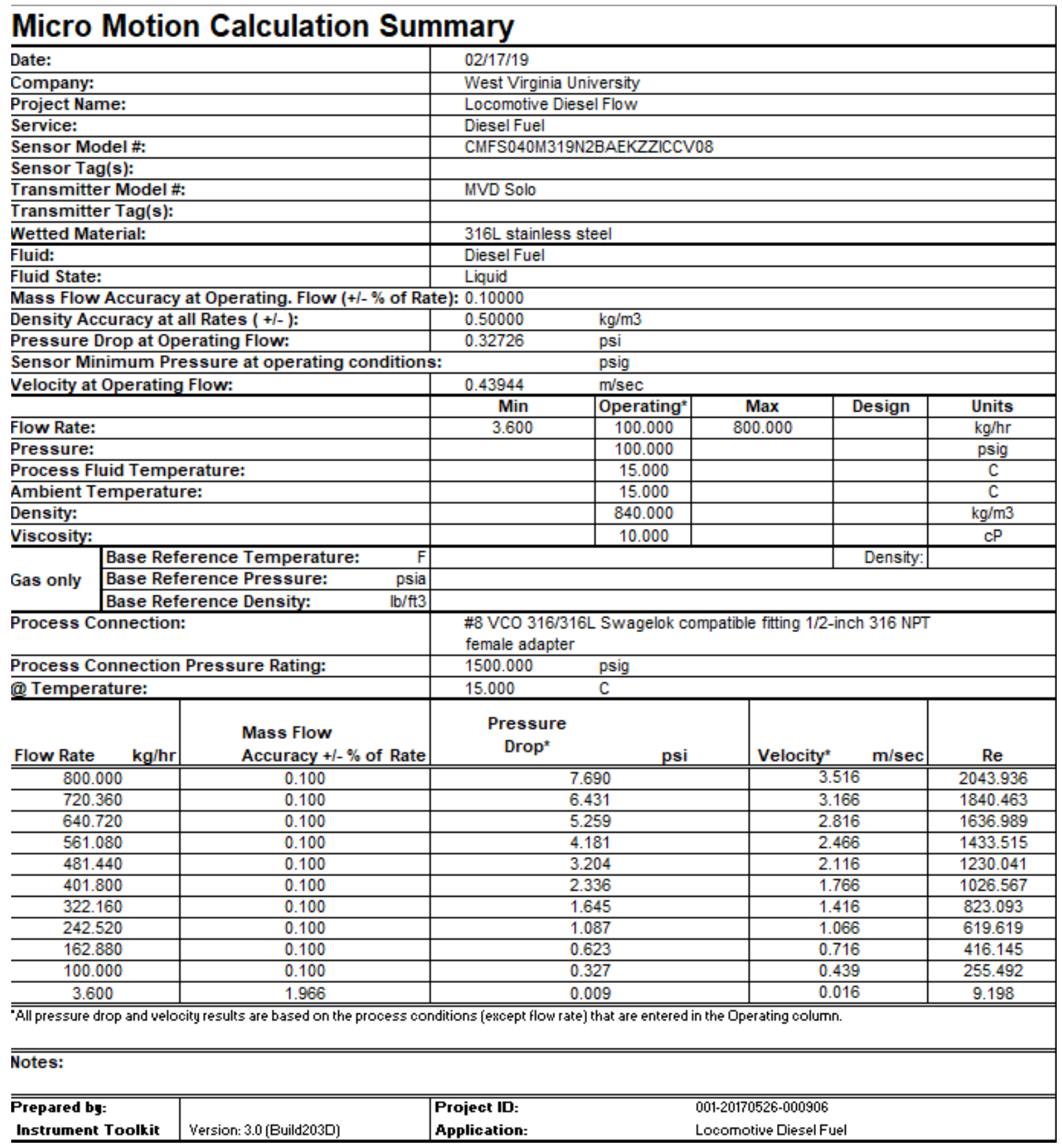




\section{Appendix C6 - Emerson MR98H Series Operational Schematics}

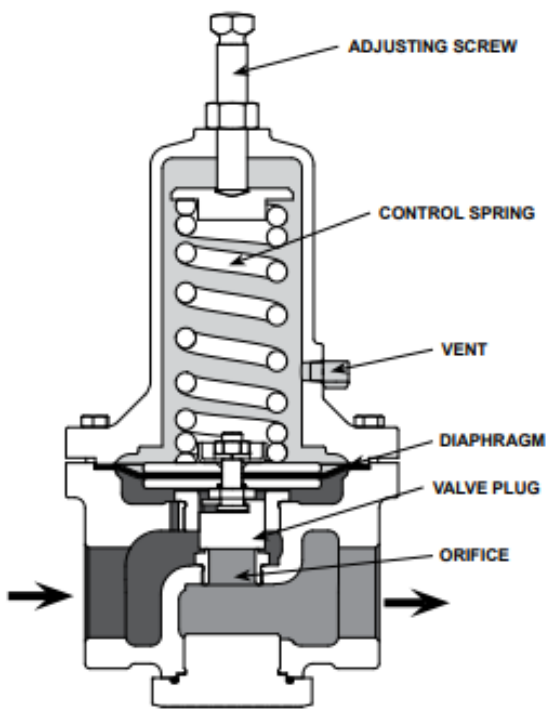

TYPE MR98H WITH INTERNAL PRESSURE REGISTRATION

NLET PRESSURE OUTLET PRESSURE

$\square$ ATMOSPHERIC PRESSURE

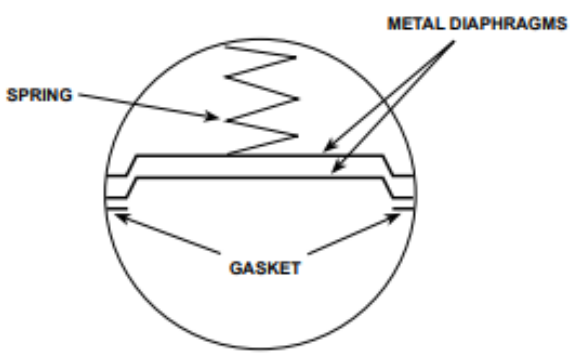

FOR TYPE MR98H WITH TWO METAL DIAPHRAGMS (ALSO TYPICAL OF TYPES MR98HH AND MR98L EXCEPT FOR TYPE MR98L, 1/4 NPT BODY, 2 TO 7 psi / 0.1 TO 0.48 bar RANGE)

Figure 2. MR98 Series Operational Schematics

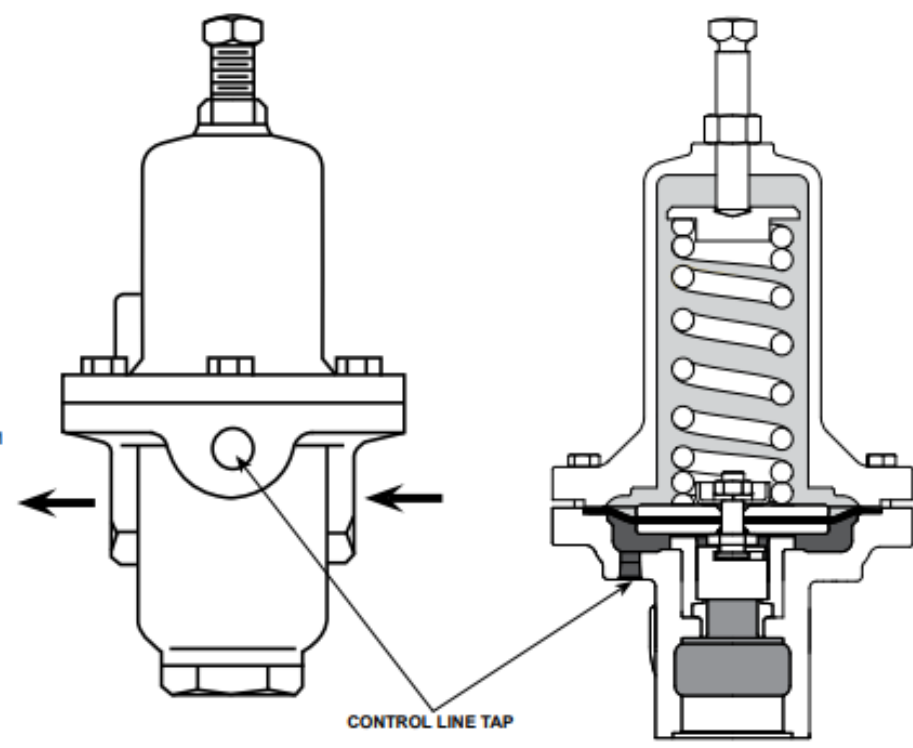

BACK VIEW OF 12 IN. / DN 15 TYPE MR98H WITH EXTERNAL PRESSURE REGISTRATION
SIDE AND INTERNAL VIEW OF $3 / 4$ TO 2 IN. / DN 20 TO 50 TYPE MR98H WITH EXTERNAL PRESSURE REGISTRATION (ALSO TYPICAL OF TYPE MR98L, $1 / 2$ TO 2 IN. / DN 15 TO 50 BODIES)

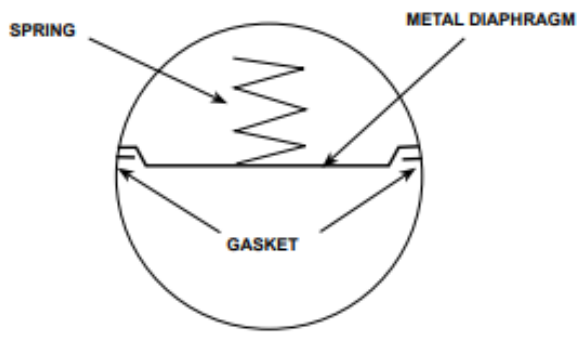

TYPE MR98L (1/4 NPT BODY, 2 TO 7 psi / 0.14 TO 0.48 bar RANGE) WITH ONE METAL DIAPHRAGM 
Appendix C7 - Test ID: R0007-002-198 Emissions Analyzer Data

Appendix C7.1 - Test ID: R0007-002-198 Notch 8 Emissions Analyzer Data

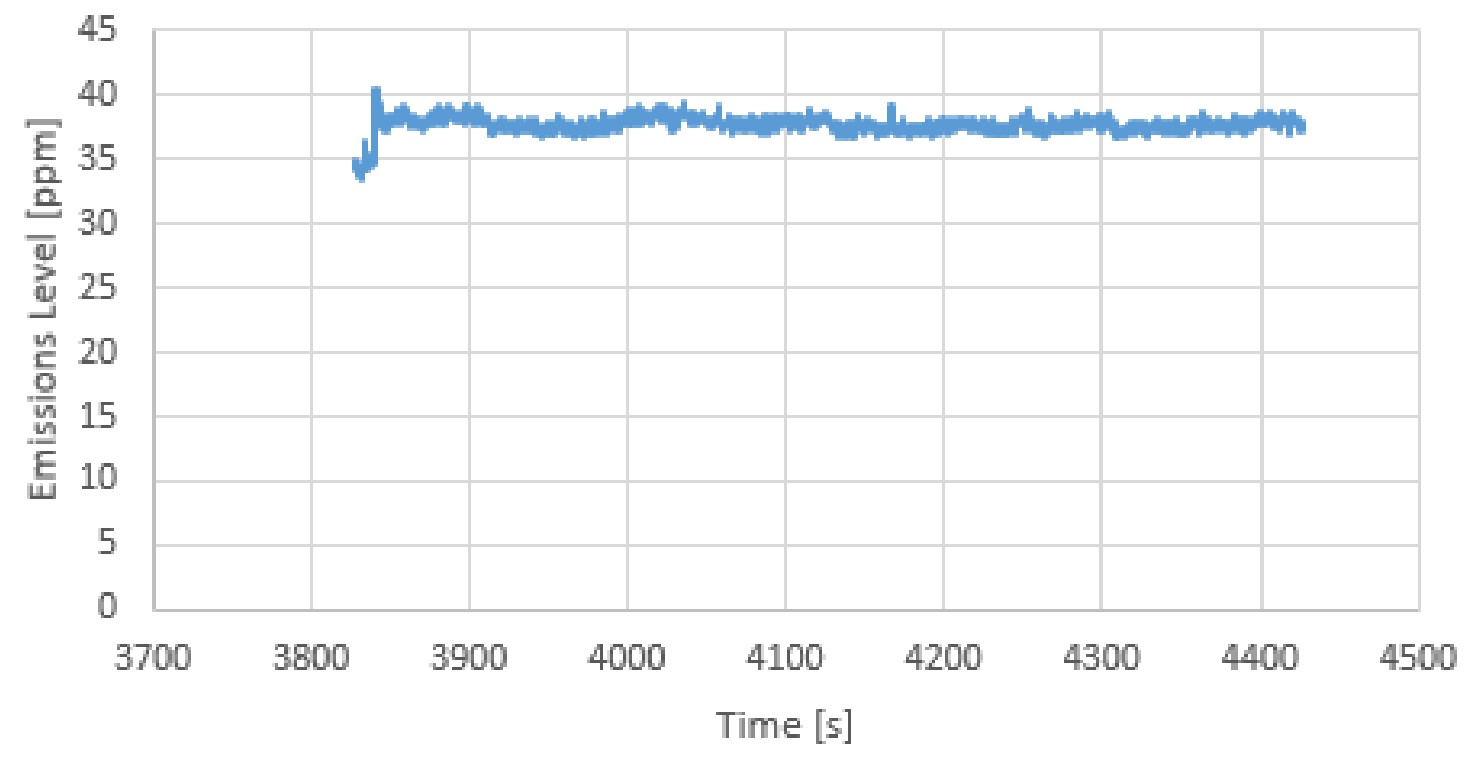

Figure 84 - THC emissions level measurement during Notch 8 for Test ID: R0007-002-198

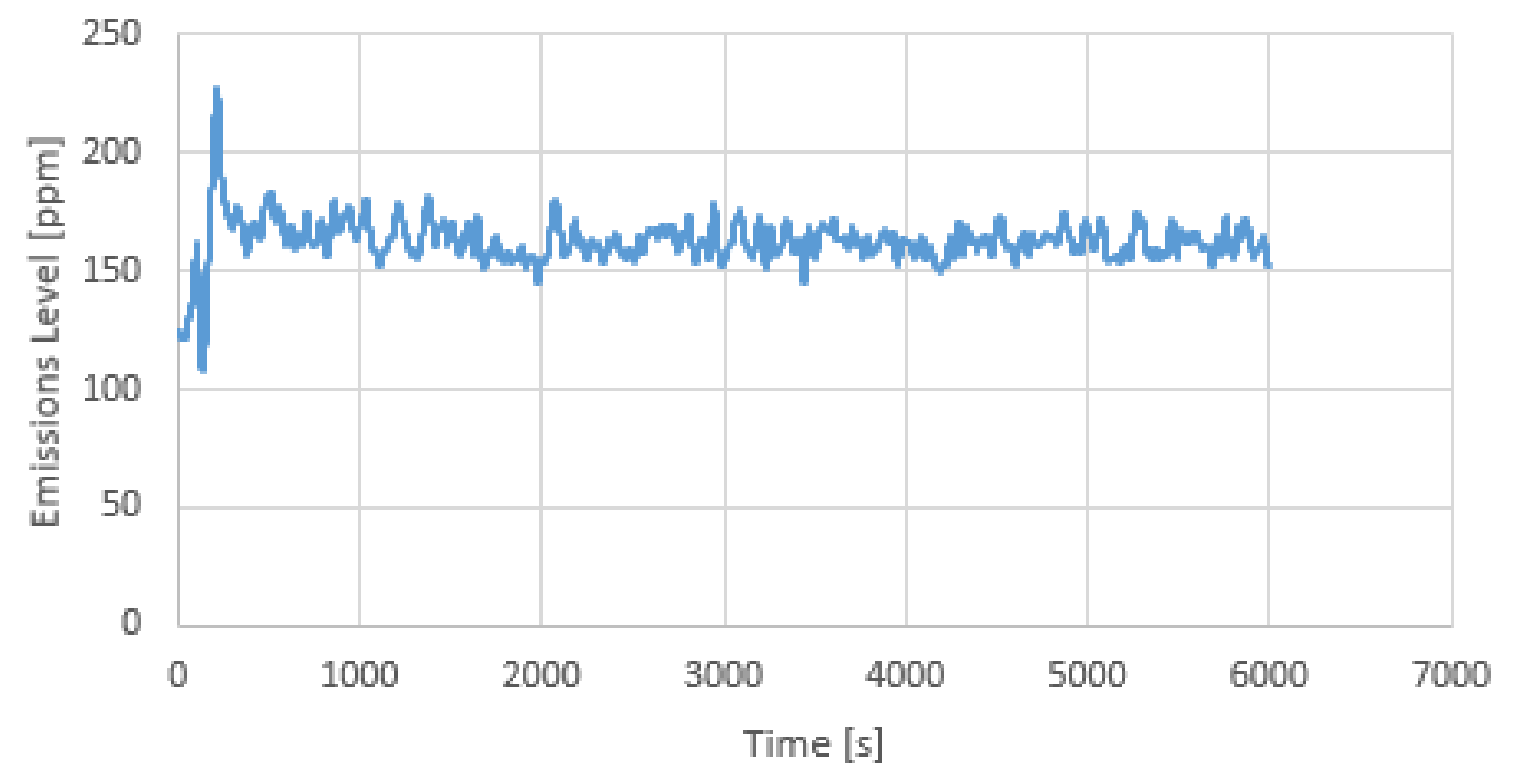

Figure 85 - CO emissions level measurement during Notch 8 for Test ID: R0007-002-198 


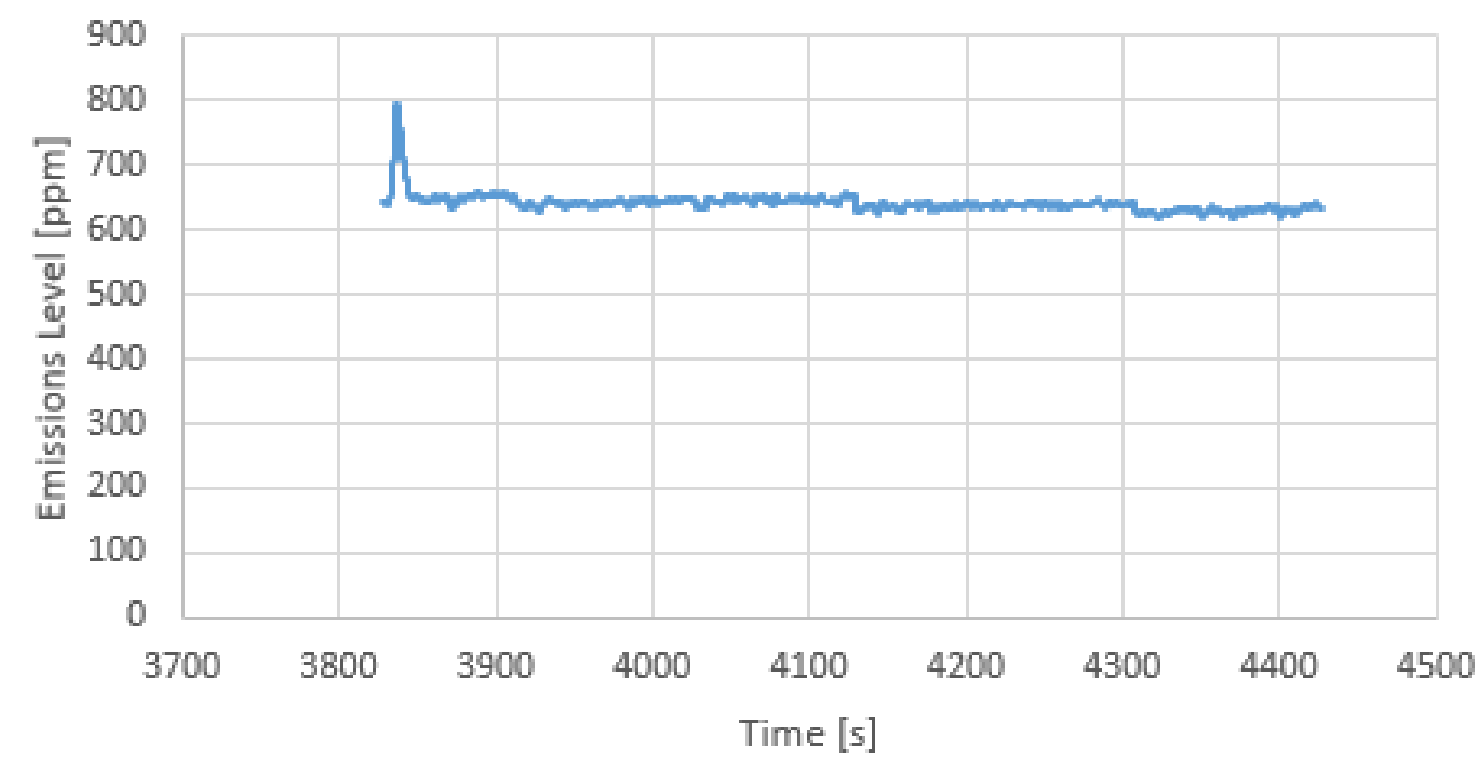

Figure 86 - NOx emissions level measurement during Notch 8 for Test ID: R0007-002-198

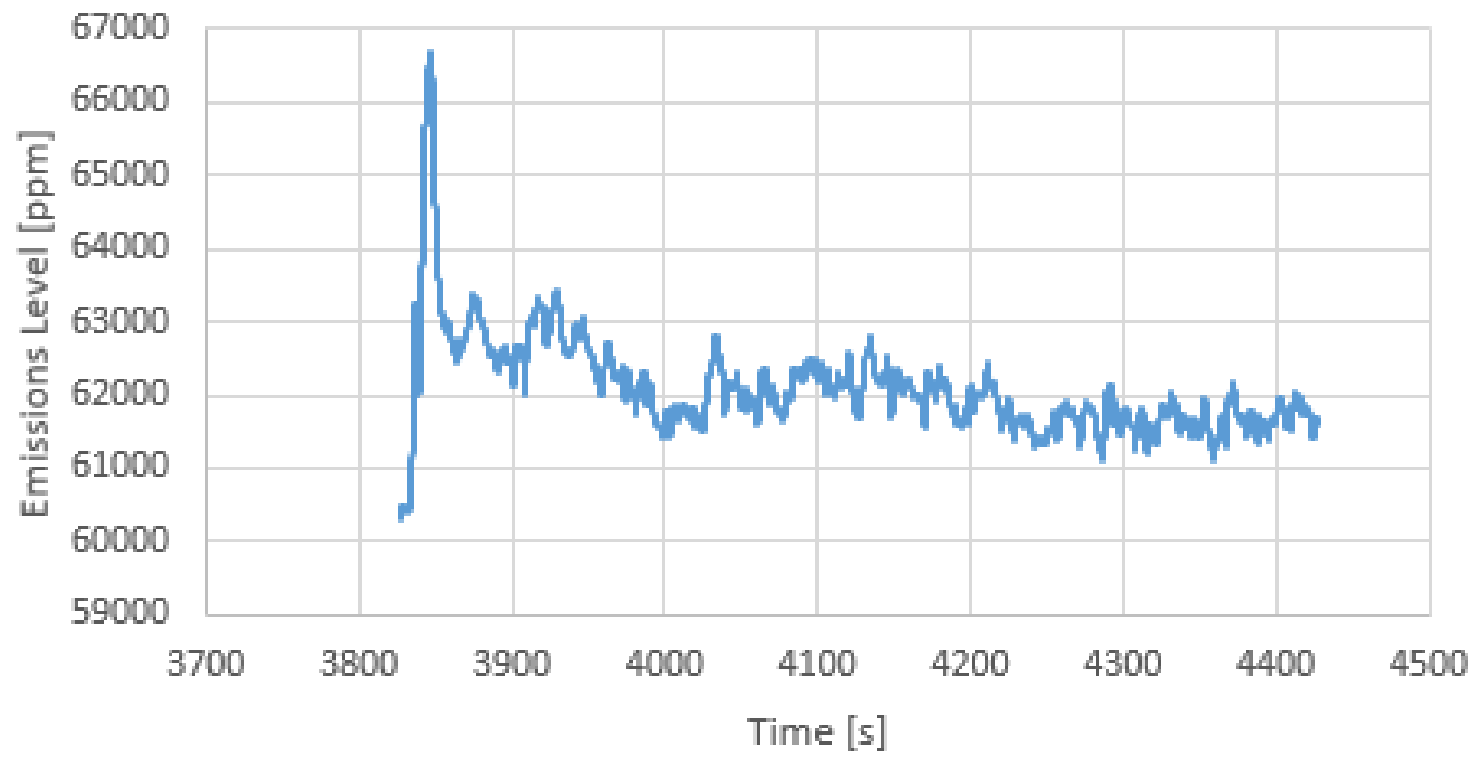

Figure 87 - CO2 emissions level measurement during Notch 8 for Test ID: R0007-002-198 


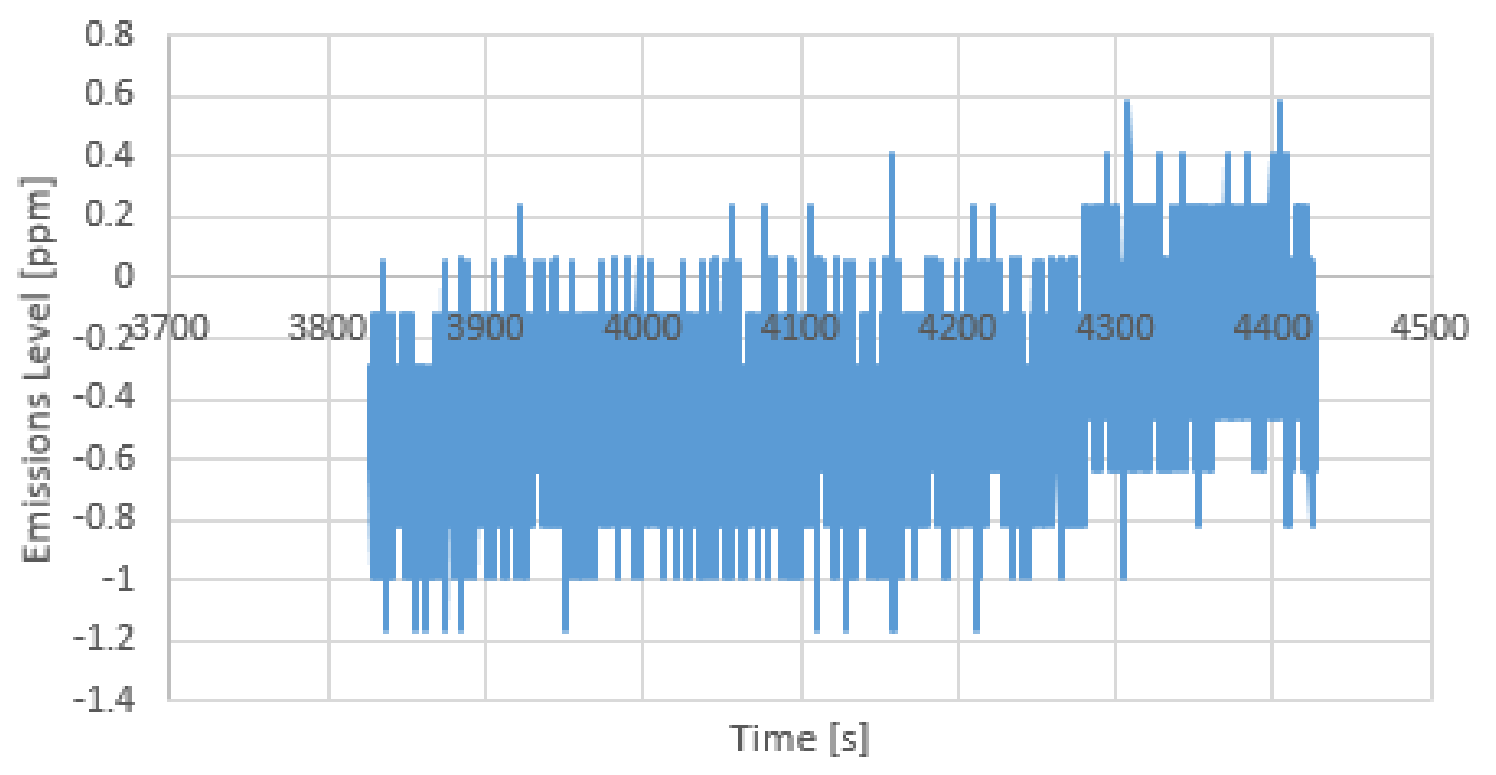

Figure 88 - NO emissions level measurement during Notch 8 for Test ID: R0007-002-198 
Appendix C7.2 - Test ID: R0007-002-198 Idle Emissions Analyzer Data

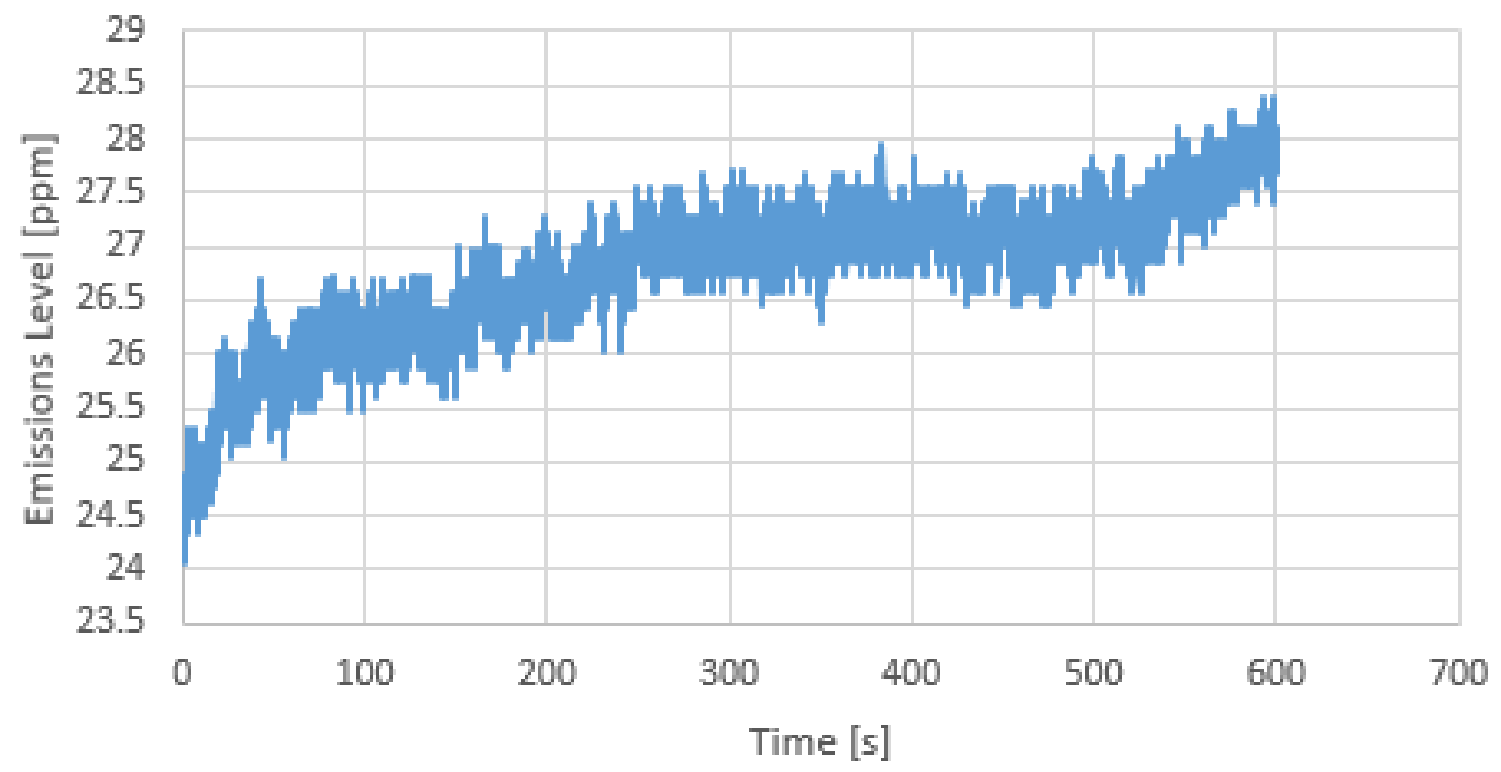

Figure 89 - THC emissions level measurement during Idle for Test ID: R0007-002-198

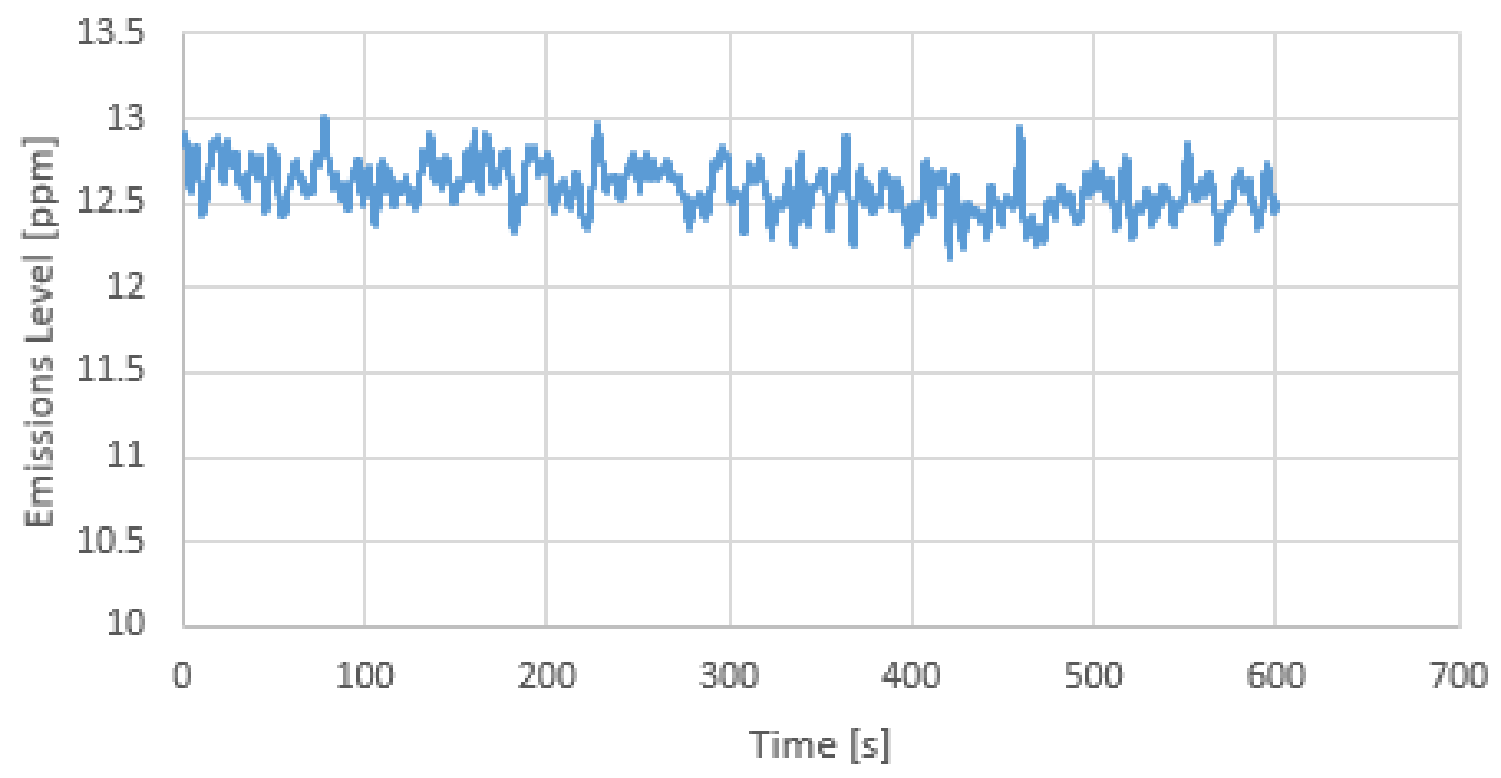

Figure 90 - CO emissions level measurement during Idle for Test ID: R0007-002-198 


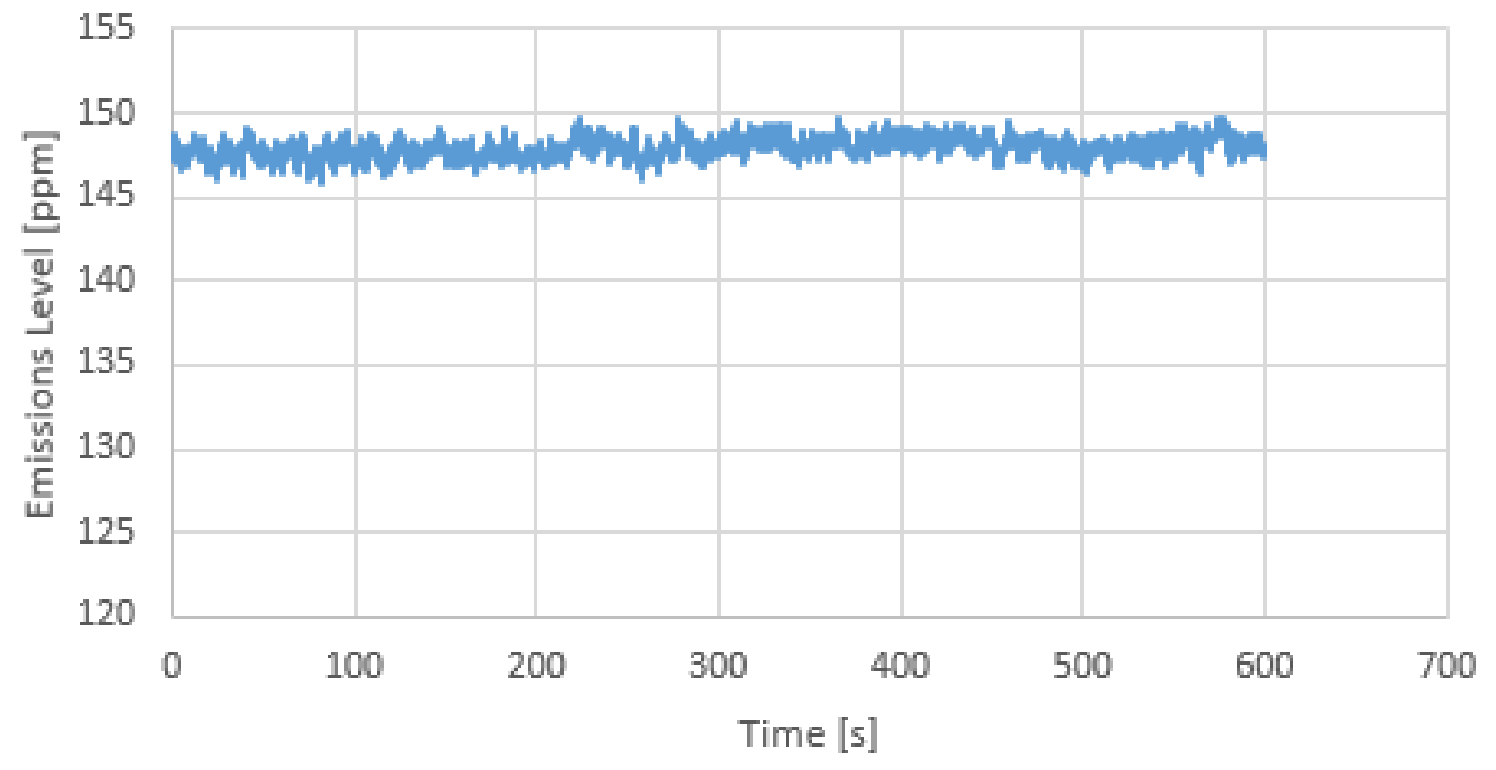

Figure 91 - NOx emissions level measurement during Idle for Test ID: R0007-002-198

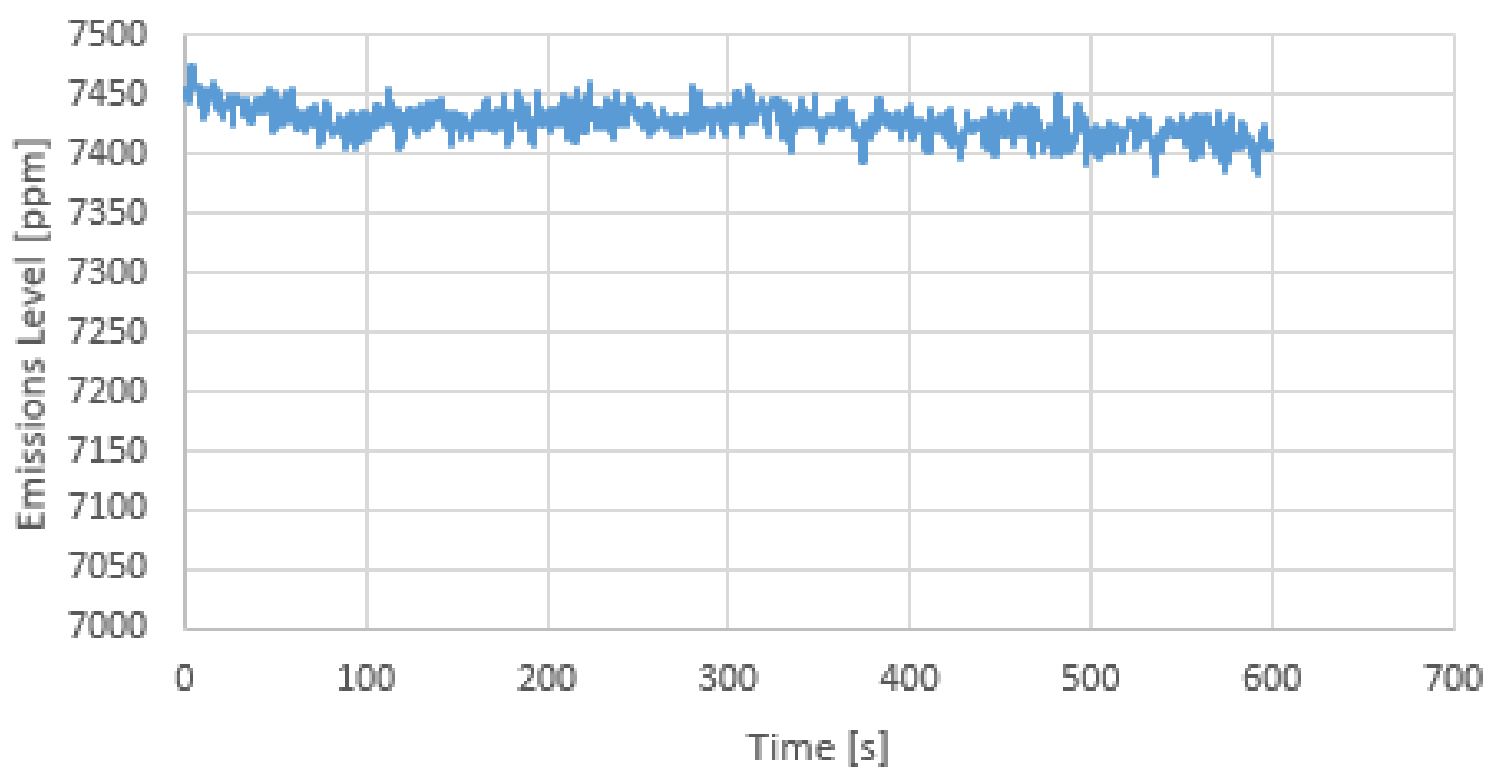

Figure 92 - CO2 emissions level measurement during Idle for Test ID: R0007-002-198 


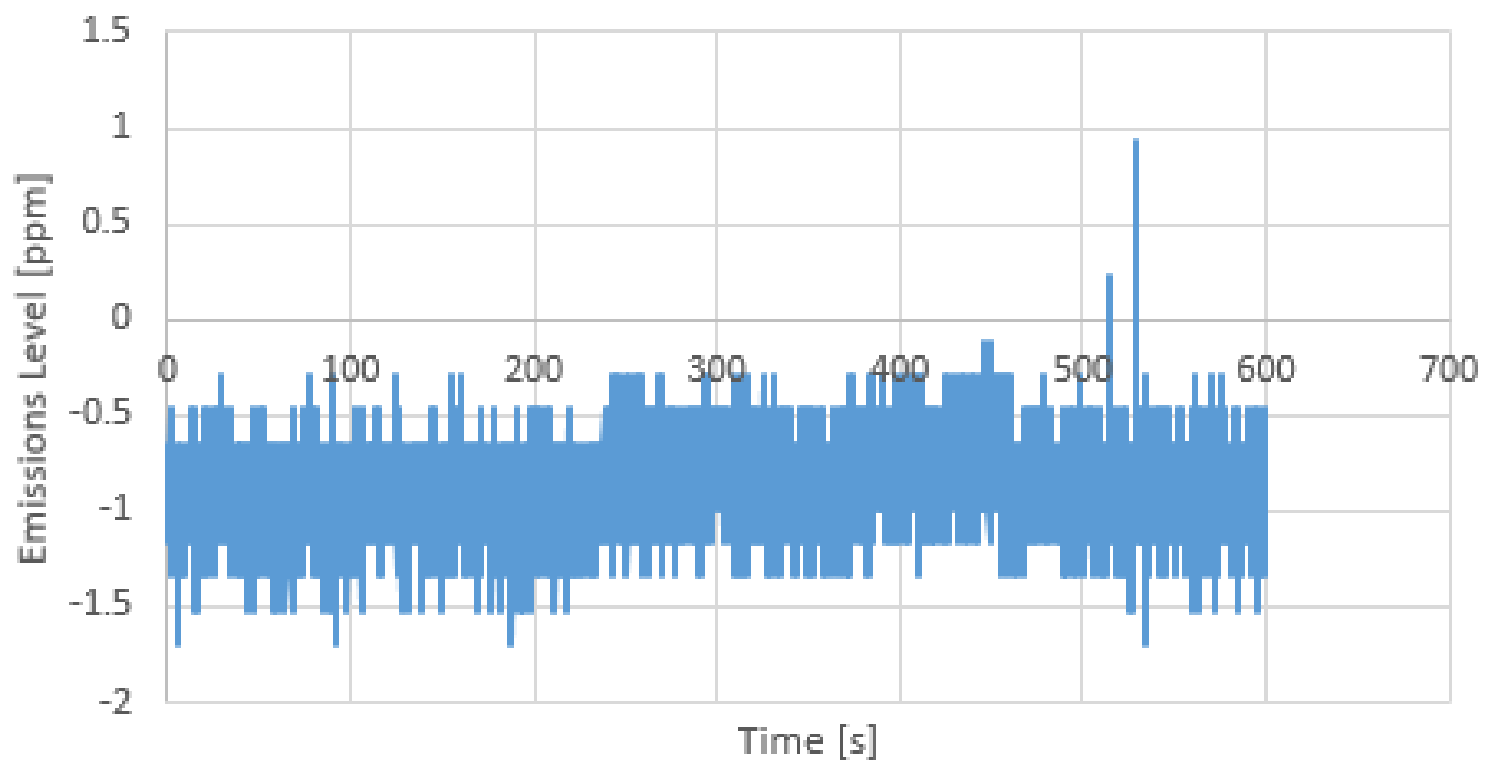

Figure 93 - NO emissions level measurement during Idle for Test ID: R0007-002-198 
Appendix C8 - Test ID: R0007-002-198 Idle Carbon Balance Results

Table 48 - Scimitar results for Idle for Test ID: R0007-002-198

\begin{tabular}{|l|r|r|r|r|r|r|}
\hline \multirow{2}{*}{ Emission } & \multicolumn{6}{|c|}{ Scimitar } \\
\cline { 2 - 7 } & Mass & $\begin{array}{c}\text { Mass } \\
\text { per } \\
\text { interval }\end{array}$ & $\begin{array}{c}\text { Switcher } \\
\text { weighted }\end{array}$ & $\begin{array}{c}\text { Line-Haul } \\
\text { weighted }\end{array}$ & $\begin{array}{c}\text { Brake- } \\
\text { Specific } \\
\text { (Switcher) }\end{array}$ & $\begin{array}{c}\text { Brake- } \\
\text { Specific } \\
\text { (Line- } \\
\text { Haul) }\end{array}$ \\
\cline { 2 - 7 } & $\mathbf{g}$ & $\mathbf{g} / \mathbf{h r}$ & $\mathbf{g} / \mathbf{h r}$ & $\mathbf{g} / \mathbf{h r}$ & \multicolumn{1}{|c|}{$\mathbf{g} / \mathbf{h p}-\mathbf{h r}$} & \multicolumn{1}{c|}{$\mathbf{g} / \mathbf{h p - h r}$} \\
\hline CO2 & 6013.8 & 36083 & 21577.0 & 13711.0 & 3269.2 & 3264.5 \\
\hline CO & 6.6 & 39.6 & 23.7 & 15.1 & 3.6 & 3.6 \\
\hline NOx & 123.9 & 743.3 & 444.5 & 282.5 & 67.3 & 67.3 \\
\hline THC & 6.8 & 40.8 & 24.4 & 15.5 & 3.7 & 3.7 \\
\hline
\end{tabular}

Table 49 - Scimitar results for Idle for Test ID: R0007-002-198

\begin{tabular}{|l|r|r|r|r|r|r|}
\hline \multirow{2}{*}{ Emission } & \multicolumn{7}{|c|}{ MATLAB $^{\circledR}$} \\
\cline { 2 - 7 } & Mass & $\begin{array}{c}\text { Mass } \\
\text { per } \\
\text { interval }\end{array}$ & $\begin{array}{c}\text { Switcher } \\
\text { weighted }\end{array}$ & $\begin{array}{c}\text { Line-Haul } \\
\text { weighted }\end{array}$ & $\begin{array}{c}\text { Brake- } \\
\text { Specific } \\
\text { (Switcher) }\end{array}$ & $\begin{array}{c}\text { Brake- } \\
\text { Specific } \\
\text { (Line- } \\
\text { Haul) }\end{array}$ \\
\cline { 2 - 7 } & $\mathbf{g}$ & $\mathbf{g} / \mathbf{h r}$ & $\mathbf{g} / \mathbf{h r}$ & $\mathbf{g} / \mathbf{h r}$ & $\mathbf{g} / \mathbf{h p - h r}$ & \multicolumn{1}{|c|}{$\mathbf{\text { hp-hr }}$} \\
\hline CO2 & 6179.6 & 37026 & 22162 & 14083 & 3338.7 & 3338.7 \\
\hline CO & 6.66 & 39.97 & 23.9 & 15.19 & 3.6 & 3.6 \\
\hline NOx & 121.72 & 730.32 & 436.73 & 277.53 & 65.8 & 65.79 \\
\hline THC & 6.59 & 39.53 & 23.64 & 15.02 & 3.56 & 3.56 \\
\hline
\end{tabular}




\section{Appendix C9 - Mass Flow Rate Measurements during Test ID: R0007-002-264}

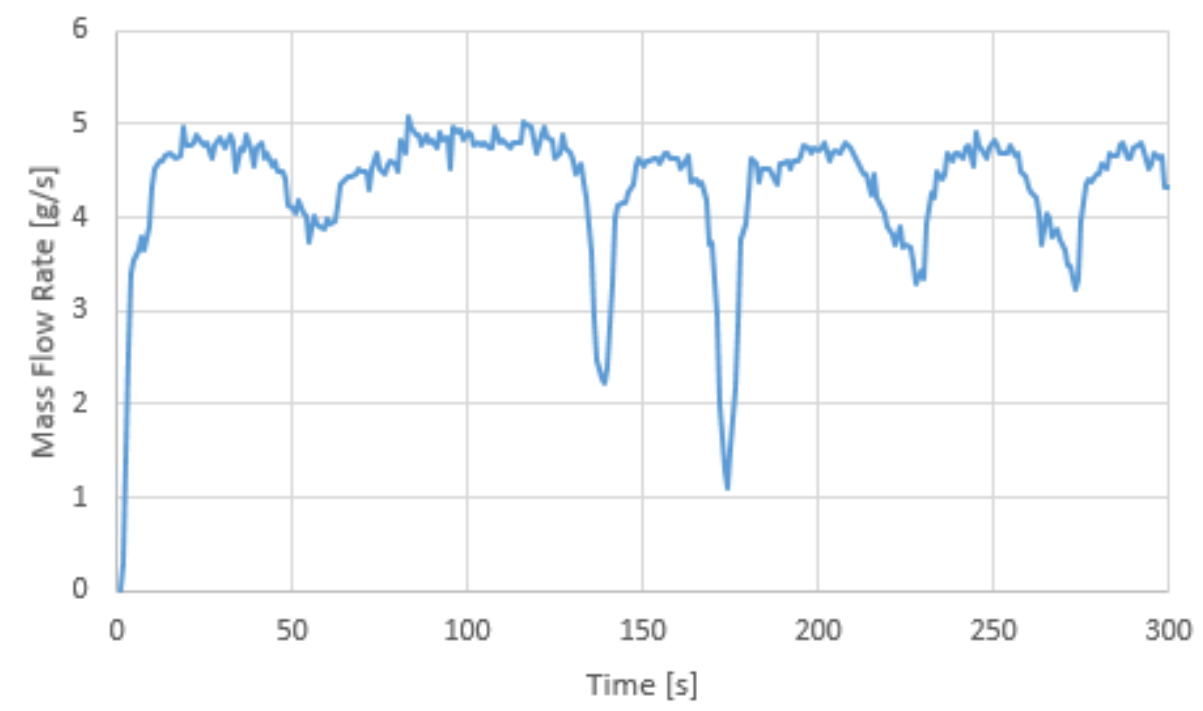

Figure 94 - Mass flow rate of fuel during Dynamic Braking for Test ID: R0007-002-264

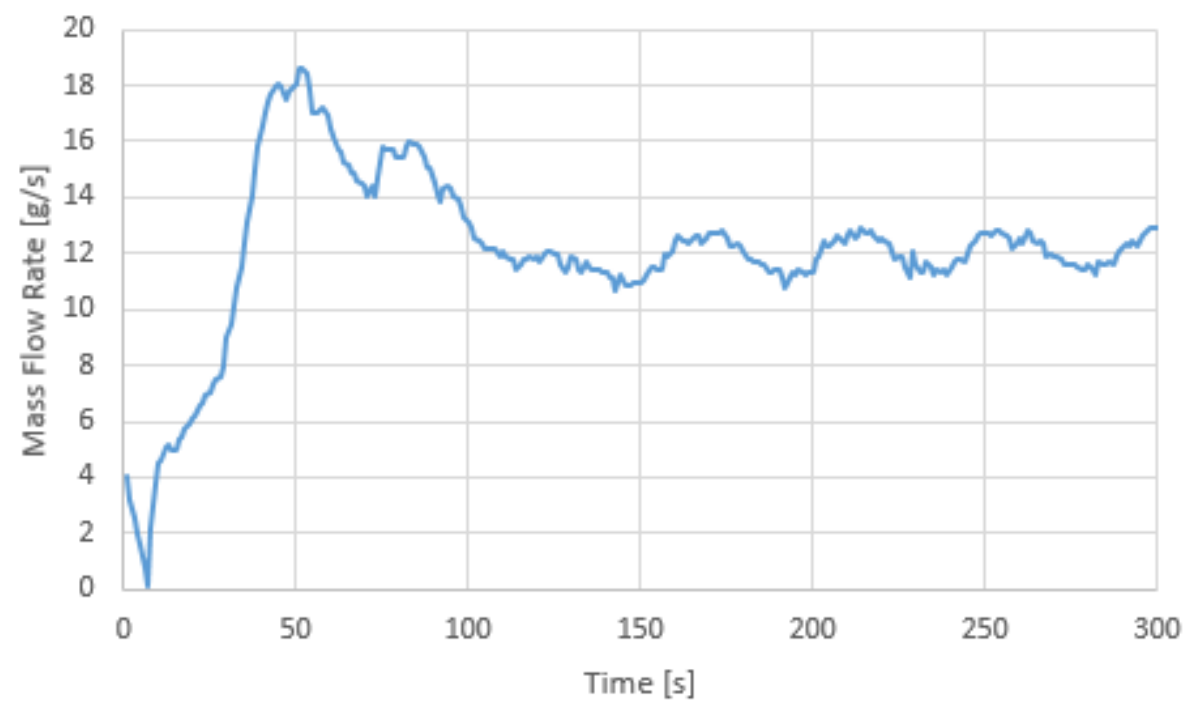

Figure 95 - Mass flow rate of fuel during Notch 1 for Test ID: R0007-002-264 


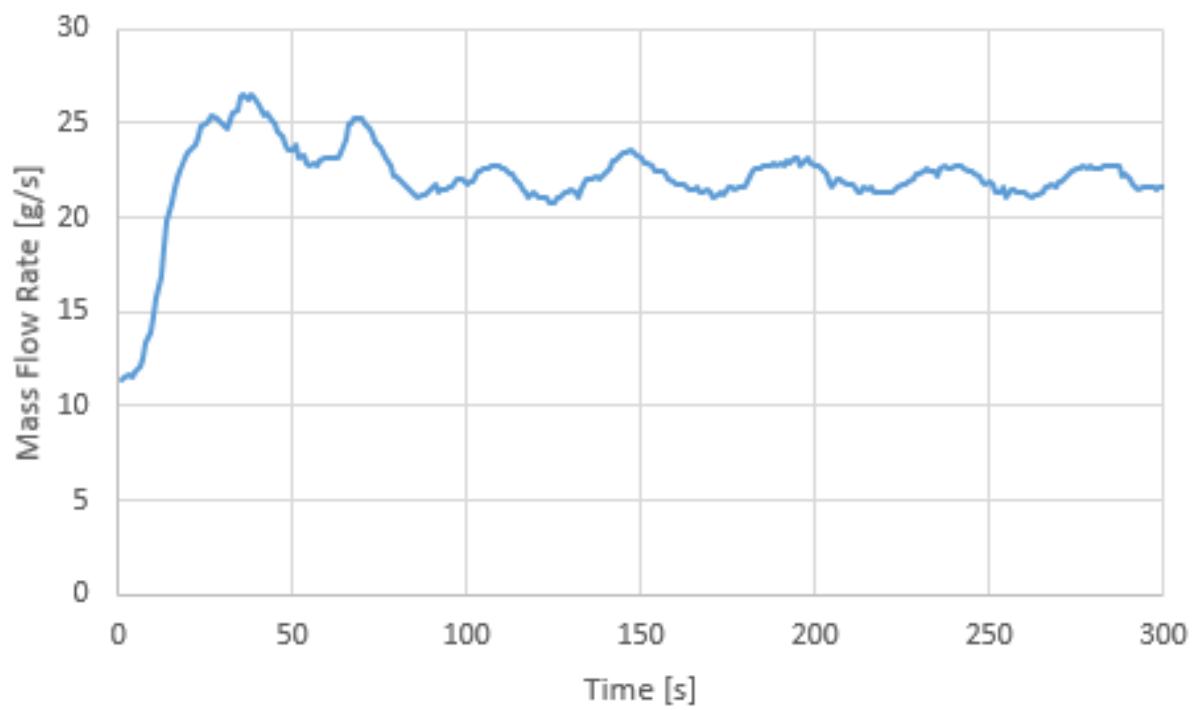

Figure 96 - Mass flow rate of fuel during Notch 2 for Test ID: R0007-002-264

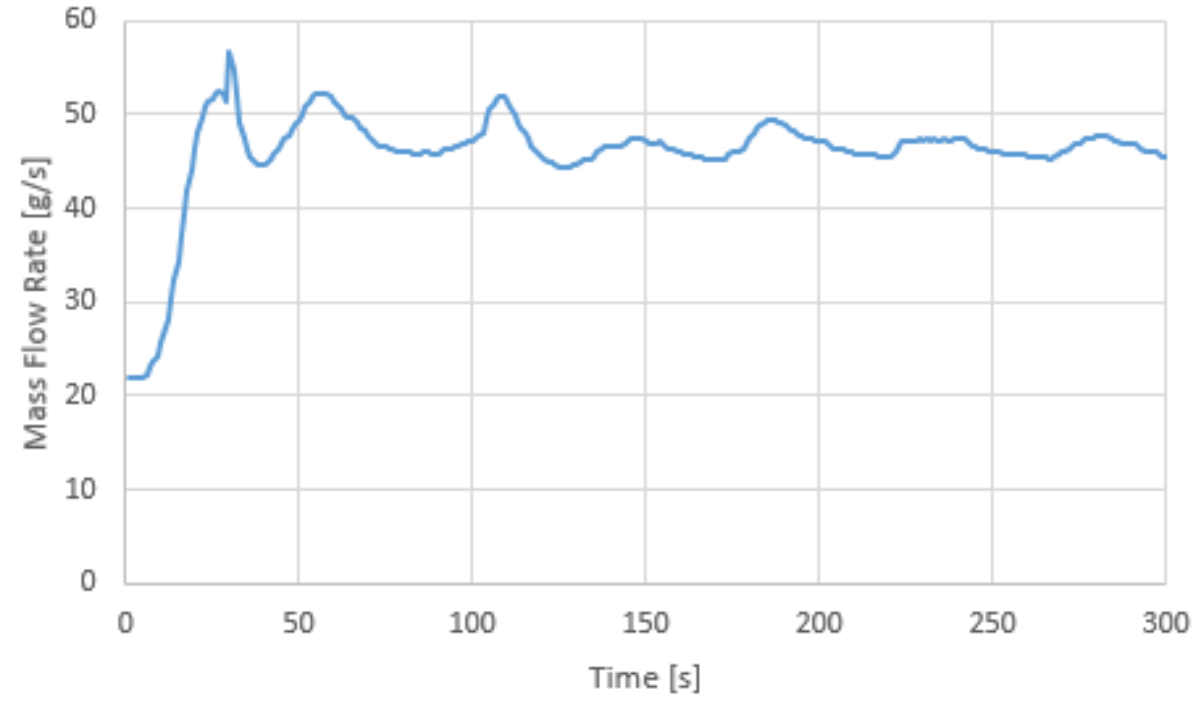

Figure 97 - Mass flow rate of fuel during Notch 3 for Test ID: R0007-002-264 


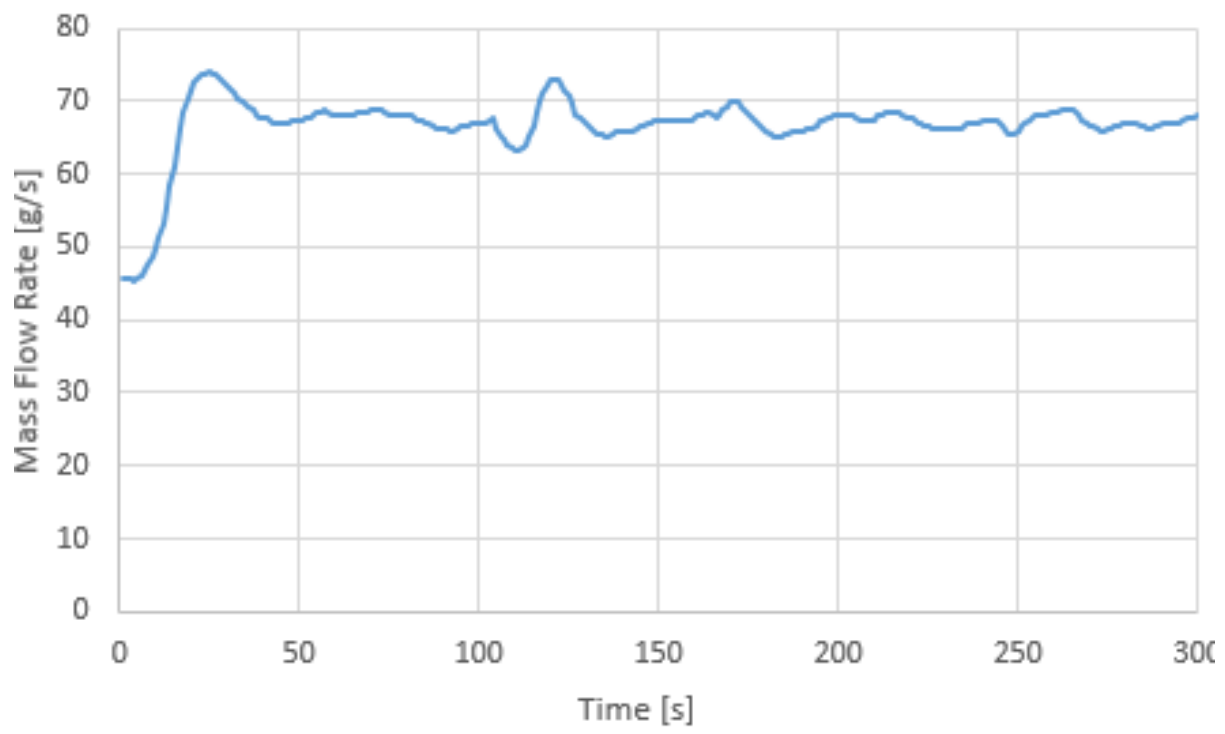

Figure 98 - Mass flow rate of fuel during Notch 4 for Test ID: R0007-002-264

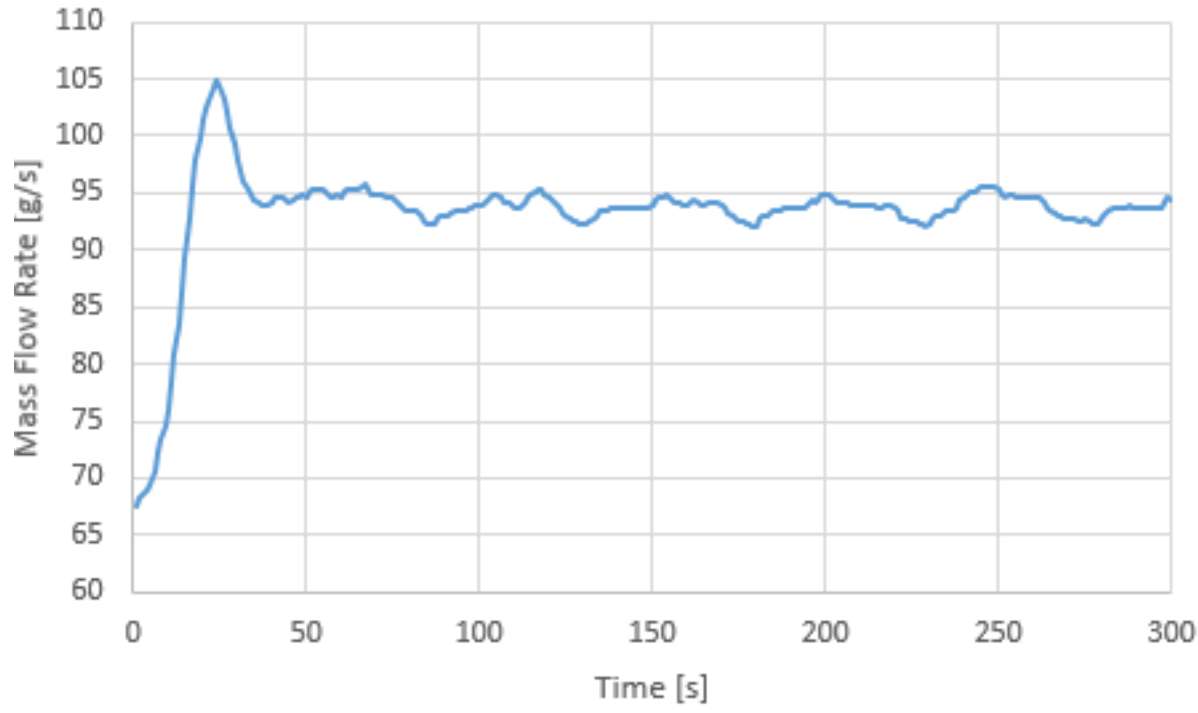

Figure 99 - Mass flow rate of fuel during Notch 5 for Test ID: R0007-002-264 


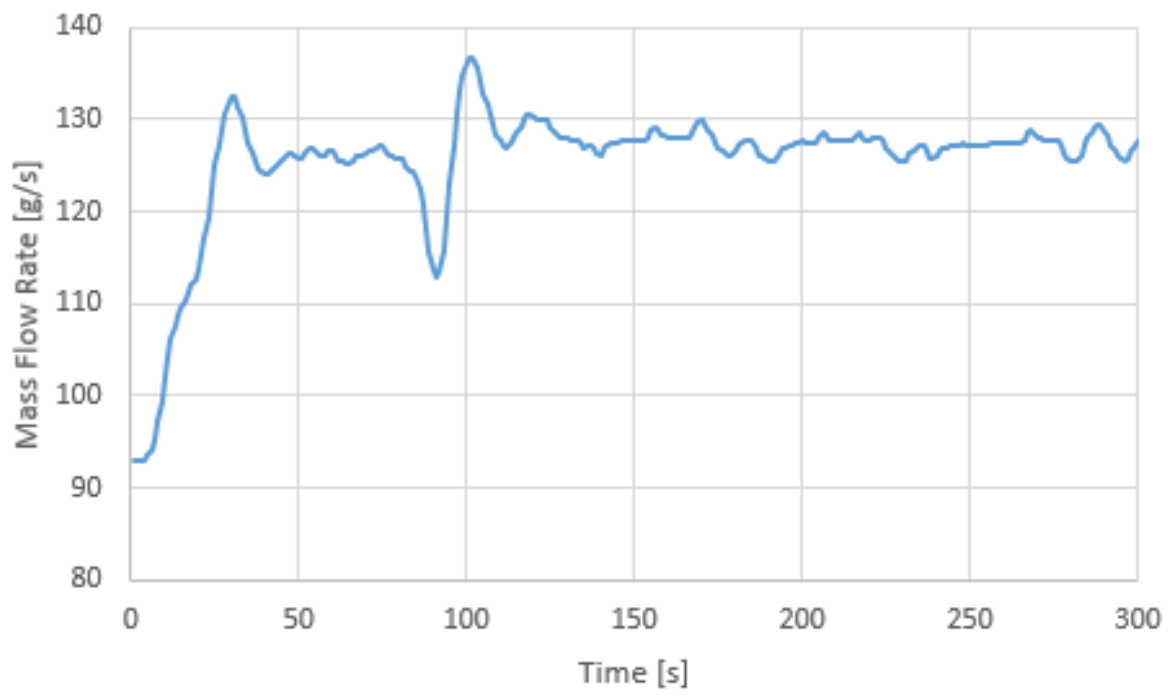

Figure 100 - Mass flow rate of fuel during Notch 6 for Test ID: R0007-002-264

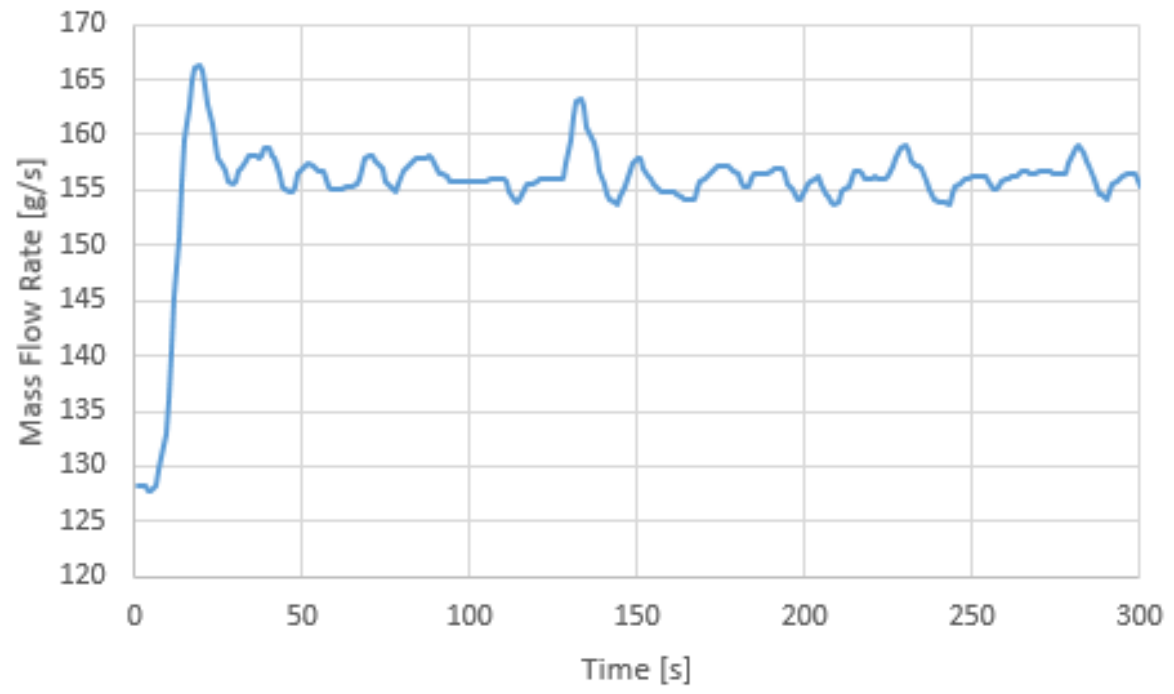

Figure 101 - Mass flow rate of fuel during Notch 7 for Test ID: R0007-002-264 